UNIVERSIDADE DE SÃO PAULO

ESCOLA DE ENFERMAGEM DE RIBEIRÃO PRETO

FLÁVIA MARTINELLI PELEGRINO

ADAPTAÇÃO CULTURAL E VALIDAÇÃO DO INSTRUMENTO DUKE ANTICOAGULATION SATISFACTION SCALE (DASS): VERSÃO PARA BRASILEIROS EM USO DE ANTICOAGULAÇÃO ORAL

RIBEIRÃO PRETO 


\title{
ADAPTAÇÃO CULTURAL E VALIDAÇÃO DO INSTRUMENTO DUKE ANTICOAGULATION SATISFACTION SCALE (DASS): VERSÃO PARA BRASILEIROS EM USO DE ANTICOAGULAÇÃO ORAL
}

\author{
Dissertação apresentada ao Programa de Pós-Graduação em \\ Enfermagem Fundamental da Escola de Enfermagem de \\ Ribeirão Preto da Universidade de São Paulo para a obtenção \\ do título de Mestre em Enfermagem
}

Linha de pesquisa: Processo de cuidar do adulto e idoso com doenças agudas e crônico-degenerativas.

Orientadora: Profa. Dra. Rosana Aparecida Spadoti Dantas. 
AUTORIZO A REPRODUÇÃO E A DIVULGAÇÃO TOTAL OU PARCIAL DESTE

TARABALHO, POR QUALQUER MEIO CONVENCIONAL OU ELETRÔNICO, PARA

FINS DE ESTUDO E PESQUISA, DESDE QUE CITADA A FONTE.

\section{FICHA CATALOGRÁFICA}

Pelegrino, Flávia Martinelli.

Adaptação cultural e validação do instrumento Duke Anticoagulation Satisfaction Scale (DASS): versão para brasileiros em uso de anticoagulação oral.

/ Flávia Martinelli Pelegrino; orientadora: Rosana Aparecida Spadoti Dantas Ribeirão Preto / 2009.

168: fig.

Dissertação (Mestrado) - Programa de Pós-Graduação da Escola de Enfermagem de Ribeirão Preto da Universidade de São Paulo. Linha de pesquisa: Processo de cuidar do adulto e idoso com doenças agudas e crônico-degenerativas Escola de Enfermagem de Ribeirão Preto da Universidade de São Paulo.

1. Qualidade de vida 2. Anticoagulantes 3. Estudos de Validação I. Dantas, Rosana Aparecida Spadoti. II. Universidade de São Paulo. Escola de Enfermagem de Ribeirão Preto. III. Título. 


\section{FOLHA DE APROVAÇÃO}

Flávia Martinelli Pelegrino

Adaptação cultural e validação do instrumento Duke Anticoagulation Satisfaction Scale (DASS): versão para brasileiros em uso de anticoagulação oral

Dissertação apresentada ao Programa de Pós-Graduação em

Enfermagem Fundamental da Escola de Enfermagem de Ribeirão Preto da Universidade de São Paulo para a obtenção do título de Mestre em Enfermagem

Linha de pesquisa: Processo de cuidar do adulto e idoso com doenças agudas e crônico-degenerativas.

Orientadora: Profa. Dra. Rosana Aparecida Spadoti Dantas.

Aprovado em:

Banca Examinadora

Prof. Dr.:

Instituição: Assinatura:

Prof. Dr.:

Instituição: Assinatura:

Prof. Dr.:

Instituição: Assinatura: 


\section{DEDICATÓRIA}

\section{A minha mãe, Aparecida}

...que com a sua presença constante me ensinou na pureza do seu coração a vislumbrar os primeiros passos, as primeiras palavras, os primeiros desafios e me inspiram a caminhar ...

\section{A meu pai, Gerson}

...minha fortaleza que com suas virtudes busca, dia a dia, para que eu viva melhor mostrando-me sempre o caminho da vida, que está pela frente...

\section{A minha irmã, Vivi}

...juntas desde o início da vida, vivemos os sonhos e certezas de um caminho que tudo transforma e descobrimos que as coisas boas estão sempre dentro de nós...

\section{A meu irmão, Jefferson}

... a sua presença nessa minha caminhada foi um incentivo para realizá-los a cada novo desafio...

Obrigada por estarem em meu caminho sempre! 


\section{AGRADECIMENTOS}

Profa. Dra. Rosana Aparecida Spadoti Dantas, "um sonho sonhado sozinho permanece apenas um sonho; um sonho sonhado junto pode tornar-se realidade”.

(Edward Schillebeeckx)

Prof. Dr. Antonio Pazin Filho e Prof. Dra. Namie Sawada, "não se pode ensinar tudo a alguém, pode-se apenas ajudá-lo a encontrar por si mesmo”.

(Galileu Galilei)

Aos colegas de trabalhos do Bloco Cirúrgico, "o melhor lugar para ter sucesso é onde você está, com aquilo que você tem”.

(Charles Schwab)

Aos pacientes do ambulatório de anticoagulação oral, "ignorar o inesperado seria viver sem os ricos momentos dos quais a vida é feita”.

(Stephen Cohen)

Às minhas amigas Inaiara Scalçone Almeida Corbi, Fernanda Gaspar Torrati e Ariana Rodrigues da Silva Carvalho, há pessoas que nos falam e nem as escutamos; há pessoas que nos ferem e nem cicatrizes deixam; mas há pessoas que, simplesmente, aparecem em nossa vida e que marcam para sempre”.

(Cecília Meireles)

Às minhas grandes e eternas amigas Fabiana "Boleta” e Carina Aparecida Marosti, “o valor das coisas não está no tempo que elas duram, mas na intensidade com que acontecem e por isso existem momentos inesquecíveis e pessoas incomparáveis”.

(Fernando Pessoa)

À DEUS, “as tuas mãos me fizeram e me formaram; dá-me inteligência para entender os teus mandamentos”. 
“...sonhe com aquilo que você quiser; vá para onde você queira ir; seja o que você quer ser; porque você possui apenas uma vida e nela só temos uma chance de fazer aquilo que queremos; por isso, tenha felicidade bastante para fazê-la doce; dificuldades para fazê-la forte; tristeza para fazê-la humana; esperança suficiente para fazê-la feliz; porque a vida é curta, mas as emoções que podemos deixar duram uma eternidade...” 


\section{SUMÁRIO}

\section{RESUMO}

\section{ABSTRACT}

\section{RESUMEN}

\section{LISTA DE QUADROS}

\section{LISTA DE FIGURAS}

\section{LISTA DE TABELAS}

1. INTRODUÇÃO ....................................................................................................................17

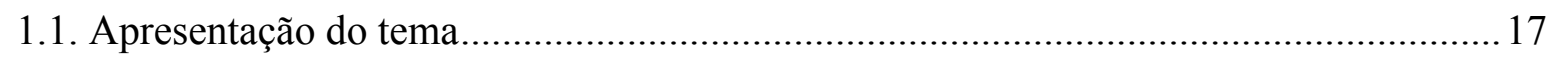

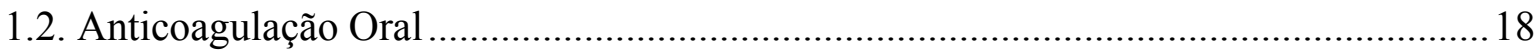

1.3. Qualidade de Vida à Relacionada à Saúde e a Anticoagulação Oral .............................21

1.4. Instrumentos de medida de Qualidade de Vida Relacionada à Saúde e a

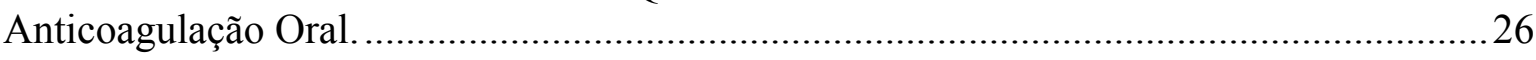

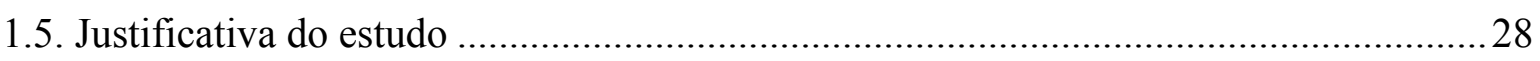

2. REFERENCIAL TEÓRICO E METODOLÓGICO .................................................31

2.1 Duke Anticoagulation Satisfaction Scale (DASS): descrição do instrumento ................31

2.2. O processo de adaptação cultural de instrumentos ...................................................... 35

2.3. Avaliação das propriedades psicométricas de um instrumento para outra cultura........41

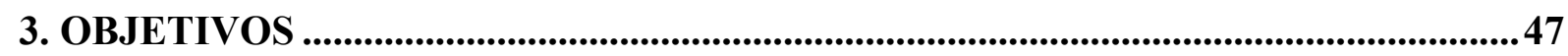

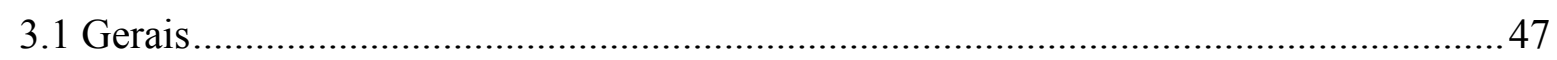

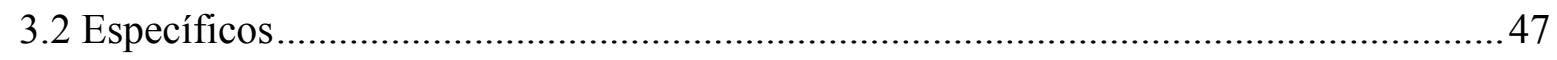

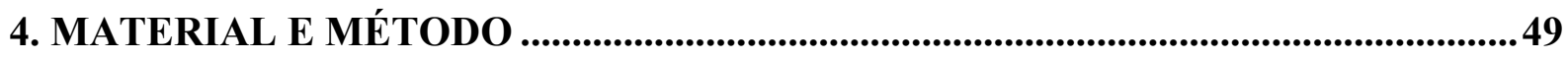

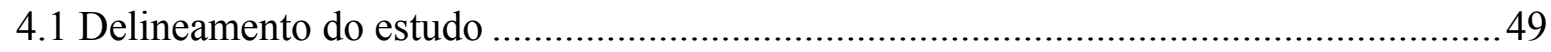

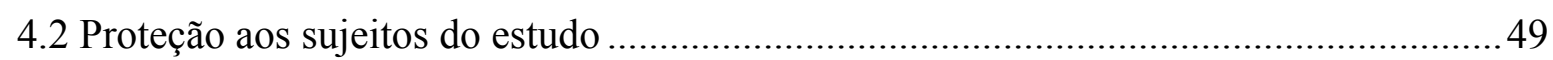

4.3 Permissão dos autores para a adaptação cultural e uso do instrumento ..........................50

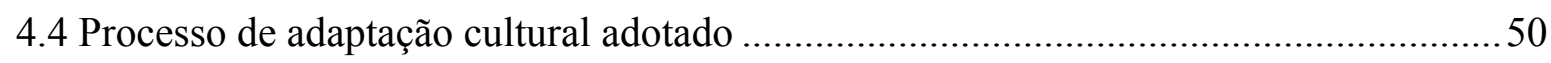

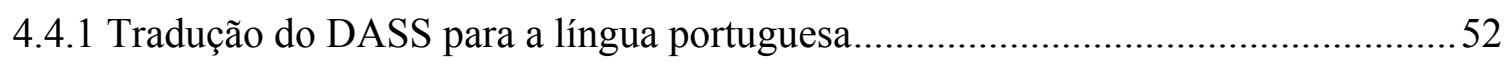

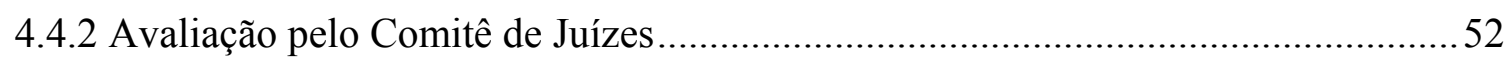

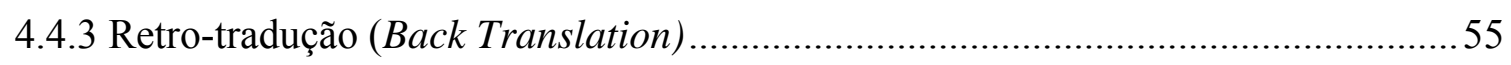

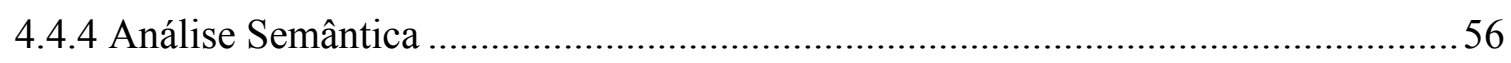

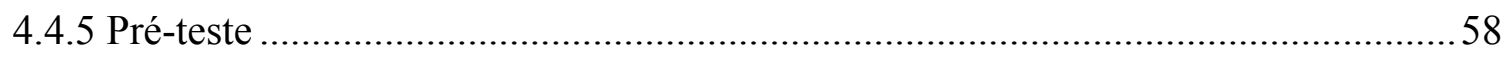

4.5 Análise das propriedades psicométricas da versão adaptada para o português do instrumento Duke Anticoagulation Satisfaction Scale (DASS) .........................................5

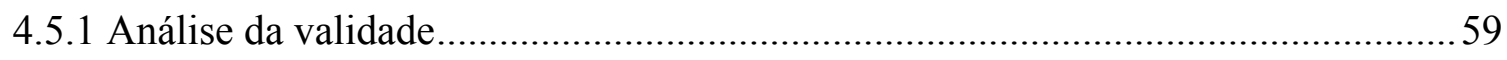

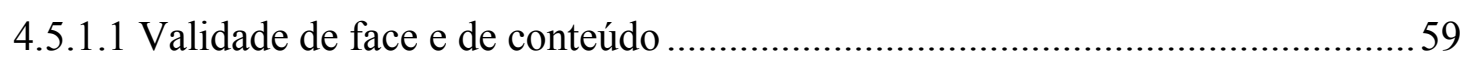

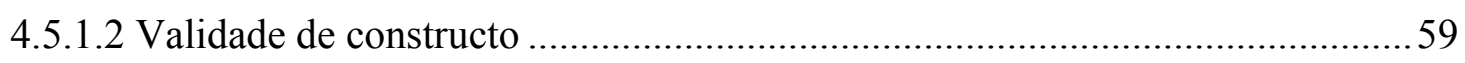

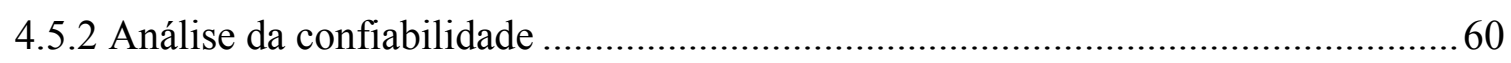




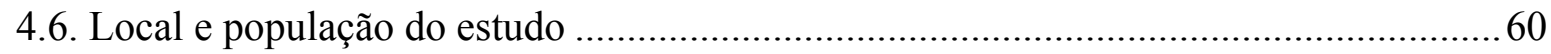

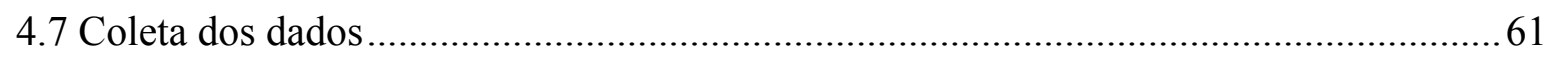

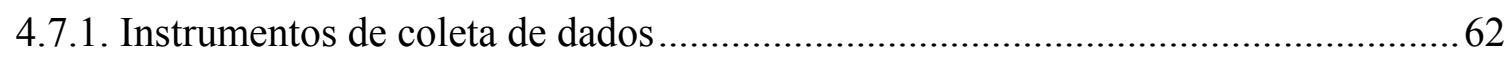

4.7.1.1 Instrumento para caracterização sócio-demográfica e clínica .........................62

4.7.1.2 Instrumento para avaliação do estado de saúde percebido (SF-36)..................63

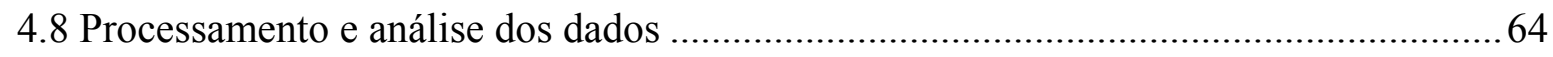

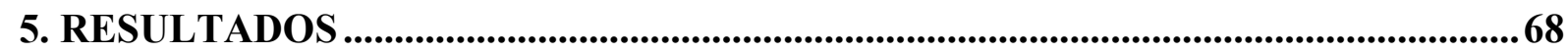

5.1. Resultados relacionados à caracterização sócio-demográfica e clínica........................6 68

5.2. Resultados relacionados às análises descritivas da versão adaptada do instrumento

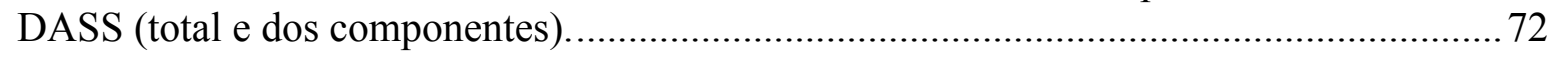

5.3 Resultados relacionados às análises descritivas da versão adaptada do instrumento

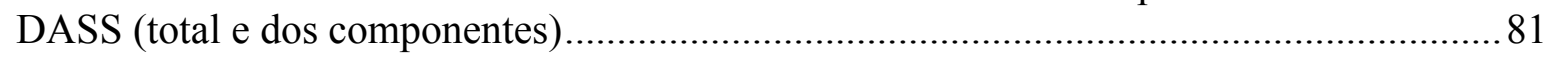

5.3.1 Resultados relacionados à análise da confiabilidade......................................... 81

5.3.2 Resultados relacionados à análise da validade de constructo da versão adaptada

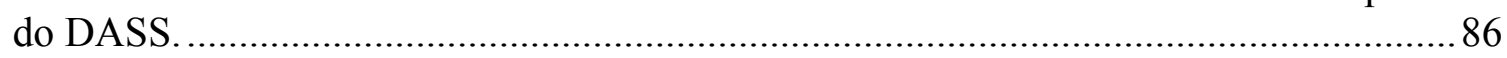

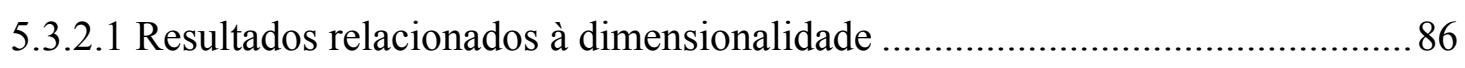

5.3.2.2 Resultados relacionados à validade de constructo convergente ........................ 88

5.3.2.3 Resultados relacionados à validade de constructo diergente...........................90

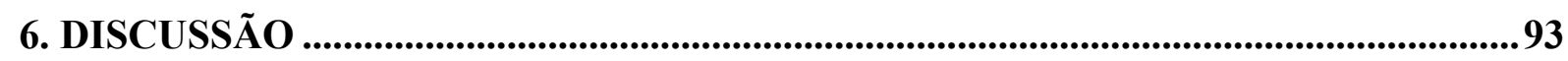

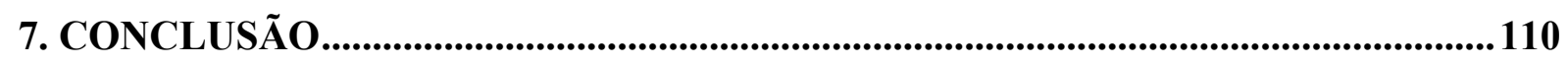

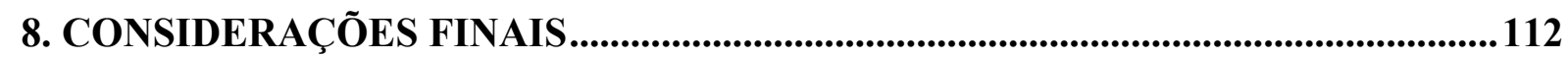

9. REFERÊNCIAS BIBLIOGRÁFICAS ...........................................................114

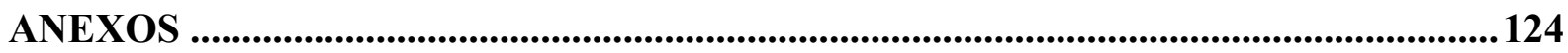

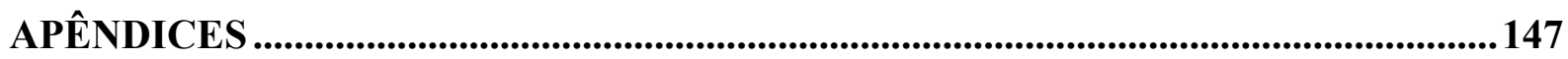




\section{RESUMO}

PELEGRINO, F. M. Adaptação cultural e validação do instrumento Duke Anticoagulation Satisfaction Scale (DASS): versão para brasileiros em uso de anticoagulação oral. 2009. 168f. Dissertação (Mestrado) - Escola de Enfermagem de Ribeirão Preto, Universidade de São Paulo, Ribeirão Preto, 2009.

O uso de anticoagulantes orais (ACO) esta indicado para a prevenção e tratamento de eventos tromboembólicos decorrentes de várias doenças, principalmente, as cardiovasculares. O uso de ACO representa mudanças na percepção da vida pelo individuo sob constante risco de complicações, sendo a redução desses riscos associadas à melhora da qualidade de vida relacionada à saúde (QVRS) e resultados clínicos satisfatórios. Este estudo de delineamento metodológico teve como objetivos realizar e testar as propriedades psicomtéricas do instrumento Duke Anticoagulation Satisfaction Scale (DASS) para brasileiros em uso de ACO. A DASS possui 25 itens distribuídos em três domínios, Limitação, Tarefa/Sobrecarga e Impacto Psicológico, com respostas de um (1) "nada" a sete (7) "muitíssimo", com um intervalo possível para o total da medida de 25 a 175 , no qual menores valores refletem melhor QVRS e maior satisfação com o uso do ACO. O processo de adaptação seguiu os passos preconizados pela literatura. Os dados foram coletados no ambulatório de um hospital público e de ensino do interior do Estado de São Paulo, por meio de entrevistas e consultas aos prontuários, no período de março a agosto de 2008, tendo participado do estudo 180 sujeitos abordados aleatoriamente. As propriedades psicométricas analisadas foram: a validade de face e de conteúdo (comitê de juízes); a validade de constructo (análise fatorial); a validade de constructo convergente (testes de correlação de Pearson entre os domínios da DASS e do SF-36); validade de constructo divergente (testes de correlação de Pearson entre a DASS e idade e tempo de uso do ACO); a confiabilidade (consistência interna-alfa de Cronbach). O nível de significância adotado foi de 0,05 . Os resultados demonstraram que a maioria dos participantes era do sexo feminino $(65,6 \%)$, com idade média de 55 anos, em uso de varfarina $(83,3 \%)$ há mais de 6,9 anos, em média, sendo a prótese cardíaca metálica a principal indicação para anticoagulação (50\%). Apesar de 72,8\% terem recebido algum tipo de informação sobre o uso do ACO, 41,7\% tiveram complicações, principalmente do tipo hemorrágica (94,6\%), com necessidade de internações (15,6\%). Na avaliação das propriedades psicométricas, a validade de constructo convergente teve a maioria das correlações negativas, de pouco valor para a prática e estatisticamente significantes. Em relação à validade de constructo divergente, as correlações foram positivas, de pouco valor para prática e não estatisticamente significantes A análise fatorial indicou a presença de três componentes, conforme preconizado pelo autor. A confiabilidade demonstrou um valor adequado para a consistência interna da versão adaptada da DASS ( $\alpha$ de Cronbach $=0,79$ ). Assim, podemos concluir que a versão adaptada da DASS para o português mostrou-se válida e confiável na amostra estudada.

Descritores: qualidade de vida; anticoagulantes; estudos de validação. 


\begin{abstract}
PELEGRINO, F. M. Cultural adaptation and the instrument Duke Anticoagulation Satisfaction Scale (DASS) validity: version for brazilian patients undergoing oral anticoagulant therapy. 2009. 168f. Dissertation (Master's degree) - Nursing School of Ribeirão Preto, University of São Paulo, Ribeirão Preto, 2009.

The therapy with oral anticoagulant (OAC) is indicated in the prevention and treatment of tromboembolic events due to many different clinical conditions, specially the cardiovascular ones. The use of OAC represents changes in the way an individual under constant risk of complications bares life, and the reduction of the risks is associated to improvement in quality of life related to health (QLRH) and satisfactory clinical studies. This methodological study aims at performing and testing the psychometrics properties of the instrument Duke Anticoagulation Satisfaction Scale (DASS) for brazilian patients undergoing OAC therapy. The instrument DASS has 25 items distributed in three domains: Limitation, Task/Overload and Psychological Impact, and responses from one (1) "none" to seven (7) "great", with a possible interval from 25 to 175 for the total measure in which the smallest values reflect better QLRH and greater satisfaction with the use of OAC. The adaptation process followed the steps recommended in specialized literature. Data has been collected in the ambulatory of a public hospital school in the countryside of the state of São Paulo, through interviews to 180 subjects chosen randomly and through consultation to medical records from March to August, 2008. The analysis of the psychometric properties were: face and content validity (judges committee); construct validity (factor analysis); convergent construct validity (Pearson's correlation analysis among the DASS and the SF-36); divergent construct validity (Pearson's correlation analysis among the DASS and age and the time of use of OAC); reliability (Cronbach's alpha and internal consistency). The adopted significance level was 0,05 . The results show that most participants were female $(65,6 \%)$, average age of 55 years old, in therapy with warpharine over 6,9 years, having the metallic cardiac prosthesis as the main indication for anticoagulation (50\%). Despite 72,8\% having received some information about the use of OAC, $41,7 \%$ had complications, specially hemorrhage $(94,6 \%)$ and hospital inpatient $(15,6 \%)$. Evaluating the psychometric properties, the convergent construct validity had mostly negative correlations, of little value to the practice and statistically significant. Regarding the divergent construct validity, there were mainly positive correlations, of little value to the practice and not statistically significant. The factor analysis indicated three components according to what had been recommended by the author. The reliability showed an adequate value for the internal consistency of the DASS adapted version (Cronbach=0,79). Thus, it shall be concluded that the adapted version of the DASS into portugues is authentic and reliable in the studied sample.
\end{abstract}

Key words: quality of life; anticoagulation; instruments; validity studies 


\section{RESUMEN}

PELEGRINO, F. M. Adaptación cultural y validación del instrumento Duke Anticoagulation Satisfaction Scale (DASS): versión para brasileños en uso de anticoagulación oral. 2009. 168f. Tesis (Maestría) - Facultad de Enfermería de Ribeirao Preto, Universidad de Sao Paulo, Ribeirao Preto, 2009.

El uso de anticuagulantes orales (ACO) está indicado para prevenir y tratar eventos tromboembolíticos provenientes de varias enfermedades, principalmente, las cardiovasculares. El uso de ACO representa cambios en la percepción de la vida del individuo que se encuentra bajo riesgo de constantes complicaciones, siendo que la reducción de esos riesgos está asociada a la mejora de la calidad de vida relacionada con la salud (CVRS) y a resultados clínicos satisfactorios. Este estudio, de delineamiento metodológico, tuvo por objetivo estudiar las propiedades psicométricas del instrumento Duke Anticoagulation Satisfaction Scale (DASS) para brasileños usuarios de ACO. La DASS está compuesta por 25 ítems distribuidos en tres dominios: limitación, tarea/sobrecarga e impacto psicológico, con respuestas de un (1) "nada" a siete (7) "muchísimo" y un intervalo posible para el total de la medida de 25 a 175. Menores valores reflejan mejor CVRS y mayor satisfacción con el uso de ACO. El proceso de adaptación siguió los siguientes pasos recomendados en la literatura. Los datos fueron recogidos por medio de entrevista y consultas en las historias clínicas de 180 individuos abordados de forma aleatoria en los ambulatorios externos de un hospital público y universitario del Estado de Sao Paulo, en el periodo de marzo a agosto del 2008. Las propiedades psicométricas analizadas fueron: validez aparente y de contenido (comité de jueces); validez de constructo (análisis factorial); validez de constructo convergente (test de correlación de Pearson entre los dominios de la DASS e del SF-36); validez de constructo divergente (test de correlación de Pearson entre la DASS, la edad y el tiempo de uso de ACO) y la confiabilidad (consistencia interna-Alfa de Cronbach). Fue adoptado como nivel significante 0,05 . Los resultados demuestran que la mayoría de los participantes eran de sexo femenino (65,6\%), con edad media de 55 años, usando Varfarina $(83,3 \%)$ hace más de 6,9 años, en media, siendo la prótesis cardiaca metálica la principal indicación para anticoagulación (50\%). A pesar de 72,8\% haber recibido algún tipo de información sobre el uso da ACO, 41,7\% tuvieron complicaciones, principalmente del tipo hemorrágica $(94,6 \%)$ y con necesidad de internaciones (15,6\%). En la evaluación de las propiedades psicométricas, la validez de constructo convergente tuvo la mayoría de las correlaciones negativas, siendo de poco valor para la práctica y estadísticamente significantes. En relación a la validez de constructo divergente, las correlaciones fueron positivas, siendo de poco valor para la práctica y no estadísticamente significante. El análisis factorial, en conformidad con la propuesta del autor, indicó tres componentes. La confiabilidad mostró un valor adecuado para la consistencia interna de la versión adaptada de la DASS ( $\alpha$ de Cronbach=0,79). Así, podemos concluir que la versión adaptada de la DASS para el portugués se mostró válida y confiable en la muestra estudiada.

Descriptores: calidad de vida; anticoagulantes; estudios de validación 


\section{LISTA DE QUADROS}

Quadro 1 - Valores ideais do INR, segundo American College of Chest Physicians 20

Quadro 2 - Itens do instrumento Duke Anticoagulation Satisfaction Scale (DASS) segundo seus domínios

Quadro 3 - Modificações sugeridas pelo comitê de juízes para a Versão Português Consenso 2 do DASS. 53

Quadro 4 - Modificações na Versão Português Consenso 2 após comparação da versão original (VO) e da versão inglês final (VIF) 56 


\section{LISTA DE FIGURAS}

Figura 1 - Processo de adaptação cultural do instrumento Duke Anticoagulation Satisfaction

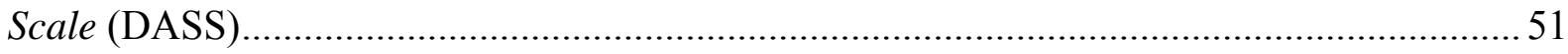




\section{LISTA DE TABELAS}

Tabela 1 - Análise descritiva das características sócio-demográficas dos participantes. Ribeirão Preto, 2009

Tabela 2 - Caracterização clínica dos participantes segundo indicação do ACO, presença de comorbidades e números de medicamentos usados. Ribeirão Preto, 2009

Tabela 3 - Caracterização clínica dos participantes segundo tipo de ACO, tempo de uso, dosagem e controle do INR. Ribeirão Preto, 2009

Tabela 4 - Caracterização clínica dos participantes segundo informações recebidas, complicações, internações e interrupção do ACO. Ribeirão Preto, 2009.

Tabela 5 - Distribuição das freqüências de respostas aos 25 itens do instrumento DASS, sem reposição dos dados. Ribeirão Preto, 2009.

Tabela 6 - Análise descritiva da medida e dos 25 itens do instrumento DASS, sem reposição dos dados. Ribeirão Preto, 2009

Tabela 7 - Distribuição das freqüências de respostas aos 25 itens do instrumento DASS, com reposição dos dados. Ribeirão Preto, 2009.

Tabela 8 - Análise descritiva da medida e dos 25 itens do instrumento DASS, com reposição dos dados. Ribeirão Preto, 2009

Tabela 9 - Análise descritiva do DASS total e de seus componentes (limitação, tarefa/sobrecarga, impacto psicológico positivo e negativo). Ribeirão Preto, 2009 .

Tabela 10 - Coeficiente de correlação de Pearson* entre os domínios do DASS e o total do instrumento. Ribeirão Preto 2009

Tabela 11 - Coeficiente de correlação item-total*, alfa de Cronbach para o total e os itens do domínio Limitação e quando cada um dos itens foi excluído. Ribeirão Preto, 2009

Tabela 12 - Coeficiente de correlação item-total*, o alfa total do domínio Tarefa/sobrecaga e alfas quando cada um dos itens foi excluído. Ribeirão Preto, 2009.

Tabela 13 - Coeficiente de correlação item-total*, alfa total dos itens do domínio Impacto Psicológico e alfa quando cada um dos itens foi excluído. Ribeirão Preto, 2009.

Tabela 14 - Coeficiente de correlação item-total* , alfa total dos itens da sub-escala Impacto Psicológico Positivo e alfas quando cada um dos itens foi excluído. Ribeirão Preto, 2009....86

Tabela 15 - Coeficiente de correlação item-total*, alfa total da sub-escala Impacto Psicológico Negativo e alfas quando cada um dos itens foi excluído. Ribeirão Preto, 2009 .. 86

Tabela 16 - Matrix de rotação Varimax dos componentes da versão adaptada do DASS. Ribeirão Preto, 2009 
Tabela 17 - Análise descritiva e consistência interna dos oito domínios do SF-36. Ribeirão Preto, 2009 88

Tabela 18 - Coeficiente de correlação de Pearson entre os domínios do instrumento DASS e os domínios do SF-36. Ribeirão Preto, 2009

Tabela 19 - Coeficiente de correlação de Pearson entre os domínios do instrumento DASS e a idade e tempo de uso de ACO. Ribeirão Preto, 2009 


\section{INTRODUÇÃO}

\subsection{Apresentação do tema}

$\mathrm{O}$ uso de anticoagulantes orais (ACO) tem se tornado uma alternativa eficaz na prevenção e no tratamento de eventos tromboembólicos de doenças como infarto agudo do miocárdio, acidente vascular cerebral, trombose venosa profunda e embolia pulmonar, os quais constituem uma das principais causas de morbidade e mortalidade nas cardiopatias. Essa temática me despertou uma especial atenção ao iniciar o Curso de Especialização, modalidade Residência em Enfermagem Clínico Cirúrgica, na área de Cardiologia oferecido pelo Departamento de Enfermagem Geral e Especializado da Escola de Enfermagem de Ribeirão Preto da Universidade de São Paulo (EERP-USP). Tendo em vista os resultados obtidos com a finalização da monografia, pude perceber o quão complexo, rigoroso e constante era o seguimento dos indivíduos submetidos à terapia de anticoagulação oral (TAO). Diante desses aspectos não se pode deixar de imaginar como a qualidade de vida relacionada à saúde (QVRS) desses indivíduos pode estar afetada. Estudos revelam que questionários e/ou instrumentos tem sido desenvolvidos e adaptados em diversos países, sendo a adaptação cultural uma metodologia primordial para disponibilizar essas importantes ferramentas para outros paises e população. A tradução e adaptação cultural de um instrumento de medida de QVRS para indivíduos em uso de ACO foi o foco da nossa investigação durante o programa de Pós-graduação em Enfermagem Fundamental da EERP-USP, nível mestrado. Este estudo faz parte de um amplo projeto de investigação intitulado Avaliação da qualidade de vida relacionada à saúde, atitudes, satisfação e adesão ao tratamento de pacientes em uso de anticoagulação oral. Tal projeto é coordenado pela professora Rosana Aparecida Spadoti Dantas e vinculado ao Grupo de Investigação em Reabilitação e Qualidade de Vida (GIRQ) da EERP-USP. 


\subsection{Anticoagulação Oral}

A coagulação sangüínea é o processo em que os componentes do sangue são transformados em um material semi-sólido (coágulo) com a finalidade de limitar as perdas sangüíneas de lesões de artérias ou vasos. No entanto, a formação do coágulo certamente progrediria até a oclusão do vaso todas as vezes que esse processo fosse desencadeado. Para que isso não ocorra é necessário mecanismos reguladores de modo a contrapor-se à perda sangüínea e, simultaneamente, evitar a formação trombos intravasculares (SPÓSITO; CARAMELLI, 1999; GRINBERG, 2003).

Os mecanismos reguladores estão representados por uma série de inibidores que ocorrem normalmente na circulação (os chamados anticoagulantes naturais) e os anticoagulantes obtidos industrialmente. As proteínas que atuam como anticoagulantes naturais são: proteína C (PC), proteína S (PS), antitrombina (AT) e inibidor da via tecidual (TFPI- tissue factor pathway inhibitor). Já os anticoagulantes industriais mais utilizados são os antagonistas da vitamina K, como a Varfarina (Marevam $\left.{ }^{\circledR}\right)$, a fenidiona (Dindevan $\left.{ }^{\circledR}\right)$ e a fenprocumona (Marcoumar®) (FRANCO, 2001; GRINBERG, 2003; LOURENÇO, 1997).

A TAO pode ser definida como sendo um processo que por meio do uso dos ACOs prolonga-se o tempo em que o sangue leva para coagular (FRANCO, 2001; GRINBERG, 2003). Os ACOs são indicados para a prevenção e tratamento do tromboembolismo venoso, prevenção e tratamento de tromboembolismo pulmonar, fibrilação atrial, infarto agudo do miocárdio, próteses valvares cardíacas, cardiomiopatia dilatada, acidente vascular encefálico, síndrome antifosfolipídica. No entanto, indicar a ACO em algumas situações clínicas como nas discrasias sangüíneas, aneurismas cerebrais, lesões ativas do trato gastrintestinal ou urinário, cirurgias neurológicas, oftalmológicas e urológicas recentes e gestação implicaria na ocorrência de eventos adversos e/ou teratogênicos (CAMPOS; MENEGUELO; BATLOUNI, 1993; SPÓSITO; CARAMELLI, 1999; GRINBERG, 2003; PARRONDO et al. 2003). 
A hemorragia é o principal efeito adverso podendo ocorrer em até $50 \%$ dos indivíduos (HUSTED, ANDREASEN, 1976; CAMPOS; MENEGUELO; BATLOUNI, 1993; PARRONDO et al. 2003). Outros efeitos adversos incluem distúrbios gastrintestinais (como diarréia, náuseas, vômitos) reações de hipersensibilidade, erupção cutânea, prurido, alopecia (CAMPOS; MENEGUELO; BATLOUNI, 1993; PARRONDO et al., 2003; GRINBERG, 2003; SANTOS et al. 2006) e complicações raras como necrose de pele (conhecida também como síndrome do pé roxo/síndrome purpúrica dos pés), trombocitopenia, abortamento espontâneo, prematuridade e malformações fetais graves (HIRSH; FUSTER, 1994; SULLANO; ORTIZ, 2001; GRINBERG, 2003; TEDOLDI, 2006).

Para avaliar a coagulação sangüínea são indicados testes laboratoriais capazes de mensurar o tempo que leva a formação do trombo de fibrina quando o sangue do paciente entra em contato com a tromboplastina. São exemplos desses testes, o tempo de tromboplastina parcial (TTP), tempo de protombina (TP) (os mais utilizados no Brasil), e o tempo de trombina (TT) ou o nível de fibrinogênio (FRANCO, 2001). Porém, o resultado desses testes diferencia de acordo com a origem do reagente, a tromboplastina, ou seja, o tecido (cérebro, pulmão, placenta), método de preparação ou animal (coelho e rato) (SPÓSITO; CARAMELLI, 1999; SULLANO; ORTIZ, 2001; GRINBERG, 2003).

Para minimizar as diferenças no controle laboratorial da coagulação sangüínea a Organização Mundial de Saúde (OMS) recomendou a utilização de um sistema uniforme de calibração conhecido como International Normalized Ratio (INR). O INR é definido como o índice do tempo de protrombina obtido através da divisão do tempo de protrombina do paciente pelo tempo de protrombina controle. O valor obtido é corrigido pelo Índice de Sensibilidade Internacional (ISI), definido como sendo a relação da sensibilidade da tromboplastina usada com a sensibilidade da tromboplastina padrão (internacional) (SPÓSITO; CARAMELLI, 1999). 
Os valores de INR refletem a intensidade da coagulação sangüínea. A determinação desses valores para cada situação clínica impulsionou a realização de diversos estudos randomizados os quais comprovaram que um nível baixo de INR é geralmente mais seguro e igualmente efetivo (HIRSH; FUSTED, 1994; SPÓSITO; CARAMELLI, 1999; GRINBERG, 2003). O quadro abaixo (Quadro 1) correlaciona a situação clínica com o nível de INR.

Quadro 1: Valores ideais do INR, segundo American College of Chest Physicians.

\begin{tabular}{|l|l|}
\hline Situação Clínica & INR \\
\hline Profilaxia da trombose venosa & $2,0-3,0$ \\
Tratamento da trombose venosa profunda (TVP) & \\
Tratamento de embolia pulmonar & \\
Tratamento da embolia sistêmica & \\
Embolia Sistêmica recorrente & \\
Embolia arterial pós-operatória & \\
Prótese cardíaca com válvula de tecido & \\
Infarto agudo do miocárdio (IAM) & \\
Doença da valva Cardíaca & \\
Fibrilação Atrial & \\
Prevenção de AVC isquêmico em pacientes com fibrilação atrial & $2,5-3,5$ \\
\hline Prótese cardíaca com válvula mecânica (exceto idosos) & $3,0-4,0$ \\
\hline Síndrome Antifosfolipidica & \\
\hline
\end{tabular}

Fonte: Hirsh e Fusted, 2001; Levine et al. 2001

Mesmo com a determinação do intervalo ideal do INR relacionada à situação clínica, a resposta terapêutica do indivíduo em uso de ACO sofre influências tanto de fatores genéticos como ambientais que modificam a farmacocinética e farmacodinâmica dos ACO.

Fatores genéticos incluem mutações no gene da enzima do citocromo P450 2C9 que podem reduzir as necessidades do ACO. A mutação do gene do fator IX pode aumentar os riscos de sangramentos e a resistência genética da varfarina com o aumento de até 20 vezes a dose para o alcance do efeito desejado (SANTOS et al. 2006).

Fatores ambientais incluem variações na ingestão alimentar relacionada às flutuações da vitamina k provavelmente da alimentação, dietas ricas em gordura, (HIRSH; FUSTED, 1994; SULLANO; ORTIZ, 2001; PARRONDO et al. 2003; GRINBERG, 2003) e associação 
medicamentosa. Embora muitas drogas tenham potencial de interação elas podem ser utilizadas em associação desde que cuidados especiais sejam tomados (GRINBERG, 2003). O estado patológico do paciente é outro fator importante que condiciona uma maior ou menor sensibilidade a uma dada dose do ACO (CAMPOS; MENEGUELO; BATLOUNI, 1993; SULLANO; ORTIZ, 2001; GRINBERG, 2003).

Assim, ao iniciar o ACO são necessários controles sangüíneos freqüentes e uma vez conseguidos os valores ideais do INR, os controles podem ser realizados quinzenalmente, a cada quatro semanas ou, até mesmo, em intervalos mais longos como oito semanas. Há que se ressaltar que qualquer alteração clínica, como iniciar um medicamento, presença de doença ou substituição do ACO, requer novos controles sangüíneos (SPÓSITO; CARAMELLI, 1999; PARONDO et al.2003; GRINBERG, 2003).

A eficácia e o impacto de determinados tratamentos, como o uso de ACO, tem sido consideradas como indicadores na avaliação de intervenções, impacto físico e psicossocial que as enfermidades, disfunções ou incapacidades podem acarretar às pessoas acometidas sendo incluídas como medidas da QVRS (SEIDL; ZANNON, 2004).

\subsection{Qualidade de Vida à Relacionada à Saúde e a Anticoagulação Oral}

No contexto dos estudos clínicos as investigações sobre qualidade de vida (QV) estão centradas, predominantemente, na evolução dos aspectos que são afetados pela doença em si e/ou pelo seu tratamento e não nos aspectos mais globais de QV. Assim, o termo QVRS, da expressão em inglês "health-related quality of life" é usado para diferenciar os aspectos relevantes para os profissionais da saúde daqueles com sentido mais amplo. Esses aspectos devem incluir tanto os benefícios como os prejuízos da terapêutica adotada, tais como os efeitos colaterais e a toxicidade das drogas. Muitas vezes o tratamento indicado para as 
doenças crônicas não visam à cura, mas o alívio dos sintomas ou aumento da sobrevida (FAYERS; MACHIN, 2007).

A QVRS também é considerada como sinônimo do termo "perceived health status” (estado de saúde percebido) o qual inclui três grandes domínios: físico (capacidade funcional e capacidade para o trabalho), psicológico (satisfação, bem estar, auto-estima, ansiedade e depressão) e social (reabilitação para o trabalho, lazer, interação social e familiar) (PASCHOAL, 2000; FAYERS; MACHIN, 2007).

No entanto, não há um consenso entre os pesquisadores sobre o uso dos termos QV/QVRS/estado de saúde percebido. Os autores têm chamado de QV os aspectos avaliados por instrumentos como o Medical Outcoumes Study 36 - Item Short-Form Health Survey (MOS SF-36), o qual, segundo seus próprios criadores, foi construído para avaliar o estado de saúde percebido pelos indivíduos (WARE; SHERBOURNE, 1992).

Podemos ressaltar que a QVRS abrange aqueles aspectos do bem estar auto-percebido que estão relacionados à, ou que são afetados pela presença da doença e/ou do tratamento. Os aspectos relevantes podem variar de um estudo a outro, mas, geralmente, incluem saúde geral, capacidade física, sintomas e toxicidade, estado emocional, capacidade cognitiva, bem-estar social e funcional, função sexual e questões existenciais (FAYERS; MACHIN, 2007).

Mas recentemente, novos termos têm surgido na literatura científica e nos congressos sobre o tema QV, como a expressão em inglês "patient-reported outcomes"(PROs), significando os resultados percebidos pelos pacientes. Esse termo indica o interesse dos pesquisadores em entender melhor às conseqüências de condições crônicas nas vidas dos pacientes bem como avaliar os benefícios de novos tratamentos, principalmente em estudos clínicos. Todo o tipo de resultado abrangendo desde dor, fadiga, depressão até outros sintomas físicos como náuseas e vômitos tem sido apontados como aspectos importantes a serem avaliados na QVRS (FAYERS; MACHIN, 2007). 
Nas investigações sobre QVRS e uso de ACO os resultados percebidos pelos pacientes sofrem a influencia de dois componentes importantes, o modo como é obtido os resultados laboratoriais para verificação do INR e o modo como os pacientes são acompanhados ao longo do tratamento. Tanto um fator como outro está diretamente relacionado à qualidade da anticoagulação oral e são parte do que é representado como definição pelos investigadores desse tema sobre QVRS de pacientes anticoagulados (LANCASTER et al. 991; SCHULMAN, 1994; SAWICKI, 1999; KULLINA et al. 1999; CROMHEECKE et al.2000; BARCELLONA et al. 2000; GADISSEUR et al. 2003; WILSON et al. 2003; GADISSEUR et al. 2004; SAMSA et al. 2004; CASAIS et al. 2005).

Sobre o primeiro componente, ou seja, o modo de como é obtido os resultados laboratoriais para verificação do INR, temos que esse pode ser realizado por meio de coleta de sangue venoso e posterior análise em laboratórios ou coletar uma gota de sangue, por meio de uma picada na ponta do dedo, que será analisada em um monitor portátil domiciliar (“coagulômetro") sendo o resultado obtido imediatamente (BEYTH; QUIN; LANDEFELD, 2000, CONNOR; WRIGHT; FEGAN, 2002; TAYLOR et al.1997).

O segundo componente se refere ao modo de seguimento do indivíduo em uso de ACO. Na literatura encontramos os seguintes modelos de seguimento: cuidado convencional, auto-monitorização e o auto-gerenciamento.

O cuidado convencional é descrito na literatura como um modelo em que o indivíduo é submetido a coletas de sangue venoso, o médico então checará os valores do INR e, em seguida, direcionará a dosagem ideal do ACO. Esse controle pode ser feito tanto em ambulatórios hospitalares como em clínicas especializadas (BARCELLONA et al. 2000; GADISSEUR et al. 2003; WILSON et al. 2003). A auto-monitorização é caracterizada pela participação direta do paciente na realização do teste sangüíneo utilizando o coagulômetro para dosar o INR, porém a dosagem da medicação é ainda direcionada pelo médico. Já o auto- 
gerenciamento, que também pode ser chamado de auto-manejo, auto-administração ou autocontrole, caracteriza-se pela autonomia do indivíduo em checar os valores do INR com o coagulômetro e, em seguida, ele próprio ajusta a dosagem do ACO (KULLINA et al.1999; SAWICKI, 1999; GADISSEUR et al. 2003).

Quando o uso de ACO está baseada na auto-monitorização e auto-gerenciamento muitos aspectos da QVRS melhoram. Cromheecke et al. (2000) relatou que o seguimento por clínicas especializadas resultou em melhor controle da anticoagulação, quando comparada ao controle praticado em clínicas convencionais. Nesse sentido, Kullina et al. (1999) constatou que o uso do coagulômetro permitiu um aumento de 79,5\% para $85,6 \%$ nos valores de INR ideais o que refletiu na melhoria na qualidade da anticoagulação e na QVRS entre os indivíduos de uma clínica especializada.

Os resultados afirmam que os modelos de auto-monitorização e o auto-gerenciamento são confiáveis, bem aceitos e apreciados pelos participantes que fazem uso desse tipo de seguimento da TAO, principalmente, por serem considerados como uma moderna e efetiva estratégia para melhoria da QVRS, pois resulta em maior independência, responsabilidade, controle maior dos efeitos da ACO e possibilidade de realizar o teste do INR em casa, ou durante uma viagem, ou durante o período de trabalho, diminuindo a dependência das clínicas de anticoagulação (CROMHEECKE et al. 2000; SAWICKI, 1999).

Porém, a oportunidade de mensurar o INR em casa apesar de aumentar a satisfação geral com o tratamento não diminui o impacto emocional (GADISSEUR et al. 2004). Isso pode estar relacionado ao fato de que a indicação do ACO já proporciona insatisfação e atua negativamente na QVRS. Casais et al. (2005) cita como fatores associados às percepções negativas: menor tempo de seguimento do ACO (menos que um ano), insatisfação com atendimento médico, pacientes do sexo feminino, portadores de fibrilação atrial e tromboembolismo venoso. 
Sawicki (1999) observou que indivíduos recebendo ACO preocupavam-se com complicações relacionadas à terapia, possuíam menos liberdade ao viajarem devido às constantes punções venosas e regulares visitas médicas e aos laboratórios. Esses fatores se tornavam mais expressivos entre indivíduos jovens quando comparados aos mais idosos. Já a percepção de angústia relacionada ao uso de ACO foi mais pronunciada entre as mulheres do que entre homens (GADISSEUR et al. 2004).

As preocupações com complicações relacionadas ao uso do ACO também foram as responsáveis pelo sentimento de piora na saúde de indivíduos que iniciaram o tratamento (CASAIS et al. 2005). Já no estudo de Barcellona et al. (2000) as preocupações com a possibilidade de sangramento, os episódios de trombose, dificuldades em praticar atividades favoritas no tempo livre e esquecer de tomar o ACO foram responsáveis por limitação das atividades da vida diária de 11\% dos participantes do estudo. Em particular, os episódios de sangramentos não estavam associados com percepções negativas pelos pacientes, pois a maioria considerou que suas emergências foram eficientemente resolvidas.

Indivíduos com baixo risco de sangramento estavam mais preocupados com a hemorragia do que aqueles com alto risco e as possíveis justificativas para esse paradoxo pode ser que indivíduos com alto risco de sangramento estão mais sujeitos as explicações detalhadas sobre o tratamento. Porém, cerca de 33\% dos indivíduos não conheciam as razões para a indicação do ACO e ainda 87,5\% não mudaram seus hábitos (dieta e estilo de vida) (CASAIS et al. 2005).

Vimos que diversos aspectos podem influir na QVRS seja pelo seguimento convencional como em seguimentos inovadores como a auto-monitorização e o autogerenciamento. Para mensurar a QVRS, os pesquisadores utilizaram instrumentos ou questionários que propiciaram uma melhor avaliação dos pacientes em uso de ACO. 


\subsection{Instrumentos de medida de Qualidade de Vida Relacionada à Saúde e a Anticoagulação Oral.}

Mensurar a QVRS tem sido foco de inúmeras pesquisas desenvolvidas recentemente. O interesse crescente pelos autores se justifica pela tentativa de descrever os vários aspectos de vida das populações em estudos epidemiológicos a fim de conduzir a subjetividade dos indivíduos frente à presença ou gravidade da doença e dos seus sintomas e mostrar como as manifestações de uma doença ou tratamento são sentidas por eles (SNEED et al. 2001). Tais medidas são frequentemente utilizadas em grandes estudos multicêntricos e randomizados (“clinical trials”) e, por isso, vários instrumentos têm sido desenvolvidos.

Com relação à abrangência das populações e dos conceitos a serem investigados os instrumentos podem ser classificados em: genéricos, específicos (para doenças, populações ou domínios) e medidas de preferências (“utilities”) (BOWLING, 2001; FAYERS; MACHIN, 2007). Como os instrumentos fornecem informações diferentes, eles podem ser empregados concomitantemente.

Os instrumentos de QVRS podem ser classificados em genéricos, se usam questionários de base populacional sem especificar patologias, sendo mais apropriadas aos estudos epidemiológicos, de planejamento e de avaliação do sistema de saúde. As medidas genéricas de avaliação da QVRS não são capazes de dizer exatamente, para o profissional de saúde, o que fazer; entretanto, são capazes de demonstrar se os indivíduos conseguem executar determinadas atividades, e como eles se sentem quando as estão praticando (CICONELLI et al. 1999). Instrumentos específicos de QVRS abordam situações relacionadas à experiência de doenças, agravos ou intervenções médicas nas condições crônicas específicas tais como o câncer, diabetes, doença coronariana, uso de medicamentos, dentre outros. Porém, devido às suas especificidades eles não permitem comparações entre doenças diferentes (MINAYO; HARTZ; BUSS, 2000). 
Dentre os estudos revisados para a identificação de instrumentos de QVRS e o uso de ACO temos o de Casais et al. (2005) que analisou as percepções e a QV de indivíduos em uso de ACO, utilizando dois questionários: o SF-36 e um questionário desenvolvido especificamente para o estudo. Esse último possuía 17 itens sobre conhecimento, implicações da vida diária, impacto econômico da terapia, questões gerais de epidemiologia e dados socioeconômicos, questões relativas à terapia de anticoagulação oral propriamente dita, como duração, indicação, presença de complicações, atendimento clínico no âmbito do conhecimento, tempo dispensado ao paciente no atendimento, necessidade de atendimento de urgência, capacidade de solucionar problemas e confiança. Participaram desse estudo, 905 pacientes atendidos em uma clínica especializada de anticoagulação oral na Argentina.

Kullina et al. (1999) modificou um questionário utilizado no estudo de Dammann (1994 apud Kullina et al. 1999) para avaliar, em um período de seis meses, a influência do auto-monitoramento do INR e mudanças na qualidade de vida de 100 pacientes alemães em tratamento a longo prazo com ACO. Esse questionário abordava a independência da vida, organização de férias, organização do tempo livre, qualidade da anticoagulação, planos e projetos para a vida, auto-segurança, autoconfiança, humor geral, taxa de complicações, cooperação com médico, modificação da vida familiar, estado geral de saúde, sentimentos subjetivos da vitalidade e energia, influência da sociedade, capacidade física e mental e mudanças na aparência externa. Também foi levantado dados sobre a educação, profissão, experiências anteriores com auto-monitoramento (por exemplo, nas doenças como diabetes que utilizam o glicosímetro), aceitação do coagulômetro, tratamento médico, independência e a dosagem do medicamneto.

Em contrapartida, Sawicki (1999) desenvolveu o “Questionário de Qualidade de Vida para Terapia de Anticoagulação Oral de Sawicki” composto por 40 itens distribuídos em cinco dimensões: satisfação geral com tratamento, auto-eficácia, rede de apoio social, 
desagrados diários e angústia. Os itens eram avaliados em uma escala de resposta variando do número 1(totalmente insatisfeito) ao número 6 (totalmente satisfeito). Esse instrumento foi respondido por 179 pacientes, de cinco centros especializados em ACO na Alemanha. Estudos semelhantes adotando esse mesmo questionário foram desenvolvidos na Alemanha (CROMHEECKE et al. 2000) e em outros países, tais como Holanda (GADISSEUR et al. 2003) e Espanha (GONZÁLEZ et al. 2004).

Nos EUA, Samsa et al. (2004) propuseram o desenvolvimento e a validação preliminar de um instrumento denominado "Duke Anticoagulation Satisfaction Scale - DASS” com o objetivo de mensurar a qualidade de vida e a satisfação com a assistência à terapia de anticoagulação oral e foi aplicado a 262 pacientes de uma Clínica Especializada em anticoagulação oral. $\mathrm{Na}$ Espanha, esse instrumento foi validado e adaptado entre 137 pacientes em uso de ACO de um hospital universitário, sendo que os resultados relacionados à validade e confiabilidade foram semelhantes aos obtidos pelos autores da versão original (CARROBLES et al., 2006). Em um estudo recente, The Home INR (THINRS), desenvolvido também nos EUA, o instrumento DASS foi aplicado a 2.922 pacientes de uma clínica os quais foram randomizados em dois grupos, o auto-gerenciamento e o cuidado convencional, demonstrando como um dos seus resultados, maior satisfação com o uso de ACO no grupo do auto-gerenciamento (JEFFREY, 2008).

\subsection{Justificativa do estudo}

Alguns pontos se mostraram relevantes diante da literatura revisada para a temática ACO e QVRS, principalmente o pequeno número de estudos que utilizaram instrumentos específicos de QVRS em ACO. Identificamos apenas dois instrumentos específicos de QVRS: “Duke Anticoagulation Satisfaction Scale - DASS” e "Questionário de Qualidade de Vida para Terapia de Anticoagulação Oral de Sawicki”. Outro ponto importante a ser considerado 
é que inexistem publicações na literatura nacional que abordaram a utilização de instrumentos específicos de QVRS como método para avaliar o uso de ACO.

Entendemos que validar um instrumento de QVRS direcionado a esses pacientes para a realidade brasileira surge como uma ferramenta para compreendermos a complexidade da ACO entre nossos pacientes, principalmente se considerarmos que essa terapia pode acompanhar o paciente por um período de semanas, anos ou por toda sua vida.

Visando disponibilizar um instrumento de avaliação da QVRS para pacientes brasileiros submetidos à ACO decidimos entrar em contato com o autor do "Questionário de Qualidade de Vida para Terapia de Anticoagulação Oral de Sawicki”. Inicialmente, optamos por esse questionário por ser o mais usado até o momento e ter se mostrado válido e confiável em sua versão original (alfa de Cronbach de 0,64-086), bem como em sua versão adaptada para a Espanha (alfa de Cronbach de 0,67-0,74). Entretanto, não conseguimos obter a permissão do autor para a sua adaptação para o Brasil, não tendo o autor respondido aos nossos contatos por via eletrônica.

Diante deste resultado, nos voltamos para o instrumento DASS que, embora ainda recente, possui itens que avaliam aspectos importantes para os pacientes em uso de ACO e com propriedades psicométricas adequadas em sua avaliação inicial como apresentaremos a seguir. A permissão para a adaptação da versão original do DASS nos foi concedida pelos seus autores por via eletrônica (Anexo 1). 


\section{REFERENCIAL TEÓRICO E METODOLÓGICO}




\section{REFERENCIAL TEÓRICO E METODOLÓGICO}

\subsection{Duke Anticoagulation Satisfaction Scale (DASS): descrição do instrumento}

A versão original do instrumento DASS (Anexo 2) foi desenvolvido por Greg Samsa e colaboradores em 2004, nos EUA, para avaliar a QVRS e a satisfação do paciente em uso de ACO.

Para a construção do instrumento, os autores inicialmente buscaram identificar as dimensões relacionadas à $\mathrm{QV}$ relacionada à $\mathrm{ACO}$. Para tanto, realizaram buscas na base de dados Medline no período de 1985 a 2000, com a utilização dos termos “anticoagulation” e "quality of life" e buscas no periódico Archives of Internal Medicine, por se tratar de um periódico com publicações freqüentes sobre anticoagulação. Em seguida, foram formados grupos focais com pacientes em uso de ACO a fim de identificar os domínios de interesse e determinar suas sentenças (itens). Os pacientes foram recrutados em clínicas de anticoagulação e a maioria fazia uso de ACO por longo período de tempo. Entrevistas com especialista (médicos e farmacêuticos) também auxiliaram na identificação dos domínios e dos itens.

Como resultado desta etapa, os autores obtiveram um instrumento preliminar com 27 itens o qual foi aplicado, por meio de entrevistas, em nove pacientes da Clínica de Anticoagulação de Duke. Alguns dos itens do instrumento foram modificados e o processo de aplicação do instrumento foi repetido com outros nove sujeitos. A última versão do instrumento foi aplicada em 122 pacientes dessa mesma clínica sendo que 105 sujeitos responderam ao instrumento uma vez e 17 responderam novamente ao instrumento um mês depois. Com a finalidade de avaliar a confiabilidade do instrumento (teste-reteste). Os resultados do teste-reteste foram examinados por meio do coeficiente de correlação intraclasse e análise fatorial, médias e desvio-padrão para descrever as diferenças entre a aplicação 
do instrumento nos dois períodos. Foi obtido que as médias de pontuação e os desviospadrões do DASS total foram de $53,4(\mathrm{DP}=17,6)$ e $54,9(\mathrm{DP}=18,9)$ na primeira e na segunda entrevistas, respectivamente. O coeficiente de correlação intra-classe foi de 0,80 , valor considerado pelos autores superior ao ideal, mas aceitável. Assim, muitos itens tiveram suficiente variação e se agruparam nas dimensões esperadas, dentre esses itens, alguns podem ser relacionados aos aspectos específicos da QVRS e ACO como, por exemplo, "se a possibilidade de sangrar-se ou machucar-se limita a prática de atividade física"; mas também podem abordar aspectos globais, por exemplo, "se a possibilidade de sangrar-se ou machucarse afeta a sua vida" (SAMSA et al., 2004).

A próxima etapa realizada foi a avaliar a validade de constructo do DASS com a aplicação do instrumento entre 262 pacientes em uso de ACO de duas clínicas dos EUA, sendo 125 em seguimento pelo cuidado inovador e 137 pelo cuidado usual. Para tanto, os autores coletaram dados sócio-demográficos e clínicos e aplicaram os seguintes instrumentos: SF-36 (Short-Form Medical Outcomes Survey 36 itens) para avaliar o estado geral de saúde, PSQ-18 (Satisfaction with Medical Care Scale) para avaliar a satisfação com cuidado médico e o SDS-5 (Socially Desirable Response Set Scale) para obter uma tendência para as respostas socialmente desejáveis (SAMSA et al., 2004).

O PSQ-18 é um instrumento cujo escore total varia de 18 a 90 sendo que escores mais altos indicam grande satisfação com o cuidado médico. O SDS-5 trata-se de um instrumento cujos escores maiores indicam uma tendência para as respostas socialmente desejáveis sendo que o escore total pode variar de 5 a 25 . O SF-36 apresenta oito domínios cujos valores variam de 0 a100 (maiores valores indicam melhor avaliação do estado geral de saúde). (SAMSA et al., 2004). Tanto o instrumento PSQ-18 como o SDS-5 não são validados no Brasil. 
As análises estatísticas realizadas foram freqüências de distribuição, média e desviopadrão para obter o grau de variabilidade entre os itens; análises exploratórias, consistência interna pelo alfa de Cronbach e correlações item-total do DASS total e suas sub-escalas (confiabilidade); correlação dos escores do DASS com as variáveis demográficas, clínicas, escores do SF-36, PSQ-18 e SDS-5 (validade).

Nesta etapa do estudo, os participantes eram predominantemente casados, do sexo masculino, brancos com idade entre 69 anos, com segundo grau completo. Eles recebiam anticoagulação oral acima de quatro anos sendo a indicação mais freqüente, a fibrilação atrial e ainda faziam uso de outras medicações (média de seis medicamentos). Os itens do DASS mostraram suficiente variação e os itens foram agrupados de modo a refletir o impacto positivo e negativo da anticoagulação oral. A consistência interna da escala total foi boa (alfa de Cronbach foi de 0,88), assim como as sub-escalas também apresentaram resultados semelhantes (alfa de Cronbach de 0,87 para limitação; 0,88 para tarefa/sobrecarga; 0,78 para impacto psicológico positivo e 0,91 para impacto psicológico negativo). As sub-escalas do DASS se correlacionaram consistentemente com vários domínios do SF-36 e com a PSQ-18. Essas correlações foram, em sua maioria, inversas e estatisticamente significantes. Por exemplo, o impacto positivo foi mais fortemente correlacionado com a idade e o tempo de anticoagulação oral. Os escores do SDS-5 mostraram que os sujeitos tinham tendência para dar respostas socialmente desejáveis, o PSQ-18 indicou que, geralmente, existe uma alta satisfação com o sistema de cuidado médico como um todo (SAMSA et al. 2004).

$\mathrm{Na}$ avaliação dos autores, alguns itens não obtiveram resultados satisfatórios e foram excluídos do instrumento, são eles: 4c ("How much do you worry about your anti-clot treatment?") e 4e ("How much do you worry about the bad things (for example, stroke) which your anti-clot treatment is intended to prevent?”). A versão final do DASS ficou, então, composta por 25 itens dispostos de modo a englobar três dimensões pertinentes à ACO: 
limitação ("limitation”), tarefa/sobrecarga ("hassles and burdens”) e impacto psicológico

(“psychological impacts”) representados no Quadro 2.

Quadro 2: Itens do instrumento Duke Anticoagulation Satisfaction Scale (DASS) segundo seus domínios.

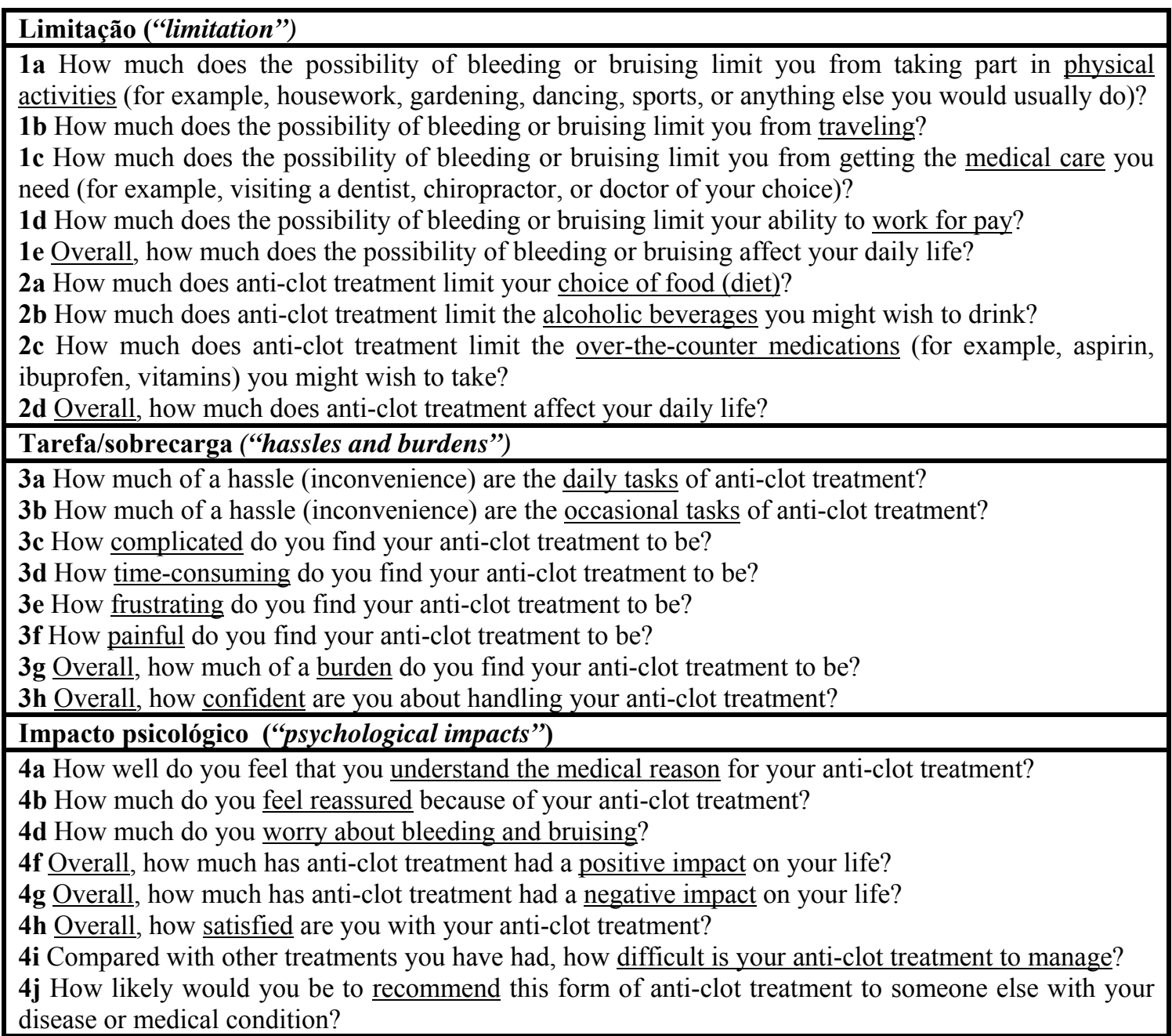

Fonte: Samsa et al., 2004

Para todos os itens, os pacientes respondem a uma escala de resposta com sete categorias: "nada", "muito pouco", "pouco", "moderadamente", "bastante", "muito" e “muitíssimo" na qual, (1) representa "nada" e (7) “muitíssimo". Exceção se faz àqueles itens que abordam sobre o consumo de bebidas alcoólicas e atividades remuneradas. Nessas 
situações, os pacientes que não consomem álcool e não exercem atividades remuneradas deverão ter a sua resposta considerada como "não se aplica".

O intervalo numérico da escala total do DASS varia de 25 a 175. Para o domínio limitação, com nove itens, o intervalo possível está entre 9 a 63; o domínio tarefa/sobrecarga conta com oito itens e contempla um intervalo de 8 a 56; o domínio impacto psicológico também contém oito itens divididos entre impacto psicológico positivo com cinco itens (4a, 4b, 4f, $4 \mathrm{~h}, 4 \mathrm{j})$, intervalo de 5 a 35, e o impacto psicológico negativo com três itens $(4 \mathrm{~d}, 4 \mathrm{~g}, 4 \mathrm{i})$ e intervalo de 3 a 21. A obtenção dos valores numéricos da escala total e se dá pela soma das respostas de todos os itens, assim como, a obtenção dos valores numéricos das sub-escalas ocorre ao somar as respostas aos itens de cada domínio, cujos valores numéricos menores refletem melhor satisfação com o uso de ACO, menor limitação, menor tarefa sobrecarga e menor impacto psicológico (tanto positivo como negativo). Para tanto são necessários considerar os itens reversos (3h, $4 \mathrm{a}, 4 \mathrm{~b}, 4 \mathrm{f}, 4 \mathrm{~h}$ e $4 \mathrm{j})$.

Os autores concluíram que o novo instrumento apresentou propriedades psicométricas aceitáveis e tem um potencial para auxiliar na identificação de razões para a insatisfação, assim como para a satisfação, além de poder ser aplicado a diferentes modelos de seguimento de indivíduos em uso de ACO (auto-monitorização e auto-gerenciamento) (SAMSA et al. 2004).

\subsection{O processo de adaptação cultural de instrumentos}

Pesquisas de adaptação cultural ou transcultural têm sido freqüentes nos últimos anos no campo das ciências sociais e sua importância tem ganhado reconhecimento para estudos em outros campos como nas ciências da saúde, especialmente com o crescimento de pesquisas sobre a QVRS e outras variáveis de medida do estado de saúde. Pesquisas com esse enfoque são utilizadas para estudos espidemiológicos a fim de se analisar as crenças, atitudes e 
comportamentos relacionados à saúde além de aspectos administrativos e econômicos (GUILLEMIN; BOMBARDIER; BEATON, 1993; SPERBER, 2004).

Vimos que QV/QVRS é comumente medida por uma complexa coleção de itens, escalas, domínios e instrumentos. A esse respeito, Gill e Feinstein (1994) definem:

\begin{abstract}
"Item representa uma simples questão, como por exemplo, "como está seu apetite?". Escala compreende a resposta a essa questão que pode ser categorizadas em expressões (como, "terrível, fraco, médio, excelente") ou por meio de uma linha visual analógica (de "terrível a excelente"). Domínio identifica um foco de atenção em particular, como a digestão, e pode ser alcançado com a resposta de um único item ou resposta de vários itens relacionados. Instrumento é uma coleção de itens usados para obter os dados desejados, pode conter uma questão global ou muitos itens a serem categorizados em domínios"(pg. 620).
\end{abstract}

Com poucas exceções, os instrumentos de QVRS são desenvolvidos em língua inglesa e têm como população alvo indivíduos de países que falam inglês. Porém, a necessidade de utilização dos resultados obtidos por esses instrumentos, como indicadores de QVRS, também se faz presente em outros países de língua não inglesa, que têm como opções: criar um novo instrumento ou adaptar culturalmente os já existentes (GUILLEMIN; BOMBARDIER; BEATON, 1993; SWAIDE-VERDIER et al. 2004; CASTRO; PORTELA; LEÃO, 2007).

Como a tarefa de desenvolver um novo instrumento para mensurar QVRS pode ser árduo, e requer um considerável investimento de tempo e de dinheiro, frequentemente os instrumentos são adaptados para realidades culturais distintas das quais foram criados. Esse processo envolve dois estágios: a tradução do instrumento e a sua adaptação propriamente dita e a análise das suas propriedades psicométricas na nova versão (SPERBER, 2004; MCKENNA; DOWARD, 2005). O instrumento adaptado precisa satisfazer todos os critérios metodológicos exigidos para a medida original, ou seja, ser válido e confiável, medindo realmente aquilo que se propõe avaliar (CHWALOW, 1995; SPEBER, 2004). 
Neste sentido, Anguita; Repullio-Labrador e Pereira-Candel (2001) defendem que a adaptação de instrumentos é preferível e cita as três razões principais: 1) a complexidade do processo de criação de um instrumento; 2) a adaptação pode resultar em um instrumento confiável e válido similar ao instrumento original e 3) a adaptação permite elementos de referência para serem utilizados em investigações nas quais participam vários países.

No que se refere à adaptação de instrumentos de QVRS temos que considerar que há vários fatores envolvidos nesse conceito, como a percepção da saúde, a descrição de sintomas e as expectativas do cuidado. A necessidade de se interpretar o conceito de QVRS, dada as diferentes culturas, implica na noção de equivalência, ou seja, se os domínios inseridos no conceito a ser estudado também são importantes para a cultura na qual serão investigados (equivalência conceitual); se os itens presentes em cada um dos domínios são relevantes para a cultura alvo (equivalência dos itens); se a tradução realizada garante a equivalência dos significados dos itens (equivalência semântica); se o método usado para a aplicação do instrumento adaptado é compatível com as recomendações do autor da versão original (equivalência operacional) e se o formato usado para a escala de resposta aos itens e as instruções para o preenchimento do instrumento estão adequados para a cultura do país onde a versão adaptada será usada (equivalência da medida) (SCHMIDT; BULLINGER, 2003). Portanto há, inúmeras e diferentes equivalências a serem verificadas nas etapas do processo de adaptação cultural de um instrumento. Segundo Ramos de Carvalho et al. (1991), ainda não há um consenso entre os pesquisadores sobre a melhor metodologia a ser seguida na realização da adaptação cultural de um instrumento, razão pela qual muitos autores têm utilizado seus próprios métodos.

Assim, como diversos métodos têm sido propostos para a adaptação cultural de instrumentos de QVRS, Castro, Portela e Leão (2007) avaliou criticamente essa metodologia dos principais instrumentos de QVRS bucal. O autor verificou que existe uma grande 
variedade de metodologias empregadas para a adaptação cultural de instrumentos desde a simples traduções até metodologias seguindo diretrizes internacionalmente aceitas. Constatou, ainda, que a maioria dos autores não publica informações importantes sobre a metodologia utilizada tais como a quantidade e as características dos tradutores, a realização ou não de um comitê de revisão e características da amostra utilizada no estudo piloto.

De modo similar, Guillemin, Bombardier e Beaton (1993) já haviam constatado a falta de padronização na metodologia de adaptação cultural de instrumentos para mensurar QVRS e propuseram diretrizes a serem seguidas contemplando cinco passos essenciais descritos a seguir:

(1) a tradução inicial do instrumento original feita por, pelo menos, dois tradutores diferentes e nativos da língua alvo que conheçam os objetivos do estudo e os conceitos envolvidos, a fim de detectar erros e interpretações divergentes de itens ambíguos da versão original, obtendo uma versão que preserve o mesmo significado de cada item entre as duas línguas.

(2) a retro-tradução ("back-translation”) consiste em verter para o idioma original o instrumento traduzido. Cada retro-tradução será traduzida novamente para a língua de origem independentemente uma da outra. É mais adequado ser feito por pessoas que sejam fluentes na língua, nas expressões idiomáticas e nas formas coloquiais do idioma de origem, o que é realizado por pessoas nativas do idioma do instrumento em questão. Ao contrário dos tradutores, os retro-tradutores, de preferência, não devem conhecer a intenção, nem os conceitos do estudo. A seguir, a versão original e as versões traduzidas devem ser comparadas, sendo as divergências discutidas com os tradutores e o pesquisador responsável. O objetivo é corrigir possíveis erros de tradução que comprometam os significados dos itens e rever interpretações equivocadas ocorridas durante as etapas de tradução e retro-tradução, as quais deverão ser corrigidas. 
(3) o comitê de juízes deverá produzir uma versão final do instrumento baseado nas várias traduções e nas retro-traduções obtidas nas etapas anteriores visando preservar as equivalências das instruções, preenchimento, itens e escala de resposta entre as duas versões do instrumento (original e adaptada). Para tanto, esse comitê deverá ser composto por indivíduos bilíngües, especialistas nos conceitos a serem explorados e que sejam representativos do grupo em questão. Em caso de divergências, o comitê pode modificar ou eliminar itens inadequados e ambíguos e, ainda, substituir itens que melhor se ajustem à situação designada, mantendo o conceito cultural dos itens excluídos. Dessa maneira, foram propostas várias taxonomias de equivalência com o objetivo de avaliar as versões, original e final, do instrumento de medida. A seguir, são definidos os tipos de equivalências relatadas por Guillemin, Bombardier e Beaton (1993):

a) equivalência semântica: alterações gramaticais são muitas vezes necessárias na construção das sentenças (itens); assim, a equivalência semântica avalia o significado das palavras na tentativa de preservar o significado e a formulação dos termos originais.

b) equivalência idiomática: algumas expressões e coloquialismos são raramente traduzíveis, assim, devem ser substituídas por expressões equivalentes na cultura alvo.

c) equivalência experimental: avalia itens que remetem a experiências de determinada cultura, na tentativa de compensar um item não significante na cultura-alvo por outro significante.

d) equivalência conceitual: refere-se à validade do conceito explorado e aos eventos vivenciados pelos indivíduos da cultura-alvo; assim, itens podem ser equivalentes quanto ao significado, mas não equivalentes quanto ao conceito.

(4) o pré-teste é realizado com a aplicação do instrumento na versão original e adaptada em uma amostra de indivíduos leigos bilíngües que deverá responder ao instrumento com objetivo de checar os erros e as divergências da tradução. Essa etapa do processo de 
adaptação consiste na avaliação da equivalência das versões original e final. Os autores também sugerem a aplicação da versão adaptada em uma amostra da população alvo, objetivando garantir sua compreensão e clareza.

(5) a ponderação dos escores é um aspecto importante a ser observado, pois nem sempre significa que "pesagem" dos escores do instrumento original se aplica a nova situação cultural. Para minimizar esse aspecto, a adaptação cultural dos escores pode ser avaliada por especialistas como, por exemplo, profissionais da área da saúde, pacientes e pessoas leigas e também por meio de técnicas estatísticas.

As etapas para a adaptação cultural de instrumentos de QVRS proposta por Guillemin, Bombardier e Beaton (1993) têm sido seguidas por vários autores no Brasil. São exemplos de instrumentos adaptados Segundo estas etapas: Medical Outcomes 36 Item Short Form Health Survey - SF-36 (CICONELLI, 1997); Quality of life index de Ferrans e Powers (KIMURA, 1999); King's Health Questionnaire (KHQ) (FONSECA et al. 2005), Functional Assessment of Cancer Therapy - Bone Marrow Transplantation (FACT-BMT) (MASTROPRIETO et al. 2007); Pediatric Asthma Quality of Life Questionnaire (PAQLQ-A) (LA SCALA et al. 2005).

No entanto, com a finalidade de aprimorar o processo metodológico apresentado por Guillemin, Bombardier e Beaton (1993), alguns autores apresentam uma nova proposta para conduzir a adaptação cultural.

Dentre eles, Ferrer et al. (1996) sugerem que depois de obtidas as traduções, essas deverão ser sintetizadas (síntese das traduções) e avaliada por um comitê de juízes e somente depois seguir para a retro-tradução. Segundo esses autores, a alteração proposta permitirá que sejam detectados erros ou problemas de compreensão os quais não poderiam ser notados após a retro-tradução ter sido feita, visando assegurar o objetivo da retro-tradução que é o de observar possíveis erros de significado na primeira versão traduzida. Utilizando a proposta de Ferrer et al. (1996), alguns pesquisadores brasileiros têm ainda acrescentado outra etapa 
denomina de Análise/validação Semântica (ESCHEVARRIA-GUANILO, 2005; DANTAS, 2007; FERREIRA, 2006).

A análise semântica foi originalmente desenvolvida em experimentos cognitivos, sociais e psicológicos, testadas em sujeitos para entender a real compreensão dos mesmos sobre determinada situação descrita por uma determinada variável. A análise semântica na área da QV/QVRS foi introduzida recentemente, sendo um ingrediente essencial em todo o processo. A finalidade é saber como os entrevistados compreendem os itens ou se eles modificariam alguns deles. Ela pode ser realizada individualmente ou em grupo e seus resultados devem ser apresentados de forma padronizada, por meio de instrumentos específicos de coleta de dados das informações e documentados (SCHMIDT; BULLINGER, 2003). Acrescenta-se, ainda, que nesse tipo de análise, uma das preocupações relevantes é verificar se os itens são inteligíveis para o estrato mais baixo da população alvo e evitar deselegância na formulação dos itens para o estrato mais sofisticado da população alvo. O grupo deve ser composto por até quatro indivíduos, com as características anteriormente mencionadas. O pesquisador deverá apresentar o instrumento para os sujeitos, abordando item por item. $\mathrm{O}$ entendimento de cada item não deverá apresentar-se como fator complicador na resposta dos indivíduos e nem apresentar itens que sejam demasiadamente primitivos, mas sim com suficiente seriedade para todos os sujeitos (PASQUALI, 1999).

A trajetória metodológica para a adaptação cultural de um instrumento de medida compreende um processo sistemático e rigoroso para garantir que a validade e a confiabilidade do instrumento original se mantenham na versão adaptada.

\subsection{Avaliação das propriedades psicométricas de um instrumento para outra cultura}

Outra etapa para a adaptação cultural de um instrumento de medida é avaliar as propriedades psicométricas, as quais incluem a validade (ou fidedignidade) e a confiabilidade 
(ou precisão/reprodutibilidade). Essa fase é fundamental, pois a equivalência de uma medida pode ser apenas demonstrada por meio da análise dessas propriedades e sua coerência com o questionário original (FAYERS; MACHIN, 2007).

A validade de um instrumento evidencia se o que está sendo medido é aquilo o que pesquisador pretende avaliar, ou seja, é a habilidade de um método em medir o que se propõe. A validade pode ser avaliada por meio da validade de face, de construto ou de conceito, de conteúdo e validade relacionada ao critério (CLARK-CARTER, 1997; PASQUALI, 1999).

A validade de face ou aparente está relacionada ao fato do instrumento estar medindo o constructo apropriado, reporta à compreensão e aceitação dos itens do instrumento pelos próprios pesquisadores e pelos sujeitos, é o julgamento de quão relevante os itens ou questões são. Para tanto, algumas questões podem ser formuladas como, "o que os sujeitos pensam que a escala está medindo?" ou ainda "eles compreendem as questões?" (CHWALOW, 1995; FAYERS; MACHIN, 2007).

A validade de conteúdo de um instrumento examina a capacidade dos itens de representar adequadamente todas as dimensões do conteúdo a ser abordado no instrumento. Tende a ser julgada de forma empírica, uma vez que não existem métodos totalmente objetivos para garantir que um instrumento abranja adequadamente o conteúdo a ser medido (POLIT; HUNGLER, 2004; FAYERS; MACHIN, 2007). Para que ela possa ser determinada, o instrumento deve ser submetido à, pelo menos, dois juízes, sendo o mais comum a avaliação por um painel de especialistas e leigos que irão avaliar a relevância de cada item para o domínio e julgar se eles representam o conteúdo do domínio em questão (WALTZ; STRICKLAND; LENZ, 2005)

A validade de constructo ou de conceito examina a ligação teórica dos itens conjuntamente com a escala hipotética. Refere-se a habilidade do instrumento para confirmar as hipóteses esperadas. Trata-se de uma propriedade complexa e difícil de ser determinada pois trata- 
se da busca de evidências que apóiam a interpretação de valores com o constructo a ser investigado. Constructo é uma idéia científica desenvolvida ou hipotetizada para descrever ou explicar um fenômeno, como, por exemplo, a percepção da qualidade de vida, do estado de saúde ou de um comportamento (FAYERS; MACHIN; 2007). Poderíamos elaborar as seguintes questões, "os itens da escala refletem a dimensão que se pretende testar, de acordo com as definições dos peritos?" ou "há um julgamento teórico, por peritos, na estrutura da escala?" (CHWALOW, 1995). A validade de constructo pode ser subdividida em duas vertentes distintas: validade de constructo convergente e validade de constructo discriminante ou divergente.

A validade de constructo convergente refere-se à associação significativa da medida obtida pelo instrumento com outras variáveis com as quais o contructo medido deveria estar relacionado, isto é, a aplicação conjunta de algum instrumento de medida semelhante que seja confiável e válido (padrão ouro) (PASQUALI, 1999; CLARK-CARTER, 1997). Altas correlações entre as medidas dos instrumentos sugerem que ambos estão medindo um mesmo fator, confirmando valores observados com as predições (FAYERS; MACHIN, 2007).

A validade de constructo discriminante ou divergente reconhece que as dimensões entre os instrumentos apresentam, comparativamente, baixas correlações (FAYERS; MACHIN, 2007). São exemplos de testes para avaliar essa validade, comparação entre grupos distintos, ou seja, comparar grupos que têm altos valores em uma escala que mede determinado constructo com grupos que têm menores valores para o mesmo constructo.

A análise fatorial é outro teste que visa avaliar a validade de constructo analisando as dimensões ou componentes do instrumento adaptado. Realizada por meio de procedimentos matemáticos ela identifica agrupamentos de variáveis a partir da análise das inter-correlações entre elas e cada agrupamento, denominado de fator ou dimensão. Um fator é definido para aquele grupo de variáveis cujos itens da escala correlacionam-se mais altamente entre si do que com as variáveis de outros agrupamentos não relacionados (WALTZ; STRICKLAND; LENZ, 2005). 
A validade de critério considera se a escala tem associação empírica com critérios externos relacionados às medidas de outros instrumentos, com validades confirmadas, e que avaliam o mesmo constructo (FAYERS; MACHIN, 2007). Pode ser testada confrontando a medida proveniente do instrumento com outras medidas clínicas objetivas ou medidas provenientes de como instrumentos que avaliam estado de saúde. A validade relacionada ao critério pode ser classificada em concorrente e preditiva (WALTZ; STRICKLAND; LENZ, 2005).

A validade de critério preditiva ressalta a capacidade da escala em predizer outras variáveis, ou seja, os escores numa dada escala são usados para predizer seu comportamento ou seu desempenho num critério predeterminado, por exemplo, um nível pior de qualidade de vida seria prognóstico de um índice de mortalidade maior? (CHWALOW, 1995).

A validade de critério concorrente refere-se a capacidade da escala correlacionar-se com alguma medida de um critério externo obtido no mesmo momento, por exemplo, a qualidade de vida piora de acordo com o progresso da doença? (CHWALOW, 1995).

A confiabilidade (reliability) de um instrumento está relacionada à capacidade de medir com precisão, consistência e estabilidade ao longo do tempo o atributo que se deseja medir, isto é, o grau que o instrumento produz os mesmos resultados quando aplicados em um mesmo sujeito em diferentes ocasiões ou em uma única ocasião por dois observadores distintos (CLACK-CARTER, 1999; PASQUALI, 2001). A confiabilidade do instrumento pode ser avaliada pelo grau de consistência com que ele mede o atributo proposto e com que permite evidenciar se os itens que compõem o instrumento estejam positivamente relacionados, o que confirmaria a medida de um mesmo atributo. Há diferentes métodos: estabilidade, consistência interna e equivalência (POLIT; HUNGLER, 1999). A confiabilidade é, usualmente, estimada pelos seguintes procedimentos estatísticos: o testereteste e a avaliação da consistência interna, sendo este último o mais utilizado. O teste-reteste 
avalia a estabilidade da medida e consiste em calcular a correlação entre as distribuições de escores obtidos num mesmo teste pelos mesmos sujeitos em duas ocasiões diferentes de tempo. A consistência interna visa verificar a homogeneidade dos itens do instrumento, o qual pode ser obtido pelo teste de duas metades, Kuder-Richardson e alfa de Cronbach (WALTZ; STRICKLAND; LENZ, 2005).

Especial consideração é dada ao alfa de Cronbach, pois, é o método mais utilizado para verificar a consistência interna de instrumento. Seus valores variam de zero a um com correlações positivas entre os itens. Valores abaixo de 0,70 são geralmente considerados como aceitáveis para escalas psicométricas embora seja recomendado que o seu valor deva ser acima de 0,80 (bom) ou mesmo 0,90 (excelente). Entretanto, um valor acima de 0,90 pode indicar redundância dos itens sendo considerados aceitáveis valores entre 0,70 e 0,90 (CUMMINGS; STWART; RULLEY, 2003).

Segundo Sapnas e Zeller (2002), os pesquisadores tem considerado que o poder da análise das propriedades psicométricas está na determinação adequada do tamanho da amostra, a qual está embasada na psicometria tradicional que aconselha "10 respondents per iten” (dez respondentes por item do questionário). Assim, para o DASS que contêm 25 itens necessitaríamos de uma amostra de 250 pacientes para haver uma análise adequada. Baseados em exemplos de pesquisas hipotéticas e reais esses autores demonstraram que sub-amostras de, no mínimo, 50 e, no máximo, de 100 sujeitos são suficientes quando se pretende analisar as propriedades psicométricas de instrumentos para medidas de constructos sociais. Acreditam que "10 respondent por item" representa uma "sample size overkill”, ou seja, um "tamanho da amostra acima do necessário" para se chegar a uma conclusão desejável. E defendem a premissa de que uma amostra de 100 sujeitos é suficiente para verificar as propriedades psicométricas de um instrumento que está sendo testado em outra população (SAPNAS; ZELLER, 2002). 


\section{OBJETIVOS}




\section{OBJETIVOS}

\subsection{Gerais}

- Disponibilizar, para o Brasil, a versão adaptada do instrumento Duke Anticoagulation Satisfaction Scale-DASS;

- Testar as propriedades psicometricas da versão adaptada em uma amostra de pacientes brasileiros em uso de terapia de anticoagulação oral.

\subsection{Específicos}

- Avaliar a validade de face e de conteúdo da versão adaptada do instrumento Duke Anticoagulation Satisfaction Scale-DASS por meio da análise de um comitê de juízes;

- Avaliar a validade de constructo da versão adaptada do instrumento Duke Anticoagulation Satisfaction Scale-DASS por meio da análise fatorial verificando a manutenção da sua dimensionalidade;

- Avaliar a validade de contructo convergente da versão adaptada do instrumento Duke Anticoagulation Satisfaction Scale-DASS associando seus resultados com as medidas obtidas por um instrumento de avaliação do estado de saúde percebido;

- Avaliar a validade de constructo divergente do instrumento Duke Anticoagulation Satisfaction Scale-DASS associando seus resultados com idade e o tempo de uso do ACO;

- Avaliar a confiabilidade da versão adaptada do Duke Anticoagulation Satisfaction Scale-DASS por meio da consistência interna de seus itens. 
MATERIAL E MÉTODO 


\section{MATERIAL E MÉTODO}

\subsection{Delineamento do estudo}

Trata-se de um estudo metodológico cuja proposta foi adaptar e validar um instrumento de qualidade de vida relacionada à saúde para pacientes brasileiros em uso de ACO. Um estudo metodológico difere de outros delineamentos de pesquisa por não abranger todas as etapas do processo de pesquisa, sendo que o pesquisador metodológico está interessado em identificar um constructo intangível e torná-lo tangível com uma ferramenta de papel e lápis ou protocolo de investigação. Basicamente, esse tipo de estudo abrange, entre outras etapas, o teste de confiabilidade e validade da ferramenta (LOBIONDO-WOOD; HABER, 2001).

\subsection{Proteção aos sujeitos do estudo}

Este projeto foi aprovado pelo Comitê de Ética em Pesquisa do HCFMRP - USP sob o processo no. 6736/2007 (Anexo 3). Na abordagem dos sujeitos apresentávamos os objetivos da pesquisa por escrito e verbalmente. Com a concordância do participante, entregávamos o Termo de Consentimento Livre e Esclarecido (Apêndice 1) para assinatura dos envolvidos, paciente e pesquisador. Tal procedimento visou atender aos dispositivos da Resolução 196/96 do Conselho Nacional de Saúde (BRASIL. MS, 1998), os quais regulamentam a realização de pesquisas envolvendo seres humanos. Foi assegurada ao participante a privacidade durante o preenchimento do questionário, a sua não identificação e o direito de desistir da participação da pesquisa a qualquer momento, sem prejuízo do seu atendimento na instituição hospitalar. 


\subsection{Permissão dos autores para a adaptação cultural e uso do instrumento}

A permissão para a adaptação cultural do instrumento Duke Anticoagulation Satisfaction Scale (DASS) foi solicitada ao Dr. Greg Samsa, principal autor do instrumento. Em e-mail recebido dia 13 de abril de 2006, o referido pesquisador concedeu permissão para que o instrumento fosse adaptado para língua portuguesa.

\subsection{Processo de adaptação cultural adotado}

O processo de adaptação cultural adotado para o instrumento DASS foi aquele proposto por Ferrer e colaboradores (1996) o qual já foi utilizado em outros estudos brasileiros (ESCHEVARRIA-GUANILO, 2005; DANTAS, 2007; FERREIRA, 2006).

Os passos percorridos foram: 1) tradução do DASS para a língua portuguesa; 2) obtenção do primeiro consenso da versão em português; 3) avaliação pelo comitê de juízes; 4) retro-traduação ou Back-translation); 5) obtenção do consenso das versões em inglês e comparação com a versão original; 6) análise semântica dos itens e 7) pré-teste. Esses passos estão esquematizados na Figura 1 e serão detalhados a seguir. 

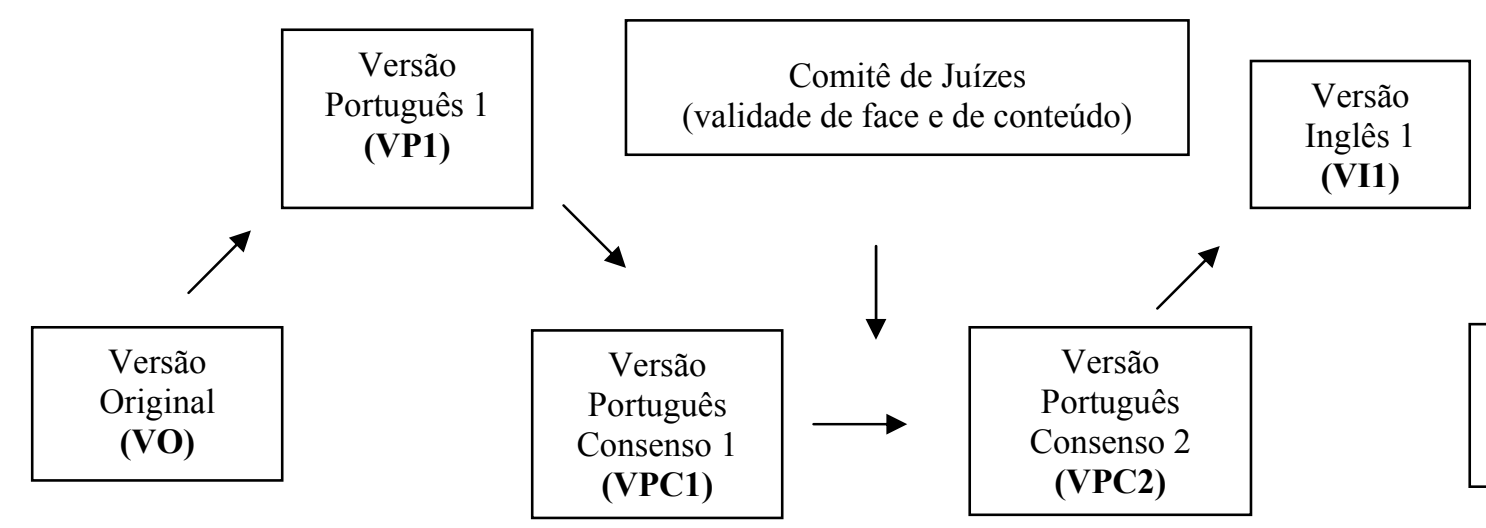

(VI1)
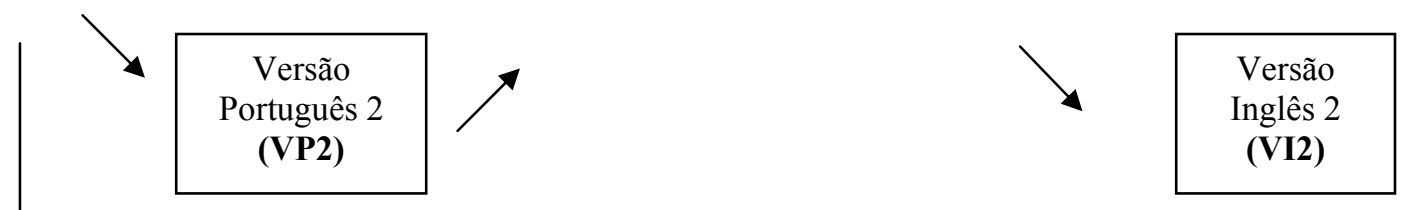

Versão Inglês

Final

(VIF)

(VPC1)

Consenso 2
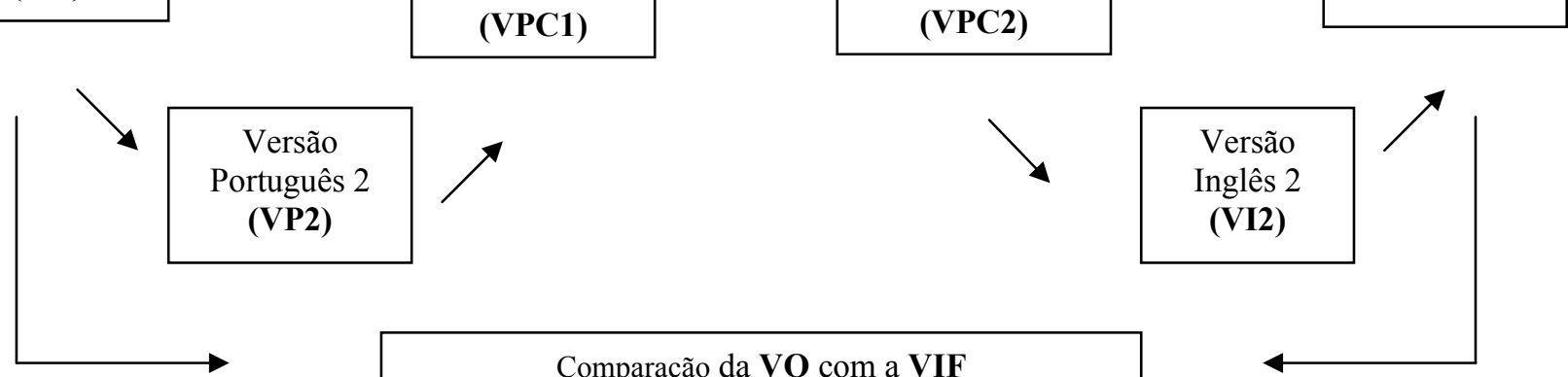

Comparação da VO com a VIF

Versão Português Consenso 3 (VPC3)

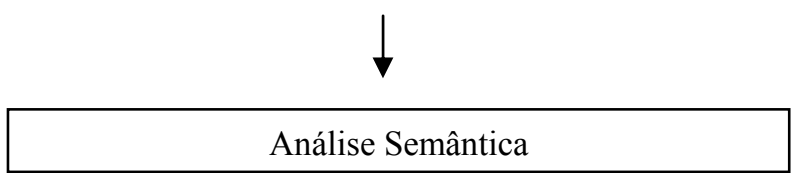

Análise Semântica
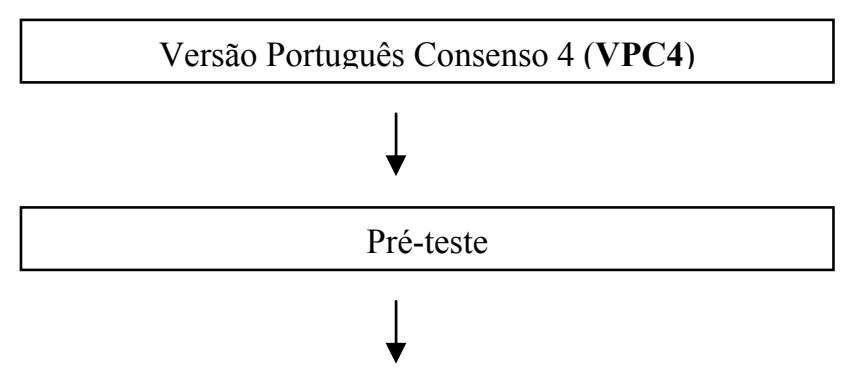

Versão Português Final (VPF)

$\downarrow$

Análise da Confiabilidade pela consistência Interna (Coeficiente Alfa de Cronbach)
Validade de Construto (análise fatorial), validade convergente (SF-36) e validade divergente (idade e tempo de uso do ACO)

Figura1-Processo de adaptação cultural do instrumento Duke Anticoagulation Satisfaction Scale (DASS) 


\subsubsection{Tradução do DASS para a língua portuguesa}

A tradução do DASS em sua Versão Original (VO) para a língua portuguesa foi realizada por uma brasileira que leciona aulas de inglês e pela pesquisadora e originaram a Versão Português 1 (VP1) (Anexo 4) e Versão Português 2 (VP2) (Anexo 5), respectivamente. Com as duas versões em português (VP1 e VP2), a pesquisadora e sua orientadora se reuniram com o intuito de selecionar as frases de melhor expressão e como resultado dessa etapa, obtiveram a Versão Português Consenso 1 (VPC1) (Apêndice 2).

\subsubsection{Avaliação pelo Comitê de Juízes}

Para a realização desta etapa, foram selecionados seis juízes: 1) médico cardiologista e docente da Divisão de Cardiologia do Hospital das Clínicas da Faculdade de Medicina de Ribeirão Preto da Universidade de São Paulo; 2) enfermeira e docente do Departamento de Enfermagem Geral e Especializada da Escola de Enfermagem de Ribeirão da Universidade de São Paulo; 3) enfermeira, especialista em cardiologia e pós-graduanda, nível doutorado, do programa de Enfermagem Fundamental da Escola de Enfermagem de Ribeirão da Universidade de São Paulo; 4) enfermeira, especialista em cardiologia e pós-graduanda, nível mestrado, do programa de Enfermagem Fundamental da Escola de Enfermagem de Ribeirão da Universidade de São Paulo; 5) orientadora desse estudo e docente do Departamento de Enfermagem Geral e Especializada da Escola de Enfermagem de Ribeirão da Universidade de São Paulo e; 6) a pesquisadora.

Os membros do Comitê de Juízes foram convidados a participar de uma reunião com o intuito de avaliarem as equivalências cultural, conceitual, semântica e idiomática entre a VPC1 e a VO do instrumento DASS. Para a avaliação das equivalências solicitadas procedeuse a leitura da VO do DASS e da VPC1 de cada item do instrumento e, em conjunto, foram 
feitas as discussões. As modificações foram acatadas quando obtiveram, pelo menos, $80 \%$ dos os juízes, ou seja, cinco deles concordavam com as propostas.

No geral, as questões que continham a expressão "Quanto" foi substituída por "O quanto que", já o termo "te limita" foi acompanhado pelo verbo "atrapalha" entre parênteses \{te limita (atrapalha)\}, assim como após "anticoagulação" foi acrescentado a expressão "afinar o sangue" entre parênteses \{anticoagulação (afinar o sangue)\}. As demais modificações dos itens e enunciados sugeridas pelo comitê de juízes encontram-se no Quadro 3.

Quadro 3 - Modificações sugeridas pelo comitê de juízes para a Versão Português Consenso 2 do DASS

\begin{tabular}{|c|c|c|}
\hline Itens do DASS & Versão Português Consenso 1 & Modificado por \\
\hline $1 \mathrm{a}$ & $\begin{array}{l}\text { "Quanto a possibilidade de sangrar ou se machucar } \\
\text { limita você a fazer atividade física (por exemplo, } \\
\text { serviços domésticos, jardinagem, dançar, esportes, ou } \\
\text { qualquer outra atividade que usualmente você faz)?" }\end{array}$ & Retirada da frase \\
\hline $1 b$ & $\begin{array}{l}\text { "Quanto a possibilidade de sangrar ou se machucar te } \\
\text { limita viajar?" }\end{array}$ & "passear fora de casa" \\
\hline $1 \mathrm{c}$ & $\begin{array}{l}\text { "Quanto a possibilidade de sangrar ou se machucar } \\
\text { limita a realização de qualquer outro tratamento } \\
\text { médico que você precisa (por exemplo, ir ao dentista, } \\
\text { ao quiroprata, ou outro médico de sua escolha)?" }\end{array}$ & "tratamento de saúde" \\
\hline $1 \mathrm{~d}$ & $\begin{array}{l}\text { "Quanto a possibilidade de sangrar ou se machucar } \\
\text { limita o seu emprego?" }\end{array}$ & "trabalho remunerado" \\
\hline $1 \mathrm{e}$ & $\begin{array}{l}\text { "No geral, quanto a possibilidade de sangrar ou se } \\
\text { machucar afeta sua rotina diária?" }\end{array}$ & $\begin{array}{l}\text { "afeta (atrapalha) o seu } \\
\text { dia-a-dia }\end{array}$ \\
\hline Enunciado & $\begin{array}{l}\text { "Precisar de tratamento de anticoagulação significa } \\
\text { mudar também alguns dos seus outros hábitos." }\end{array}$ & $\begin{array}{l}\text { "anticoagulação (afinar o } \\
\text { sangue)" e "costumes" }\end{array}$ \\
\hline $2 \mathrm{a}$ & $\begin{array}{l}\text { "Quanto o seu tratamento de anticoagulação limita sua } \\
\text { escolha na alimentação (dieta)?" }\end{array}$ & $\begin{array}{l}\text { "muda a sua alimentação } \\
\text { por causa do tratamento } \\
\text { de anticoagulação" }\end{array}$ \\
\hline $2 b$ & $\begin{array}{l}\text { "Quanto o seu tratamento de anticoagulação limita o } \\
\text { consumo de bebidas alcoólicas que você desejaria } \\
\text { tomar?" }\end{array}$ & $\begin{array}{l}\text { "uso" e foi retirada a } \\
\text { expressão e "que você } \\
\text { desejaria tomar" }\end{array}$ \\
\hline $2 \mathrm{c}$ & $\begin{array}{l}\text { "Quanto o seu tratamento de anticoagulação limita o } \\
\text { uso de medicamentos sem receita médica (por } \\
\text { exemplo, aspirina, ibuprofeno, vitaminas) que você } \\
\text { desejaria usar?" }\end{array}$ & $\begin{array}{l}\text { "medicamentos para dor, } \\
\text { para febre e vitaminas" e } \\
\text { "que você desejaria } \\
\text { tomar" }\end{array}$ \\
\hline Enunciado & $\begin{array}{l}\text { "Tarefas diárias relacionadas ao tratamento podem } \\
\text { incluir: lembrar de tomar o remédio num determinado } \\
\text { horário, tomar a dose correta do remédio, não beber } \\
\text { muito álcool, seguir dieta alimentar moderada, evitar } \\
\text { machucados e sangramentos, e assim por diante." }\end{array}$ & $\begin{array}{l}\text { "Atividades diárias" e foi } \\
\text { retirada a palavra "álcool" }\end{array}$ \\
\hline $3 a$ & $\begin{array}{l}\text { "Quanto as tarefas diárias do tratamento de } \\
\text { anticoagulação são difíceis ou inconvenientes?" }\end{array}$ & $\begin{array}{l}\text { "dicultam (atrapalham) a } \\
\text { sua vida?" }\end{array}$ \\
\hline
\end{tabular}


Quadro 3 - Modificações sugeridas pelo comitê de juízes para a Versão Português Consenso 2 do DASS (continuação)

\begin{tabular}{|c|c|c|}
\hline Itens do DASS & Versão Português Consenso 1 & Modificado por \\
\hline Enunciado & $\begin{array}{l}\text { "Tarefas ocasionais relacionadas ao tratamento podem } \\
\text { incluir: ir ao hospital para fazer exame de sangue, } \\
\text { procurar serviços médicos em caso de sangramento ou } \\
\text { outros eventos importantes, e assim por diante." }\end{array}$ & $\begin{array}{l}\text { "De vez em quando, outras } \\
\text { atividades" } \\
\text { relacionados ao tratamento" }\end{array}$ \\
\hline $3 b$ & $\begin{array}{l}\text { "Quanto as tarefas ocasionais do tratamento de } \\
\text { anticoagulação são difíceis ou inconvenientes?" }\end{array}$ & $\begin{array}{l}\text { "O quanto que essas atividades } \\
\text { dificultam (atrapalham) sua vida?" }\end{array}$ \\
\hline $3 \mathrm{c}$ & $\begin{array}{l}\text { "Quanto você acha complicado o seu tratamento de } \\
\text { anticoagulação ?" }\end{array}$ & "difícil de seguir" \\
\hline $3 \mathrm{~d}$ & $\begin{array}{l}\text { "Quanto você acha demorado o seu tratamento de } \\
\text { anticoagulação?" }\end{array}$ & "gasta do seu tempo para seguir" \\
\hline $3 \mathrm{e}$ & $\begin{array}{l}\text { "Quanto você acha frustrante o seu tratamento de } \\
\text { anticoagulação?" }\end{array}$ & "te incomoda" \\
\hline $3 g$ & $\begin{array}{l}\text { "No geral, quanto você acha o seu tratamento de } \\
\text { anticoagulação um tratamento pesado/sacrificado?" }\end{array}$ & "um sacrifício" \\
\hline $3 \mathrm{~h}$ & $\begin{array}{l}\text { "No geral, quanto confiante você esta em controlar } \\
\text { seu tratamento de anticoagulação?" }\end{array}$ & "acredita que consegue seguir" \\
\hline Enunciado & $\begin{array}{l}\text { "Estas últimas perguntas são sobre o que você conhece } \\
\text { e sente sobre seu tratamento de anticoagulação" }\end{array}$ & "entende" \\
\hline $4 a$ & $\begin{array}{l}\text { "Quanto você entende o porquê está tomando } \\
\text { anticoagulantes?" }\end{array}$ & otivo" \\
\hline $4 \mathrm{~b}$ & $\begin{array}{l}\text { "Quanto você sente seguro devido o seu tratamento de } \\
\text { anticoagulação?" }\end{array}$ & "protege a sua saúde" \\
\hline $4 d$ & $\begin{array}{lllll}\text { "O quanto você se preocupa com relação a } \\
\text { sangramentos ou machucados?" }\end{array}$ & "se preocupa com o risco de ter" \\
\hline $4 \mathrm{f}$ & $\begin{array}{l}\text { "No geral, quanto o tratamento de anticoagulação teve } \\
\text { um impacto positivo em sua vida?" }\end{array}$ & "melhorou" \\
\hline $4 g$ & $\begin{array}{l}\text { "No geral, quanto o tratamento de anticoagulação teve } \\
\text { um impacto negativo em sua vida?" }\end{array}$ & "piorou" \\
\hline $4 \mathrm{f}$ & $\begin{array}{l}\text { "No geral, quanto satisfeito você está com o seu } \\
\text { tratamento de anticoagulação?" }\end{array}$ & "você está satisfeito" \\
\hline $4 \mathrm{i}$ & $\begin{array}{l}\text { "Quanto é difícil para lidar com o seu tratamento de } \\
\text { anticoagulação comparado com outros tratamentos que } \\
\text { você fez?" }\end{array}$ & $\begin{array}{l}\text { "Comparado com } r \text { outros } \\
\text { tratamentos que você fez, o quanto } \\
\text { é difícil esse tratamento de } \\
\text { anticoagulação" }\end{array}$ \\
\hline $4 \mathrm{j}$ & $\begin{array}{l}\text { "Qual a probabilidade de você recomendar esta forma } \\
\text { de tratamento de anticoagulação para alguém com a } \\
\text { sua doença ou condição médica?" }\end{array}$ & $\begin{array}{l}\text { "possibilidade de você incentivar } \\
\text { uma outra pessoa (com o mesmo } \\
\text { problema de saúde que você tem) a } \\
\text { seguir o tratamento de } \\
\text { anticoagulação" }\end{array}$ \\
\hline \multicolumn{3}{|l|}{$\begin{array}{ll}\begin{array}{l}\text { Escala } \\
\text { resposta }\end{array} & \text { de } \\
\end{array}$} \\
\hline $2 a$ & "não limita" & Retirado \\
\hline $2 \mathrm{c}$ & "nada" & Retirado \\
\hline $4 \mathrm{j}$ & $\begin{array}{l}\text { "nada" "pouco" "muito" "muitíssimo/grande } \\
\text { probabilidade" }\end{array}$ & $\begin{array}{l}\text { "nenhuma" "pouca" } \\
\text { "muitíssima" }\end{array}$ \\
\hline
\end{tabular}

No item 1a a palavra "jardinagem” foi retirada da questão pelos juízes julgarem que essa ação estaria implícita em "atividades domésticas". 
Na Versão Português Consenso 1 o enunciado traz afirmativas sobre "Tarefas diárias" e "Tarefas ocasionais" e em seguida duas questões sendo uma sobre tarefas diárias e outra sobre tarefas ocasionais, item 3a e 3b, respectivamente. Os juízes decidiram pela alteração desta ordem e propuseram a seguinte ordem: enunciado com a afirmativa sobre "Tarefas diárias", seguida da questão sobre as tarefas diárias, item 3a e o enunciado com a afirmativa sobre "Tarefas ocasionais", seguido pelo item $3 b$.

Ao término desse processo foi obtida a Versão Português Consenso 2 (VPC2) (Apêndice 3).

\subsubsection{Retro-tradução (Back Translation)}

A VPC2 do DASS foi submetida a dois tradutores, sendo eles nascidos nos Estados Unidos e residentes no Brasil há alguns anos, onde desempenham atividades como professores de língua inglesa. Eles realizaram as retrotraduções individualmente e obtivemos a Versão Inglês 1 (VI1) (Anexo 6) e Versão Inglês 2 (VI2) (Anexo 7).

Em seguida, essas retrotraduções foram comparadas entre si em uma reunião entre os dois tradutores, a pesquisadora e sua orientadora na qual foi determinada a Versão Inglês Final (VIF) (Apêndice 4). Essa versão ainda foi submetida à avaliação do autor principal do DASS, Dr. Greg Samsa e em correspondência, via e-mail, o autor se manifestou em concordância (Anexo 8)

A comparação entre as versões VO e VIF resultou em algumas modificações na VPC2, descritas no Quadro 4. 
Quadro 4 - Modificações na Versão Português Consenso 2 após comparação da versão original (VO) e da versão inglês final (VIF)

\begin{tabular}{|l|l|l|}
\hline Itens do DASS & Versão Português Consenso 2 & Modificado por \\
\hline $2 \mathrm{c}$ & $\begin{array}{l}\text { "O quanto que o seu tratamento de anticoagulação } \\
\text { (afinar o sangue) limita (atrapalha) o uso de } \\
\text { medicamentos para dor, para febre e vitaminas?" }\end{array}$ & $\begin{array}{l}\text { (medicamentos sem prescrição } \\
\text { (por exemplo,...)" }\end{array}$ \\
\hline Enunciado & $\begin{array}{l}\text { "Precisar de tratamento de anticoagulação (afinar o } \\
\text { sangue) significa fazer muitas coisas, algumas coisas } \\
\text { todos os dias e outras com menos freqüência." }\end{array}$ & "O" \\
\hline Enunciado & $\begin{array}{l}\text { "Estas últimas perguntas são sobre o que você } \\
\text { entende sobre seu tratamento de anticoagulação } \\
\text { (afinar o sangue)." }\end{array}$ & "sabe" \\
\hline $4 \mathrm{a}$ & $\begin{array}{l}\text { "O quanto que você sabe sobre o motivo de estar } \\
\text { tomando o anticoagulante?" }\end{array}$ & $\begin{array}{l}\text { "compreende" e "do seu } \\
\text { tratamento de anticoagulação" }\end{array}$ \\
\hline $4 \mathrm{i}$ & $\begin{array}{l}\text { "Comparado com outros tratamentos que você fez, o } \\
\text { quanto é difícil esse tratamento de anticoagulação } \\
\text { (afinar o sangue)?" }\end{array}$ & \\
\hline
\end{tabular}

Uma observação pertinente foi feita ao item $4 \mathrm{j}$. Em sua formulação original “How likely would you be to recommend this form of anti-clot treatment to someone else with your disease or medical condition?” o qual foi traduzido por "Qual a possibilidade de você incentivar uma outra pessoa (com o mesmo problema de saúde que você tem) a seguir o tratamento de anticoagulação (afinar o sangue)?” foi criticada por um dos tradutores. Para ele essa interrogativa conota que um paciente em uso de terapia de anticoagulação pode estar indicando essa terapia para outro paciente, ou seja, configurando um ato de "prescrição de um tratamento" ou "uma tomada de conduta clínica", ações essas inerentes exclusivamente a determinadas categorias profissionais. Esse tradutor considerou a frase em inglês mal elaborada. No entanto, optamos por manter o item.

Essas modificações foram acatadas o que resultou na Versão Português Consenso 3 (VPC3)(Apêndice 5).

\subsubsection{Análise Semântica}

A análise semântica proposta para o DASS baseou-se na análise semântica realizada por Medina Castro (2007) em seu estudo, cujo objetivo foi adaptar culturalmente o 
questionário DISABKIDS 37 para o México segundo as normas do grupo DISABKIDS (MEDINA CASTRO, 2007). A análise semântica do DASS foi realizado por um questionário (Apêndice 6) em que a avaliação geral (parte A) foi composta por sete itens relacionados à impressão geral do instrumento e os itens da parte específica (parte B) foi composta segundo os domínios do DASS (limitação, tarefa/sobrecarga e impacto psicológico). Tanto as questões da parte A como a parte B foram obtidas por respostas de múltipla escolha.

Para realizarmos a analise ou validação semântica determinamos o número de três pacientes para cada domínio do DASS. Assim, nove pacientes foram convidados para a participarem dessa etapa. Todos os indivíduos responderam a Parte A (Avaliação Geral), já para a parte B (Avaliação Específica), esses mesmos pacientes foram sorteados de modo que o primeiro paciente respondeu aos itens relativos ao primeiro domínio (limitação), o segundo paciente respondeu ao segundo domínio (tarefa e sobrecarga), o terceiro respondeu aos itens do domínio impacto psicológico. O quarto paciente então retornou a responder os itens sobre o domínio limitação e, assim, sucessivamente. Esses nove pacientes do ambulatório de anticoagulação tinham um tempo de uso de ACO entre dois meses a 26 anos sendo seis mulheres e três homens, com idade de 39 a 73 anos e um nível de escolaridade variando de analfabeto ao segundo grau completo.

A análise semântica do DASS nos revelou que o item 4f ("No geral, o quanto que o tratamento de anticoagulação (afinar o sangue) melhorou sua vida?”) não foi bem compreendido por dois participantes, pois obtemos respostas como “...melhorou a minha vida porque o inchaço das minhas pernas diminuíram...” como também “...melhorou a batedeira do coração...". Ambas as falas nos reportam ao uso de diuréticos e antiarrítmicos, respectivamente, e não ao uso do ACO.

Porém, no geral, os participantes classificaram o instrumento como bom e com questões fáceis de serem compreendidas sendo essas importantes para quem faz uso de 
anticoagulante oral. Não obtivemos nenhuma sugestão em relação à mudança ou acréscimo de alguma questão e todas foram respondidas pelos participantes.

Quanto à avaliação específica da análise semântica do DASS os itens 3c ("O quanto que você acha difícil seguir o seu tratamento de anticoagulação (afinar o sangue)?”), $3 \mathrm{~g}$ ("No geral, o quanto que você acha o seu tratamento de anticoagulação (afinar o sangue) um sacrifício?”), 4g (“No geral, quanto o tratamento de anticoagulação (afinar o sangue) piorou sua vida?”) não foram considerados importantes na avaliação de três pacientes. Eles argumentaram que se estão tomando esse medicamento, é por que era necessário à saúde deles. Os itens $3 \mathrm{f}$ ("O quanto que você acha doloroso o seu tratamento de anticoagulação (afinar o sangue)?”) e $4 \mathrm{~d}$ (“O quanto que você se preocupa com o risco de ter sangramentos ou se machucar?") foram respondidos com a alternativa "as vezes importantes" por dois pacientes. Nenhum paciente teve dificuldade de entendimento das questões como não houve sugestões na reformulação das questões. Após a análise semântica do DASS obtivemos a Versão Português Consenso 4 (VPC4) (Apêndice 7).

\subsubsection{Pré-teste}

O pré-teste foi realizado com a versão adaptada do instrumento DASS em sua VPC4 e 20 pacientes do ambulatório de anticoagulação participaram do pré-teste. Eles foram esclarecidos sobre o propósito da pesquisa e assinaram o termo de consentimento livre esclarecido. A pesquisadora coletou os dados do instrumento mediante entrevistas. A duração média da aplicação do DASS foi de dez minutos e não houve nenhuma modificação necessária, sendo assim, manteve-se a VPC4 como a Versão Português Final (VPF) (Apêndice 7). 


\subsection{Análise das propriedades psicométricas da versão adaptada para o português do instrumento Duke Anticoagulation Satisfaction Scale (DASS)}

\subsubsection{Análise da validade}

\subsubsection{Validade de face e de conteúdo}

A validade de face ou aparente e a validade de conteúdo do instrumento DASS foram verificadas pelo consenso obtido entre os profissionais que participaram do comitê de juízes quanto à avaliação do instrumento estar medindo o que se propõe medir (validade de face) e a relevância de cada item/domínio no construto estudado (validade de conteúdo).

\subsubsection{Validade de constructo}

Em nosso estudo, a validade de constructo foi testada seguindo as análises dos autores da versão original. Embora o valor do instrumento DASS seja uma medida classificada como variável discreta, a análise fatorial foi utilizada pelos autores originais para confirmar a existência dos três componentes: limitação, tarefa/sobrecarga, impacto psicológico (positivo e negativo) (SAMSA et al., 2004).

Assim, a validade de construto relacionada à dimensionalidade do instrumento, foi verificada pela análise fatorial. Para compararmos os resultados obtidos pela versão adaptada para o português com os resultados do estudo original. Os autores testaram as associações dos domínios do DASS com os oito domínios do SF-36 e obtiveram correlações inversas e estatisticamente significantes.

Em nosso estudo, a validade de constructo convergente também foi verificada pela correlação entre os escores obtidos do DASS total e suas sub-escalas com escores dos oito 
domínios do instrumento SF-36 o qual avalia o constructo correlacionado ao estado de saúde percebido pelo indivíduo.

Os autores também fizeram a análise de validade de constructo discriminante associando os valores dos domínios do DASS com a idade e o tempo de uso do ACO. Essas associações se mostraram negativas ou inversas. Os mesmos testes de associação foram realizados com os resultados provenientes da versão adaptada.

\subsubsection{Análise da confiabilidade}

A análise da confiabilidade da versão adaptada do DASS foi verificada pela medida de consistência interna dos itens do instrumento, calculada pelo coeficiente alfa de Cronbach. Ele é o indicador mais freqüentemente utilizado na análise da consistência interna de instrumentos, pois reflete o grau de covariância dos itens entre si. Os valores de alfa de Cronbach variam de 0 a 1 e esses valores são considerados aceitáveis para os que estão no intervalo de 0,70 a 0,90 (CUMMINGS; STWART; RULLEY, 2003).

\subsection{Local e população do estudo}

O estudo foi realizado no Ambulatório de Anticoagulação da Divisão de Cardiologia do HCFMRP-USP que funciona às quartas-feiras e às quintas-feiras das 12:30 horas às 18:00 horas, havendo um número médio de 80 agendamentos em cada dia. No período de realização do estudo, 981 pacientes compareceram ao ambulatório em 1832 consultas para o ajustamento da dosagem do ACO. A que se destacar que os agendamentos dos pacientes em uso de ACO são realizados de acordo com a necessidade de controle dos níveis de INR sendo alguns pacientes agendados semanalmente enquanto outros podem ser agendados a cada três meses. Outra característica peculiar no atendimento ambulatorial desses indivíduos está no fato de que eles aguardam a consulta médica, para a checagem do valor do INR; cujo sangue foi coletado na manhã da consulta. Algumas vezes, é o familiar do paciente que aguarda, até o 
período da tarde, para ser informando, pelo médico, sobre o valor do INR e posteriormente, transmitir essa informação ao seu ente. Quando o INR está dentro dos valores desejáveis, o paciente é dispensado para um novo retorno sendo sua consulta realizada de forma rápida. Atendimento médico mais minucioso é realizado quando o paciente apresenta um caso de difícil controle. Ressalta-se a capacidade de atendimento volumosa característica desse ambulatório.

Para compor a população do estudo, os participantes foram abordados, de maneira aleatória, enquanto aguardavam para serem atendidos e entrevistados seguindo como critérios de inclusão: estar em seguimento ambulatorial devido ao uso de $\mathrm{ACO}$; ter idade igual ou superior a 18 anos; concordar em responder aos instrumentos de coleta de dados mediante assinatura do termo de consentimento livre e esclarecido e demonstrar capacidade cognitiva para responder as questões do instrumento à pesquisadora. Dessa maneira, elegemos uma amostra representativa de indivíduos atendidos nesse ambulatório, pois conforme a definição de Belle et al. (2004), uma amostra representativa é composta por indivíduos que representam à população de interesse do estudo, embora não tenha sido realizado um sorteio entre todos os potenciais participantes do estudo (pacientes atendidos no ambulatorio de ACO).

\subsection{Coleta dos dados}

Para compreendermos como foi realizada a coleta de dados, ressaltamos aqui que o paciente deste ambulatório apresenta uma característica que lhe é peculiar. Eles comparecerem ao hospital no período da manhã para realizarem a coleta de sangue e então aguardam até o período da tarde para consulta médica a fim de checar o resultado do exame de sangue para a verificação o valor do INR. Assim, os dados foram coletados no intervalo entre a coleta de sangue e a consulta médica e também após a consulta médica, num período de março a agosto de 2008 . 


\subsubsection{Instrumentos de coleta de dados}

Os dados foram coletados por meio de entrevistas individuais realizadas pela autora do estudo e por outra pesquisadora inserida no projeto "Avaliação da qualidade de vida relacionada à saúde, atitudes, satisfação e adesão ao tratamento de pacientes em uso de anticoagulação oral".

Foram aplicados instrumentos para a caracterização sócio-demográfica e clínica, o DASS em sua versão final em português e o SF-36. Dados clínicos como a dosagem do último INR, medicamentos usados e presença de comorbidades foram obtidas nos prontuários dos participantes.

\subsubsection{Instrumento para caracterização sócio-demográfica e clínica}

Os dados coletados para a caracterização sócio-demográfica foram: data de nascimento (para posterior cálculo da idade, em anos), sexo, cor da pele, estado civil, religião, grau de escolaridade (anos que freqüentou o ensino formal), situação profissão, renda familiar mensal, número de pessoas que mora com o indivíduo, procedência.

Os dados clínicos investigados foram: tipo de ACO (varfarina ou femprocumona), indicação do ACO; data do início da terapia (que foi a base para o cálculo do tempo de terapia em anos), dose do ACO (em mg); coleta de sangue nos últimos três meses; valor do INR; presenças de complicações (hemorrágicas ou trombóticas); necessidade de internações devido à essas complicações; presença de comorbidades; tipo e quantidade de medicamentos usados; recebimento de informações sobre o ACO (p.ex.: sangramento, alimentos, medicamento, etc.), motivo da interrupção do ACO.

O instrumento para a caracterização sócio-demográfica e clínica foi elaborada pela pesquisadora e sua orientadora e foi submetido a validação de face e de conteúdo por três enfermeiros e dois médicos, todos com atuação na área da ACO (Apêndice 8). 


\subsubsection{Instrumento para avaliação do estado de saúde percebido (SF-36)}

Este instrumento foi originalmente desenvolvido nos EUA para avaliar o estado de saúde percebido pelos indivíduos em um estudo denominado de Medical Outcomes Study (MOS). Na construção do instrumento os autores incluíram, além da uma revisão bibliográfica, a adoção de um modelo conceitual de saúde e utilização de outras escalas bem como a experiência clínica para a seleção de itens. Os autores optaram por um conceito amplamente utilizado em pesquisas de saúde que incluem os aspectos físicos, sociais, capacidade funcional, saúde mental e percepção geral de saúde; e ainda acrescentaram dois conceitos fortemente sustentados por estudos empíricos: dor no corpo e vitalidade (WARE; SHERBOUNE, 1992).

No Brasil, o instrumento Medical Outcomes Survey 36-Item Short-Form (SF-36) (WARE; SHERBOUNE, 1992) foi adaptada para o português por Ciconelli (1997) (Anexo 9). A tradução para o português do SF-36 e sua adequação às condições sócio-econômicas e culturais de nossa população, bem como a demonstração de sua reprodutibilidade e validade, tornam esse instrumento uma ferramenta adicional e útil que pode ser utilizada na avaliação da artrite reumatóide ou até de outras doenças, seja para fins de pesquisa ou clínicos (CICONELLI et al., 1999).

Trata-se de um questionário multidimensional que tem por finalidade prover avaliação do estado de saúde percebido, com ênfase nas funções física, mental e social. Tem sido também considerado como um instrumento genérico de avaliação de QVRS, de fácil administração e compreensão sem ser extenso. É formado por 36 itens, englobados em oito escalas ou componentes: capacidade funcional (10 itens) avalia as limitações físicas para realizar atividades desde vigorosas, como correr, até atividades da vida diária como tomar banho ou vestir-se; aspectos físicos (4 itens) investiga se o indivíduo encontra problemas para realizar atividades profissionais e/ou domésticas decorrentes da sua saúde física; dor (2 itens) 
infere sobre a presença e a gravidade da dor durante as últimas quatro semanas; estado geral de saúde (5 itens) é a percepção de saúde do indivíduo e o quanto isso poderia ser falso ou verdadeiro; vitalidade (4 itens) avalia a freqüência com que o indivíduo sente-se cheio de energia e vontade ou cansado e esgotado; aspectos sociais (2 itens) refere-se sobre realização ou a participação em atividades sociais como visitar parentes e amigos; aspectos emocionais (3 itens) avalia a existência de problemas para realizar atividades profissionais e/ou domésticas em decorrência da saúde emocional, como sentir-se deprimido ou ansioso; saúde mental (5 itens) implica os diferentes graus de nervosismo, depressão, desânimo, tranqüilidade e felicidade sentidos pelo sujeito, e uma questão global para avaliação comparativa do estado geral de saúde atual e a de um ano atrás.

Esse instrumento pode ser administrado por entrevista (pessoal ou por telefone), autoadministrável, via computador, com tempo de preenchimento em torno de 10 minutos e que pode ser usado para indivíduos acima de 14 anos (CICONELLI, 1997). A avaliação dos resultados obtidos com a aplicação deste instrumento de medida é feita através da transformação dos valores de cada domínio em uma escala de 0 a 100 . O valor zero corresponde ao pior estado de saúde e o 100 ao melhor estado (WARE, SHERBOURNE, 1992).

\subsection{Processamento e análise dos dados}

Os dados foram processados e analisados no programa Statistical Package for the Social Sciencies (SPSS) versão 15.0.

Foram realizadas análises descritivas para todas as variáveis sendo que as variáveis categóricas (sexo, grau de escolaridade, estado civil, com quem reside, situação profissional e religião) foram analisadas por freqüência simples enquanto para as variáveis numéricas (ex.: 
idade e as medidas da escala DASS) foram também analisadas segundo as medidas de tendência central (mediana e média) e de dispersão (desvio-padrão).

A confiabilidade da versão final em português do DASS foi verificada pela consistência interna de seus itens analisado pelo alfa de Cronbach, tanto da escala total como das suas sub-escalas. O cálculo do alfa de Cronbach que é um coeficiente de correlação que tem como premissa para sua análise que os itens que compõem os instrumentos são positivamente relacionados entre si e assim medem o mesmo atributo. Há vários fatores que podem interferir nos coeficientes de alfa de Cronbach, tais como, a extensão (quanto maior o teste, maior o número de itens e maior o número do alfa) e a variância do teste (quanto maior a variância, maior o valor do alfa, ou seja, quando o alfa é calculado para um grupo de sujeitos mais homogêneos no atributo investigado, o alfa é menor do que quando os sujeitos são mais heterogêneos) (WALTZ; STRIKLAND; LENZ, 2005). Os valores do alfa de Cronbach variam de 0 a 1 e esses valores são considerados aceitáveis para os que estão no intervalo de 0,70 a 0,90 (CUMMINGS; STWART; RULLEY, 2003).

A validade de constructo da versão adaptada para o português do DASS (dimensionalidade) foi analisada pela análise fatorial, com rotação varimax entre o número dos itens dos três domínios do instrumento DASS com o objetivo de analisar se os itens foram agrupados da mesma maneira como na versão original do DASS. A análise fatorial também foi utilizada para análise da validade de constructo através da confirmação da existência das dimensões do instrumento original.

Ainda para a avaliação relacionada ao constructo foi realizada testes de correlação linear de Pearson`s entre os valores do DASS total e das sub-escalas com os valores dos domínios do SF-36 (validade de constructo convergente), e entre a idade e o tempo de tratamento com ACO dos participantes (validade de constructo divergente). Para a classificação da força de correlações entre as variáveis, utilizamos os critérios propostos por 
Ajzen e Fishbeim (1980) que consideram os valores de correlação próxima de 0,30 como sendo satisfatórios, entre 0,30 e 0,50 uma correlação de moderada magnitude, acima de 0,50 de forte magnitude e valores abaixo de 0,30 de pouco valor para a prática, mesmo que estatisticamente significante. A escolha para tal classificação se justifica uma vez que estamos investigando uma medida de constructo subjetiva (QVRS) que não pode ser observada diretamente pelo pesquisador.

As respostas aos itens do instrumento DASS do tipo "não se aplica" e "não informada" pelos participantes desse estudo foram substituídos pelo cálculo da média das respostas dos sujeitos aos itens dos instrumentos, baseando-se no critério de Cohen e Cohen (1983) o qual estabelece que caso algum sujeito tenha $20 \%$ ou mais de suas respostas não preenchidas, ele deverá ser excluído da amostra. Seguindo esse critério, não ocorreu exclusão de sujeitos em nosso estudo.

O nível de significância adotado para o estudo foi de 0,05 . 
RESULTADOS 


\section{RESULTADOS}

\subsection{Resultados relacionados à caracterização sócio-demográfica e clínica}

Entre os pacientes atendidos no ambulatório de anticoagulação oral do HCFMRPUSP, participaram do estudo 180 indivíduos que atenderam os critérios de inclusão estipulados. Com relação às características demográficas dos participantes do estudo, tivemos que a maioria dos sujeitos era do sexo feminino $(118 ; 65,6 \%)$, brancos $(115 ; 63,9 \%)$, com idade média de 55,6 (DP=13,3) anos, casados $(118 ; 65,6 \%)$, católicos $(127 ; 70,6 \%)$, procedentes de outras cidades do estado de São Paulo (104; 57,8\%), com média de 4,62 anos de estudo formal, aposentados $(66 ; 36,7 \%)$ com renda familiar média e mensal de 896,93 reais e que residiam, em média, com três pessoas (Tabela 1). 
Tabela 1 - Análise descritiva das características sócio-demográficas dos participantes. Ribeirão Preto, 2009

\begin{tabular}{|c|c|c|c|c|}
\hline Variáveis & n (\%) & Média (D.P.) & Mediana & Intervalo \\
\hline \multicolumn{5}{|l|}{ Sexo } \\
\hline feminino & $118(65,6)$ & & & \\
\hline masculino & $62(34,4)$ & & & \\
\hline \multicolumn{5}{|l|}{ Cor da pele } \\
\hline branca & $115(63,9)$ & & & \\
\hline parda & $36(20,0)$ & & & \\
\hline negra & $29(16,1)$ & & & \\
\hline Idade (em anos) & & $55,6(13,3)$ & 56,5 & $24,8-86,1$ \\
\hline \multicolumn{5}{|l|}{ Estado civil } \\
\hline casado/união consensual & $118(65,6)$ & & & \\
\hline separado/divorciado & $25(13,9)$ & & & \\
\hline viúvo & $23(12,8)$ & & & \\
\hline solteiro & $14(7,8)$ & & & \\
\hline \multicolumn{5}{|l|}{ Religião } \\
\hline católica & $127(70,6)$ & & & \\
\hline evangélica & $33(18,3)$ & & & \\
\hline outra & $25(13,9)$ & & & \\
\hline espírita & $23(12,8)$ & & & \\
\hline Escolaridade (anos) & & $4,62(3,4)$ & 4,00 & $0-15$ \\
\hline analfabetos & $16(8,9)$ & & & \\
\hline ensino fundamental incompleto & $128(71,1)$ & & & \\
\hline ensino fundamental completo & $13(7,2)$ & & & \\
\hline ensino médio incompleto & $2(1,1)$ & & & \\
\hline ensino médio completo & $14(7,8)$ & & & \\
\hline ensino superior incompleto & $5(2,8)$ & & & \\
\hline ensino superior completo & $2(1,1)$ & & & \\
\hline \multicolumn{5}{|l|}{ Ocupação* } \\
\hline aposentado & $66(36,7)$ & & & \\
\hline do lar & $52(28,9)$ & & & \\
\hline ativo & $49(27,2)$ & & & \\
\hline afastado & $9(5)$ & & & \\
\hline aposentado com atividade remunerada & $1(0,6)$ & & & \\
\hline outras & $1(0,6)$ & & & \\
\hline Renda mensal familiar (reais) $* *$ & & $896,93(507,7)$ & 800,0 & $300-4500$ \\
\hline Número de pessoas com quem residiam & & $3(1,7)$ & 3,0 & $0-10$ \\
\hline \multicolumn{5}{|l|}{ Procedência } \\
\hline Outras cidades do estado de São Paulo & $104(57,8)$ & & & \\
\hline Ribeirão Preto & $46(25,6)$ & & & \\
\hline Outras cidades de outros estados & $30(16,7)$ & & & \\
\hline
\end{tabular}

Quanto à caracterização clínica dos participantes (Tabela 2) constatamos que a presença de próteses cardíacas metálicas foi a principal responsável para a indicação do ACO (90; 50\%), seguida da fibrilação atrial $(59 ; 32,8 \%)$. Além do grupo de condições clínicas responsável pela indicação do ACO, 178 (98,9\%) dos participantes ainda apresentaram outras comorbidades associadas e relatadas em seus prontuários, tais como a hipertensão arterial (92; 
$51,1 \%)$, outras arritmias $(86 ; 47,8 \%)$ e doença arterial coronariana $(79 ; 43,9 \%)$. Dessa maneira, o uso de outros medicamentos também foi investigado e verificamos que a população do estudo utilizava, em média, quatro medicamentos por dia, além do ACO, sendo que a maioria dos participantes $(87 ; 48,3 \%)$ ingeria de três a cinco comprimidos. No grupo, a média de medicamentos usados foi de 4,2, variando de nenhum até 12 .

Tabela 2 - Caracterização clínica dos participantes segundo indicação do ACO, presença de comorbidades e números de medicamentos usados. Ribeirão Preto, 2009

\begin{tabular}{lc}
\hline \multicolumn{1}{c}{ Variáveis } & $\mathbf{n}(\mathbf{\%})$ \\
\hline Indicação do ACO & \\
prótese cardíaca metálica & $90(50,0)$ \\
fibrilação atrial & $59(32,8)$ \\
trombo cardíaco & $15(8,3)$ \\
trombo embolismo pulmonar & $6(3,3)$ \\
acidente vascular encefálico & $4(2,2)$ \\
infarto agudo do miocardio & $2(1,1)$ \\
marcapasso & $2(1,1)$ \\
trombose venosa profunda & $1(0,6)$ \\
doença de Chagas & $1(0,6)$ \\
Presença de outras comorbidades (sim) & $178(98,9)$ \\
hipertensão arterial & $92(51,1)$ \\
outras arritmias & $86(47,8)$ \\
doença arterial coronariana & $79(43,9)$ \\
doenças endócrinas & $52(28,9)$ \\
doenças respiratórias & $35(19,4)$ \\
doenças neurológicas & $22(12,2)$ \\
acidente vascular encefálico & $19(10,6)$ \\
doenças muscoesqueléticas & $8(4,4)$ \\
doenças hepáticas & $6(3,3)$ \\
Número de medicamentos (além do ACO) & \\
até 2 & $49(27,2)$ \\
de 3 a 5 & $87(48,3)$ \\
5 ou mais & $44(24,4)$ \\
\hline
\end{tabular}

Ainda sobre a caracterização dos participantes segundo o uso de ACO (Tabela 3), constatamos que o ACO mais frequentemente prescrito era a varfarina $(150 ; 83,3 \%)$ e que a maioria dos participantes $(125 ; 69,4 \%)$ adquiria o medicamento via Sistema Único de Saúde. A média do tempo de uso do ACO foi de 6,9 anos e a dose média utilizada foi de $31,1 \mathrm{mg}$ por semana. O controle dos níveis da anticoagulação, realizado por coleta de sangue e posterior 
checagem dos valores do INR, foi realizado pelos participantes deste estudo, em média duas vezes nos últimos três meses. O valor médio do INR foi de 2,4 variando de 0,5 a 6,8 .

Tabela 3 - Caracterização clínica dos participantes segundo tipo de ACO, tempo de uso, dosagem e controle do INR. Ribeirão Preto, 2009

\begin{tabular}{|c|c|c|c|c|}
\hline Variáveis & n (\%) & Média (D.P.) & Mediana & Intervalo \\
\hline $\begin{array}{l}\text { ACO prescrito } \\
\left.\text { varfarina (Marevan }{ }^{\circledR}\right) \\
\text { femprocumona (Marcoumar }(\text { ) }\end{array}$ & $\begin{array}{c}150(83,3) \\
30(16,7)\end{array}$ & & & \\
\hline $\begin{array}{l}\text { Aquisição do ACO } \\
\text { Sistema Único de Saúde } \\
\text { recurso particular } \\
\text { Outras fontes }\end{array}$ & $\begin{array}{c}125(69,4) \\
54(30) \\
1(0,6)\end{array}$ & & & \\
\hline $\begin{array}{l}\text { Tempo de uso ACO (anos) } \\
\text { Dose do ACO (mg/semana)* } \\
\text { Coleta de sangue nos últimos } 3 \text { meses* } \\
\text { Valor do INR }\end{array}$ & & $\begin{array}{c}6,9(6,5) \\
31,1(14,9) \\
1,9(0,9) \\
2,4(0,9)\end{array}$ & $\begin{array}{c}5,2 \\
30 \\
2 \\
2,3\end{array}$ & $\begin{array}{c}0-36 \\
7,5-105 \\
0-6 \\
0,5-6,8\end{array}$ \\
\hline
\end{tabular}

Além do controle constante e rigoroso para verificação dos níveis sangüíneos da anticoagulação, $131(72,8 \%)$ participantes relataram que receberam informações sobre o ACO referentes ao: risco de sangramentos $(163 ; 90,6 \%)$, risco de trombos $(129 ; 71,1 \%)$, interações com alimentos $(129 ; 71,7 \%)$ e com medicamentos $(117 ; 65,0 \%)$. Contudo, cerca de 71 $(94,6 \%)$ sujeitos apresentaram complicações hemorrágicas e três $(4,0 \%)$ apresentaram complicações do tipo trombóticas, sendo que essas complicações culminaram em internações hospitalares para $28(15,6 \%)$ dos entrevistados. Do total dos participantes, $87(48,3 \%)$ interromperam o ACO sendo que desses, apenas $60(68,9 \%)$ o fizeram com orientação médica. Os motivos mais comuns referidos pelos pacientes foram complicações decorrentes do uso do ACO, como por exemplo, epistaxe e hematúria $(30 ; 34,4 \%)$, seguido de outros motivos como, por exemplo, a falta de dinheiro e esquecimento $(23 ; 26,4 \%)$ (Tabela 4$)$. 
Tabela 4 - Caracterização clínica dos participantes segundo informações recebidas, complicações, internações e interrupção do ACO. Ribeirão Preto, 2009

\begin{tabular}{lc}
\hline \multicolumn{1}{c}{ Variáveis } & $\mathbf{n}(\mathbf{\%})$ \\
\hline Informações sobre o ACO & $131(72,8)$ \\
sim & $49(27,2)$ \\
não & \\
Tipos de informações & $163(90,6)$ \\
risco de sangramentos & $131(72,8)$ \\
necessidade do ACO & $129(71,7)$ \\
risco de trombos & $129(71,7)$ \\
interação com alimentos & $117(65,0)$ \\
interação com medicamentos & $1(0,6)$ \\
outras & $105(58,3)$ \\
Presença de complicações & $75(41,7)$ \\
não & \\
sim & $71(94,6)$ \\
Tipo de complicações (n=75) & $3(4,0)$ \\
hemorrágica & $1(1,4)$ \\
trombótica & $28(15,6)$ \\
não informada & $87(48,3)$ \\
Internaçóes por complicações (sim) & \\
Interrupção do ACO (sim) & $60(68,9)$ \\
Motivo da interrupção (n=87) & $30(34,4)$ \\
Orientação médica & $23(26,4)$ \\
complicações pelo uso de ACO & $15(17,4)$ \\
outros & $13(14,9)$ \\
cirurgia/exame & $6(6,8)$ \\
tratamento dentário & \\
gravidez &
\end{tabular}

\subsection{Resultados relacionados às análises descritivas da versão adaptada do instrumento}

DASS (total e dos componentes).

Com relação à análise descritiva da versão adaptada do DASS, ela foi realizada pela soma das respostas dos pacientes aos 25 itens (intervalo possível de 25-175) e pela média das respostas aos itens (intervalo possível de 1 a 7), após a inversão dos itens com valores contrários ou reversos (o qual indicamos com o símbolo r). Os resultados foram avaliados considerando que valores maiores correspondem a melhor QVRS e maior satisfação com o ACO.

Visando uma melhor descrição dos itens que compõem o instrumento serão apresentadas na Tabela 6 as freqüências de respostas para cada item do DASS, sem reposição das respostas aos itens considerados como "não se aplica" ou "não informado". Baseadas na 
escala tipo Likert de 7 pontos, verificamos que para maioria dos itens do instrumento, os sujeitos referiram o valor um (nada/não limita) variando de $83,3 \%(n=150)$ para o item $4 \mathrm{i}$ (“comparado com outros tratamentos que você já fez, o quanto é difícil lidar com esse tratamento de anticoagulação") a 26,7\% (n=48) para o item $4 \mathrm{~d}$ ("o quanto que você se preocupa com o risco de ter sangramentos ou se machucar"). Ressaltamos aqui que esse mesmo item (4d) também apresentou a mesma porcentagem $(26,7 \% ; n=48)$ para a resposta com o valor cinco (bastante). A segunda opção de resposta mais citada foi a de número três (pouco) para seis itens $(3 \mathrm{hr}, 4 \mathrm{ar}, 4 \mathrm{br}, 4 \mathrm{fr}, 4 \mathrm{hr}, 4 \mathrm{jr}$ ) cuja freqüência de escolha variou de 51,1\% $(n=92)$ a $49,4 \%(n=89)$.

Podemos observar a presença de vários itens cujas freqüências de respostas excederam aos 50\% para os valores extremos, principalmente para a opção um (nada/não limita), havendo uma grande tendência entre os participantes de pontuarem o valor um para suas respostas. Isso ocorreu em 18 dos 25 itens do DASS (itens 1a, 1b, 1c, 1d, 1e, 2a, 2b, 2c, 2d, 3a, 3b, 3c, 3d, 3e, 3f, 3g, 4g e 4i) ) (Tabela 5).

Com relação aos itens considerados como "não se aplica" e "não informado" pelos participantes, tivemos uma porcentagem relevante de sujeitos que consideraram os itens $1 \mathrm{~d}$ $(9,4 \% ; n=17)$ e $2 b(12,2 \% ; n=22)$ como não aplicáveis. Esses itens referem-se " $a$ quanto à possibilidade de sangrar ou se machucar limita no emprego" e ao "quanto o tratamento com o ACO limita o consumo de bebidas alcoólicas", respectivamente. Quanto aos itens não respondidos, foram eles, os itens $3 \mathrm{hr}$ e $4 \mathrm{jr}$, que referem as questões "o quanto que você acredita que consegue seguir seu tratamento de anticoagulação (afinar o sangue)" com ausência de resposta de dois indivíduos $(1,1 \%)$ e "qual a possibilidade de você incentivar uma outra pessoa (com o mesmo problema de saúde que você tem) a seguir o tratamento de anticoagulação (afinar o sangue)" não respondido por um individuo $(0,6 \%)$, respectivamente (Tabela 5). 
Ainda, sobre a freqüência das respostas aos 25 itens do DASS, analisamos os resultados referentes aos domínios do instrumento, uma vez que os itens de 1a a $2 \mathrm{~d}$ correspondem ao domínio Limitação, itens de $3 \mathrm{a}$ a $3 \mathrm{hr}$ correspondem ao domínio Tarefa/Sobrecarga, e dos itens 4ar a 4jr correspondem ao domínio Impacto Psicológico. Nesse último domínio, os itens $4 \mathrm{ar}, 4 \mathrm{br}, 4 \mathrm{fr}, 4 \mathrm{hr}$ e $4 \mathrm{jr}$ referem se ao impacto psicológico positivo e os itens $4 \mathrm{~d}, 4 \mathrm{~g}$ e $4 \mathrm{i}$ ao impacto psicológico negativo.

As respostas aos itens do domínio Limitação foi predominantemente nada/não limita (valor 1) variando de $80 \%(\mathrm{n}=144)$ a $73,9 \%(\mathrm{n}=133)$. Isso, também ocorreu no domínio Tarefa/Sobrecarga, em que a resposta nada/não limita variou de $78,3 \%(n=141)$ a $37,2 \%$ $(\mathrm{n}=67)$. Já o domínio impacto psicológico obteve maiores porcentagem na resposta pouco (valor 3) com 51,1\% ( $\mathrm{n}=92)$ das respostas. Porém, se considerarmos os itens relativos ao Impacto Psicológico Positivo, a freqüência maior de resposta também permaneceu na opção pouco (valor 3) sendo que, para o Impacto Psicológico Negativo a opção que mais predominou foi a nada/não limita (valor 1) para 83,3\% ( $\mathrm{n}=150$ dos sujeitos) (Tabela 6). 
Tabela 5 - Distribuição das freqüências de respostas aos 25 itens do instrumento DASS, sem reposição dos dados. Ribeirão Preto, 2009

\begin{tabular}{|c|c|c|c|c|c|c|c|c|c|}
\hline $\begin{array}{l}\text { DASS } \\
\text { itens }\end{array}$ & $\begin{array}{c}1 \\
(\%)\end{array}$ & $\begin{array}{c}2 \\
(\%)\end{array}$ & $\begin{array}{c}3 \\
(\%)\end{array}$ & $\begin{array}{c}4 \\
(\%)\end{array}$ & $\begin{array}{c}5 \\
(\%)\end{array}$ & $\begin{array}{c}6 \\
(\%)\end{array}$ & $\begin{array}{c}7 \\
(\%)\end{array}$ & $\begin{array}{l}\text { NA } \\
(\%)\end{array}$ & $\begin{array}{c}\text { NI } \\
(\%)\end{array}$ \\
\hline $1 \mathrm{a}$ & $116(64,4)$ & $9(5)$ & $24(13,3)$ & $15(8,3)$ & $13(7,2)$ & $3(1,7)$ & 0 & 0 & 0 \\
\hline $1 b$ & 144(80) & $2(1,1)$ & $8(4,4)$ & $6(3,3)$ & $11(6,1)$ & $8(4,4)$ & $1(0,6)$ & 0 & 0 \\
\hline $1 \mathrm{c}$ & $107(59,4)$ & $5(2,8)$ & $17(9,4)$ & $13(7,2)$ & $21(11,7)$ & $15(8,3)$ & $2(1,1)$ & 0 & 0 \\
\hline $1 d$ & $127(70,6)$ & $2(1,1)$ & $14(7,8)$ & $5(2,8)$ & $10(5,6)$ & $4(2,2)$ & $1(0,6)$ & $17(9,4)$ & 0 \\
\hline $1 \mathrm{e}$ & $130(72,2)$ & $8(4,4)$ & $13(7,2)$ & $13(7,2)$ & $8(4,4)$ & $8(4,4)$ & 0 & 0 & 0 \\
\hline $2 \mathrm{a}$ & $86(47,8)$ & $11(6,1)$ & $26(14,4)$ & $22(12,2)$ & $21(11,7)$ & $12(6,7)$ & $2(1,1)$ & 0 & 0 \\
\hline $2 b$ & $116(64,4)$ & $8(4,4)$ & $7(3,9)$ & $1(0,6)$ & $11(6,1)$ & $10(5,6)$ & $5(2,8)$ & $22(12,2)$ & 0 \\
\hline $2 \mathrm{c}$ & $91(50,6)$ & $6(3,3)$ & $12(6,7)$ & $8(4,4)$ & $28(15,6)$ & $27(15)$ & $8(4,4)$ & 0 & 0 \\
\hline $2 \mathrm{~d}$ & $133(73,9)$ & $12(6,7)$ & $13(7,2)$ & $4(2,2)$ & $13(7,2)$ & $4(2,2)$ & $1(0,6)$ & 0 & 0 \\
\hline $3 a$ & $132(73,3)$ & $6(3,3)$ & $19(10,6)$ & $7(3,9)$ & $11(6,1)$ & $5(2,8)$ & 0 & 0 & 0 \\
\hline $3 b$ & $115(63,9)$ & $10(5,6)$ & $17(9,4)$ & $12(6,7)$ & $18(10)$ & $7(3,9)$ & $1(0,6)$ & 0 & 0 \\
\hline $3 \mathrm{c}$ & $116(64,4)$ & $7(3,9)$ & $17(9,4)$ & $17(9,4)$ & $13(7,2)$ & $10(5,6)$ & 0 & 0 & 0 \\
\hline $3 d$ & $67(37,2)$ & $16(8,9)$ & $36(20)$ & $13(7,2)$ & $33(18,3)$ & $14(7,8)$ & $1(0,6)$ & 0 & 0 \\
\hline $3 e$ & $130(72,2)$ & $11(6,1)$ & $15(8,3)$ & $10(5,6)$ & $9(5,0)$ & $4(2,2)$ & $1(0,6)$ & 0 & 0 \\
\hline $3 \mathrm{f}$ & $129(71,7)$ & $11(6,1)$ & $15(8,3)$ & $14(7,8)$ & $4(2,2)$ & $7(3,9)$ & 0 & 0 & 0 \\
\hline $3 g$ & $141(78,3)$ & $5(2,8)$ & $12(6,7)$ & $5(2,8)$ & $9(5)$ & $8(4,4)$ & 0 & 0 & $2(1,1)$ \\
\hline $3 \mathrm{hr}$ & $23(12,8)$ & $53(29,4)$ & $76(42,2)$ & $17(9,4)$ & $3(1,7)$ & $2(1,1)$ & $4(2,2)$ & 0 & 0 \\
\hline 4ar & $11(6,1)$ & $27(15)$ & $84(46,7)$ & $34(18,9)$ & $12(6,7)$ & $6(3,3)$ & $6(3,3)$ & 0 & 0 \\
\hline $4 \mathrm{br}$ & $25(13,9)$ & $50(27,8)$ & $89(49,4)$ & $5(2,8)$ & $3(1,7)$ & $4(2,2)$ & $4(2,2)$ & 0 & 0 \\
\hline $4 d$ & $48(26,7)$ & $9(5)$ & $20(11,1)$ & $13(7,2)$ & $48(26,7)$ & $29(16,1)$ & $13(7,2)$ & 0 & 0 \\
\hline $4 \mathrm{fr}$ & $13(7,2)$ & $40(22,2)$ & $92(51,1)$ & $5(2,8)$ & $6(3,3)$ & $4(2,2)$ & $20(11,1)$ & 0 & 0 \\
\hline $4 \mathrm{~g}$ & $150(83,3)$ & $6(3,3)$ & $9(5)$ & $3(1,7)$ & $6(3,3)$ & $5(2,8)$ & $1(0,6)$ & 0 & 0 \\
\hline $4 \mathrm{hr}$ & $20(11,1)$ & $47(26,1)$ & $86(47,8)$ & $10(5,6)$ & $12(6,7)$ & $2(1,1)$ & $3(1,7)$ & 0 & 0 \\
\hline $4 \mathrm{i}$ & $108(60)$ & $12(6,7)$ & $16(8,9)$ & $18(10)$ & $12(6,7)$ & $13(7,2)$ & $1(0,6)$ & 0 & $1(0,6)$ \\
\hline $4 \mathrm{jr}$ & $22(12,2)$ & $29(16,1)$ & $74(41,1)$ & $35(19,4)$ & $8(4,4)$ & $4(2,2)$ & $7(3,9)$ & 0 & 0 \\
\hline
\end{tabular}

(1) nada/não limita; (2) muito pouco (3) pouco; (4) moderadamente/mais ou menos; (5) bastante; (6) muito; (7) muitíssimo; (NA) não se aplica; (NI) dado não informado.

Na tabela 6, apresentamos as análises do DASS total, média de respostas aos 25 itens e de cada um dos itens do instrumento, individualmente. Quanto aos resultados da medida do DASS total obtivemos um intervalo entre 25 a 100. No geral, não se observou grande diferença entre os valores da mediana e da média (desvio-padrão) para o total da medida do DASS, cujos escores foram de 54,0 e 57,6 ( $\mathrm{DP}=15,9)$, respectivamente. Ao analisarmos as 
respostas dadas aos itens do instrumento observamos que elas variaram englobando os valores possíveis que é de um a sete. Da mesma forma, a mediana da média de respostas aos 25 itens do instrumento DASS apresentou valor de 2,2 aproximando-se da média cujo valor foi de 2,3 $(\mathrm{DP}=0,6)$. As medianas dos itens, individualmente, variaram entre 1,0 (item 1a, 1b, 1c, 1d, 1e, 2b, 2c, 2d, 3a, 3b, 3c, 3e, 3f, 3g, 4g e 4i) a 4,5 (item 4d). Quanto à média dos itens do DASS, essa variou de 1,5 (item 4g) a 3,8 (item 4d).

Tabela 6 - Análise descritiva da medida e dos 25 itens do instrumento DASS, sem reposição dos dados. Ribeirão Preto, 2009

\begin{tabular}{ccccc}
\hline DASS & Intervalo obtido & Mediana & Média & Desvio-padrão \\
\hline Total dos 25 itens* & $25-100$ & 54,0 & 57,6 & 15,9 \\
Média dos 25 itens* & $1-4$ & 2,2 & 2,3 & 0,6 \\
Item 1a & $1-6$ & 1,0 & 1,9 & 1,4 \\
Item 1b & $1-7$ & 1,0 & 1,7 & 1,5 \\
Item 1c & $1-7$ & 1,0 & 2,4 & 1,9 \\
Item 1d & $1-7$ & 1,0 & 1,7 & 1,4 \\
Item 1e & $1-6$ & 1,0 & 1,8 & 1,5 \\
Item 2a & $1-7$ & 2,0 & 2,6 & 1,8 \\
Item 2b & $1-7$ & 1,0 & 1,9 & 1,8 \\
Item 2c & $1-7$ & 1,0 & 2,9 & 2,2 \\
Item 2d & $1-7$ & 1,0 & 1,7 & 1,4 \\
Item 3a & $1-6$ & 1,0 & 1,7 & 1,4 \\
Item 3b & $1-7$ & 1,0 & 2,1 & 1,6 \\
Item 3c & $1-6$ & 1,0 & 2,1 & 1,6 \\
Item 3d & $1-7$ & 3,0 & 2,9 & 1,8 \\
Item 3e & $1-7$ & 1,0 & 1,7 & 1,4 \\
Item 3f & $1-6$ & 1,0 & 1,7 & 1,4 \\
Item 3g & $1-6$ & 1,0 & 1,8 & 1,4 \\
Item 3hr & $1-7$ & 3,0 & 2,7 & 1,2 \\
Item 4ar & $1-7$ & 3,0 & 3,3 & 1,3 \\
Item 4br & $1-7$ & 3,0 & 2,7 & 1,2 \\
Item 4d & $1-7$ & 4,5 & 3,8 & 2,0 \\
Item 4fr & $1-7$ & 3,0 & 3,2 & 1,6 \\
Item 4g & $1-7$ & 1,0 & 1,5 & 1,2 \\
Item 4hr & $1-7$ & 3,0 & 2,8 & 1,2 \\
Item 4i & $1-7$ & 1,0 & 2,2 & 1,7 \\
Item 4jr & $1-7$ & 3,0 & 3,1 & 1,4 \\
\hline
\end{tabular}

Diante da pequena porcentagem de itens do DASS que tiveram respostas consideradas como "não se aplica" pelos sujeitos (itens 1d e 2b) e de respostas "não informada" (itens $3 \mathrm{hr}$ e 
4jr) e baseado na proposta de reposição desses dados pela média das respostas dos sujeitos aos itens, foram calculados novos resultados para o DASS total e dos seus itens. Utilizamos o critério de Cohen e Cohen (1983) o qual estabelece que caso algum sujeito tenha $20 \%$ ou mais de suas respostas não preenchidas, ele deverá ser excluído da amostra. Seguindo esse critério não ocorreu exclusão de sujeitos no presente estudo.

Na tabela 7 estão apresentadas às novas freqüências das respostas aos itens $1 \mathrm{~d}$ e $2 \mathrm{~b}$ do DASS os quais estão relacionados aos itens em que o participante tinha como opção de resposta, além dos valores de um a sete, a opção "não se aplica". Observamos que houve uma nova redistribuição das freqüências de respostas, após a reposição dos dados dos itens $1 \mathrm{~d}$ e $2 \mathrm{~b}$ do instrumento DASS, principalmente entre os valores de 1 a 3 . No entanto, mesmo procedendo essa reposição dos dados não respondidos/não aplicáveis, as respostas aos itens 1d e 2 b permaneceram em sua maioria na opção 1 (nada/não limita) (Tabela 7). 
Tabela 7 - Distribuição das freqüências de respostas aos 25 itens do instrumento DASS, com reposição dos dados. Ribeirão Preto, 2009

\begin{tabular}{cccccccc}
\hline $\begin{array}{c}\text { DASS } \\
\text { itens }\end{array}$ & $\begin{array}{c}\mathbf{1} \\
\mathbf{( \% )}\end{array}$ & $\begin{array}{c}\mathbf{2} \\
\mathbf{( \% )}\end{array}$ & $\begin{array}{c}\mathbf{3} \\
\mathbf{( \% )}\end{array}$ & $\begin{array}{c}\mathbf{4} \\
\mathbf{\%}\end{array}$ & $\begin{array}{c}\mathbf{5} \\
\mathbf{( \% )}\end{array}$ & $\begin{array}{c}\mathbf{6} \\
\mathbf{( \% )}\end{array}$ & $\mathbf{7}$ \\
\hline 1a & $116(64,4)$ & $9(5)$ & $24(13,3)$ & $15(8,3)$ & $13(7,2)$ & $3(1,7)$ & 0 \\
1b & $144(80)$ & $2(1,1)$ & $8(4,4)$ & $6(3,3)$ & $11(6,1)$ & $8(4,4)$ & $1(0,6)$ \\
1c & $107(59,4)$ & $5(2,8)$ & $17(9,4)$ & $13(7,2)$ & $21(11,7)$ & $15(8,3)$ & $2(1,1)$ \\
1d & $132(73,3)$ & $8(4,4)$ & $17(9,4)$ & $7(3,9)$ & $10(5,6)$ & $4(2,2)$ & $1(0,6)$ \\
1e & $130(72,2)$ & $8(4,4)$ & $13(7,2)$ & $13(7,2)$ & $8(4,4)$ & $8(4,4)$ & 0 \\
2a & $86(47,8)$ & $11(6,1)$ & $26(14,4)$ & $22(12,2)$ & $21(11,7)$ & $12(6,7)$ & $2(1,1)$ \\
2b & $121(67,2)$ & $17(9,4)$ & $12(6,7)$ & $4(2,2)$ & $11(6,1)$ & $10(5,6)$ & $5(2,8)$ \\
2c & $91(50,6)$ & $6(3,3)$ & $12(6,7)$ & $8(4,4)$ & $28(15,6)$ & $27(15)$ & $8(4,4)$ \\
2d & $133(73,9)$ & $12(6,7)$ & $13(7,2)$ & $4(2,2)$ & $13(7,2)$ & $4(2,2)$ & $1(0,6)$ \\
3a & $132(73,3)$ & $6(3,3)$ & $19(10,6)$ & $7(3,9)$ & $11(6,1)$ & $5(2,8)$ & 0 \\
3b & $115(63,9)$ & $10(5,6)$ & $17(9,4)$ & $12(6,7)$ & $18(10)$ & $7(3,9)$ & $1(0,6)$ \\
3c & $116(64,4)$ & $7(3,9)$ & $17(9,4)$ & $17(9,4)$ & $13(7,2)$ & $10(5,6)$ & 0 \\
3d & $67(37,2)$ & $16(8,9)$ & $36(20)$ & $13(7,2)$ & $33(18,3)$ & $14(7,8)$ & $1(0,6)$ \\
3e & $130(72,2)$ & $11(6,1)$ & $15(8,3)$ & $10(5,6)$ & $9(5,0)$ & $4(2,2)$ & $1(0,6)$ \\
3f & $129(71,7)$ & $11(6,1)$ & $15(8,3)$ & $14(7,8)$ & $4(2,2)$ & $7(3,9)$ & 0 \\
3g & $141(78,3)$ & $5(2,8)$ & $12(6,7)$ & $5(2,8)$ & $9(5)$ & $8(4,4)$ & 0 \\
3hr & $23(12,8)$ & $53(29,4)$ & $76(42,2)$ & $17(9,4)$ & $3(1,7)$ & $2(1,1)$ & $4(2,2)$ \\
4ar & $11(6,1)$ & $27(15)$ & $84(46,7)$ & $34(18,9)$ & $12(6,7)$ & $6(3,3)$ & $6(3,3)$ \\
4br & $25(13,9)$ & $50(27,8)$ & $89(49,4)$ & $5(2,8)$ & $3(1,7)$ & $4(2,2)$ & $4(2,2)$ \\
4d & $48(26,7)$ & $9(5)$ & $20(11,1)$ & $13(7,2)$ & $48(26,7)$ & $29(16,1)$ & $13(7,2)$ \\
4fr & $13(7,2)$ & $40(22,2)$ & $92(51,1)$ & $5(2,8)$ & $6(3,3)$ & $4(2,2)$ & $20(11,1)$ \\
4g & $150(83,3)$ & $6(3,3)$ & $9(5)$ & $3(1,7)$ & $6(3,3)$ & $5(2,8)$ & $1(0,6)$ \\
4hr & $20(11,1)$ & $47(26,1)$ & $86(47,8)$ & $10(5,6)$ & $12(6,7)$ & $2(1,1)$ & $3(1,7)$ \\
4i & $108(60)$ & $12(6,7)$ & $16(8,9)$ & $18(10)$ & $12(6,7)$ & $13(7,2)$ & $1(0,6)$ \\
4jr & $22(12,2)$ & $29(16,1)$ & $74(41,1)$ & $35(19,4)$ & $8(4,4)$ & $4(2,2)$ & $7(3,9)$ \\
\hline
\end{tabular}

(1) nada/não limita; (2) muito pouco (3) pouco; (4) moderadamente/mais ou menos; (5) bastante; (6) muito; (7) muitíssimo.

A Tabela 8 demonstra as medidas de tendência central e dispersão após substituição dos dados não aplicáveis e não respondidos pela média das repostas dos sujeitos aos demais itens do instrumento. Pode-se verificar que a maioria dos resultados (intervalo obtido, mediana, média e desvio-padrão) não se alteraram e para aqueles resultados que apresentaram alguma diferença, essa foi de pequena proporção. Constatamos que para a medida total dos 25 
itens do instrumento DASS as diferenças nos resultados, após a reposição dos dados, relacionaram-se ao intervalo obtido da medida total do instrumento DASS (de 25 a 100 para 25 a 109), a mediana (de 54,0 para 54,5), a média (de 57,6 para 57,9) e o desvio-padrão (de $15,9$ para 16,4$)$. Já a medida da média dos 25 itens do instrumento DASS apresentou o mesmo valor da medida da média dos 25 itens sem reposição dos dados referentes as respostas "não se aplica" e "não informada". O mesmo ocorreu com o intervalo obtido, a mediana e o desviopadrão. Entre os itens do instrumento DASS apenas o item $3 \mathrm{~g}$ apresentou uma pequena alteração no valor obtido da média e o do desvio-padrão (de 1,8 para 1,7 e de 1,2 para 1,4, respectivamente) (Tabela 8).

Tabela 8 - Análise descritiva da medida e dos 25 itens do instrumento DASS, com reposição dos dados. Ribeirão Preto, 2009

\begin{tabular}{ccccc}
\hline DASS & Intervalo obtido & Mediana & Média & Desvio-padrão \\
\hline Total dos 25 itens & $25-109$ & 54,5 & 57,9 & 16,4 \\
Média dos 25 itens & $1-4$ & 2,2 & 2,3 & 0,6 \\
& & & & \\
Item 1a & $1-6$ & 1,0 & 1,9 & 1,4 \\
Item 1b & $1-7$ & 1,0 & 1,7 & 1,5 \\
Item 1c & $1-7$ & 1,0 & 2,4 & 1,9 \\
Item 1d & $1-7$ & 1,0 & 1,7 & 1,4 \\
Item 1e & $1-6$ & 1,0 & 1,8 & 1,5 \\
Item 2a & $1-7$ & 2,0 & 2,6 & 1,8 \\
Item 2b & $1-7$ & 1,0 & 1,9 & 1,8 \\
Item 2c & $1-7$ & 1,0 & 2,9 & 2,2 \\
Item 2d & $1-7$ & 1,0 & 1,7 & 1,4 \\
Item 3a & $1-6$ & 1,0 & 1,7 & 1,4 \\
Item 3b & $1-7$ & 1,0 & 2,1 & 1,6 \\
Item 3c & $1-6$ & 1,0 & 2,1 & 1,6 \\
Item 3d & $1-7$ & 3,0 & 2,9 & 1,8 \\
Item 3e & $1-7$ & 1,0 & 1,7 & 1,4 \\
Item 3f & $1-6$ & 1,0 & 1,7 & 1,4 \\
Item 3g & $1-6$ & 1,0 & 1,7 & 1,4 \\
Item 3hr & $1-7$ & 3,0 & 2,7 & 1,4 \\
Item 4ar & $1-7$ & 3,0 & 3,3 & 1,3 \\
Item 4br & $1-7$ & 3,0 & 2,7 & 1,2 \\
Item 4d & $1-7$ & 4,5 & 3,8 & 2,0 \\
Item 4fr & $1-7$ & 3,0 & 3,2 & 1,6 \\
Item 4g & $1-7$ & 1,0 & 1,5 & 1,2 \\
Item 4hr & $1-7$ & 3,0 & 2,8 & 1,2 \\
Item 4i & $1-7$ & 1,0 & 2,2 & 1,7 \\
Item 4jr & $1-7$ & 3,0 & 3,1 & 1,4 \\
\hline
\end{tabular}


Assim, a partir dessa reposição, constatamos que não houve grandes mudanças nos resultados das análises descritivas do instrumento DASS. Diante desta observação, decidimos realizar as análises das propriedades psicométricas usando a nova versão dos dados e mantendo-se a amostra em 180 pacientes.

Neste estudo obteve-se um intervalo de 25 a 109 para a medida total da versão adaptada do instrumento, lembrando que o intervalo possível é de 25 a 175 . Para o domínio Limitação obtive-se um intervalo de 9 a 48 (intervalo possível de 9 a 63), para o domínio Tarefa/Sobrecarga o intervalo foi de 8 a 41 (intervalo possível de 8 a 56) e para o domínio impacto psicológico foi de 8 a 40 (intervalo possível de 8 a 56). Quando esse último domínio foi dividido em duas sub-escalas os valores para o Impacto Psicológico Positivo variou de 3 a 18 (intervalo possível de 3 a 21) e para o Impacto Psicológico Negativo entre 5 a 31 (intervalo possível de 5 a 35). Portanto, constatamos variações com valores próximos aos intervalos possíveis para cada domínio do DASS. A medida do DASS total apresentou média de 57,9 $(\mathrm{DP}=16,4)$. Entre os seus domínios, o que apresentou maior valor médio foi o domínio Impacto Psicológico com 22,6 ( $\mathrm{DP}=5,4)$, sendo que o Impacto Psicológico Positivo apresentou média de 15,0 (DP=4,4) e o Negativo de 7,5 $(3,4)$. O domínio Tarefa/Sobrecarga foi aquele que apresentou menor média $(16,6 ; \mathrm{DP}=7,3)$ (Tabela 9).

Tabela 9 - Análise descritiva do DASS total e de seus componentes (limitação, tarefa/sobrecarga, impacto psicológico positivo e negativo). Ribeirão Preto, 2009

\begin{tabular}{lcccccc}
\hline \multicolumn{1}{c}{ Domínios do DASS } & $\begin{array}{c}\text { No. de } \\
\text { Itens }\end{array}$ & $\begin{array}{c}\text { Alfa de } \\
\text { Cronbach }\end{array}$ & $\begin{array}{c}\text { Intervalo } \\
\text { possível }\end{array}$ & $\begin{array}{c}\text { Intervalo } \\
\text { obtido }\end{array}$ & Mediana & Média (D.P.) \\
\hline DASS total & 25 & 0,79 & $25-175$ & $25-109$ & 54,5 & $57,9(16,4)$ \\
DASS limitação & 9 & 0,72 & $9-63$ & $9-48$ & 17,0 & $18,7(8,2)$ \\
DASS tarefa/sobrecarga & 8 & 0,76 & $8-56$ & $8-41$ & 14,0 & $16,6(7,3)$ \\
DASS impacto psicológico & 8 & 0,46 & $8-56$ & $8-40$ & 22,0 & $22,6(5,4)$ \\
$\quad$ Positivo & 3 & 0,67 & $3-21$ & $3-18$ & 15,0 & $15,0(4,4)$ \\
$\quad$ Negativo & 5 & 0,38 & $5-35$ & $5-31$ & 7,0 & $7,5(3,4)$ \\
\hline
\end{tabular}


As correlações entre as medidas do DASS total com as medidas dos seus domínios foram avaliadas pelo coeficiente de correlação produto-momento de Pearson. As correlações obtidas entre as medidas do DASS total e de seus domínios apresentaram valores maiores de moderada a forte magnitude e estatisticamente significantes. Os valores do coeficiente de correlação foi de 0,81 para os domínios Limitação e Tarefa/Sobrecarga e de 0,71 para Impacto Psicológico. Entretanto, as correlações dos domínios entre si apresentaram menores valores: 0,45 (Tarefa/Sobrecarga com Impacto Psicológico); 0,43 (Limitação e Tarefa/Sobrecarga) e de 0,36 (Limitação e Impacto Psicológico) (Tabela 10).

Tabela 10 - Coeficiente de correlação de Pearson* entre os domínios do DASS e o total do instrumento. Ribeirão Preto 2009

\begin{tabular}{lcccc}
\hline \multicolumn{1}{c}{ Domínios } & DASS total & Limitação & Tarefa/sobrecarga & $\begin{array}{c}\text { Impacto } \\
\text { Psicológico }\end{array}$ \\
\hline DASS total & 1 & 0,81 & 0,81 & 0,71 \\
Limitação & & 1 & 0,43 & 0,36 \\
Tarefa/sobrecarga & & & 1 & 0,45 \\
Impacto Psicológico & & & & 1 \\
\hline$* p<0,05$ & & &
\end{tabular}

\subsection{Resultados relacionados às análises descritivas da versão adaptada do instrumento DASS (total e dos componentes)}

\subsubsection{Resultados relacionados à análise da confiabilidade}

A primeira propriedade psicométrica a ser apresentada será a confiabilidade da versão adaptada do instrumento DASS, avaliada pela consistência interna de seus itens considerando a medida total e de seus componentes.

Para avaliação da consistência interna foram realizados os cálculos do alfa de Cronbach cujos valores obtidos foram: 0,79 (DASS total), 0,72 (Limitação), 0,76 
(Tarefa/Sobrecarga), 0,46 (Impacto Psicológico), 0,67 (Impacto Psicológico Positivo) e 0,38 (Impacto Psicológico Negativo). Nessa avaliação, tanto o DASS total como dois dos seus domínios obtiveram valores de alfa de Cronbach acima de 0,70 . O domínio Limitação foi o que apresentou melhor consistência interna entre os seus itens, já o domínio Impacto Psicológico foi o que obteve pior avaliação (Tabela 9).

Nas tabelas 11, 12, 13, 14, 15 estão representados os resultados obtidos e relacionados aos valores do alfa de Cronbach, aos valores do coeficiente de correlação produto-momento de Pearson entre cada um dos itens e o total da escala, e os valores dos alfas quando cada um dos itens foi excluído da análise.

No domínio Limitação constatou-se que o alfa de Cronbach total foi de 0,72 , o que indica uma boa consistência interna entre seus nove itens. Com a retirada da cada um dos itens, individualmente, observamos uma variação de 0,68 a 0,72 , nos valores do alfa de Cronbach Os valores de correlações, entre cada um dos itens com o valor total do domínio, variaram de 0,24 a 0,45 indicando correlações de baixa a moderada magnitudes (todos os itens, exceto o item 1b) (Tabela 11). 
Tabela 11 - Coeficiente de correlação item-total*, alfa de Cronbach para o total e os itens do domínio Limitação e quando cada um dos itens foi excluído. Ribeirão Preto, 2009

\begin{tabular}{|c|c|c|}
\hline DASS - Limitação $(\alpha$ total $=0,72)$ & $\begin{array}{l}\text { Correlação } \\
\text { item-total }\end{array}$ & $\begin{array}{c}\text { Alfa de } \\
\text { Cronbach se o } \\
\text { item for excluído }\end{array}$ \\
\hline $\begin{array}{l}\text { 1a. O quanto que a possibilidade de sangrar ou se machucar limita } \\
\text { (atrapalha) você a fazer atividade física (por exemplo, serviços } \\
\text { domésticos, dançar, esportes, ou qualquer outra atividade que } \\
\text { usualmente você faz)? }\end{array}$ & 0,48 & 0,68 \\
\hline $\begin{array}{l}\text { 1b. O quanto que a possibilidade de sangrar ou se machucar te } \\
\text { limita (atrapalha) passear fora de sua de cidade? }\end{array}$ & 0,24 & 0,72 \\
\hline $\begin{array}{l}\text { 1c. O quanto que a possibilidade de sangrar ou se machucar limita } \\
\text { a realização de qualquer outro tratamento de saúde que você } \\
\text { precisar (por exemplo, ir ao dentista, ao fisioterapeuta, ou outro } \\
\text { serviço de saúde)? }\end{array}$ & 0,46 & 0,68 \\
\hline $\begin{array}{l}\text { 1d. O quanto que a possibilidade de sangrar ou se machucar limita } \\
\text { (atrapalha) em seu emprego? }\end{array}$ & 0,39 & 0,69 \\
\hline $\begin{array}{l}\text { 1e. No geral, o quanto que a possibilidade de sangrar ou se } \\
\text { machucar afeta (atrapalha) seu dia-a-dia? }\end{array}$ & 0,48 & 0,68 \\
\hline $\begin{array}{l}\text { 2a. O quanto que você muda a sua alimentação por causa do } \\
\text { tratamento de anticoagulação (afinar o sangue)? }\end{array}$ & 0,32 & 0,70 \\
\hline $\begin{array}{l}\text { 2b. O quanto que o seu tratamento de anticoagulação (afinar o } \\
\text { sangue) limita (atrapalha) o uso de bebidas alcoólicas? }\end{array}$ & 0,34 & 0,70 \\
\hline $\begin{array}{l}\text { 2c. O quanto que o seu tratamento de anticoagulação (afinar o } \\
\text { sangue) limita (atrapalha) o uso de medicamentos sem prescrição } \\
\text { (por exemplo para dor, febre e vitaminas)? }\end{array}$ & 0,41 & 0,69 \\
\hline $\begin{array}{l}\text { 2d. No geral, quanto o seu tratamento de anticoagulação afeta sua } \\
\text { vida diária? }\end{array}$ & 0,47 & 0,68 \\
\hline
\end{tabular}

* Correlação produto momento de Pearson

Na tabela 12 observamos que o alfa de Cronbach para o domínio Tarefa/Sobrecarga foi de 0,76 . Entre os três domínios do DASS, foi o que melhor apresentou consistência interna entre os seus oito itens. Houve uma variação de 0,71 a 0,79 nos valores dos alfas de Cronbach com a retirada de cada um dos itens do domínio, separadamente. Os valores de correlações entre cada um dos itens com o total do domínio apresentaram uma variação de 0,04 a 0,64 indicando correlações de pouco valor para a prática (item 3h) até correlações de forte magnitude (itens 3b, 3c, 3e, 3f e 3g). 
Tabela 12 - Coeficiente de correlação item-total*, o alfa total do domínio Tarefa/sobrecaga e alfas quando cada um dos itens foi excluído. Ribeirão Preto, 2009

\begin{tabular}{|c|c|c|}
\hline Tarefa/sobrecarga $(\alpha$ total $=0,76)$ & $\begin{array}{c}\text { Correlação } \\
\text { item-total }\end{array}$ & $\begin{array}{l}\text { Alfa de Cronbach } \\
\text { se o item for } \\
\text { excluído }\end{array}$ \\
\hline $\begin{array}{l}\text { 3a. O quanto essas atividades dificultam (atrapalham) a sua } \\
\text { vida? }\end{array}$ & 0,46 & 0,73 \\
\hline $\begin{array}{l}\text { 3b. O quanto que essas atividades dificultam (atrapalham) sua } \\
\text { vida? }\end{array}$ & 0,50 & 0,73 \\
\hline $\begin{array}{l}\text { 3c. O quanto que você acha difícil seguir o seu tratamento de } \\
\text { anticoagulação (afinar o sangue)? }\end{array}$ & 0,58 & 0,71 \\
\hline $\begin{array}{l}\text { 3d. O quanto que você gasta de seu tempo para seguir o } \\
\text { tratamento de anticoagulação (afinar o sangue)? }\end{array}$ & 0,37 & 0,76 \\
\hline $\begin{array}{l}\text { 3e. O quanto que você acha que o seu tratamento de } \\
\text { anticoagulação (afinar o sangue) te incomoda? }\end{array}$ & 0,64 & 0,70 \\
\hline $\begin{array}{l}\text { 3f. O quanto que você acha doloroso o seu tratamento de } \\
\text { anticoagulação (afinar o sangue)? }\end{array}$ & 0,57 & 0,72 \\
\hline $\begin{array}{l}\text { 3g. No geral, o quanto que você acha o seu tratamento de } \\
\text { anticoagulação (afinar o sangue) um sacrifício? }\end{array}$ & 0,52 & 0,72 \\
\hline $\begin{array}{l}\text { 3h. No geral, o quanto que você acredita que consegue seguir } \\
\text { seu tratamento de anticoagulação (afinar o sangue)? }\end{array}$ & 0,04 & 0,79 \\
\hline
\end{tabular}

* Correlação produto momento de Pearson

A pior avaliação da consistência interna foi constatada no domínio Impacto Psicológico com o alfa de Cronbach de 0,46. Nesse domínio, os valores de alfa de Cronbach apresentaram uma alteração mais visível ao se remover cada um dos itens variando de 0,35 a 0,61. Já os valores de correlações entre cada um dos itens com o total do domínio variaram de $-0,11$ a 0,45 os quais representam correlações de fraca (e inversa para o item 4d) a moderada magnitude (itens 4f e 4h) (Tabela 13). 
Tabela 13 - Coeficiente de correlação item-total*, alfa total dos itens do domínio Impacto Psicológico e alfa quando cada um dos itens foi excluído. Ribeirão Preto, 2009

\begin{tabular}{|c|c|c|}
\hline Impacto Psicológico $(\alpha$ total $=0,46)$ & $\begin{array}{l}\text { Correlação } \\
\text { item-total }\end{array}$ & $\begin{array}{l}\text { Alfa de Cronbach } \\
\text { se o item foi } \\
\text { excluído }\end{array}$ \\
\hline $\begin{array}{l}\text { 4a. O quanto que você compreende o motivo do seu tratamento } \\
\text { de anticoagulação? }\end{array}$ & 0,29 & 0,40 \\
\hline $\begin{array}{l}\text { 4b. O quanto que você acha que o seu tratamento de } \\
\text { anticoagulação (afinar o sangue) protege a sua saúde? }\end{array}$ & 0,29 & 0,40 \\
\hline $\begin{array}{l}\text { 4d. O quanto que você se preocupa com o risco de ter } \\
\text { sangramentos ou se machucar? }\end{array}$ & $-0,11$ & 0,61 \\
\hline $\begin{array}{l}\text { 4f. No geral, o quanto que o tratamento de anticoagulação } \\
\text { (afinar o sangue) melhorou sua vida? }\end{array}$ & 0,31 & 0,38 \\
\hline $\begin{array}{l}\text { 4g. No geral, quanto o tratamento de anticoagulação (afinar o } \\
\text { sangue) piorou sua vida? }\end{array}$ & 0,27 & 0,41 \\
\hline $\begin{array}{l}\text { 4h. No geral, o quanto que você esta satisfeito com o seu } \\
\text { tratamento de anticoagulação (afinar o sangue)? }\end{array}$ & 0,45 & 0,35 \\
\hline $\begin{array}{l}\text { 4i. Comparado com outros tratamentos que você fez, o quanto é } \\
\text { difícil lidar com esse tratamento de anticoagulação (afinar o } \\
\text { sangue)? }\end{array}$ & 0,23 & 0,42 \\
\hline $\begin{array}{l}\text { 4j. Qual a possibilidade de você incentivar uma outra pessoa } \\
\text { (com o mesmo problema de saúde que você tem) a seguir o } \\
\text { tratamento de anticoagulação (afinar o sangue)? }\end{array}$ & 0,19 & 0,44 \\
\hline
\end{tabular}

O domínio Impacto Psicológico foi analisado separadamente seus itens em duas subescalas, Impacto Psicológico Positivo e Impacto Psicológico Negativo. O valor de alfa de Cronbach para a sub-escala Impacto Psicológico Positivo foi de 0,67 , variando de 0,56 a 0,67 com a remoção de cada um dos cinco itens que a compõem. Os valores de correlações entre cada um dos itens com o total do domínio variaram de 0,35 a 0,59 indicando correlações de moderada a forte magnitude (Tabela 14). Na sub-escala Impacto Psicológico Negativo obteve-se um valor de alfa de Cronbach de 0,38 , com variação de 0,19 a 0,35 quando cada um dos três itens que a compõem. Os valores de correlações entre cada um dos itens com o total da sub-escala variaram de 0,20 a 0,27 o que indica correlação de pouco valor para a prática (Tabela 15). 
Tabela 14 - Coeficiente de correlação item-total* , alfa total dos itens da sub-escala Impacto Psicológico Positivo e alfas quando cada um dos itens foi excluído. Ribeirão Preto, 2009

\begin{tabular}{|c|c|c|}
\hline Impacto Psicológico Positivo $(\alpha$ total $=0,67)$ & $\begin{array}{l}\text { Correlação } \\
\text { item-total }\end{array}$ & $\begin{array}{c}\text { Alfa de Cronbach } \\
\text { se o item for } \\
\text { excluído }\end{array}$ \\
\hline $\begin{array}{l}\text { 4a. O quanto que você compreende o motivo do seu tratamento } \\
\text { de anticoagulação? }\end{array}$ & 0,42 & 0,63 \\
\hline $\begin{array}{l}\text { 4b. O quanto que você acha que o seu tratamento de } \\
\text { anticoagulação (afinar o sangue) protege a sua saúde? }\end{array}$ & 0,50 & 0,60 \\
\hline $\begin{array}{l}\text { 4f. No geral, o quanto que o tratamento de anticoagulação } \\
\text { (afinar o sangue) melhorou sua vida? }\end{array}$ & 0,35 & 0,67 \\
\hline $\begin{array}{l}\text { 4h. No geral, o quanto que você esta satisfeito com o seu } \\
\text { tratamento de anticoagulação (afinar o sangue)? }\end{array}$ & 0,59 & 0,56 \\
\hline $\begin{array}{l}\text { 4j. Qual a possibilidade de você incentivar uma outra pessoa } \\
\text { (com o mesmo problema de saúde que você tem) a seguir o } \\
\text { tratamento de anticoagulação (afinar o sangue)? }\end{array}$ & 0,35 & 0,66 \\
\hline
\end{tabular}

Tabela 15 - Coeficiente de correlação item-total*, alfa total da sub-escala Impacto Psicológico Negativo e alfas quando cada um dos itens foi excluído. Ribeirão Preto, 2009

\begin{tabular}{lcc}
\hline \multicolumn{1}{c}{ Impacto Psicológico Negativo ( $\boldsymbol{\alpha}$ total = 0,38 ) } & $\begin{array}{c}\text { Correlação } \\
\text { item-total }\end{array}$ & $\begin{array}{c}\text { Alfa de Cronbach } \\
\text { se o item for } \\
\text { excluído }\end{array}$ \\
\hline $\begin{array}{l}\text { 4d. O quanto que você se preocupa com o risco de ter } \\
\text { sangramentos ou se machucar? }\end{array}$ & 0,22 & 0,31 \\
$\begin{array}{l}\text { 4g. No geral, quanto o tratamento de anticoagulação (afinar o } \\
\text { sangue) piorou sua vida? }\end{array}$ & 0,20 & 0,35 \\
$\begin{array}{l}\text { 4i. Comparado com outros tratamentos que você fez, o quanto é } \\
\text { difícil lidar com esse tratamento de anticoagulação (afinar o } \\
\text { sangue)? }\end{array}$ & 0,27 & 0,19 \\
\hline * Correlação produto momento de Pearson
\end{tabular}

\subsubsection{Resultados relacionados à análise da validade de constructo da versão adaptada do} DASS.

\subsubsection{Resultados relacionados à dimensionalidade}

A análise fatorial confirmatória foi realizada por meio da matrix de rotação Varimax para os componentes do DASS, Limitação, Tarefa/Sobrecarga e Impacto Psicológico, utilizando os 25 itens do instrumento (Tabela 16). Em geral, considera-se como componentes mais importantes aqueles com autovalores (eigenvalues) igual ou superior a um. No entanto, na análise inicial não 
foram encontrados valores maiores ou iguais a um dentre os 25 itens do DASS, sendo que o menor valor encontrado foi de $-0,007$ para o item 4 i no componente 3 e o maior valor para o item 1a no componente 1 com 0,745 . Diante dos três componentes obtidos através da rotação Varimax, observamos que o componente um apresentou maiores valores relacionados ao domínio Limitação, cuja variação foi de 0,745 a 0,229 . Nesse componente apenas os itens $2 \mathrm{~b}$ e $2 \mathrm{c}$ tiveram maiores cargas em outro componente. Já o componente dois relacionou-se mais fortemente com os itens do domínio Tarefa/Sobrecarga cujos valores obtidos foram de $-0,061$ a 0,740 , sendo o menor valor relacionado ao item $3 \mathrm{hr}$. O componente três em sua maioria, apresentou valores positivos e maiores em relação aos outros domínios, e desse modo, o componente três se relaciona mais intensamente com o domínio Impacto Psicológico.

Tabela 16 - Matrix de rotação Varimax dos componentes da versão adaptada do DASS. Ribeirão Preto, 2009

\begin{tabular}{|c|c|c|c|c|}
\hline & \multirow{2}{*}{$\begin{array}{c}\text { DASS } \\
\text { Item }\end{array}$} & \multicolumn{3}{|c|}{ COMPONENTES } \\
\hline & & 1 & 2 & 3 \\
\hline & Item $1 \mathrm{a}$ & 0,745 & 0,096 & $-0,051$ \\
\hline & Item $1 \mathrm{~b}$ & 0,355 & 0,157 & 0,132 \\
\hline & Item $1 \mathrm{c}$ & 0,482 & 0,208 & $-0,280$ \\
\hline Itens do domínio & Item $1 d$ & 0,635 & 0,103 & $-0,088$ \\
\hline \multirow{7}{*}{ Limitação } & Item $1 \mathrm{e}$ & 0,689 & 0,106 & 0,039 \\
\hline & Item $2 \mathrm{a}$ & 0,336 & 0,174 & $-0,211$ \\
\hline & Item $2 b$ & 0,229 & 0,360 & $-0,141$ \\
\hline & Item $2 \mathrm{c}$ & 0,239 & 0,381 & $-0,222$ \\
\hline & Item $2 d$ & 0,509 & 0,420 & 0,110 \\
\hline & Item $3 a$ & 0,303 & 0,477 & 0,261 \\
\hline & Item $3 b$ & 0,201 & 0,566 & 0,143 \\
\hline Itens do domínio & Item $3 c$ & 0,190 & 0,637 & 0,247 \\
\hline \multirow{7}{*}{ Tarefa/sobrecarga } & Item $3 d$ & 0,009 & 0,602 & $-0,086$ \\
\hline & Item $3 \mathrm{e}$ & 0,095 & 0,740 & 0,140 \\
\hline & Item $3 \mathrm{f}$ & 0,092 & 0,675 & 0,071 \\
\hline & Item $3 g$ & 0,038 & 0,666 & 0,098 \\
\hline & Item $3 \mathrm{hr}$ & 0,008 & $-0,061$ & 0,473 \\
\hline & Item 4ar & $-0,109$ & 0,231 & 0,505 \\
\hline & Item $4 \mathrm{br}$ & $-0,124$ & 0,186 & 0,613 \\
\hline Itens do domínio & Item $4 d$ & 0,482 & 0,142 & $-0,468$ \\
\hline \multirow{5}{*}{ Impacto Psicológico } & Item $4 \mathrm{fr}$ & 0,026 & 0,172 & 0,483 \\
\hline & Item $4 \mathrm{~g}$ & 0,631 & 0,038 & 0,270 \\
\hline & Item $4 \mathrm{hr}$ & 0,088 & 0,169 & 0,726 \\
\hline & Item $4 \mathrm{i}$ & 0,271 & 0,516 & $-0,007$ \\
\hline & Item $4 \mathrm{jr}$ & 0,150 & $-0,212$ & 0,694 \\
\hline
\end{tabular}




\subsubsection{Resultados relacionados à validade de constructo convergente}

O instrumento SF-36 que avalia o estado de saúde percebido pelos pacientes foi usado para testar a validade do constructo convergente da versão adaptada do DASS seguindo os procedimentos feitos pelos autores da versão original. Entre os participantes constatamos maiores valores (melhor avaliação) nos domínios: Aspectos Sociais $(M=82,0 ; D P=26,5)$ e Estado de Saúde Percebido ( $M=69,0 ; \mathrm{DP}=24,6)$ e menores valores (pior avaliação) nos domínios Dor $(M=60,9 ; \mathrm{DP}=30,0)$ e Aspectos Físicos $(\mathrm{M}=54,7 ; \mathrm{DP}=47,8)$. Lembrando que os domínios têm uma variação possível entre zero a 100, obtivemos intervalos com valores máximos em todos os oito domínios avaliados e com valores mínimos que diferiram de zero, apenas para o domínio Dor (mínimo = 5) $($ Tabela 17).

Com relação à consistência interna do SF-36 constatamos, de modo geral, uma consistência interna satisfatória do instrumento para a amostra estudada, ou seja, valores de alfa de Cronbach acima de 0,70, com exceção do domínio Aspectos Sociais o qual apresentou um valor de alfa de Cronbach de 0,60 o qual está abaixo do recomendado $(\alpha=0,70)$. O maior valor de alfa de Cronbach foi para o domínio Aspectos Emocionais $(\alpha=0,99)$, seguido do domínio Aspectos Físicos $(\alpha=0,97)$, Capacidade Funcional $(\alpha=0,89)$, Dor $(\alpha=0,86)$, Saúde Mental $(\alpha=0,82)$, Estado de Saúde Percebido $(\alpha=0,78)$, Vitalidade $(\alpha=0,75)$ e por fim, o domínio Aspectos Sociais $(\alpha=0,60)$ (Tabela 17).

Tabela 17 - Análise descritiva e consistência interna dos oito domínios do SF-36. Ribeirão Preto, 2009

\begin{tabular}{lcccccc}
\hline Domínios do SF-36 & $\begin{array}{c}\text { No. } \\
\text { de } \\
\text { Itens }\end{array}$ & $\begin{array}{c}\text { Alfa de } \\
\text { Cronbach }\end{array}$ & $\begin{array}{c}\text { Intervalo } \\
\text { possível }\end{array}$ & $\begin{array}{c}\text { Intervalo } \\
\text { obtido }\end{array}$ & Mediana & Média (D.P.)* \\
\hline Aspectos Físicos & 4 & 0,97 & $0-100$ & $0-100$ & 75,0 & $54,7(47,8)$ \\
Aspectos emocionais & 3 & 0,99 & $0-100$ & $0-100$ & 100,0 & $62,7(48,0)$ \\
Capacidade Funcional & 10 & 0,89 & $0-100$ & $0-100$ & 70,0 & $63,0(27,2)$ \\
Dor & 2 & 0,86 & $0-100$ & $5-100$ & 61,0 & $60,9(30,0)$ \\
Estado geral de saúde & 5 & 0,78 & $0-100$ & $0-100$ & 77,0 & $69,0(24,6)$ \\
Vitalidade & 4 & 0,75 & $0-100$ & $0-100$ & 70,0 & $66,0(24,7)$ \\
Saúde Mental & 5 & 0,82 & $0-100$ & $0-100$ & 70,0 & $66,7(25,1)$ \\
Aspectos sociais & 2 & 0,60 & $0-100$ & $0-100$ & 100,0 & $82,0(26,5)$ \\
\hline
\end{tabular}

* D.P.: Desvio-padrão 
Para testar a validade de constructo, avaliamos as correlações existentes entre as medidas dos domínios do SF-36 e as medidas obtidas nos domínios do DASS, por meio do coeficiente de correlação produto-momento de Pearson (Tabela 18). Cabe ressaltar que os autores da versão original não apresentaram a correlação entre a medida do domínio Impacto psicológico (sem sua subdivisão) com os domínios do SF-36.

Ao se analisar os valores referentes às correlações entre as medidas dos domínios do DASS e as medidas dos domínios do SF-36, constatamos correlações de moderada magnitude entre os domínios Limitação e Estado de Saúde Percebido $(r=-0,36)$; Limitação e Vitalidade $(\mathrm{r}=-0,38) ;$ Tarefa/Sobrecarga e Estado de Saúde Percebido $(\mathrm{r}=-0,32)$; Impacto Psicológico Positivo e Capacidade Funcional $(r=-0,30)$; Impacto Psicológico Negativo e Estado de Saúde Percebido $(\mathrm{r}=-0,36)$; Impacto Psicológico Negativo e Vitalidade $(\mathrm{r}=-0,36)$; Impacto Psicológico negativo e Saúde Mental $(r=-0,30)$. As demais correlações entre os domínios do DASS e do SF-36 corresponderam a pouco valor para prática. Alguns valores obtidos das correlações entre as medidas dos domínios do DASS e as medidas dos domínios do SF-36, representados na Tabela 18 com $(*)$, não foram estatisticamente significantes $(p>0,05)$ neste estudo.

Todos os valores de correlações entre os componentes do SF-36 e os domínios do instrumento DASS foram negativos, ou seja, com correlações inversas entre as medidas. Isso se deve ao fato de que altos valores numéricos nos domínios do instrumento SF-36 refletem uma percepção de boa saúde, ausência de incapacidades ou limitações físicas e ausência de dor enquanto que baixos valores numéricos para o instrumento do DASS indicam melhor satisfação com o tratamento com ACO, menor limitação, menor tarefa/sobrecarga e menor impacto psicológico. 
Tabela 18 - Coeficiente de correlação de Pearson entre os domínios do instrumento DASS e os domínios do SF-36. Ribeirão Preto, 2009

\begin{tabular}{lccccc}
\hline SF-36 & $\begin{array}{c}\text { DASS } \\
\text { Total }\end{array}$ & Limitação & $\begin{array}{c}\text { Tarefa/ } \\
\text { Sobrecarga }\end{array}$ & $\begin{array}{c}\text { Impacto Psicológico } \\
\text { Positivo }\end{array}$ & $\begin{array}{c}\text { Impacto Psicológico } \\
\text { Negativo }\end{array}$ \\
\hline Aspectos Físicos & $-0,08^{*}$ & $-0,09^{*}$ & $-0,04^{*}$ & $-0,06^{*}$ & $-0,10^{*}$ \\
Aspectos emocionais & $-0,24$ & $-0,29$ & $-0,06^{*}$ & $-0,09^{*}$ & $-0,24$ \\
Capacidade Funcional & $-0,22$ & $-0,15$ & $-0,09^{*}$ & $-0,30$ & $-0,10^{*}$ \\
Dor & $-0,25$ & $-0,27$ & $-0,10^{*}$ & $-0,11^{*}$ & $-0,17$ \\
Estado geral de saúde & $-0,47$ & $-0,36$ & $-0,32$ & $-0,29$ & $-0,36$ \\
Vitalidade & $-0,44$ & $-0,37$ & $-0,28$ & $-0,25$ & $-0,36$ \\
Saúde Mental & $-0,42$ & $-0,38$ & $-0,24$ & $-0,23$ & $-0,30$ \\
Aspectos sociais & $-0,30$ & $-0,26$ & $-0,12^{*}$ & $-0,24$ & $-0,24$ \\
\hline
\end{tabular}

$* p>0,05$ apenas para os valores assinalados sendo as outras correlações estatisticamente significativas.

\subsubsection{Resultados relacionados à validade de constructo diergente}

Para testar a validade de constructo discriminante / divergente correlacionamos as medidas do DASS total e suas sub-escalas com a idade e o tempo de uso do ACO. Os resultados estão apresentados na Tabela 19, com a inclusão dos valores obtidos pelos autores da versão original do instrumento DASS.

Os valores obtidos da análise das correlações entre as medidas dos domínios do DASS e idade e tempo de uso do ACO demonstraram correlações de pouco valor para a prática (valores de $\mathrm{r}$ menores de 0,30) a forte magnitude (valores de $\mathrm{r}$ acima de 0,50). Predominantemente obtivemos correlações de pouco valor para a prática e estatisticamente significantes entre a idade e as medidas do DASS total $(r=-0,28)$, Limitação $(r=-0,37)$, Tarefa/Sobrecarga $(r=-0,16)$ e Impacto Psicológico Negativo $(r=-0,29)$, exceto para o Impacto Psicológico Positivo, que obtivemos valor positivo e não estatisticamente significante $(\mathrm{r}=0,13)$. A maioria das correlações entre os domínios do DASS e tempo de uso do ACO corresponderam a resultados de pouco valor para prática, variando de 0,01 para o DASS total e Tarefa/Sobrecarga, de $-0,04$ para Impacto Psicológico Positivo e $-0,05$ para Impacto Psicológico Negativo. Apenas a correlação entre tempo de uso do ACO e o domínio 
Limitação obteve valor de forte magnitude $(r=0,58)$. Contudo, a maioria das correlações entre tempo de uso do ACO e os domínios do DASS não foram estatisticamente significantes ( $p$ adotado de 0,05 neste estudo) (Tabela 19).

Comparando com os resultados obtidos das correlações entre idade e tempo de uso do ACO e os domínios do DASS da versão original, constatamos que há uma pequena variação nos valores obtidos em relação aos resultados encontrados em nosso estudo, no entanto, são valores classificados, em sua maioria, como de pouco valor para a prática $(\mathrm{r}<0,30)$ e estatisticamente significantes $(\mathrm{p}<0,05)$ (Tabela 19).

Tabela 19 - Coeficiente de correlação de Pearson entre os domínios do instrumento DASS e a idade e o tempo de uso de ACO. Ribeirão Preto, 2009

\begin{tabular}{lcccc}
\hline \multicolumn{1}{c}{ Domínios do DASS } & \multicolumn{2}{c}{ DASS original } & \multicolumn{2}{c}{ DASS adaptado } \\
& Idade & Tempo de ACO & Idade & Tempo de ACO \\
DASS & & & & \\
Total & $-0,17^{*}$ & $-0,05$ & $-0,28^{*}$ & 0,01 \\
Limitação & $-0,24^{*}$ & 0,01 & $-0,37^{*}$ & $0,58^{*}$ \\
Tarefa / Sobrecarga & $-0,24^{*}$ & 0,01 & $-0,16^{*}$ & 0,01 \\
Impacto Psicológico Positivo & $0,19^{*}$ & $-0,14^{*}$ & 0,13 & $-0,04$ \\
Impacto Psicológico Negativo & $-0,27^{*}$ & 0,01 & $-0,29^{*}$ & $-0,05$ \\
\hline
\end{tabular}

$* p<0,05$ 
DISCUSSÃO 


\section{DISCUSSÃO}

É necessário salientar que estudar QVRS em pacientes em uso de ACO foi um desafio em detrimento aos poucos artigos científicos relacionados a essa temática, sendo estes artigos, frequentemente desenvolvidos em países americanos e europeus. No Brasil, o interesse por essa temática ainda é incipiente, haja vista que os artigos científicos sobre ACO encontrados em nossa revisão bibliográfica datam de 1989, sendo estes, ainda, relacionados à fisiopatologia do processo de anticoagulação sangüínea e indicação dos ACOs frente as diversas doenças cardiovasculares. Assuntos sobre QVRS e ACO são de raras publicações.

O presente estudo buscou adaptar e disponibilizar para o Brasil o instrumento DASS, escolhido por ser construído para avaliar a QVRS e a satisfação do paciente em uso de ACO. $\mathrm{O}$ instrumento original contêm itens que avaliam aspectos importantes para os pacientes em uso de ACO e mostrou propriedades psicométricas adequadas em sua avaliação inicial (SAMSA et al. 2004). Entretanto, há poucas publicações referentes ao uso do instrumento DASS, sendo essas, relacionadas ao desenvolvimento e preliminar validação da suas propriedades psicométricas (SAMSA et al., 2004), adaptação cultural e validação entre a população da Espanha (CARROBLES et al., 2006) e avaliação da satisfação entre dois grupos de pacientes em uso de ACO no mesmo país de origem do instrumento DASS (JEFFREY, 2008), até o momento.

Decidir pela realização da adaptação cultural e validação do instrumento DASS para brasileiros em uso de ACO significou envolver-se em uma metodologia cujo processo se compõe de múltiplos passos devendo ser esses seguidos de forma rigorosa.

Com relação ao processo adotado para a adaptação cultural de instrumentos de avaliação da QVRS seguimos as recomendações preconizadas pela literatura nacional e internacional. A literatura nacional contribuiu para fundamentar algumas modificações na ordem dos passos propostos em estudos internacionais de adaptação e validação de 
instrumentos de QVRS (ESCHEVARRIA-GUANILO, 2005; DANTAS, 2007; FERREIRA, 2006). Destacam-se as seguintes modificações: 1) retro-tradução (back translation) da versão português consenso 2 (VPC2) foi realizada após a avaliação pelo comitê de juízes; comitê esse formado por pessoas com comprovado conhecimento no cuidado a pacientes com doenças cardiovasculares, bem como, na temática de QVRS e adaptação de instrumentos de avaliação. Assim pode-se contar com a participação de profissionais de diferentes áreas da saúde os quais contribuíram na avaliação das equivalências (cultural, conceitual, semântica e idiomática) dos itens do instrumento DASS. 2) tradução da versão em português consenso 2 (VPC2) para o inglês e sua comparação com a versão original permitiu assegurar que não houvessem mudanças no significado dos itens originando a versão em inglês final (VIF). Ainda, ressaltamos que essa etapa foi reforçada pela avaliação da versão final em inglês pelo autor principal do DASS, Dr. Greg Samsa, o qual se manifestou em concordância com a VIF; 3) análise semântica foi realizada com a versão em português consenso 3 (VPC3) aplicada a nove pacientes com doenças cardiovasculares em uso de ACO e em seguimento ambulatorial no HCFMRP-USP, sendo os passos para a tal realização embasados no estudo de adaptação cultural e validação das propriedades psicométricas de um instrumento de QVRS para criança e adolescentes mexicanas, o DISABKIDS 37 (MEDINA CASTRO, 2007).

Acreditamos que essas modificações permitiram detectar erros ou problemas de compreensão os quais não poderiam ser notados após a retro-tradução ter sido feita, visando assegurar o objetivo da retro-tradução que é o de observar possíveis erros de significado na primeira versão traduzida. (FERRER et al., 1996). Outra preocupação foi verificar se os itens eram inteligíveis para o estrato mais baixo da população alvo, evitando-se deselegância na formulação dos itens para o estrato com maior escolaridade da população alvo. O entendimento de cada item não deveria apresentar-se como fator complicador na resposta dos 
indivíduos e nem poderíamos apresentar itens que fossem demasiadamente primitivos, sem mostrar suficiente seriedade para todos os sujeitos (PASQUALI, 1999).

Obtida a versão português final do instrumento DASS, ela foi aplicada a 180 pacientes com doenças cardiovasculares submetidos ao uso de ACO em seguimento ambulatório a fim de disponibilizar a versão adaptada do instrumento DASS, na língua portuguesa para ser usada em nosso país.

Em relação às características sócio-demográficas dos 180 participantes constatamos maior número de pacientes do sexo feminino, brancos, com idade média de 55,6 anos, casados, católicos, procedentes de outras cidades do estado de São Paulo, com ensino fundamental incompleto, aposentados, com renda familiar média e mensal de 896,93 reais e residiam em média com três pessoas.

Como em nosso estudo, pesquisadores no Brasil e no exterior analisaram pacientes acompanhados em ambulatórios ou em clínicas especializadas em uso de ACO e constataram que paises em desenvolvimento apresentaram uma população com idade média de 50 anos (LOURENÇO, 1997; SANTOS, 2006), resultado semelhante ao nosso, e idades acima de 65 anos foram características de população dos estudos de paises Europeus e Americanos (LIP, 2002; FREIXA, 2003; BARREIRA, 2003; NADAR, 2003; TANG, 2003; SAMSA et al., 2004, DAVIS, 2005; WALRAVEN, 2006; KIMMEL, 2007). Com relação ao sexo, a maioria dos estudos levantados teve participantes do sexo masculino (LOURENÇO, 1997; BARCELLONA, 2000; LIP, 2002; GADISSEUR, 2003; SAMSA et al., 2004, TORN, 2005; KIMMEL, 2007) e em apenas alguns estudos apresentaram resultados semelhantes ao nosso, ou seja, com maior participação de mulheres (NADAR, 2003; TANG, 2003; DAVIS, 2005; SANTOS, 2006).

Com relação às características clínicas, observamos que os participantes faziam uso predominantemente, de varfarina, adquirida pelo Sistema Único de Saúde. A principal 
indicação foi à presença de próteses cardíacas metálicas, porém, esses participantes ainda apresentavam outras comorbidades associadas, tais como a hipertensão arterial e doença arterial coronariana e, consequentemente, faziam uso de outros medicamentos além do ACO (média de 4,2 medicamentos). O tempo médio de seguimento ambulatorial devido o uso de ACO foi de 6,9 anos, sendo que em média, os participantes compareciam ao ambulatório para dosar o INR cerca de duas vezes nos últimos três meses, os quais demonstraram um valor médio de 2,4. Esses pacientes ainda receberam algum tipo de informação ao longo da terapia com ACO, principalmente sobre: riscos de sangramentos e de trombos, necessidade do uso do ACO e interações com alimentos.

A varfarina, predominantemente, foi a droga mais utilizada entre os participantes dos estudos levantados na literatura (LOURENÇO, 1997; LOURENÇO, 1998; SANCHES, 2001; LIP, 2002; NADAR, 2003; TANG, 2003; CABRAL, 2004; DAVIS, 2005; SANTOS, 2006; KIMMEL, 2007). Já a indicação mais comumente relatada na literatura para o uso do ACO foi a fibrilação atrial (FREIXA, 2003; BARREIRA, 2003; TANG, 2003; SAMSA et al., 2004; WALRAVEN, 2006; KIMMEL, 2007). Comorbidades associadas a esse grupo de pacientes também foram encontradas em outros estudos (CABRAL, 2004; DAVIS, 2005; KIMMEL, 2007) assim como o uso de outros medicamentos, que pode ocorrer em $80 \%$ dos pacientes em uso de ACO (TANG, 2003, DAVIS, 2005; KIMMEL, 2007), com uma freqüência média de seis comprimidos por dia (SAMSA et al., 2004). O seguimento ambulatorial dos pacientes brasileiros está acima da média em relação aos estudos pesquisados, que em média, estão em seguimento ambulatorial há mais de dois anos (LOURENÇO et al., 1997; LIP, 2002; TANG, 2003), bem como a freqüência estimada para as coletas sangüíneas para a verificação do INR, variando entre 2 a 8 semanas (PARONDO, 2003; GRINBERG,2003; ROMANO, 2006). Os valores médio de INR foi de 2,4 para os pacientes desse estudo concordam com os guidelines internacionais, os quais indicam uma faixa terapêutica moderada (INR entre 2 e 3 ) para 
minimizar os riscos de hemorragias, sem elevar os riscos trombóticos (HIRSH, 1994; ANSELL, 2008).

Entretanto, alguns estudos têm avaliado a evolução clínica e a identificação dos fatores responsáveis pelo mau controle do INR dos pacientes que necessitam de terapia com ACO, dentre eles, Freixa et al. (2003) constataram como fatores preditores para um maior risco de excessiva anticoagulação, os portadores de prótese cardíaca mecânica, mau cumprimento terapêutico, adição de novos fármacos e enfermidade intercorrente no último mês.

Em nosso estudo $41,7 \%$ dos pacientes relataram algum tipo de complicação durante todo o tempo que se submeteram a terapia com $\mathrm{ACO}$, sendo que uma freqüência maior foi observada em relação às complicações hemorrágicas, com uma taxa de 94,6\%, sendo que destes, $38 \%$ necessitaram de internação hospitalar. Nossos resultados foram significativamente superiores ao encontrado no estudo de Beyth (2000) e de Santos (2006), os quais estimaram uma percentagem de 7 a 15\% de complicações hemorrágicas, das quais, $1,9 \%$ foram consideradas hemorragias graves, impondo risco à vida de pacientes em uso de ACO e apenas 5\% foram dos pacientes em uso de ACO necessitaram de internação hospitalar (SAMSA et al., 2004).

Sabe-se que a incidência anual de sangramentos por cumarínicos é de $3 \%$ aumentando em 10 vezes no primeiro mês de uso do ACO (FARHOUD, 2001). Dentre outros fatores que levam ao risco de sangramentos em decorrência do uso de ACO, temos: idade acima de 65 anos, sexo feminino, intensidade da ACO (INR $>4$ ), tempo de ACO, existência de outras doenças concomitantes como acidente vascular encefálico, história de sangramento gastrointestinal, insuficiência renal, infarto do miocárdio recente ou anemia, associação de certos medicamentos como AAS e antiinflamatórios-não-esteróidais (AINES) (LOURENÇO et al., 1997; LOURENÇO, 1998; RANGEL, 2001; FARHOUD, 2001; PARRONDO, 2003; FARIA, 2004; TORN, 2005; KLACK, 2006). 
Vimos em nosso estudo, 87 indivíduos que interromperam o uso do ACO, 68,9\% ocorreu por orientação médica tendo como principal motivo, complicações em decorrência do uso de ACO (como por exemplo, epistaxe e hematúria). Complicações decorrentes do uso de medicamentos são eventos que podem afetar gravemente a saúde. Calcula-se que entre 59 a 81\% das reações adversas de medicamentos são preveníveis ou completamente evitáveis e entre 0,34 a $23 \%$ das reações adversas a medicamentos podem levar a hospitalização. Um estudo de farmacovigilância realizado em serviços de urgências da Colômbia identificou que os medicamentos mais frequentemente associados a hospitalizações por reações adversas são os AINES, seguidos dos ACOs (MACHADO-ALBA, 2006).

No entanto, frequentemente não são registrados nos prontuários dos pacientes em seguimento nesse ambulatório, as complicações que sofreram ao longo do uso de ACO, os quais foram apenas identificados por relatos dos pacientes em entrevistas às pesquisadoras. Sabe-se que muitas vezes, esses pacientes têm complicações do uso do ACO resolvidas em serviços de saúde do tipo primário ou secundário. Esses aspectos se colocam como fatores limitantes na descrição do perfil sócio-demográfico, clínico e laboratorial dos indivíduos em seguimento ambulatorial do HCFMRP-USP, tendo em vista a enorme variabilidade individual em termos de dose-resposta da terapia com ACO, há a necessidade de se ampliar essa investigação.

Em relação à informação sobre o uso do $\mathrm{ACO}$, observamos que ela é dada, aos pacientes desse estudo, durante a consulta médica, as quais incluíam informações sobre os riscos de complicações e das interações dos ACO com alimentos e outros medicamentos. Reforçando a idéia de que a informação é um elo importante para o sucesso da terapia com ACO, Kimmel (2007) constatou que a principal causa de um controle inadequado dos níveis de anticoagulação sangüínea está na fraca adesão ao regime terapêutico e muitos desses pacientes ainda possuem um baixo conhecimento de sua condição clínica e da sua terapia 
(LIP, 2002; NADAR, 2003). Certos pesquisadores têm sugerido algumas alternativas, tais como o uso de um cartão individualizado para que sejam anotados a data, a dose do ACO, o valor do INR e observações como à presença de complicações, uso de outras medicações, intercorrências, além de alterações na dose diária ou na dieta (STULTS, 1989; LOURENÇO,1997; SULLANO, 2001).

Após o levantamento sobre as características sócio-demográficas e clínicas, os participantes responderiam ao instrumento DASS em sua versão final em português. Foram abordados, de maneira aleatória, 180 pacientes em uso de ACO em seguimento ambulatorial pelo HCFMRP-SP, dos quais todos concordaram em participar da pesquisa e atendiam aos critérios de inclusão definidos no estudo.

Em relação às respostas obtidas para os 25 itens que compõem o instrumento DASS, no estudo da versão original, Samsa et al. (2004) obtiveram itens não respondidos pelos participantes, como o "quanto que você acredita que consegue seguir seu tratamento de anticoagulação" (item 3h) e "qual a possibilidade de você incentivar uma outra pessoa (com o mesmo problema de saúde que você tem) a seguir o tratamento de anticoagulação" (item 4j), o "quanto que o tratamento de anticoagulação melhorou a sua vida" (item 4f) e, em menor número, o item que "compara com outros tratamentos, o quanto é difícil lidar com esse tratamento de anticoagulação" (item 4i). Segundo o autor do instrumento DASS, esses itens "não informados" pelos participantes americanos tendem ser àqueles itens em que os participantes encontraram dificuldades na sua conceituação. Outros itens não respondidos pelos participantes americanos foram os itens referentes a "quanto que a possibilidade de sangrar ou se machucar limita (atrapalha) em seu emprego" (item 1d) e o "quanto que o seu tratamento de anticoagulação (afinar o sangue) limita (atrapalha) o uso de bebidas alcoólicas" (item 2b). Em relação a esses últimos itens, Samsa et al. (2004) acreditam que, seja provável, que a maioria dos sujeitos ao invés de assinalarem a opção "não se aplica" sob 
circunstâncias de não ingerir bebidas alcoólicas ou estarem desempregados, os participantes não assinalarem nenhuma opção, não seguindo as instruções do instrumento DASS, já que a aplicação dos instrumentos do DASS entre os americanos se deu de forma auto-aplicável (SAMSA et al., 2004).

Entre os participantes brasileiros os itens frequentemente "não informados" dizem respeito ao "quanto que você acredita que consegue seguir seu tratamento de anticoagulação (afinar o sangue)" (item 3h) e sobre a "possibilidade de você incentivar uma outra pessoa (com o mesmo problema de saúde que você tem) a seguir o tratamento de anticoagulação (afinar o sangue)" (item 4j). Para esses itens "não informados" pelos participantes do nosso estudo, podemos inferir a mesma constatação sugerida por Samsa et al. (2004), ou seja, os participantes tiveram dificuldades na compreensão desses itens, não os respondendo. Apesar de resultados da análise semântica não evidenciar dificuldades de compreensão dos itens do instrumento DASS entre os participantes, um dos tradutores que participou da fase de retrotradução (Back-translation) observou que o item $4 \mathrm{j}$ poderia conotar "prescrição de um tratamento" ou "uma tomada de conduta clínica", sendo considerado como uma frase mal elaborada em inglês. Também obtivemos respostas "não se aplica" para os itens relacionados ao "quanto que a possibilidade de sangrar ou se machucar limita (atrapalha) em seu emprego" (item 1d ) e "quanto que o seu tratamento de anticoagulação (afinar o sangue) limita (atrapalha) o uso de bebidas alcoólicas” (item 2b), as quais foram corretamente respondidas com a adição da opção "não se aplica" na escala de resposta aos itens do instrumento DASS, conforme preconizado pelo autor principal da versão original (SAMSA et al., 2004).

Como em nosso estudo houve uma pequena porcentagem de respostas consideradas como "não se aplica" e "não informadas" entre os itens do instrumento DASS, optamos pelo cálculo de novos valores para esses itens segundo o critério de Cohen e Cohen (1983). A 
substituição dos poucos dados não aplicáveis/não respondidos não ocasionou grandes mudanças nos resultados e confirmaram a pertinência dos itens para os pacientes que responderam à versão adaptada.

Sobre as freqüências de respostas dadas aos itens do instrumento DASS, de maneira geral, a maioria dos participantes respondeu a opção nada/não limita, sendo o item "quanto o tratamento de anticoagulação (afinar o sangue) piorou sua vida" (item 4g) com a maior porcentagem dessa opção de resposta $(83,3 \%)$. Em relação às freqüências de respostas dadas aos itens referentes aos domínios do instrumento DASS, verificamos que os participantes também consideraram como nada/não limita aspectos relacionados aos domínios Limitação e Tarefa/Sobrecarga. Já os participantes escolheram a resposta "pouco" para os aspectos relacionados ao domínio Impacto Psicológico frente à terapia de ACO. Entretanto, ao considerarmos os itens relativos ao domínio Impacto Psicológico Positivo, a freqüência maior de resposta manteve-se na opção "pouco" enquanto para o domínio Impacto Psicológico Negativo a opção que mais predominou foi "nada/não limita".

Samsa et al. (2004) também identificaram que a maioria das respostas aos itens do instrumento DASS foi a opção "nada/não limita". O item 1b ("o quanto que a possibilidade de sangrar ou se machucar te limita passear fora de sua de cidade") foi o que apresentou maior freqüência dessas respostas, diferindo do nosso estudo. Essa discordância pode estar relacionada à disponibilidade da população norte-americana em adquirir e utilizar o monitor domiciliar (coagulômetro) para verificação dos níveis de INR bem como a existência de modalidades de seguimento (auto-monitorização e auto-gerenciamento) que facilitam o ajuste da dose do ACO. Em relação aos domínios do instrumento DASS, tanto os participantes americanos como os brasileiros, optaram pela opção "nada/não limita".

O grande número de respostas nada/não limita como avaliação da QVRS e a satisfação com o uso do ACO entre os participantes, tanto do estudo americano como em nosso estudo, 
foram semelhantes aos resultados encontrados por Lancaster et al. (1191) na avaliação da QVRS e o impacto da terapia com varfarina a longo prazo. Este estudo utilizou de um instrumento não específico para avaliar a QVRS nessa população e constatou que apenas 6,5\% dos indivíduos avaliaram que o uso de ACO limitava as suas vida, pois os pacientes consideravam que o tratamento com o uso de ACO era similar aos de outras condições crônicas, como hipertensão e hipercolesterolemia e, desse modo, aceitavam as imposições e inconveniências decorrentes do uso do ACO ao invés de submeterem ao risco de complicações mais severas (LANCASTER et al., 1991).

O intervalo possível de pontuação total do instrumento DASS varia de 25 a 175 . Em nosso estudo, o intervalo obtido ficou entre 25 a 109. Com relação à média da medida total do DASS tivemos um valor de 57,9 $(\mathrm{DP}=16,4)$. Tal resultado se aproximou daqueles obtidos pelos autores do instrumento $(\mathrm{M}=54,0 ; \mathrm{DP}=17,6)$. As médias para os domínios Limitação, Impacto Psicológico Positivo e Impacto Psicológico Negativo foram menores em comparação às médias obtidas pela versão original do instrumento DASS (SAMSA et al.; 2004). Já para o domínio Tarefa/Sobrecarga a média foi maior em nosso estudo. A mediana e a média dos itens do DASS, obtidas em nosso estudo, se aproximaram, com valores de 2,2 e 2,3 respectivamente. Esses resultados não foram publicados em relação à versão original do instrumento DASS.

Com relação à confiabilidade do instrumento DASS, ela foi verificada, originalmente, pela consistência interna de seus itens (alfa de Cronbach) e pela estabilidade da medida (testereteste) (SAMSA et al., 2004). Esse mesmo procedimento foi realizado no estudo de adaptação e validação do instrumento DASS para a Espanha (CARROBLES et al., 2006). Em nosso estudo, analisamos a confiabilidade por meio da consistência interna de itens da versão adaptada do instrumento DASS, verificada pelo alfa de Cronbach. Fatores operacionais como as dificuldades dos novos retornos apenas para a participação no estudo e preenchimento do 
instrumento DASS desmotivaram as pesquisadoras a buscarem junto à equipe médica o agendamento dos pacientes para a segunda avaliação psciométrica (teste-reteste).

O resultado obtido da análise da consistência interna para a versão total da versão adaptada do instrumento DASS foi adequada $(0,79)$. Os valores de alfas para os domínios do instrumento foram menores do que para o total da medida: 0,72 (Limitação), 0,76 (Tarefa/Sobrecarga), 0,46 (Impacto Psicológico), 0,68 (Impacto Psicológico Positivo) e 0,38 (Impacto Psicológico Negativo), sendo que o domínio Impacto Psicológico apresentou pior consistência interna $(\alpha<0,46)$. Esses resultados diferem dos valores obtidos pela versão original e pela versão adaptada e validada para a Espanha. Samsa et al. (2004) constataram valores de alfa de Cronbach maiores quanto da escala total (total $\alpha=0,88$ ) quanto para os domínios (Limitação $\alpha=0,87$; Tarefa/Sobrecarga $\alpha=0,88$; Impacto Psicológico Positivo $\alpha=$ 0,78; Impacto Psicológico Negativo $\alpha=0,91$ ). Carrobles at al. (2006) também verificaram resultados semelhantes aos encontrados por Samsa et al. (2004).

Para obter a validade de constructo da versão original do instrumento DASS, seus autores a correlacionaram com alguns resultados obtidos da caracterização sócio-demográfica e clínica que possibilitaram a formação de grupos distintos, como idade, anos de terapia com ACO (menor que três meses), números de medicamentos, sexo, cor da pele, escolaridade, renda familiar, trabalho remunerado, mudanças na dose do ACO no último ano, hospitalização por sangramento, número de medicamentos, uso de antibióticos no último mês, uso do monitor domiciliar para verificar o INR e presença de comorbidades. As medidas do instrumento DASS também foram correlacionadas com os resultados obtidos da aplicação do instrumento SF-36, do instrumento PSQ-18 e do instrumento SDS-5 para analisar a validade de constructo convergente da versão original do instrumento DASS. A análise fatorial também foi realizada para analisar a validade de constructo da medida do instrumento original do DASS (SAMSA et al., 2004). 
As correlações obtidas pelas medidas dos instrumentos PSQ-18 e do SDS-5 não foram realizadas na análise das propriedades psicométricas do instrumento DASS para os brasileiros, uma vez que, os instrumentos PSQ-18 e SDS-5 não são validados no Brasil. Por outro lado, efetuamos análises relacionadas à validade de constructo utilizando a análise fatorial, as correlações entre as medidas do DASS (total e seus domínios) com as medidas do SF-36, as correlações entre grupos distintos (idade e tempo de uso do ACO) com as medidas obtidas do DASS total e seus domínios.

Quanto aos resultados relacionados à análise da validade de constructo da versão adaptada do DASS, buscamos encontrar a confirmação através de diferentes técnicas de análises como tem sido feito na literatura consultada. Dessa forma, optamos por analisar a validade de constructo da versão adaptada para o português do instrumento DASS por meio da análise fatorial verificando a manutenção da sua dimensionalidade; analisar a validade de constructo convergente correlacionando a medida obtida pela versão adaptada com uma medida de avaliação do estado geral da saúde de um instrumento já validado para a população brasileira, o SF-36. Tais análises também foram realizadas para verificar a validade da versão original (SAMSA et al.; 2004).

A análise fatorial confirmatória, realizada pela rotação de Varimax, resultou em três componentes os quais nos permitiram identificar que componente um apresentou maiores valores relacionados ao domínio Limitação $(0,745$ a 0,229$)$, o componente dois relacionou-se mais fortemente com os itens do domínio Tarefa/Sobrecarga $(-0,061$ a 0,740$)$, já o componente três, Impacto Psicológico, em sua maioria, apresentou valores positivos e maiores em relação aos outros domínios $(-0,007$ a 0,726). Samsa et al. (2004) constataram valores de 0,43 a 0,81 para o domínio Limitação, 0,44 a 0,81 para o domínio Tarefa/Sobrecarga e 0,51 a 0,83 para Impacto Psicológico Positivo. No entanto, assim como em nosso estudo, a análise fatorial do DASS da versão original também apresentou alguns 
itens em que uma carga maior foi verificada em domínios diferentes dos quais esses itens foram originalmente determinados. Valores da análise fatorial relacionados ao Impacto Psicológico Negativo não foram mencionados pelos autores da versão original.

Seguindo os mesmos procedimentos feitos pelos autores da versão original do instrumento DASS (SAMSA et al.; 2004), o instrumento SF-36 foi usado para testar a validade de constructo convergente da versão em português. Entre os participantes brasileiros constatamos maiores valores (melhor avaliação) no domínio Aspectos Sociais ( $\mathrm{M}=82,0$; $\mathrm{DP}=26,5)$ e menores valores (pior avaliação) no domínio Aspectos Físicos $(\mathrm{M}=54,7$; $\mathrm{DP}=47,8)$. Já os americanos tenderam a avaliar como melhor o domínio Saúde Mental $(\mathrm{M}=76,1 ; \mathrm{DP}=18,0)$. Assim como os brasileiros, eles avaliaram como pior o domínio Aspectos Físicos com média de 45,2 (DP=42,3) para os americanos (SAMSA et.al., 2004) e média de 54,7 ( $\mathrm{DP}=47,8)$ para os nossos participantes. No nosso estudo, o instrumento SF-36 apresentou uma boa consistência interna para todos os seus domínios, exceto para o domínio Aspectos Sociais, com uma alfa de Cronbach de 0,60. Essa última informação não foi relatada no estudo de Samsa et al. (2004).

Quanto à análise da validade de constructo convergente, obtida pela correlação entre as medidas dos domínios do instrumento DASS e as medidas dos domínios do SF-36, constatamos apenas 12 correlações moderadas entre as medidas dos domínios do DASS e as medidas dos domínios do SF-36 e estatisticamente significantes (adotando $p<0,05$ ) para esse estudo.

Da mesma forma, os autores do instrumento original obtiveram resultados semelhantes aos nossos, com correlações entre as medidas dos domínios do SF-36 e as medidas dos domínios do DASS, em sua maioria, foram negativos, de pouco valor para a prática, mas estatisticamente significantes (adotando $p<0,05)$ (SAMSA et al. 2004). 
Outro aspecto importante a ser ressaltado é que as correlações foram inversas ou negativas entre todos os valores das medidas dos domínios do instrumento SF-36 e as medidas dos domínios do DASS (total e seus domínios), pois se tratam de escalas inversamente ordenadas. Enquanto no instrumento SF-36 valores menores refletem uma percepção pior do estado geral da saúde, no DASS esses valores indicam melhor satisfação com o tratamento com ACO, menor limitação, menor tarefa/sobrecarga e menor impacto psicológico, tanto no que se refere à avaliação para o impacto psicológico positivo como para o impacto psicológico negativo.

Com relação aos resultados das correlações entre as medidas do DASS (total e seus domínios) com a idade e tempo de uso do ACO, constatamos resultados semelhantes aos obtidos pela versão original (SAMSA et al., 2004), exceto para as correlações entre o domínio Limitação, que tiveram maiores valores em nosso estudo. Quanto à idade, Samsa et al. (2004) obtiveram valores inversos, de pouco valor para a prática, porém estatisticamente significantes indicando que quanto maior a idade melhor a satisfação e a QVRS entre pacientes em uso de ACO. Quanto ao tempo de uso do ACO, os valores obtidos por Samsa et al. (2004) refletem que quanto maior o tempo de uso do ACO melhor a satisfação e a QVRS entre esse a população.

Em um estudo que analisou a percepção dos pacientes sobre a terapia de anticoagulação oral e seus efeitos na QV foi constatada uma associação entre a melhora no estado de saúde percebido pelos pacientes em uso de ACO e o menor nível de escolaridade, satisfação com o atendimento médico e tempo de seguimento maior do que cinco anos (CASAIS et al. 2005). No entanto, há que se considerar que os autores dessa pesquisa não utilizaram um instrumento específico de avaliação da QVRS para a população em uso de ACO. 
Um instrumento específico de avaliação da QVRS entre os pacientes em uso de ACO tem relevância clínica, pois indicam uma capacidade de avaliar a satisfação com a terapia de ACO e a identificação de aspectos que podem dificultar a anticoagulação do indivíduo, como por exemplo, não manter os níveis de anticoagulação dentro do intervalo terapêutico recomendado, internações por hemorragias ou múltiplas mudanças na dose do ACO. Os indivíduos diante dessas condições tendem a apresentar maior pontuação para os domínios Limitação e Tarefas/Sobrecarga sendo cada vez mais sensibilizados para os aspectos potencialmente negativos da anticoagulação envolvido em um ciclo de insatisfação, baixa adesão, mau controle do INR, e pior QRVS, reduzindo os efeitos clínicos da indicação da terapia de ACO (SAMSA et al. 2004).

No entanto, vários estudos com o enfoque na identificação dos aspectos envolvidos na QVRS entre os pacientes em uso de ACO são muitas vezes obtidos por instrumentos não específicos a essa população, o que implica em dificuldades na comparação dos seus resultados com outros estudos dessa natureza.

Algumas das condições que levam a redução da satisfação com o tratamento com ACO e menor QVRS podem ser modificadas diretamente como, por exemplo, o fornecimento de uma educação estruturada, a realização de testes sangüíneos no domicílio e uma vigilância próxima aos pacientes que permita reforçar, especialmente, aqueles aspectos positivos que são considerados importantes para cada um dos pacientes. Muitas dessas intervenções destinam a melhorar a anticoagulação, a qualidade do atendimento, e assim reduzir o tempo fora do intervalo terapêutico recomendado e, em última análise, evitar complicações hemorrágicas e trombóticas (SAMSA et al., 2004).

Estudos com enfoque nos modelos de seguimento, cuidado convencional e autogerenciamento, a pacientes em uso de ACO são frequentemente relatados na literatura internacional e seus resultados confluem para uma melhor avaliação da QVRS e satisfação 
com a terapia de ACO entre os pacientes que são acompanhados pelo modelo de autogerenciamento. Samsa et al. (2004) consideram, como relevância científica do instrumento DASS, a possibilidade de se identificar os aspectos envolvidos na terapia com ACO como subsídio para o desenvolvimento de um modelo de seguimento e cuidado no gerenciamento da terapia com ACO, e consequentemente, compreender melhor a relação entre QVRS e ACO, a aderência aos esquemas terapêuticos refinando a atuação dos profissionais de saúde.

Os resultados preliminares do desenvolvimento e da validação das propriedades psicométricas do instrumento DASS permitem a disponibilização de um instrumento válido, confiável e específico para avaliação da QVRS e a satisfação com o tratamento contribuindo para comprometimento dos pacientes com o seu próprio cuidado a fim de melhorar ainda mais seu controle da coagulação sangüínea. Pode ainda representar subsídios para a implementação de um modelo alternativo de seguimento aos pacientes em uso de ACO. E futuramente, esse modelo, pode possibilitar ao paciente adquirir conhecimentos amplos sobre sua terapia, escolher o modo de seguimento e ainda permitir uma assistência clínica de alta qualidade entre os casos em que o acesso do paciente é difícil devido à deficiência, distância ou outras limitações. Idealmente, os pacientes deveriam receber uma resposta imediata a fim de minimizar o risco de super ou sub-dosagem de anticoagulantes e permitir a correção imediata de eventuais problemas. 
CONCLUSÃO 


\section{CONCLUSÃO}

Os processos de adaptação cultural e validação da versão em português do DASS foram conduzidos conforme preconizado pela literatura cientifica e resultou em um instrumento adaptado a realidade brasileira, uma vez que, garantiu bons resultados para as propriedades de validade e de confiabilidade. Concluímos que a versão adaptada do instrumento DASS:

- manteve as equivalências cultural, conceitual, semântica, e idiomática confirmando a validade de face e de conteúdo segundo a avaliação do comitê de juízes;

- mostrou, através da análise fatorial, a presença de três componentes confirmando a dimensionalidade existente na versão original;

- obteve correlações inversas e de moderada magnitude na maioria das medidas do instrumento DASS total e seus domínios e as medidas dos domínios do SF-36 confirmando a validade de constructo convergente;

- não confirmamos a validade de constructo divergente do instrumento avaliada pelas correlações das medidas do DASS total e seus domínios com idade e tempo de uso do ACO. Correlações menores que 0,30 também foram obtidas com a versão original;

- mostrou um valor adequado de alfa de Cronbach para o DASS total e para os domínios Limitação e Tarefa/Sobrecarga, exceto para o domínio Impacto Psicológico, indicando a confiabilidade do instrumento através da consistência interna de seus itens na amostra estudada. 
CONSIDERACÕES FINAIS 


\section{CONSIDERAÇÕES FINAIS}

Embora estes primeiros resultados parecem-nos promissores, várias limitações devem ser assinaladas. A adaptação e a validação de um instrumento é um processo de múltiplos passos exigindo resultados satisfatórios por meio de avaliações psicométricas para que só então o instrumento seja disponibilizado para ser aplicado de forma confiável. Obtemos um instrumento válido e confiável em amostra de pacientes brasileiros atendidos em uma instituição hospitalar publica. A proposta de estudos de acompanhamento que incluirá uma aplicação mais ampla desse instrumento entre os pacientes em uso de ACO é uma alternativa eficaz para obter mecanismos de comparação do instrumento DASS bem como avaliações entre pacientes de diferentes instituições de saúde, como por exemplo, as instituições privadas o que nos incentiva, futuramente, embasar uma assistência de saúde diferenciada a esses pacientes. 


\section{REFERÊNCIAS BIBLIOGRÁFICAS}




\section{REFERÊNCIAS BIBLIOGRÁFICAS}

1. AJZEN, I; FISHBEIN, M. Understanding attitudes and predicting social behavior. New Jersey: Prentice-Hall, 1980. p. 278.

2. ANGUITA, C.J.; REPULLO-LABRADOR, J.R.; PEREIRA-CANDEL, J.P. Medidas de calidad de vida relacionada con la salud. Conceptos básicos, construcción y adaptación cultural. Med Clin., v.116, p. 789-96, 2001.

3. ANSELL, J. et al. Pharmacology and Management of the Vitamin K Antagonists. American College of Chest Physicians Evidence-Based Clinical Practice Guidelines (8th Edition). CHEST., v. 133, (Suppl 1), p.160-98, 2008.

4. BARCELLONA, D. et al. The management of oral anticoagulant therapy: the patient's point of view. Thromb Haemost, v. 83, p. 49-53, 2000.

5. BARREIRA, R. et al. Monitorização da terapêutica com anticoagulantes orais: consulta de anticoagulação vs médico assistente. Acta Med Port., v.17, p. 17: 413-6, 2004.

6. BELLE, G. et al. Biostattistics: A Methodology for the Health Sciences. 2a. ed. New Jersey: Hoboken, 2004, p.100.

7. BEYTH, R.J.; QUIN, N.L.; LANDEFELD, C.S.; A Multicomponent Intervention to Prevent Major Bleeding Complications in Older Patients Receiving Warfarin. A randomized, controlled trial. Ann Intern Med, v. 133, n.9, p. 687-97, 2000.

8. BOWLING, A. Measuring Disease. 2nd ed. Buckingham-Philadelphia: Open University Press, 2001. 20p.

9. BRASIL. Ministério da Saúde. Secretaria de Assistência à Saúde. Programa nacional das doenças sexualmente transmissíveis e AIDS. Conselho Nacional de Saúde. Resolução n.1, de 13 de junho de 1988. Normas de pesquisa em saúde: aspectos éticos da pesquisa em seres humanos. Brasília, 1998. p. 4-7.

10. CABRAL, N.L. et al. Fibrilação atrial crônica, AVC e anticoagulação: sub-uso da warfarina? Arq Neuropsiquiatr., v.62, n.4, p.1016-21, 2004. 
11. CAMPOS, C.R.; MENEGUELO, Z.M.; BATLOUNI, M. Anticoagulação nas Cardiopatias. Arq. Bras. Cardiol., v. 61, n.6, p.361-6, 1993.

12. CARROBLES, J.A et al. Assessment of satisfaction and quality of life in long term anticoagulated patients. Handb Health Technol Assess., v. 3, p.162, 2006.

13. CASAIS, P. et al. Patients' perceptions regarding oral anticoagulation therapy and its effect on quality of life. Curr Med Res Opin., v.21, n.7, p. 1085-90, 2005.

14. CASTRO, R.A.L.; PORTELA, M.C.; LEÃO, A.T. Adaptação transcultural de índices de qualidade de vida relacionada à saúde bucal. Cad. Saúde Pública, v.23, n.10, p. 2275-84, 2007.

15. CHWALOW, A.J. Cross-cultural validation of existing quality of life scales: Patient Education and Counseling, v.26, p.313-18, 1995.

16. CICONELLI, R.M. et al. Tradução para língua portuguesa e validação do questionário genérico de avaliação de qualidade de vida SF-36. Rev Bras Reumatol, v.39, n.39, p.143-50, 1999.

17. CICONELLI, R.M. Tradução para o português e validação do questionário genérico de avaliação de qualidade de vida "Medical Outcomes 36 Iten Short Form Health Survey-SF-36". São Paulo, 1997. 143f. Tese (Doutorado) - Escola Paulista de Medicina, Universidade Federal de São Paulo, São Paulo, 1997.

18. CLARCK-CARTER, D. Doing quantitative psychological research: fron desing to report. $3^{\text {rd }}$ ed. Hove: Psychologycal Press. 1999.

19. COHEN, J.; COHEN, P. Applied multiple regression/correlation for the behavioral sciences. 2a. ed. Hillsdale: N.J., 1983.

20. CONNOR, C.A.; WRIGHT, C.C.; FEGAN, C.D. The safety and effectiveness of a nurse-led anticoagulant service. J Adv Nursing, v.38, n.4, p.407-15, 2002.

21. CROMHEECKE, M.E. et al. Oral anticoagulantion self-management and management by a specialist anticoagulation clinic: a randomized cross-over comparison. Lancet, v.356, n.8, p. 97-102, 2000. 
22. CUMMINGS, S.R.; STWART, A.; RULLEY, S.B. Elaboração de questionários e instrumentos de coleta de dados. In: HULLEY, S.B. et al. Delineando a pesquisa clinica. Uma abordagem epidemiológica. Porto Alegre: Artmed, 2003, p.265-81.

23. DANTAS, R.A.S. Adaptação cultural e validação do Questionário de Senso de Coerência de Antonovsky em uma amostra de pacientes cardíacos brasileiros. Ribeirão Preto, 115f. Tese (Livre-Docência) - Escola de Enfermagem de Ribeirão Preto, Universidade de São Paulo, 2007.

24. DAVIS, N.J. et al. Impact of Adherence, Knowledge, and Quality of Life on Anticoagulation Control. Ann Pharmacother., v.39, p.632-6, 2005.

25. eSCHEVARRIA-GUANILO, M.E. "Burns Specific Pain Anxiety Scale - BSPAS": adaptação transcultural e validação preliminar. Ribeirão Preto, 2005. 161f. Dissertação (Mestrado) - Escola de Enfermagem de Ribeirão Preto, Universidade de São Paulo, 2005.

26. FARHOUD, S.; STEPHANI, S.M.; BROMBERG, S.H. Pancreatite aguda devido a hematoma intramural do duodeno por uso de anticoagulante. Arq Gastroenterol., v.38, n.1, p. 53-6, 2001.

27. FARIA J. et al. Hematoma intramural duodenal como complicação de terapia anticoagulante com warfarin: relato de caso e revisão de literatura. Radiol Bras., v.37, v.6, p. 461-3, 2004.

28. FAYERS, P.M.; MACHIN, D. Scores and Measurements: Validity, Reliability and Sensitivity. Quality of life. Assessment, Analisis and Interpretation. Chichester, England: John Wiley \& Sons. 2007.

29. FERREIRA, E. Adaptação cultural da "Burns Specific Health Scale-Revised" (BSHS-R): versão para brasileiros que sofreram queimaduras. Ribeirão Preto, 2006. 108f. Dissertação (Mestrado) - Escola de Enfermagem de Ribeirão Preto, Universidade de São Paulo, São Paulo, 2006.

30. FERRER, M. et al. Validity and reability of the St Geroge`s Respiratory Questionaire after adaptation to a different language and culture: the Spanish example. Eur Respir J., v. 9, p.1160-6, 1996. 
31. FONSECA, E.S.M. et al. Validação do questionário de qualidade de vida (King's Health Questionnaire) em mulheres brasileiras com incontinência urinária. Rev Bras Ginecol Obstet., v. 27, n.5, p. 235-42, 2005.

32. FRANCO, R.F. Fisiologia da Coagulação do Sangue e da Fibrinólise. In: ZAGO, M.A.; FALCÃO, R.P.; PASQUINI, R. Hematologia: Fundamentos e Prática. 1. ed. São Paulo: Atheneu, 2001, p.739-748.

33. FREIXA $\mathrm{R}$ et al. Identificación de factores responsables de anticoagulación oral excessiva em pacientes ambulatorios con cardiopatia. Rev Esp Cardiol., v.56, n.1, p.65-72, 2003.

34. GADISSEUR, A.P.A. et al. Comparasion of the Quality of Oral Anticoagulant herapy Through Patient Self-management and Management by Specialized Anticoagulation Clinics in the Netherlands. Arch Intern Med., v. 163, p. 2639-46, 2003.

35. GADISSEUR, A.P. et al. Patient self-management of oral anticoagulant care vs. management by specialized anticoagulation clinics: positive effects on quality of life. J Thromb Haemost, v.2, n.4, p.584-91, 2004.

36. GILL, T.M.; FEINSTEIN, A.R. A critical appraisal of the quality of quality-of-life measurements. JAMA, v.272, n.8, p. 619-26, 1994

37. GONZALEZ, R.S. et al. Cross-cultural adaptation of a questionnaire for measuring the quality of life of patients taking oral anticoagulants. Aten Primaria, v.34, n.7, p. 353-9, 2004.

38. GRINBERG, M. Anticoagulação Oral: Uma Abordagem Biótica. Caderno de Terapêutica-Tradição e Confiança na Anticoagulação Oral do Laboratório FQM-Farmoquímica S/A, Brasil, maio, p.5-45, 2003.

39. GUILLEMIN, F.; BOMBARDIER, C.; BEATON, D.E. Cross-cultural adaptation of health-related quality of life measures: literature rewiew and proposed guidelines. J. Clin Epidemiol, v.46, n.12, p.1412-32, 1993.

40. HIRSH, J.; FUSTER, V. Guide to anticoagulant therapy. Part 2: Oral anticoagulants. Circulation, v.89, p. 1469-80, 1994. 
41. HUSTED, S.; ANDREASEN, F. Problems encountered in long-term treatment with anticoagulants. Acta Med Scand, v.200, p. 379, 1976.

42. JEFFREY, S. AHA 2008: THINRS: Home INR Monitoring as Effective as ClinicBased Care. Medscape Medical News, Nov. 13, 2008.

43. KIMMEL, S.E. et al The Influence of Patient Adherence on Anticoagulation Control With Warfarin Results From the International Normalized Ratio Adherence and Genetics (IN-RANGE) Study. Arch Intern Med., v.167, p.229-235, 2007.

44. KIMURA, M. Tradução para o portugues e validação do "Quality of life index" de Ferrans e Powers. São Paulo, 1999. 143f. Tese (Livre-Docência) - Escola de Enfermagem, Universidade de São Paulo, São Paulo, 1999.

45. KLACK, K.; CARVALHO, J.F. Vitamina k: metabolismo, fonts e interação com o anticoagulante varfarina. Rev Bras Reumatol., v.46, n.6, p. 398-406, 2006.

46. KULINNA, W. et al. The effect of self-monitoring the INR on quality of anticoagulation and quality of life. Semin Thromb Hemost, v.25, n.1, p. 123-6, 1999.

47. LA SCALA, C.S.K. et al. Adaptação e validação do PAQLQ-A. J Ped, v.81, n. 1, p. 54-60, 2005.

48. LANCASTER, T.R. et al. The impact f long-term warfarin therapy on quality of life evidence from a randomized trial. Arch Intern Méd, v.151, p. 1944-9, 1991.

49. LEVINE, M.N. et al. Hemorrhagic complications of anticoagulant treatment. Chest, v.119, p. 108-21, 2001.

50. LIP, G.Y.H. et al. Ethnic Differences in Patient Perceptions of Atrial Fibrillation and Anticoagulation Therapy The West Birmingham Atrial Fibrillation Project. Stroke., v. 33, p. 238-44, 2002.

51. LO-BIONDO, G.W.; HABER, J. Pesquisa em Enfermagem, Métodos, Avaliação, Crítica e Utilização. 4.ed. Rio de Janeiro: Guanabara Koogan, 2001, 330 p. 
52. LOURENÇO, D.M. Mecanismos envolvidos na formação do trombo. Rev. Soc. Cardiol. Estado de São Paulo, v. 7, n. 3, p. 333-9, 1997.

53. LOURENÇO, D.M.; MORELLI, V.M.; VIGNAL, C.V. Terapia da superdosagem de anticoagulantes orais. Arq Bras Cardiol., v.7, n.3, p. 9-13, 1998.

54. MACHADO-ALBA, J.E.; MONCADA-ESCOBAR, J.C. Reacciones adversas medicamentosas em pacientes que consultaron a Instituciones Prestadoras de Serviços en Pereira, Colômbia. Rev Salud Publica., v.8, n.2, p.200-8, 2006.

55. MASTROPIETRO, A.P. et al. Functional Assessment of Cancer Therapy Bone Marrow Transplantation: tradução e validação. Rev Saúde Pública, v. 41, n.2, p. 260 8, 2007.

56. MCKENNA, S.P.; DOWARD L.C. The translation and cultural adaptation of patientreported outcome measures. Value in Health, v.8, n. 2, p. 89-91, 2005.

57. MEDINA CASTRO, ME. Adaptação trnascultural e validação do instrumento genérico da mensuração de Qualidade de Vida Relacionada à Saúde, DISABKIDS 37, para crianças e adolescentes mexicanos com doenças crônicas e seus pais ou cuidadores: fase I. Ribeirão Preto, 2007. 182f. Tese (Doutorado) Escola de Enfermagem de Ribeirão Preto, Universidade de São Paulo, 2007.

58. MINAYO, M.C.S.; HARTZ, Z.M.A.; BUSS, P.M. Qualidade de vida e saúde: um debate necessário. Ciência e Saúde Coletiva, v.5, n.1, p. 7-18, 2000.

59. NADAR, S. et al. Patients' understanding of anticoagulant therapy in a multiethnic population. J R Soc Med., v.96, p.175-9, 2003.

60. PARRONDO, C.D. et.al. Anticoagulácion Oral. An. Med. Interna, v. 20, n.7, p. 49$56,2003$.

61. PASCHOAL, S.M.P. Qualidade de vida no idoso: elaboração de um instrumento que privilegia a sua opinião. São Paulo, 2000. 227f. Dissertação (Mestrado) Faculdade de Medicina, Universidade de São Paulo, 2000.

62. PASQUALI, L. Instrumentos psicológicos: Manual prático de elaboração. Brasília: LabPAM/IBAPP, 1999. 
63. POLIT, D.F.; HUNGLER, B.P. Nursing Research. Principles and Methods. 6 ed. Philadelphia: Lippincott. 1999, 757p.

64. RAMOS DE CARVALHO, T.R. et al. Tradução do inglês para o português do Questionário de Auto-avaliação da Escala de Hamilton para Depressão. J Bras Psiq, v.42, n5, p. 255-60, 1993.

65. RANGEL FOD. Anticoagulantes orais nas síndromes coronarianas agudas. Rev SOCERJ, v. XIV, n. 1, p. 40-6, 2001.

66. ROMANO, E.R; JR PINHEIRO, J.A; BARBOSA, M.A.O. Como iniciar a anticoagulação e sua duração. Rev Soc Cardiol Estado de São Paulo, v.4, p. 256-63, 2006.

67. SAMSA, G. et al. A new instrument for measuring anticoagulation-related quality of life: development and preliminary validation. Health Qual Life Outcomes., v.6, n.2, p. 22-33, 2004.

68. SANCHES, M.M.G.; VILLAGRA, C.A. Anticoagulación oral en atención primariaúltimos avances. Med General., v.39, p. 916-23, 2001.

69. SANTOS, F.C. et al. Complicações da terapia anticoagulante com warfarina em pacientes com doença vascular periférica: estudo coorte prospectivo. J Vasc Bras, v. 5, n. 3, p.194-202, 2006.

70. SAPNAS, K.G.; ZELLER, RA. Minimizing sample size when using exploratory factor analysis for measurement. J Nurs Meas, v. 10, n.2, p.135-54, 2002.

71. SAWICKI, P.T. A structured teaching and self-management program for patients receiving oral anticoagulation: a randomized controlled trial. Working Group for the Study of Patient Self-Management of Oral Anticoagulation. JAMA, v. 281, n.2, p. 145-50, 1999.

72. SCHMIDT, S.; BULLINGER, M. Current issues in cross-cultural quality of life instrument development. Arch Phys Med Rehabil, v.84, suppl 2, S29-34, 2003.

73. SCHULMAN S. Quality of oral anticoagulant control and treatment in Sweden. J Intern Med, v. 236, p. 143-152, 1994. 
74. SEIDL, E.M.F.; ZANNON, C.M.L.C. Qualidade de vida e saúde: aspectos conceituais e metodológicos. Cad Saúde Pública., v.20, n.2, p. 20-6, 2004.

75. SNEED, N.V.; et al. Evalution of 3 quality measurement tools in patients with chronic heart failure. Heart Lung, v.30, p.332-40, 2001.

76. SPERBER, A.D. Translation e validation of study instruments for cross-cultural research. Gastroenterology, v. 126, suppl 1, p. 124-8, 2004.

77. SPÓSITO, A.C.; CARAMELLI, B. Fisiopatologia da Coagulação e Fibrinólise. In: BATLOUNI, M.; RAMIRES, J.A.F. Farmacologia e Terapêutica Cardiovascular. 1. ed. São Paulo: Atheneu, 1999, p.353-355.

78. STULTS, B.M.; DERE, W.H.; CIANE, T.H. Long-tern anticoagulantion: indications and management. West J Med. v. 151, p.414-29, 1989.

79. SULLANO, M.A.; ORTIZ, E.J. Deep vein thrombosis and anticoagulant therapy. Nurs Clin North, v.36, n.4, p. 645-63, 2001.

80. SWANE-VERDIER, A. et al. Adapting quality of life instruments. Value in Health, v.7, suppl 1, S:27-30, 2004.

81. TANG, E.O.Y.L. et al. Relationship Between Patients' Warfarin Knowledge and Anticoagulation Control. Ann Pharmacother., v. 37, p.34-9, 2003.

82. TAYLOR, F.C. et. al. Evaluation of nurse specialist anticoagulant service. Clin. Lab. Haem. v.19, p.267-272, 1997.

83. TEDOLDI, C.L. Anticoagulação na mulher. Rev Soc Cardiol Estado de São Paulo, v.16, n. 4, p.274-81, 2006.

84. TORN, M. et al. Risks of Oral Anticoagulant Therapy With Increasing Age. Arch Intern Med., v.165, p.1527-32, 2005.

85. WALRAVEN, C. et al. Effect of Study Setting on Anticoagulation Control. A Systematic Review and Metaregression. CHEST., v. 129, p. 1155-66, 2005. 
86. WALTZ, C.F.; STRICKLAND, O.L.; LENZ, E.R. Measurement in Nursing Research. 2ed. Philadelphia: Davis Company, 2005.p.161-94.

87. WARE, J.E.; SHERBOURNE, C.D. The MOS 36-item short-form health survey (SF36). I. Conceptual framework and item selection. Med Care, v. 30, n.6, p. 473-83, 1992.

88. WILSON, S.J. et al. Comparing the quality of oral anticoagulant management by anticoagulation clinics and by family physicians: a randomized controlled trial. CMAJ, v. 169, n.4, p. 293-8, 2003. 
ANEXOS 


\section{ANEXOS}

Permissão para a adaptação e validação do instrumento "Duke Anticoagulation Satisfaction Scale (DASS)

Data: Thu, 13 Apr 2006 15:36:22 -0400

Cabeçalho Completo

De:

http://www.google.com/search?q=samsa001@mc.duke.edu Q. $g_{x}$

Para: "Flavia Martinelli Pelegrino" <flaviamp@eerp.usp.br $>$ Assunto: Re: DASS

Please feel free to use an adapted version of the DASS in your study.

"Flavia Martinelli Pelegrino" <flaviamp@eerp.usp.br>

04/08/2006 12:54 PM
To "greg samsa" < samsa001@mc.duke.edu>

cc

Subject DASS 


\section{Duke Anticoagulation Satisfaction Scale (DASS)}

We would like to know how your anti-clot treatment (warfarin/coumadin) affects you, and what you know and feel about your anti-clot treatment. Please check the answer that best fits your situation. If a question does not apply to you, then check "not at all".

When you have anti-clot treatment you tend to bleed or bruise more easily. You may limit your activities as a result. Limit means you do less of the activity, or no longer perform the activity at all.

1a. How much does the possibility of bleeding or bruising limit you from taking part in physical activities (for example, housework, gardening, dancing, sports, or anything else you would usually do)?

\begin{tabular}{|c|c|c|c|c|c|c|}
\hline Not at all & A little & Somewhat & Moderately & Quite a bit & A lot & Very much \\
\hline 1 & 2 & 3 & 4 & 5 & 6 & 7 \\
\hline
\end{tabular}

1b. How much does the possibility of bleeding or bruising limit you from traveling?

\begin{tabular}{|c|c|c|c|c|c|c|}
\hline Not at all & A little & Somewhat & Moderately & Quite a bit & A lot & Very much \\
\hline 1 & 2 & 3 & 4 & 5 & 6 & 7 \\
\hline
\end{tabular}

1c. How much does the possibility of bleeding or bruising limit you from getting the medical care you need (for example, visiting a dentist, chiropractor, or doctor of your choice)?

\begin{tabular}{|c|c|c|c|c|c|c|}
\hline Not at all & A little & Somewhat & Moderately & Quite a bit & A lot & Very much \\
\hline 1 & 2 & 3 & 4 & 5 & 6 & 7 \\
\hline
\end{tabular}

1d. How much does the possibility of bleeding or bruising limit your ability to work for pay?

\begin{tabular}{|c|c|c|c|c|c|c|}
\hline Not at all & A little & Somewhat & Moderately & Quite a bit & A lot & Very much \\
\hline 1 & 2 & 3 & 4 & 5 & 6 & 7 \\
\hline
\end{tabular}

1e. Overall, how much does the possibility of bleeding or bruising affect your daily life?

\begin{tabular}{|c|c|c|c|c|c|c|}
\hline Not at all & A little & Somewhat & Moderately & Quite a bit & A lot & Very much \\
\hline 1 & 2 & 3 & 4 & 5 & 6 & 7 \\
\hline
\end{tabular}

Being on anti-clot treatment may mean changing some of your other habits as well.

2a. How much does anti-clot treatment limit your choice of food (diet)?

\begin{tabular}{|c|c|c|c|c|c|c|}
\hline Not at all & A little & Somewhat & Moderately & Quite a bit & A lot & Very much \\
\hline 1 & 2 & 3 & 4 & 5 & 6 & 7 \\
\hline
\end{tabular}

2b. How much does anti-clot treatment limit the alcoholic beverages you might wish to drink?

\begin{tabular}{|c|c|c|c|c|c|c|}
\hline Not at all & A little & Somewhat & Moderately & Quite a bit & A lot & Very much \\
\hline 1 & 2 & 3 & 4 & 5 & 6 & 7 \\
\hline
\end{tabular}

2c. How much does anti-clot treatment limit the over-the-counter medications (for example, aspirin, ibuprofen, vitamins) you might wish to take?

\begin{tabular}{|c|c|c|c|c|c|c|}
\hline Not at all & A little & Somewhat & Moderately & Quite a bit & A lot & Very much \\
\hline 1 & 2 & 3 & 4 & 5 & 6 & 7 \\
\hline
\end{tabular}

2d. Overall, how much does anti-clot treatment affect your daily life?

\begin{tabular}{|c|c|c|c|c|c|c|}
\hline Not at all & A little & Somewhat & Moderately & Quite a bit & A lot & Very much \\
\hline 1 & 2 & 3 & 4 & 5 & 6 & 7 \\
\hline
\end{tabular}

Being on anti-clot treatment means doing a lot of things, some every day and some less often.

Daily tasks could include: remembering to take your medicine at a certain time, taking the correct does of your medicine, not drinking much alcohol, following a moderate diet, avoiding bruising and bleeding, and so forth.

Occasional tasks could include: traveling to the clinic for blood check-ups, contacting the clinic in case of bleeding or other important events, and so forth. 
3a. How much of a hassle (inconvenience) are the daily tasks of anti-clot treatment?

\begin{tabular}{|c|c|c|c|c|c|c|}
\hline Not at all & A little & Somewhat & Moderately & Quite a bit & A lot & Very much \\
\hline 1 & 2 & 3 & 4 & 5 & 6 & 7 \\
\hline
\end{tabular}

3b. How much of a hassle (inconvenience) are the occasional tasks of anti-clot treatment?

\begin{tabular}{|c|c|c|c|c|c|c|}
\hline Not at all & A little & Somewhat & Moderately & Quite a bit & A lot & Very much \\
\hline 1 & 2 & 3 & 4 & 5 & 6 & 7 \\
\hline
\end{tabular}

Considering anti-clot treatment as a whole (that is, both the daily and occasional tasks), please consider the following.

3c. How complicated do you find your anti-clot treatment to be?

\begin{tabular}{|c|c|c|c|c|c|c|}
\hline Not at all & A little & Somewhat & Moderately & Quite a bit & A lot & Very much \\
\hline 1 & 2 & 3 & 4 & 5 & 6 & 7 \\
\hline
\end{tabular}

3d. How time-consuming do you find your anti-clot treatment to be?

\begin{tabular}{|c|c|c|c|c|c|c|}
\hline Not at all & A little & Somewhat & Moderately & Quite a bit & A lot & Very much \\
\hline 1 & 2 & 3 & 4 & 5 & 6 & 7 \\
\hline
\end{tabular}

3e. How frustrating do you find your anti-clot treatment to be?

\begin{tabular}{|c|c|c|c|c|c|c|}
\hline Not at all & A little & Somewhat & Moderately & Quite a bit & A lot & Very much \\
\hline 1 & 2 & 3 & 4 & 5 & 6 & 7 \\
\hline
\end{tabular}

3f. How painful do you find your anti-clot treatment to be?

\begin{tabular}{|c|c|c|c|c|c|c|}
\hline Not at all & A little & Somewhat & Moderately & Quite a bit & A lot & Very much \\
\hline 1 & 2 & 3 & 4 & 5 & 6 & 7 \\
\hline
\end{tabular}

3g. Overall, how much of a burden do you find your anti-clot treatment to be?

\begin{tabular}{|c|c|c|c|c|c|c|}
\hline Not at all & A little & Somewhat & Moderately & Quite a bit & A lot & Very much \\
\hline 1 & 2 & 3 & 4 & 5 & 6 & 7 \\
\hline
\end{tabular}

3h. Overall, how confident are you about handling your anti-clot treatment

\begin{tabular}{|c|c|c|c|c|c|c|}
\hline Not at all & A little & Somewhat & Moderately & Quite a bit & A lot & Very much \\
\hline 1 & 2 & 3 & 4 & 5 & 6 & 7 \\
\hline
\end{tabular}

These last questions ask what you know and feel about your anti-clot treatment.

4a. How well do you feel that you understand the medical reason for your anti-clot treatment?

\begin{tabular}{|c|c|c|c|c|c|c|}
\hline Not at all & A little & Somewhat & Moderately & Quite a bit & A lot & Very much \\
\hline 1 & 2 & 3 & 4 & 5 & 6 & 7 \\
\hline
\end{tabular}

4b. How much do you feel reassured because of your anti-clot treatment?

\begin{tabular}{|c|c|c|c|c|c|c|}
\hline Not at all & A little & Somewhat & Moderately & Quite a bit & A lot & Very much \\
\hline 1 & 2 & 3 & 4 & 5 & 6 & 7 \\
\hline
\end{tabular}

4d. How much do you worry about bleeding and bruising?

\begin{tabular}{|c|c|c|c|c|c|c|}
\hline Not at all & A little & Somewhat & Moderately & Quite a bit & A lot & Very much \\
\hline 1 & 2 & 3 & 4 & 5 & 6 & 7 \\
\hline
\end{tabular}

4f. Overall, how much has anti-clot treatment had a positive impact on your life?

\begin{tabular}{|c|c|c|c|c|c|c|}
\hline Not at all & A little & Somewhat & Moderately & Quite a bit & A lot & Very much \\
\hline 1 & 2 & 3 & 4 & 5 & 6 & 7 \\
\hline
\end{tabular}

4g. Overall, how much has anti-clot treatment had a negative impact on your life?

\begin{tabular}{|c|c|c|c|c|c|c|}
\hline Not at all & A little & Somewhat & Moderately & Quite a bit & A lot & Very much \\
\hline 1 & 2 & 3 & 4 & 5 & 6 & 7 \\
\hline
\end{tabular}

4h. Overall, how satisfied are you with your anti-clot treatment?

\begin{tabular}{|c|c|c|c|c|c|c|}
\hline Not at all & A little & Somewhat & Moderately & Quite a bit & A lot & Very much \\
\hline 1 & 2 & 3 & 4 & 5 & 6 & 7 \\
\hline
\end{tabular}


4i. Compared with other treatments you have had, how difficult is your anti-clot treatment to manage?

\begin{tabular}{|c|c|c|c|c|c|c|}
\hline Not at all & A little & Somewhat & Moderately & Quite a bit & A lot & Very much \\
\hline 1 & 2 & 3 & 4 & 5 & 6 & 7 \\
\hline
\end{tabular}

$4 \mathrm{j}$. How likely would you be to recommend this form of anti-clot treatment to someone else with your disease or medical condition?

\begin{tabular}{|c|c|c|c|c|c|c|}
\hline Not at all & A little & Somewhat & Moderately & Quite a bit & A lot & Very much \\
\hline 1 & 2 & 3 & 4 & 5 & 6 & 7 \\
\hline
\end{tabular}

Items $3 \mathrm{~h}, 4 \mathrm{a}, 4 \mathrm{~b}, 4 \mathrm{f}$, $4 \mathrm{~h}$ and $4 \mathrm{j}$ should be reverse coded.

Items $4 \mathrm{c}$ and $4 \mathrm{e}$ were deleted. 
Parecer do Comitê de Ética em Pesquisa

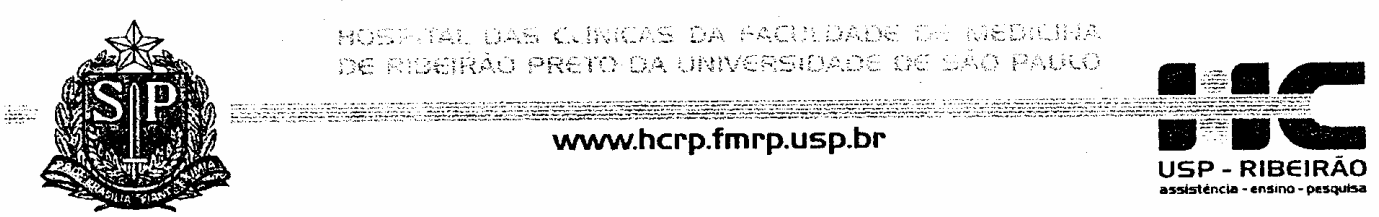

Ribeirão Preto, 09 de outubro de 2007

Oficio $\mathrm{n}^{\circ} 3508 / 2007$

$\mathrm{CEP} / \mathrm{MGV}$

Prezada Professora,

O trabalho intitulado "ADAPTAÇĀO CULTURAL E VALIDAÇÃO DO INSTRUMENTO DUKE ANTICOAGULATION SATISFACTION SCALE (DASS): VERSÃO PARA BRASILEIROS EM USO DE ANTICOAGULANTE ORAL", foi analisado pelo Comitê de Ética em Pesquisa, em sua $256^{a}$ Reuniāo Ordinária realizada em 08/10/2007, e enquadrado na categoria: APROVADO, bem como o Termo de Consentimento Livre e Esclarecido, de acordo com o Processo HCRP $n^{\circ}$ $6736 / 2007$.

Lembramos que devem ser apresentados a este CEP, 0 Relatório Parcial e o Relatório Final da pesquisa.

Atenciosamente.

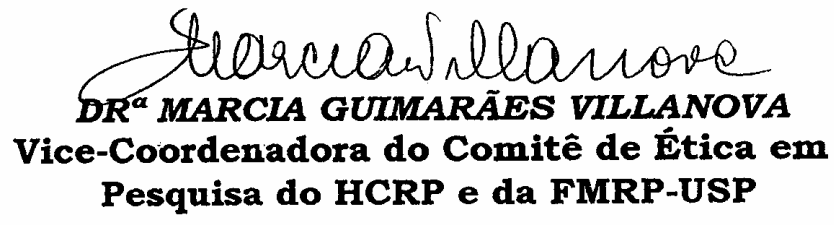

Ilustríssima Senhora

PROF ${ }^{2}$ DR $^{2}$ ROSANA APARECIDA SPADOTI DANTAS

FLÁVIA MARTINELLI PELEGRINO (Enfermeira)

Escola de Enfermagem de Ribeirāo Preto-USP

Comitê de Ética em Pesquisa HC e FMRP-USP - Campus Universitário FWA - 00002733 ; IRB - 00002186

Fone (16) 3602-2228 - E-mail : cep@hcrp.fmrp.usp.br Monte Alegre 14048-900 Ribeirão Preto SP 


\section{Escala de Satisfação da Anticoagulação de Duke}

Nós gostaríamos de conhecer como o tratamento de anticoagulação afeta você (warfaina/marcoumar), e o que você conhece e sente sobre o seu tratamento. Por favor, escolha a melhor resposta para a sua situação. Se a pergunta não aplica a você então escolha a alternativa nada.

Quando você está em tratamento de anticoagulação você pode ter sangramento ou machucar-se mais facilmente. Como resultado, você pode ter limites em suas atividades. Limite significa fazer menos uma atividade ou não fazer atividade nenhuma.

1a. Quanto à possibilidade de sangramento ou machucar-se limita você a fazer atividade física (por exemplo, serviços domésticos, jardinagem, dançar, esportes, ou qualquer outra atividade que usualmente você faz)?

\begin{tabular}{|c|c|c|c|c|c|c|}
\hline Nada & Muito pouco & Pouco & Moderadamente & Bastante & Muito & Muitíssimo \\
\hline 1 & 2 & 3 & 4 & 5 & 6 & 7 \\
\hline
\end{tabular}

1b. Quanto à possibilidade de sangramento ou machucar-se limita você para viagens?

\begin{tabular}{|c|c|c|c|c|c|c|}
\hline Nada & Muito pouco & Pouco & Moderadamente & Bastante & Muito & Muitíssimo \\
\hline 1 & 2 & 3 & 4 & 5 & 6 & 7 \\
\hline
\end{tabular}

1c. Quanto a possibilidade de sangramento ou machucar-se limita você a ter cuidado médico que necessita (por exemplo, ir ao dentista, quiroprático, ou ao médico de sua escolha)?

\begin{tabular}{|c|c|c|c|c|c|c|}
\hline Nada & Muito pouco & Pouco & Moderadamente & Bastante & Muito & Muitíssimo \\
\hline 1 & 2 & 3 & 4 & 5 & 6 & 7 \\
\hline
\end{tabular}

1d. Quanto a possibilidade de sangramento ou machucar-se limita você na sua habilidade de trabalhar?

\begin{tabular}{|c|c|c|c|c|c|c|}
\hline Nada & Muito pouco & Pouco & Moderadamente & Bastante & Muito & Muitíssimo \\
\hline 1 & 2 & 3 & 4 & 5 & 6 & 7 \\
\hline
\end{tabular}

1e. No geral, quanto à possibilidade de sangramento ou machucar-se afeta você na vida diária?

\begin{tabular}{|c|c|c|c|c|c|c|}
\hline Nada & Muito pouco & Pouco & Moderadamente & Bastante & Muito & Muitíssimo \\
\hline 1 & 2 & 3 & 4 & 5 & 6 & 7 \\
\hline
\end{tabular}

Iniciar o tratamento de anticoagulação pode significar algumas mudanças em seus outros hábitos.

2a. Quanto o tratamento de anticoagulação limita sua escolha na alimentação (dieta)?

\begin{tabular}{|c|c|c|c|c|c|c|}
\hline Nada & Muito pouco & Pouco & Moderadamente & Bastante & Muito & Muitíssimo \\
\hline 1 & 2 & 3 & 4 & 5 & 6 & 7 \\
\hline
\end{tabular}

2a. Quanto o tratamento de anticoagulação limita você a tomar bebidas alcoólicas?

\begin{tabular}{|c|c|c|c|c|c|c|}
\hline Nada & Muito pouco & Pouco & Moderadamente & Bastante & Muito & Muitíssimo \\
\hline 1 & 2 & 3 & 4 & 5 & 6 & 7 \\
\hline
\end{tabular}

2a. Quanto o tratamento de anticoagulação limita você a usar medicamento sem receita médica (por exemplo, aspirina, ibuprofeno, vitaminas)?

\begin{tabular}{|c|c|c|c|c|c|c|}
\hline Nada & Muito pouco & Pouco & Moderadamente & Bastante & Muito & Muitíssimo \\
\hline 1 & 2 & 3 & 4 & 5 & 6 & 7 \\
\hline
\end{tabular}

2d. No geral, quanto o tratamento de anticoagulação afeta você na vida diária?

\begin{tabular}{|c|c|c|c|c|c|c|}
\hline Nada & Muito pouco & Pouco & Moderadamente & Bastante & Muito & Muitíssimo \\
\hline 1 & 2 & 3 & 4 & 5 & 6 & 7 \\
\hline
\end{tabular}

Iniciar o tratamento de anticoagulação significa fazer muitas coisas, alguns diariamente e outras menos freqüentemente.

Tarefas diárias poderiam incluir: lembrar de tomar o medicamento em horário certo, tomar a dose correta do medicamento, não tomar muitas bebidas alcoólicas, seguir uma dieta moderada, evitando machucados e sangramentos, e assim sucessivamente.

Tarefas ocasionais poderiam incluir: ir a clínica para checar exame de sangue, contactar a clínica no caso de sangramento ou outros eventos importantes, e assim sucessivamente. 
3a. Quanto de desagrado (inconveniência) as tarefas diárias de tratamento de anticoagulação são?

\begin{tabular}{|c|c|c|c|c|c|c|}
\hline Nada & Muito pouco & Pouco & Moderadamente & Bastante & Muito & Muitíssimo \\
\hline 1 & 2 & 3 & 4 & 5 & 6 & 7 \\
\hline
\end{tabular}

3b. Quanto de desagrado (inconveniência) as tarefas ocasionais de tratamento de anticoagulação são?

\begin{tabular}{|c|c|c|c|c|c|c|}
\hline Nada & Muito pouco & Pouco & Moderadamente & Bastante & Muito & Muitíssimo \\
\hline 1 & 2 & 3 & 4 & 5 & 6 & 7 \\
\hline
\end{tabular}

Considerando o tratamento de anticoagulação como um todo (quer dizer, ambas as tarefas diárias e ocasionais), por favor, considere o seguinte.

3c. Quanto você acha complicado o seu tratamento de anticoagulação?

\begin{tabular}{|c|c|c|c|c|c|c|}
\hline Nada & Muito pouco & Pouco & Moderadamente & Bastante & Muito & Muitíssimo \\
\hline 1 & 2 & 3 & 4 & 5 & 6 & 7 \\
\hline
\end{tabular}

3d. Quanto você acha demorado o seu tratamento de anticoagulação?

\begin{tabular}{|c|c|c|c|c|c|c|}
\hline Nada & Muito pouco & Pouco & Moderadamente & Bastante & Muito & Muitíssimo \\
\hline 1 & 2 & 3 & 4 & 5 & 6 & 7 \\
\hline
\end{tabular}

3e. Quanto voce acha frustrante o seu tratamento de anticoagulação?

\begin{tabular}{|c|c|c|c|c|c|c|}
\hline Nada & Muito pouco & Pouco & Moderadamente & Bastante & Muito & Muitíssimo \\
\hline 1 & 2 & 3 & 4 & 5 & 6 & 7 \\
\hline
\end{tabular}

3f. Quanto você acha doloroso o seu tratamento de anticoagulação?

\begin{tabular}{|c|c|c|c|c|c|c|}
\hline Nada & Muito pouco & Pouco & Moderadamente & Bastante & Muito & Muitíssimo \\
\hline 1 & 2 & 3 & 4 & 5 & 6 & 7 \\
\hline
\end{tabular}

3g. No geral, quanto você acha sobrecarregado o seu tratamento de anticoagulação?

\begin{tabular}{|c|c|c|c|c|c|c|}
\hline Nada & Muito pouco & Pouco & Moderadamente & Bastante & Muito & Muitíssimo \\
\hline 1 & 2 & 3 & 4 & 5 & 6 & 7 \\
\hline
\end{tabular}

3h. No geral, quanto confiante você esta em controlar seu tratamento de anticoagulação?

\begin{tabular}{|c|c|c|c|c|c|c|}
\hline Nada & Muito pouco & Pouco & Moderadamente & Bastante & Muito & Muitíssimo \\
\hline 1 & 2 & 3 & 4 & 5 & 6 & 7 \\
\hline
\end{tabular}

Estas últimas perguntas são sobre o que você conhece e sente sobre seu tratamento de anticoagulação.

4a. Quanto você entende a razão médica para seu tratamento de anticoagulação?

\begin{tabular}{|c|c|c|c|c|c|c|}
\hline Nada & Muito pouco & Pouco & Moderadamente & Bastante & Muito & Muitíssimo \\
\hline 1 & 2 & 3 & 4 & 5 & 6 & 7 \\
\hline
\end{tabular}

4b. Quanto você sente seguro devido o seu tratamento de anticoagulação?

\begin{tabular}{|c|c|c|c|c|c|c|}
\hline Nada & Muito pouco & Pouco & Moderadamente & Bastante & Muito & Muitíssimo \\
\hline 1 & 2 & 3 & 4 & 5 & 6 & 7 \\
\hline
\end{tabular}

4d. Quanto você preocupa-se com sangramento ou machucado?

\begin{tabular}{|c|c|c|c|c|c|c|}
\hline Nada & Muito pouco & Pouco & Moderadamente & Bastante & Muito & Muitíssimo \\
\hline 1 & 2 & 3 & 4 & 5 & 6 & 7 \\
\hline
\end{tabular}

4f. No geral, quanto do tratamento de anticoagulação teve um impacto positivo em sua vida?

\begin{tabular}{|c|c|c|c|c|c|c|}
\hline Nada & Muito pouco & Pouco & Moderadamente & Bastante & Muito & Muitíssimo \\
\hline 1 & 2 & 3 & 4 & 5 & 6 & 7 \\
\hline
\end{tabular}

4g. No geral, quanto do tratamento de anticoagulação teve um impacto negativo em sua vida?

\begin{tabular}{|c|c|c|c|c|c|c|}
\hline Nada & Muito pouco & Pouco & Moderadamente & Bastante & Muito & Muitíssimo \\
\hline 1 & 2 & 3 & 4 & 5 & 6 & 7 \\
\hline
\end{tabular}


4f. No geral, quanto satisfeito você está com o seu tratamento de anticoagulação?

\begin{tabular}{|c|c|c|c|c|c|c|}
\hline Nada & Muito pouco & Pouco & Moderadamente & Bastante & Muito & Muitíssimo \\
\hline 1 & 2 & 3 & 4 & 5 & 6 & 7 \\
\hline
\end{tabular}

4i. Comparado com outros tratamentos que você fez, quanto difícil é para administrar o seu tratamento de anticoagulação?

\begin{tabular}{|c|c|c|c|c|c|c|}
\hline Nada & Muito pouco & Pouco & Moderadamente & Bastante & Muito & Muitíssimo \\
\hline 1 & 2 & 3 & 4 & 5 & 6 & 7 \\
\hline
\end{tabular}

4j. Quanto provável será recomendar esta forma de tratamento de anticoagulação a outra pessoa com sua doença ou condição médica?

\begin{tabular}{|c|c|c|c|c|c|c|}
\hline Nada & Muito pouco & Pouco & Moderadamente & Bastante & Muito & Muitíssimo \\
\hline 1 & 2 & 3 & 4 & 5 & 6 & 7 \\
\hline
\end{tabular}




\section{Escala de Satisfação Anti-coagulação Duke}

Nós gostaríamos de saber como o seu tratamento anti-coagulante (warfarin/coumadin) tem te afetado, o que você sabe e como você se sente a respeito do seu tratamento anticoagulante. Por favor, escolha a resposta que melhor descreve sua situação. Se a questão não se aplica a você, então escolha "nada". Quando você faz o tratamento anti-coagulante você tende a sangrar ou se machucar mais facilmente. Como resultado você tem que limitar suas atividades. Limitar significa que você faz menos de uma determinada atividade, ou então, não faz a atividade.

1a. Quanto a possibilidade de sangrar ou se machucar limita sua participação em atividades físicas (por exemplo, cuidar da casa, praticar jardinagem, dançar, praticar esportes, ou qualquer outra atividade que você faria normalmente)?

\begin{tabular}{|c|c|c|c|c|c|c|}
\hline nada & Muito pouco & Um pouco & Moderadamente & Bastante & Muito & Muitíssimo \\
\hline 1 & 2 & 3 & 4 & 5 & 6 & 7 \\
\hline
\end{tabular}

1b. Quanto a possibilidade de sangrar ou se machucar te limita viajar?

\begin{tabular}{|c|c|c|c|c|c|c|}
\hline Nada & Muito pouco & Um pouco & Moderadamente & Bastante & Muito & Muitíssimo \\
\hline 1 & 2 & 3 & 4 & 5 & 6 & 7 \\
\hline
\end{tabular}

1c. Quanto a possibilidade de sangrar ou se machucar te limita obter qualquer outro tratamento médico que você precisa (por exemplo, ir ao dentista, ao quiroprata, ou outro médico de sua escolha)?

\begin{tabular}{|c|c|c|c|c|c|c|}
\hline Nada & Muito pouco & Um pouco & Moderadamente & Bastante & Muito & Muitíssimo \\
\hline 1 & 2 & 3 & 4 & 5 & 6 & 7 \\
\hline
\end{tabular}

1d. Quanto a possibilidade de sangrar ou se machucar limita sua habilidade de trabalhar?

\begin{tabular}{|c|c|c|c|c|c|c|}
\hline nada & Muito pouco & Um pouco & Moderadamente & Bastante & Muito & Muitíssimo \\
\hline 1 & 2 & 3 & 4 & 5 & 6 & 7 \\
\hline
\end{tabular}

1e. No geral, quanto a possibilidade de sangrar ou se machucar afeta sua rotina diária?

\begin{tabular}{|c|c|c|c|c|c|c|}
\hline nada & Muito pouco & Um pouco & Moderadamente & Bastante & Muito & Muitíssimo \\
\hline 1 & 2 & 3 & 4 & 5 & 6 & 7 \\
\hline
\end{tabular}

Estar em tratamento anti-coagulante significa mudar também alguns dos seus outros hábitos.

2a. Quanto o seu tratamento anti-coagulante limita sua escolha alimentar (dieta)?

\begin{tabular}{|c|c|c|c|c|c|c|}
\hline nada & Muito pouco & Um pouco & Moderadamente & Bastante & Muito & Muitíssimo \\
\hline 1 & 2 & 3 & 4 & 5 & 6 & 7 \\
\hline
\end{tabular}

2b. Quanto o seu tratamento anti-coagulante limita o consumo de bebidas alcoólicas?

\begin{tabular}{|c|c|c|c|c|c|c|}
\hline nada & Muito pouco & Um pouco & Moderadamente & Bastante & Muito & Muitíssimo \\
\hline 1 & 2 & 3 & 4 & 5 & 6 & 7 \\
\hline
\end{tabular}

2c. Quanto o seu tratamento anti-coagulante limita o uso de medicações que não precisam de receita médica (por exemplo, aspirina, ibuprofen, vitaminas) que você pode querer utilizar?

\begin{tabular}{|c|c|c|c|c|c|c|}
\hline nada & Muito pouco & Um pouco & Moderadamente & Bastante & Muito & Muitíssimo \\
\hline 1 & 2 & 3 & 4 & 5 & 6 & 7 \\
\hline
\end{tabular}

2d. No geral, quanto o seu tratamento anti-coagulante afeta sua rotina diária?

\begin{tabular}{|c|c|c|c|c|c|c|}
\hline nada & Muito pouco & Um pouco & Moderadamente & Bastante & Muito & Muitíssimo \\
\hline 1 & 2 & 3 & 4 & 5 & 6 & 7 \\
\hline
\end{tabular}

Estar em tratamento anticoagulante significa fazer muitas coisas, algumas todos os dias e outras com menos freqüência. 
Tarefas diárias podem incluir: lembrar de tomar o remédio num determinado horário, tomar a dose correta do remédio, não beber muito álcool, seguir dieta alimentar moderada, evitar machucados e sangramentos, e assim por diante.

Tarefas ocasionais podem incluir: ir à clinica para fazer exames de sangue, contatar a clinica em caso de sangramento ou outro evento importante, e assim por diante.

3a. Quão difícil (inconveniente) são as tarefas diárias do tratamento anti-coagulante?

\begin{tabular}{|c|c|c|c|c|c|c|}
\hline nada & Muito pouco & Um pouco & Moderadamente & Bastante & Muito & Muitíssimo \\
\hline 1 & 2 & 3 & 4 & 5 & 6 & 7 \\
\hline
\end{tabular}

3b. Quão difícil (inconveniente) são as tarefas ocasionais do tratamento anti-coagulante?

\begin{tabular}{|c|c|c|c|c|c|c|}
\hline nada & Muito pouco & Um pouco & Moderadamente & Bastante & Muito & Muitíssimo \\
\hline 1 & 2 & 3 & 4 & 5 & 6 & 7 \\
\hline
\end{tabular}

Considerando o tratamento anti-coagulante no geral (ou seja, tanto as tarefas diárias como também as ocasionais), por favor considere o seguinte:

3c. Quão complicado você acha o tratamento anticoagulante?

\begin{tabular}{|c|c|c|c|c|c|c|}
\hline nada & Muito pouco & Um pouco & Moderadamente & Bastante & Muito & Muitíssimo \\
\hline 1 & 2 & 3 & 4 & 5 & 6 & 7 \\
\hline
\end{tabular}

3d. Quão demorado você acha o tratamento anticoagulante?

\begin{tabular}{|c|c|c|c|c|c|c|}
\hline nada & Muito pouco & Um pouco & Moderadamente & Bastante & Muito & Muitíssimo \\
\hline 1 & 2 & 3 & 4 & 5 & 6 & 7 \\
\hline
\end{tabular}

3e. Quão frustrante você acha o tratamento anticoagulante?

\begin{tabular}{|c|c|c|c|c|c|c|}
\hline nada & Muito pouco & Um pouco & Moderadamente & Bastante & Muito & Muitíssimo \\
\hline 1 & 2 & 3 & 4 & 5 & 6 & 7 \\
\hline
\end{tabular}

3f. Quão doloroso você acha o tratamento anticoagulante?

\begin{tabular}{|c|c|c|c|c|c|c|}
\hline nada & Muito pouco & Um pouco & Moderadamente & Bastante & Muito & Muitíssimo \\
\hline 1 & 2 & 3 & 4 & 5 & 6 & 7 \\
\hline
\end{tabular}

3g. No geral, quão sacrificado/pesado você acha o tratamento anti-coagulante?

\begin{tabular}{|c|c|c|c|c|c|c|}
\hline nada & Muito pouco & Um pouco & Moderadamente & Bastante & Muito & Muitíssimo \\
\hline 1 & 2 & 3 & 4 & 5 & 6 & 7 \\
\hline
\end{tabular}

3h. No geral, quão confiante você se sente em lidar com o seu tratamento anti-coagulante?

\begin{tabular}{|c|c|c|c|c|c|c|}
\hline nada & Muito pouco & Um pouco & Moderadamente & Bastante & Muito & Muitíssimo \\
\hline 1 & 2 & 3 & 4 & 5 & 6 & 7 \\
\hline
\end{tabular}

Estas últimas perguntas se referem ao quanto você sabe e como se sente a respeito do tratamento anticoagulante; 4a. Quão bem você entende a razão médica do seu tratamento anticoagulante?

\begin{tabular}{|c|c|c|c|c|c|c|}
\hline nada & Muito pouco & Um pouco & Moderadamente & Bastante & Muito & Muitíssimo \\
\hline 1 & 2 & 3 & 4 & 5 & 6 & 7 \\
\hline
\end{tabular}

4b. Quão tranqüilo você se sente por causa do seu tratamento anticoagulante?

\begin{tabular}{|c|c|c|c|c|c|c|}
\hline nada & Muito pouco & Um pouco & Moderadamente & Bastante & Muito & Muitíssimo \\
\hline 1 & 2 & 3 & 4 & 5 & 6 & 7 \\
\hline
\end{tabular}

4d. Quanto você se preocupa com relação a sangramentos e machucados?

\begin{tabular}{|c|c|c|c|c|c|c|}
\hline nada & Muito pouco & Um pouco & Moderadamente & Bastante & Muito & Muitíssimo \\
\hline 1 & 2 & 3 & 4 & 5 & 6 & 7 \\
\hline
\end{tabular}

Fonte: Versão Português 2 adaptada por Pelegrino (2009) do instrumento DASS de Samsa et al. (2004) 
4f No geral, quão positivo foi o impacto do tratamento na sua vida?

\begin{tabular}{|c|c|c|c|c|c|c|}
\hline nada & Muito pouco & Um pouco & Moderadamente & Bastante & Muito & Muitíssimo \\
\hline 1 & 2 & 3 & 4 & 5 & 6 & 7 \\
\hline
\end{tabular}

4g. No geral, quão negativo foi impacto do tratamento na sua vida?

\begin{tabular}{|c|c|c|c|c|c|c|}
\hline nada & Muito pouco & Um pouco & Moderadamente & Bastante & Muito & Muitíssimo \\
\hline 1 & 2 & 3 & 4 & 5 & 6 & 7 \\
\hline
\end{tabular}

4h. No geral, quão satisfeito você está com o seu tratamento anticoagulante?

\begin{tabular}{|c|c|c|c|c|c|c|}
\hline nada & Muito pouco & Um pouco & Moderadamente & Bastante & Muito & Muitíssimo \\
\hline 1 & 2 & 3 & 4 & 5 & 6 & 7 \\
\hline
\end{tabular}

4i. Comparado com outros tratamentos que você já fez, quão difícil é lidar com o seu tratamento anticoagulante?

\begin{tabular}{|c|c|c|c|c|c|c|}
\hline nada & Muito pouco & Um pouco & Moderadamente & Bastante & Muito & Muitíssimo \\
\hline 1 & 2 & 3 & 4 & 5 & 6 & 7 \\
\hline
\end{tabular}

4j. Qual a probabilidade de você recomendar esta forma de tratamento anti-coagulante para alguém com a sua doença ou condição médica?

\begin{tabular}{|c|c|c|c|c|c|c|}
\hline nada & Muito pouco & Um pouco & Moderadamente & Bastante & Muito & Muitíssimo \\
\hline 1 & 2 & 3 & 4 & 5 & 6 & 7 \\
\hline
\end{tabular}




\section{Duke Anticoagulation Satisfaction Scale}

We would like to know how your anti-clot treatment (blood thinner) affects you (Warfarin/Marcomar), and what you know and feel about your treatment. Please check the answer that best describes your situation. If a question does not apply to you, then check "not at all".

When you have anti-clot treatment you may bleed or bruise more easily. You may have to limit your activities as a result.Limit means you do less of an activity or no longer perform the activiy at all.

1a. How much does the possibility of bleeding or bruising limit you from performing a physical activity (for example, housework, dancing, sports or any other activiy you would usually do?

\begin{tabular}{|l|l|l|l|l|l|l|}
\hline $\begin{array}{l}\text { Not at all/Does not } \\
\text { limit }\end{array}$ & Very little & Somewhat & $\begin{array}{l}\text { Moderately / more } \\
\text { or less }\end{array}$ & Quite a bit & A lot & Very much \\
\hline 1 & 2 & 3 & 4 & 5 & 6 & 7 \\
\hline
\end{tabular}

1b. How much does the possibility of bleeding or bruising limit you from going out of town?

\begin{tabular}{|l|l|l|l|l|l|l|}
\hline $\begin{array}{l}\text { Not at all/Does not } \\
\text { limit }\end{array}$ & Very little & Somewhat & $\begin{array}{l}\text { Moderately / more } \\
\text { or less }\end{array}$ & Quite a bit & A lot & Very much \\
\hline 1 & 2 & 3 & 4 & 5 & 6 & 7 \\
\hline
\end{tabular}

1c. How much does the possibility of bleeding or bruising limit you from getting any other health treatment you need(for example, going to the dentist, to the pshysical therapist, or other medical care)?

\begin{tabular}{|l|l|l|l|l|l|l|}
\hline $\begin{array}{l}\text { Not at all/Does not } \\
\text { limit }\end{array}$ & Very little & Somewhat & $\begin{array}{l}\text { Moderately / more } \\
\text { or less }\end{array}$ & Quite a bit & A lot & Very much \\
\hline 1 & 2 & 3 & 4 & 5 & 6 & 7 \\
\hline
\end{tabular}

1d. How much does the possibility of bleeding or bruising limit you in your job?

\begin{tabular}{|l|l|l|l|l|l|l|}
\hline $\begin{array}{l}\text { Not at all/Does not } \\
\text { limit }\end{array}$ & Very little & Somewhat & $\begin{array}{l}\text { Moderately / more } \\
\text { or less }\end{array}$ & Quite a bit & A lot & Very much \\
\hline 1 & 2 & 3 & 4 & 5 & 6 & 7 \\
\hline
\end{tabular}

1e. In general, how much does the possibility of bleeding or bruising affect your daily life?

\begin{tabular}{|l|l|l|l|l|l|l|}
\hline $\begin{array}{l}\text { Not at all/Does not } \\
\text { limit }\end{array}$ & Very little & Somewhat & $\begin{array}{l}\text { Moderately / more } \\
\text { or less }\end{array}$ & Quite a bit & A lot & Very much \\
\hline 1 & 2 & 3 & 4 & 5 & 6 & 7 \\
\hline
\end{tabular}

Being on an anti-clot treatment means changing some of your other habits as well.

2a. How much do you change your diet because of your anti-clot treatment (blood thinner)?

\begin{tabular}{|l|l|l|l|l|l|l|}
\hline $\begin{array}{l}\text { Not at all/Does not } \\
\text { limit }\end{array}$ & Very little & Somewhat & $\begin{array}{l}\text { Moderately / more } \\
\text { or less }\end{array}$ & Quite a bit & A lot & Very much \\
\hline 1 & 2 & 3 & 4 & 5 & 6 & 7 \\
\hline
\end{tabular}

2b. How much does your anti-clot treatment limit your intake of alcoholic beverages?

\begin{tabular}{|l|l|l|l|l|l|l|}
\hline $\begin{array}{l}\text { Not at all/Does not } \\
\text { limit }\end{array}$ & Very little & Somewhat & $\begin{array}{l}\text { Moderately / more } \\
\text { or less }\end{array}$ & Quite a bit & A lot & Very much \\
\hline 1 & 2 & 3 & 4 & 5 & 6 & 7 \\
\hline
\end{tabular}

2c. How much does your anti-clot treatment(blood thinner) limit you from taking medication for pain, fever and vitamins?

\begin{tabular}{|l|l|l|l|l|l|l|}
\hline $\begin{array}{l}\text { Not at all/Does not } \\
\text { limit }\end{array}$ & Very little & Somewhat & $\begin{array}{l}\text { Moderately / more } \\
\text { or less }\end{array}$ & Quite a bit & A lot & Very much \\
\hline 1 & 2 & 3 & 4 & 5 & 6 & 7 \\
\hline
\end{tabular}

2d. In general, how much does your anti-clot treatment (blood thinner) affect your daily life?

\begin{tabular}{|l|l|l|l|l|l|l|}
\hline $\begin{array}{l}\text { Not at all/Does not } \\
\text { limit }\end{array}$ & Very little & Somewhat & $\begin{array}{l}\text { Moderately / more } \\
\text { or less }\end{array}$ & Quite a bit & A lot & Very much \\
\hline 1 & 2 & 3 & 4 & 5 & 6 & 7 \\
\hline
\end{tabular}


The need for an anti-clot treatment means doing many things, some things every day, and others less often.

Daily activities related to the treatment could include: remembering to take your medication at a certain time, taking the correct dose of your medication, not drinking alcohol, following a moderate diet, avoiding bruising or bleeding, and so on.

3a. How much of a hassle are those acitivites in your daily life?

\begin{tabular}{|l|l|l|l|l|l|l|}
\hline $\begin{array}{l}\text { Not at all/Does } \\
\text { not limit }\end{array}$ & Very little & Somewhat & $\begin{array}{l}\text { Moderately / more } \\
\text { or less }\end{array}$ & Quite a bit & A lot & Very much \\
\hline 1 & 2 & 3 & 4 & 5 & 6 & 7 \\
\hline
\end{tabular}

Occasional_activities related to your treatment could be: going to the hospital for blood check-ups, seeking medical care in case of bleeding or other problems related to your anti-clot treatment (blood thinner).

3b. How much of a hassle are those activities in your life?

\begin{tabular}{|l|l|l|l|l|l|l|}
\hline $\begin{array}{l}\text { Not at all/Does not } \\
\text { limit }\end{array}$ & Very little & Somewhat & $\begin{array}{l}\text { Moderately / more } \\
\text { or less }\end{array}$ & Quite a bit & A lot & Very much \\
\hline 1 & 2 & 3 & 4 & 5 & 6 & 7 \\
\hline
\end{tabular}

Considering anti-clot treatment in general, (both daily and occasional activities), please answer the following:

3c. How complicated do you find it is to follow your anti-clot treatment(blood thinner)?

\begin{tabular}{|l|l|l|l|l|l|l|}
\hline $\begin{array}{l}\text { Not at all/Does not } \\
\text { limit }\end{array}$ & Very little & Somewhat & $\begin{array}{l}\text { Moderately / more } \\
\text { or less }\end{array}$ & Quite a bit & A lot & Very much \\
\hline 1 & 2 & 3 & 4 & 5 & 6 & 7 \\
\hline
\end{tabular}

3d. How time-consuming do you find your anti-clot treatment?

\begin{tabular}{|l|l|l|l|l|l|l|}
\hline $\begin{array}{l}\text { Not at all/Does not } \\
\text { limit }\end{array}$ & Very little & Somewhat & $\begin{array}{l}\text { Moderately / more } \\
\text { or less }\end{array}$ & Quite a bit & A lot & Very much \\
\hline 1 & 2 & 3 & 4 & 5 & 6 & 7 \\
\hline
\end{tabular}

3e. How much does your anti-clot treatment (blood thinner) harass you?

\begin{tabular}{|l|l|l|l|l|l|l|}
\hline $\begin{array}{l}\text { Not at all/Does not } \\
\text { limit }\end{array}$ & Very little & Somewhat & $\begin{array}{l}\text { Moderately / more } \\
\text { or less }\end{array}$ & Quite a bit & A lot & Very much \\
\hline 1 & 2 & 3 & 4 & 5 & 6 & 7 \\
\hline
\end{tabular}

3f. How painful do you find your anti-clot treatment (blood thinner)?

\begin{tabular}{|l|l|l|l|l|l|l|}
\hline $\begin{array}{l}\text { Not at all/Does not } \\
\text { limit }\end{array}$ & Very little & Somewhat & $\begin{array}{l}\text { Moderately / more } \\
\text { or less }\end{array}$ & Quite a bit & A lot & Very much \\
\hline 1 & 2 & 3 & 4 & 5 & 6 & 7 \\
\hline
\end{tabular}

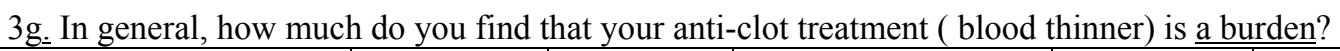

\begin{tabular}{|l|l|l|l|l|l|l|}
\hline $\begin{array}{l}\text { Not at all/Does not } \\
\text { limit }\end{array}$ & Very little & Somewhat & $\begin{array}{l}\text { Moderately / more } \\
\text { or less }\end{array}$ & Quite a bit & A lot & Very much \\
\hline 1 & 2 & 3 & 4 & 5 & 6 & 7 \\
\hline
\end{tabular}

3h. In general, how much do you believe you can manage to follow your anti-clot treatment (blood thinner)?

\begin{tabular}{|l|l|l|l|l|l|l|}
\hline $\begin{array}{l}\text { Not at all/Does not } \\
\text { limit }\end{array}$ & Very little & Somewhat & $\begin{array}{l}\text { Moderately / more } \\
\text { or less }\end{array}$ & Quite a bit & A lot & Very much \\
\hline 1 & 2 & 3 & 4 & 5 & 6 & 7 \\
\hline
\end{tabular}

These last questions ask what you understand about your anti-clot treatment (blood thinner).

4a. How much do you understand about the reason for taking the anti-clot medication?

\begin{tabular}{|l|l|l|l|l|l|l|}
\hline $\begin{array}{l}\text { Not at all/Does not } \\
\text { limit }\end{array}$ & Very little & Somewhat & $\begin{array}{l}\text { Moderately / more } \\
\text { or less }\end{array}$ & Quite a bit & A lot & Very much \\
\hline 1 & 2 & 3 & 4 & 5 & 6 & 7 \\
\hline
\end{tabular}


4b. How much do you feel your anti-clot treatment (blood thinner) protects your health?

\begin{tabular}{|l|l|l|l|l|l|l|}
\hline $\begin{array}{l}\text { Not at all/Does not } \\
\text { limit }\end{array}$ & Very little & Somewhat & $\begin{array}{l}\text { Moderately / more } \\
\text { or less }\end{array}$ & Quite a bit & A lot & Very much \\
\hline 1 & 2 & 3 & 4 & 5 & 6 & 7 \\
\hline
\end{tabular}

4d. How much do you worry about the risk of bleeding and bruising?

\begin{tabular}{|l|l|l|l|l|l|l|}
\hline $\begin{array}{l}\text { Not at all/Does not } \\
\text { limit }\end{array}$ & Very little & Somewhat & $\begin{array}{l}\text { Moderately / more } \\
\text { or less }\end{array}$ & Quite a bit & A lot & Very much \\
\hline 1 & 2 & 3 & 4 & 5 & 6 & 7 \\
\hline
\end{tabular}

4f. In general, how much has your anti-clot treatment (blood thinner) improved your life?

\begin{tabular}{|l|l|l|l|l|l|l|}
\hline $\begin{array}{l}\text { Not at all/Does not } \\
\text { limit }\end{array}$ & Very little & Somewhat & $\begin{array}{l}\text { Moderately / more } \\
\text { or less }\end{array}$ & Quite a bit & A lot & Very much \\
\hline 1 & 2 & 3 & 4 & 5 & 6 & 7 \\
\hline
\end{tabular}

4g. In general, how much has your anti-clot treatment (blood thinner) worsened your life?

\begin{tabular}{|l|l|l|l|l|l|l|}
\hline $\begin{array}{l}\text { Not at all/Does not } \\
\text { limit }\end{array}$ & Very little & Somewhat & $\begin{array}{l}\text { Moderately / more } \\
\text { or less }\end{array}$ & Quite a bit & A lot & Very much \\
\hline 1 & 2 & 3 & 4 & 5 & 6 & 7 \\
\hline
\end{tabular}

4h. In general, how satisfied are you with your anti-clot treatment (blood thinner)?

\begin{tabular}{|l|l|l|l|l|l|l|}
\hline $\begin{array}{l}\text { Not at all/Does not } \\
\text { limit }\end{array}$ & Very little & Somewhat & $\begin{array}{l}\text { Moderately / more } \\
\text { or less }\end{array}$ & Quite a bit & A lot & Very much \\
\hline 1 & 2 & 3 & 4 & 5 & 6 & 7 \\
\hline
\end{tabular}

4i. Compared with other treatments you have had, how difficult is it to deal with your anti-clot treatment (blood thinner)?

\begin{tabular}{|l|l|l|l|l|l|l|}
\hline $\begin{array}{l}\text { Not at all/Does not } \\
\text { limit }\end{array}$ & Very little & Somewhat & $\begin{array}{l}\text { Moderately / more } \\
\text { or less }\end{array}$ & Quite a bit & A lot & Very much \\
\hline 1 & 2 & 3 & 4 & 5 & 6 & 7 \\
\hline
\end{tabular}

$4 \mathrm{j}$. How likely would you motivate another person (with the same health problem (medical condition) as yours) to follow the anti-clot treatment (blood thinner)?

\begin{tabular}{|l|l|l|l|l|l|l|}
\hline $\begin{array}{l}\text { Not at all/Does not } \\
\text { limit }\end{array}$ & Very little & Somewhat & $\begin{array}{l}\text { Moderately / more } \\
\text { or less }\end{array}$ & Quite a bit & A lot & Very much \\
\hline 1 & 2 & 3 & 4 & 5 & 6 & 7 \\
\hline
\end{tabular}




\section{Duke Anticoagulation Satisfaction Scale}

We would like to know how the anticoagulation treatment (thinning the blood) affects you (warfarin/marcoumar), and what you know and feel about your treatment. Please select the answer that best explains your situation. If the question does not apply to you, select the alternative "nothing" as your answer.

When you are in a treatment with an anticoagulant, you may experience bleeding or get hurt easier. Consequently, you must limit (interfere in) your activities. Limiting (interfering) means doing one activity less or not doing any activity at all.

1a. How much does the possibility of bleeding or getting hurt limit you (interfere) in doing physical activities (for example, domestic chores, dancing, sports or any other activity you usually do)?

\begin{tabular}{|c|c|c|c|c|c|c|}
\hline $\begin{array}{l}\text { Nothing/ } \\
\text { Does not limit }\end{array}$ & Very little & Little & $\begin{array}{l}\text { Moderately/ more } \\
\text { or less }\end{array}$ & Considerably & $\begin{array}{l}\text { Very } \\
\text { much }\end{array}$ & Extremely \\
\hline 1 & 2 & 3 & 4 & 5 & 6 & 7 \\
\hline
\end{tabular}

1b. How much does the possibility of bleeding or getting hurt limit you (interfere) from traveling out of town?

\begin{tabular}{|c|c|c|c|c|c|c|}
\hline $\begin{array}{l}\text { Nothing/ } \\
\text { Does not limit }\end{array}$ & Very little & Little & $\begin{array}{l}\text { Moderately/ more } \\
\text { or less }\end{array}$ & Considerably & $\begin{array}{l}\text { Very } \\
\text { much }\end{array}$ & Extremely \\
\hline 1 & 2 & 3 & 4 & 5 & 6 & 7 \\
\hline
\end{tabular}

1c. How much does the possibility of bleeding or getting hurt limit any other health treatment you may need (for example, going to the dentist, the physiotherapist, or another health service)?

\begin{tabular}{|c|c|c|c|c|c|c|}
\hline $\begin{array}{l}\text { Nothing/ } \\
\text { Does not limit }\end{array}$ & Very little & Little & $\begin{array}{l}\text { Moderately/ more } \\
\text { or less }\end{array}$ & Considerably & $\begin{array}{l}\text { Very } \\
\text { much }\end{array}$ & Extremely \\
\hline 1 & 2 & 3 & 4 & 5 & 6 & 7 \\
\hline
\end{tabular}

1d. How much does the possibility of bleeding or getting hurt limit you (interfere) in your job?

\begin{tabular}{|c|c|c|c|c|c|c|}
\hline $\begin{array}{l}\text { Nothing/ } \\
\text { Does not limit }\end{array}$ & Very little & Little & $\begin{array}{l}\text { Moderately/ more } \\
\text { or less }\end{array}$ & Considerably & $\begin{array}{l}\text { Very } \\
\text { much }\end{array}$ & Extremely \\
\hline 1 & 2 & 3 & 4 & 5 & 6 & 7 \\
\hline
\end{tabular}

1e. In general, how much does the possibility of bleeding or getting hurt affect (interfere in) your day-to-day?

\begin{tabular}{|c|c|c|c|c|c|c|}
\hline $\begin{array}{l}\text { Nothing/ } \\
\text { Does not limit }\end{array}$ & Very little & Little & $\begin{array}{l}\text { Moderately/ more } \\
\text { or less }\end{array}$ & Considerably & $\begin{array}{l}\text { Very } \\
\text { much }\end{array}$ & Extremely \\
\hline 1 & 2 & 3 & 4 & 5 & 6 & 7 \\
\hline
\end{tabular}

Does your anticoagulation treatment (thinning the blood) also mean changing some of your other habits (customs)?

2a. How much do you change your eating habits because of the anticoagulation treatment (thinning the blood)?

\begin{tabular}{|c|c|c|c|c|c|c|}
\hline $\begin{array}{l}\text { Nothing/ } \\
\text { Does not limit }\end{array}$ & Very little & Little & $\begin{array}{l}\text { Moderately/ more } \\
\text { or less }\end{array}$ & Considerably & $\begin{array}{l}\text { Very } \\
\text { much }\end{array}$ & Extremely \\
\hline 1 & 2 & 3 & 4 & 5 & 6 & 7 \\
\hline
\end{tabular}

2b. How much does your anticoagulation treatment (thinning the blood) limit (interfere in) the use of alcoholic beverages?

\begin{tabular}{|c|c|c|c|c|c|c|}
\hline $\begin{array}{l}\text { Nothing/ } \\
\text { Does not limit }\end{array}$ & Very little & Little & $\begin{array}{l}\text { Moderately/ more } \\
\text { or less }\end{array}$ & Considerably & $\begin{array}{l}\text { Very } \\
\text { much }\end{array}$ & Extremely \\
\hline 1 & 2 & 3 & 4 & 5 & 6 & 7 \\
\hline
\end{tabular}

2c. How much does your anticoagulation treatment (thinning the blood) limit (interfere in) the use of medication for pain, fever and vitamins?

\begin{tabular}{|c|c|c|c|c|c|c|}
\hline $\begin{array}{l}\text { Nothing/ } \\
\text { Does not limit }\end{array}$ & Very little & Little & $\begin{array}{l}\text { Moderately/ more } \\
\text { or less }\end{array}$ & Considerably & $\begin{array}{l}\text { Very } \\
\text { much }\end{array}$ & Extremely \\
\hline 1 & 2 & 3 & 4 & 5 & 6 & 7 \\
\hline
\end{tabular}


2 d. In general, how much does your anticoagulation treatment affect your daily life?

\begin{tabular}{|c|c|c|c|c|c|c|}
\hline $\begin{array}{l}\text { Nothing/ } \\
\text { Does not limit }\end{array}$ & Very little & Little & $\begin{array}{l}\text { Moderately/ more } \\
\text { or less }\end{array}$ & Considerably & $\begin{array}{l}\text { Very } \\
\text { much }\end{array}$ & Extremely \\
\hline 1 & 2 & 3 & 4 & 5 & 6 & 7 \\
\hline
\end{tabular}

The need for anticoagulation treatment (thinning the blood) means doing many things; some things everyday and others less frequently.

Daily activities related to the treatment may include: remembering to take the medication at a certain time, taking the correct dose of the medication, not drinking a lot, following a moderate diet, avoiding getting hurt and bleeding, and so on.

3a. How much do these activities make your life difficult (interfere)?

\begin{tabular}{|l|c|c|c|c|c|c|}
\hline $\begin{array}{l}\text { Nothing/ } \\
\text { Does not limit }\end{array}$ & Very little & Little & $\begin{array}{l}\text { Moderately/ more } \\
\text { or less }\end{array}$ & Considerably & $\begin{array}{l}\text { Very } \\
\text { much }\end{array}$ & Extremely \\
\hline 1 & 2 & 3 & 4 & 5 & 6 & 7 \\
\hline
\end{tabular}

Occasionally, other activities related to the treatment would be: going to the hospital for blood work, seeking medical services in the event of bleeding or other problems related to the anticoagulation treatment (thinning the blood).

3b. How much do these activities make your life more difficult (interfere)?

\begin{tabular}{|c|c|c|c|c|c|c|}
\hline $\begin{array}{l}\text { Nothing/ } \\
\text { Does not limit }\end{array}$ & Very little & Little & $\begin{array}{l}\text { Moderately/ more } \\
\text { or less }\end{array}$ & Considerably & $\begin{array}{l}\text { Very } \\
\text { much }\end{array}$ & Extremely \\
\hline 1 & 2 & 3 & 4 & 5 & 6 & 7 \\
\hline
\end{tabular}

Considering the anticoagulation treatment (thinning the blood) in general (that is, both daily and occasional activities), please answer:

3c. How difficult do you think it is to follow the anticoagulation treatment (thinning the blood)?

\begin{tabular}{|c|c|c|c|c|c|c|}
\hline $\begin{array}{l}\text { Nothing/ } \\
\text { Does not limit }\end{array}$ & Very little & Little & $\begin{array}{l}\text { Moderately/ more } \\
\text { or less }\end{array}$ & Considerably & $\begin{array}{l}\text { Very } \\
\text { much }\end{array}$ & Extremely \\
\hline 1 & 2 & 3 & 4 & 5 & 6 & 7 \\
\hline
\end{tabular}

$3 \mathrm{~d}$. How much of your time do you spend to follow the anticoagulation treatment (thinning the blood)?

\begin{tabular}{|c|c|c|c|c|c|c|}
\hline $\begin{array}{l}\text { Nothing/ } \\
\text { Does not limit }\end{array}$ & Very little & Little & $\begin{array}{l}\text { Moderately/ more } \\
\text { or less }\end{array}$ & Considerably & $\begin{array}{l}\text { Very } \\
\text { much }\end{array}$ & Extremely \\
\hline 1 & 2 & 3 & 4 & 5 & 6 & 7 \\
\hline
\end{tabular}

3e. How much do you think your anticoagulation treatment (thinning the blood) bothers you?

\begin{tabular}{|c|c|c|c|c|c|c|}
\hline $\begin{array}{l}\text { Nothing/ } \\
\text { Does not limit }\end{array}$ & Very little & Little & $\begin{array}{l}\text { Moderately/ more } \\
\text { or less }\end{array}$ & Considerably & $\begin{array}{l}\text { Very } \\
\text { much }\end{array}$ & Extremely \\
\hline 1 & 2 & 3 & 4 & 5 & 6 & 7 \\
\hline
\end{tabular}

3f. How painful do you think your anticoagulation treatment (thinning the blood) is?

\begin{tabular}{|c|c|c|c|c|c|c|}
\hline $\begin{array}{l}\text { Nothing/ } \\
\text { Does not limit }\end{array}$ & Very little & Little & $\begin{array}{l}\text { Moderately/ more } \\
\text { or less }\end{array}$ & Considerably & $\begin{array}{l}\text { Very } \\
\text { much }\end{array}$ & Extremely \\
\hline 1 & 2 & 3 & 4 & 5 & 6 & 7 \\
\hline
\end{tabular}

3g. In general, how much of a sacrifice do you think your anticoagulation treatment (thinning the blood) is?

\begin{tabular}{|c|c|c|c|c|c|c|}
\hline $\begin{array}{l}\text { Nothing/ } \\
\text { Does not limit }\end{array}$ & Very little & Little & $\begin{array}{l}\text { Moderately/ more } \\
\text { or less }\end{array}$ & Considerably & $\begin{array}{l}\text { Very } \\
\text { much }\end{array}$ & Extremely \\
\hline 1 & 2 & 3 & 4 & 5 & 6 & 7 \\
\hline
\end{tabular}

$3 \mathrm{~h}$. In general, how well do you believe you are able to follow your anticoagulation treatment (thinning the blood)?

\begin{tabular}{|c|c|c|c|c|c|c|}
\hline $\begin{array}{l}\text { Nothing/ } \\
\text { Does not limit }\end{array}$ & Very little & Little & $\begin{array}{l}\text { Moderately/ more } \\
\text { or less }\end{array}$ & Considerably & $\begin{array}{l}\text { Very } \\
\text { much }\end{array}$ & Extremely \\
\hline 1 & 2 & 3 & 4 & 5 & 6 & 7 \\
\hline
\end{tabular}


These last questions are related to what you understand about your anticoagulation treatment (thinning the blood).

4a. How much do you know about the reason for taking the anticoagulant?

\begin{tabular}{|c|c|c|c|c|c|c|}
\hline $\begin{array}{l}\text { Nothing/ } \\
\text { Does not limit }\end{array}$ & Very little & Little & $\begin{array}{l}\text { Moderately/ more } \\
\text { or less }\end{array}$ & Considerably & $\begin{array}{l}\text { Very } \\
\text { much }\end{array}$ & Extremely \\
\hline 1 & 2 & 3 & 4 & 5 & 6 & 7 \\
\hline
\end{tabular}

4b. How much do you think your anticoagulation treatment (thinning the blood) protects your health?

\begin{tabular}{|c|c|c|c|c|c|c|}
\hline $\begin{array}{l}\text { Nothing/ } \\
\text { Does not limit }\end{array}$ & Very little & Little & $\begin{array}{l}\text { Moderately/ more } \\
\text { or less }\end{array}$ & Considerably & $\begin{array}{l}\text { Very } \\
\text { much }\end{array}$ & Extremely \\
\hline 1 & 2 & 3 & 4 & 5 & 6 & 7 \\
\hline
\end{tabular}

4d. How much are you concerned with the risk of bleeding or getting hurt?

\begin{tabular}{|c|c|c|c|c|c|c|}
\hline $\begin{array}{l}\text { Nothing/ } \\
\text { Does not limit }\end{array}$ & Very little & Little & $\begin{array}{l}\text { Moderately/ more } \\
\text { or less }\end{array}$ & Considerably & $\begin{array}{l}\text { Very } \\
\text { much }\end{array}$ & Extremely \\
\hline 1 & 2 & 3 & 4 & 5 & 6 & 7 \\
\hline
\end{tabular}

4f. In general, how much has the anticoagulation treatment (thinning the blood) improved your life?

\begin{tabular}{|c|c|c|c|c|c|c|}
\hline $\begin{array}{l}\text { Nothing/ } \\
\text { Does not limit }\end{array}$ & Very little & Little & $\begin{array}{l}\text { Moderately/ more } \\
\text { or less }\end{array}$ & Considerably & $\begin{array}{l}\text { Very } \\
\text { much }\end{array}$ & Extremely \\
\hline 1 & 2 & 3 & 4 & 5 & 6 & 7 \\
\hline
\end{tabular}

4g. In general, how much has the anticoagulation treatment (thinning the blood) worsened your life?

\begin{tabular}{|c|c|c|c|c|c|c|}
\hline $\begin{array}{l}\text { Nothing/ } \\
\text { Does not limit }\end{array}$ & Very little & Little & $\begin{array}{l}\text { Moderately/ more } \\
\text { or less }\end{array}$ & Considerably & $\begin{array}{l}\text { Very } \\
\text { much }\end{array}$ & Extremely \\
\hline 1 & 2 & 3 & 4 & 5 & 6 & 7 \\
\hline
\end{tabular}

4h. In general, how satisfied are you with your anticoagulation treatment (thinning the blood)?

\begin{tabular}{|c|c|c|c|c|c|c|}
\hline $\begin{array}{l}\text { Nothing/ } \\
\text { Does not limit }\end{array}$ & Very little & Little & $\begin{array}{l}\text { Moderately/ more } \\
\text { or less }\end{array}$ & Considerably & $\begin{array}{l}\text { Very } \\
\text { much }\end{array}$ & Extremely \\
\hline 1 & 2 & 3 & 4 & 5 & 6 & 7 \\
\hline
\end{tabular}

4i. Compared to other treatments you have done, how difficult is this anticoagulation treatment (thinning the blood)?

\begin{tabular}{|c|c|c|c|c|c|c|}
\hline $\begin{array}{l}\text { Nothing/ } \\
\text { Does not limit }\end{array}$ & Very little & Little & $\begin{array}{l}\text { Moderately/ more } \\
\text { or less }\end{array}$ & Considerably & $\begin{array}{l}\text { Very } \\
\text { much }\end{array}$ & Extremely \\
\hline 1 & 2 & 3 & 4 & 5 & 6 & 7 \\
\hline
\end{tabular}

$4 \mathrm{j}$. What is the probability that you will stimulate another person (with the same health problem as you) to follow the anticoagulation treatment (thinning the blood)?

\begin{tabular}{|c|c|c|c|c|c|c|}
\hline $\begin{array}{l}\text { Nothing/ } \\
\text { Does not limit }\end{array}$ & Very little & Little & $\begin{array}{l}\text { Moderately/ more } \\
\text { or less }\end{array}$ & Considerably & $\begin{array}{l}\text { Very } \\
\text { much }\end{array}$ & Extremely \\
\hline 1 & 2 & 3 & 4 & 5 & 6 & 7 \\
\hline
\end{tabular}


Concordância de Dr. Greg Samsa entre a Versão Inglês Final e a Versão Original do instrumento DASS (SAMSA et al. 2004)

Data: Fri, 14 Sep 2007 17:23:55 -0400

$\underline{\text { Cabeçalho Completo }}$

De:

http://www.google.com/search?q=samsa001\%40mc.duke.edu $\Phi_{x} s_{x}$

Para: "Flavia Martinelli Pelegrino" < flaviamp@eerp.usp.br> Assunto: Re: DASS

Your translation is fine.

"Flavia Martinelli Pelegrino"

<flaviamp@eerp.usp.br>

09/12/2007 12:59 PM
To "greg samsa" < samsa001@mc.duke.edu>

cc flavia-martinelli@bol.com.br

Subject DASS 


\section{SF-36}

Instruções: Esta pesquisa questiona você sobre sua saúde. Estas informações nos manterão informados de como você se sente e quão bem você é capaz de fazer suas atividades de vida diária. Responda cada questão marcando a resposta como indicado. Caso você esteja inseguro em como responder, por favor, tente responder o melhor que puder.

1. Em geral, você diria que sua saída é: (circule uma)

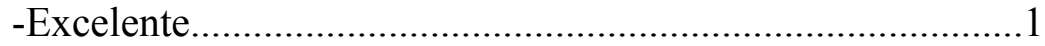

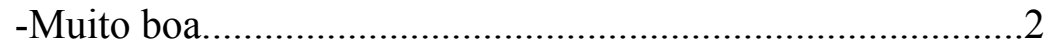

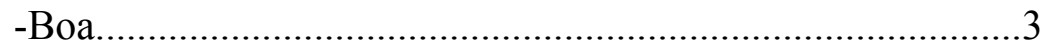

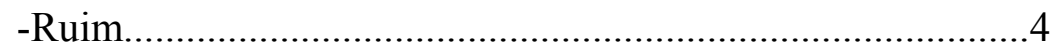

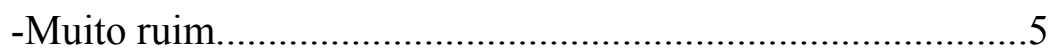

2. Comparada a um ano atrás, como você classificaria sua saúde em geral, agora? (circule uma)

Muito melhor agora do que um ano atrás...........................1

Um pouco melhor agora do que um ano atrás.....................2

Quase a mesma coisa de um ano atrás.................................3

Um pouco pior agora do que há um ano atrás......................4

Muito pior agora do que um ano atrás.................................5

3. Os seguintes itens são sobre atividades que você poderia fazer atualmente durante um dia comum. Devido a sua saúde, você tem dificuldades para fazer essas atividades? Neste caso, quanto?

(circule um numero em cada linha)

\begin{tabular}{|l|c|c|c|}
\hline Atividades & $\begin{array}{c}\text { Sim. } \\
\text { Dificulta } \\
\text { muito }\end{array}$ & $\begin{array}{c}\text { Sim. } \\
\text { Dificulta } \\
\text { um pouco. }\end{array}$ & $\begin{array}{c}\text { Não. Não } \\
\text { dificulta } \\
\text { de modo } \\
\text { algum. }\end{array}$ \\
\hline $\begin{array}{l}\text { a. Atividades vigorosas, que exigem muito } \\
\text { esforço, tais como correr, levantar objetos } \\
\text { pesados, participar em esportes árduos }\end{array}$ & 1 & 2 & 3 \\
\hline $\begin{array}{l}\text { b. Atividades moderadas, tais como mover } \\
\text { uma mesa, passar aspirador de pó, jogar bola, } \\
\text { varrer a casa. }\end{array}$ & 1 & 2 & 3 \\
\hline c. Levantar ou carregar mantimentos & 1 & 2 & 3 \\
\hline d. Subir vários lances de escada & 1 & 2 & 3 \\
\hline e. Subir um lance lances de escada & 1 & 2 & 3 \\
\hline f. Curvar-se, ajoelhar-se ou dobrar-se & 1 & 2 & 3 \\
\hline g. Andar mais de um quilometro & 1 & 2 & 3 \\
\hline h. Andar vários quarteirões & 1 & 2 & 3 \\
\hline i. Andar um quarteirão & 1 & 2 & 3 \\
\hline j. Tomar banho ou vestir-se & 1 & 2 & 3 \\
\hline
\end{tabular}


4. Durante as últimas 4 semanas, você teve algum dos seguintes problemas com o sue trabalho ou com alguma atividade diária regular, como conseqüência da sua saúde física?

(circule uma em cada linha)

\begin{tabular}{|l|c|c|}
\hline $\begin{array}{l}\text { a. Você diminui a quantidade de tempo que se dedicava ao } \\
\text { seu trabalho ou as outras atividade? }\end{array}$ & 1 & 2 \\
\hline b. Realizou menos tarefas do que você gostaria? & 1 & 2 \\
\hline $\begin{array}{l}\text { c. Esteve limitado no seu tipo de trabalho ou em outras } \\
\text { atividades? }\end{array}$ & 1 & 2 \\
\hline $\begin{array}{l}\text { d. Teve dificuldades de fazer seu trabalho ou outras } \\
\text { atividades (p.ex.:necessitou de um esforço extra)? }\end{array}$ & 1 & 2 \\
\hline
\end{tabular}

5. Durante as últimas 4 semanas, você teve algum dos seguintes problemas com o seu trabalho ou com alguma atividade diária regular, como conseqüência de algum problema emocional (como sentir-se deprimido ou ancioso)?

(circule uma em cada linha)

\begin{tabular}{|l|c|c|}
\hline $\begin{array}{l}\text { a. Você diminui a quantidade de tempo que se dedicava ao } \\
\text { seu trabalho ou as outras atividade? }\end{array}$ & Sim & 2 \\
\hline b. Realizou menos tarefas do que você gostaria? & 1 & 2 \\
\hline $\begin{array}{l}\text { c. Não trabalhou ou não fez qualquer das atividades com } \\
\text { tanto cuidado como geralmente faz? }\end{array}$ & 1 & 2 \\
\hline
\end{tabular}

6. Durante as últimas 4 semanas, de que maneira a sua saúde física ou problemas emocionais nas suas atividades sociais normais, em relação a família, vizinhos, amigos, ou em grupo?

- De forma nenhuma............................................. 1

- Ligeiramente .......................................................2

- Moderadamente......................................................3

- Bastante................................................................4

- Extremamente........................................................5

7. Quanta dor no corpo você teve durante as últimas 4 semanas?

- Nenhuma

(circule uma)

- Muito Leve.. ……................................................2

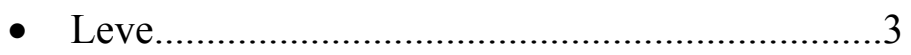

- Moderada..................................................................

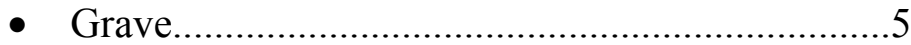

- Muito grave......................................................... 
8. Durante as últimas 4 semanas, quanto a dor interferiu com seu trabalho normal (incluindo tanto o trabalho, fora de casa e dentro de casa)?

(circule uma)

- De forma nenhuma 1

- Ligeiramente .2

- Moderadamente 3

- Bastante. 4

- Extremamente. .5

9. Estas questões são sobre como você se sente e como tudo tem acontecido com você durante as últimas 4 semanas. Para cada questão, por favor, dê uma reposta que mais se aproxima da maneira como você se sente. Em relação as 4 últimas semanas:

(circule um número em cada linha)

\begin{tabular}{|l|l|l|l|l|l|l|}
\hline & $\begin{array}{l}\text { Todo } \\
\text { tempo }\end{array}$ & $\begin{array}{l}\text { A } \\
\text { maior } \\
\text { parte } \\
\text { do } \\
\text { tempo }\end{array}$ & $\begin{array}{l}\text { Uma } \\
\text { boa } \\
\text { parte } \\
\text { do } \\
\text { tempo }\end{array}$ & $\begin{array}{l}\text { Alguma } \\
\text { parte } \\
\text { do } \\
\text { tempo }\end{array}$ & $\begin{array}{l}\text { Uma } \\
\text { pequena } \\
\text { parte do } \\
\text { tempo }\end{array}$ & Nunca \\
\hline $\begin{array}{l}\text { a. Quanto tempo você tem } \\
\text { se sentido cheio de } \\
\text { vontade, cheio de força? }\end{array}$ & & & & & \\
\hline $\begin{array}{l}\text { b. Quanto tempo voce tem } \\
\text { se sentido uma pessoa } \\
\text { muito nervosa? }\end{array}$ & & & & & & \\
\hline $\begin{array}{l}\text { c. Quanto tempo você tem } \\
\text { se sentido tão deprimido } \\
\text { que nada pode animá-lo? }\end{array}$ & & & & & & \\
\hline $\begin{array}{l}\text { d. Quanto tempo você tem } \\
\text { se sentido calmo ou } \\
\text { tranquilo? }\end{array}$ & & & & & & \\
\hline $\begin{array}{l}\text { e. Quanto tempo você tem } \\
\text { se sentido com muita } \\
\text { energia? }\end{array}$ & & & & & & \\
\hline $\begin{array}{l}\text { f. Quanto tempo você tem } \\
\text { se sentido desanimado e } \\
\text { abatido? }\end{array}$ & & & & & & \\
\hline $\begin{array}{l}\text { g. Quanto tempo você tem } \\
\text { se sentido esgotado? }\end{array}$ & & & & & & \\
\hline $\begin{array}{l}\text { h. Quanto tempo você tem } \\
\text { se sentido uma pessoa } \\
\text { feliz? }\end{array}$ & & & & & & \\
\hline $\begin{array}{l}\text { i. Quanto tempo você tem } \\
\text { se sentido cansado? }\end{array}$ & & & & & \\
\hline
\end{tabular}


10. Durante as últimas 4 semanas, quanto do seu tempo a sua saúde física ou problemas emocionais interferiram com as suas atividades sociais (como visitar amigos, parentes, etc.)?

(circule uma)

- Todo o tempo 1

- A maior parte do tempo.................................................2

- Alguma parte do tempo..................................................4

- Uma pequena parte do tempo........................................5

11. O quanto verdadeiro ou falso é cada uma das afirmações para você?

(circule um número em cada linha)

\begin{tabular}{|l|l|l|l|l|l|}
\hline & $\begin{array}{l}\text { Definiti- } \\
\text { vamente } \\
\text { verdadeiro }\end{array}$ & $\begin{array}{l}\text { A maioria } \\
\text { das vezes } \\
\text { verdadeiro }\end{array}$ & $\begin{array}{l}\text { Não } \\
\text { sei }\end{array}$ & $\begin{array}{l}\text { A maioria } \\
\text { das vezes }\end{array}$ & $\begin{array}{l}\text { Definiti- } \\
\text { vamente } \\
\text { falsa }\end{array}$ \\
\hline $\begin{array}{l}\text { a. Eu costume adoecer } \\
\text { um pouco mais } \\
\text { facilmente que as } \\
\text { outras pessoas }\end{array}$ & & & & & \\
\hline $\begin{array}{l}\text { b. Eu sou tão saudável } \\
\text { quanto qualquer } \\
\text { pessoa que eu conheço }\end{array}$ & & & & & \\
\hline $\begin{array}{l}\text { c. Eu acho que minha } \\
\text { saúde vai piorar }\end{array}$ & & & & & \\
\hline $\begin{array}{l}\text { d. Minha saúde é } \\
\text { excelente }\end{array}$ & & & & & \\
\hline
\end{tabular}


APÊNDICES 


\section{APÊNDICES}

\section{TERMO DE CONSENTIMENTO LIVRE E ESCLARECIDO}

Nome da pesquisa: Duke Anticoagulation Satisfaction Scale-DASS: adaptação transcultural para a língua portuguesa.

Sr(a) está sendo convidado a participar da pesquisa que tem por objetivo adaptar para a língua portuguesa uma escala de qualidade de vida para pacientes em tratamento de anticoagulação oral.

Sr(a) deverá responder a um questionário no qual consta os dados de identificação, história clínica e dados sócio-demográficos e uma escala de qualidade de vida para pacientes em tratamento de anticoagulação oral. Estes dados serão coletados no retorno ao ambulatório de anticoagulação oral.

Garantimos que durante a sua participação, não haverá riscos, constrangimentos e tampouco custos. Além disso, garantimos responder a qualquer pergunta ou esclarecimento de dúvidas a respeito da pesquisa, a liberdade de retirar o seu consentimento e deixar de participar da pesquisa a qualquer momento, sem que isso traga prejuízo profissional e ainda, a segurança de que não será identificado. Os dados obtidos serão utilizados unicamente para fins de pesquisa.

Assim sendo, eu , abaixo assinado, tendo sido devidamente esclarecido sobre a minha participação nesta pesquisa declaro que tenho pleno conhecimento dos direitos e das condições que me foram assegurados e concordo inteiramente com as condições que me foram apresentadas e que, livremente, manifesto a minha vontade em participar do referido projeto.

Prof. Dra. Rosana Apda Spadoti Dantas

Docente da EERP-USP

Av: Bandeirantes, 3900-RP

Tel: (0xx16) 3602-3402
Flávia Martinelli Pelegrino

Enfermeira do HCFMRP-USP

Rua: Dois de Julho, 793-RP

Tel: (0xx16) 3602-2886

Ribeirão Preto, de de 


\section{Escala de Satisfação de Anticoagulação de Duke}

Nós gostaríamos de conhecer como o tratamento de anticoagulação te afeta (warfaina/marcoumar), e o que você conhece e sente sobre o seu tratamento. Por favor, escolha a resposta que melhor descreve sua situação. Se a pergunta não se aplica a você, então escolha como resposta a alternativa "nada".

Quando você faz tratamento com anticoagulante você pode ter sangramento ou se machucar mais facilmente. Como resultado, você tem que limitar suas atividades. Limitar significa fazer menos uma atividade ou não fazer atividade nenhuma.

1a. Quanto a possibilidade de sangrar ou se machucar limita você a fazer atividade física (por exemplo, serviços domésticos, jardinagem, dançar, esportes, ou qualquer outra atividade que usualmente você faz)?

\begin{tabular}{|c|c|c|c|c|c|c|}
\hline Nada & Muito pouco & Pouco & $\begin{array}{l}\text { Moderadamente/ } \\
\text { mais ou menos }\end{array}$ & Bastante & Muito & Muitíssimo \\
\hline 1 & 2 & 3 & 4 & 5 & 6 & 7 \\
\hline
\end{tabular}

1b. Quanto a possibilidade de sangrar ou se machucar te limita viajar?

\begin{tabular}{|c|c|c|c|c|c|c|}
\hline Nada & Muito pouco & Pouco & Moderadamente & Bastante & Muito & Muitíssimo \\
\hline 1 & 2 & 3 & 4 & 5 & 6 & 7 \\
\hline
\end{tabular}

1c. Quanto a possibilidade de sangrar ou se machucar limita a realização de qualquer outro tratamento médico que você precisa (por exemplo, ir ao dentista, ao quiroprata, ou outro médico de sua escolha)?

\begin{tabular}{|l|c|c|c|c|c|c|}
\hline $\begin{array}{l}\text { Nada/ } \\
\text { Não } \\
\text { limita }\end{array}$ & Muito pouco & Pouco & Moderadamente & Bastante & Muito & Muitíssimo \\
\hline 1 & 2 & 3 & 4 & 5 & 6 & 7 \\
\hline
\end{tabular}

1d. Quanto a possibilidade de sangrar ou se machucar limita o seu trabalho remunerado?

\begin{tabular}{|l|l|c|c|c|c|c|}
\hline $\begin{array}{l}\text { Nada/ } \\
\text { Não } \\
\text { limita }\end{array}$ & Muito pouco & Pouco & Moderadamente & Bastante & Muito & Muitíssimo \\
\hline 1 & 2 & 3 & 4 & 5 & 6 & 7 \\
\hline
\end{tabular}

1e. No geral, quanto a possibilidade de sangrar ou se machucar afeta sua rotina diária?

\begin{tabular}{|c|c|c|c|c|c|c|}
\hline Nada & Muito pouco & Pouco & Moderadamente & Bastante & Muito & Muitíssimo \\
\hline 1 & 2 & 3 & 4 & 5 & 6 & 7 \\
\hline
\end{tabular}

Precisar de tratamento de anticoagulação significa mudar também alguns do seus outros hábitos.

2a. Quanto o seu tratamento de anticoagulação limita sua escolha na alimentação (dieta)?

\begin{tabular}{|c|c|c|c|c|c|c|}
\hline $\begin{array}{l}\text { Nada/ } \\
\text { Não } \\
\text { limita }\end{array}$ & Muito pouco & Pouco & Moderadamente & Bastante & Muito & Muitíssimo \\
\hline 1 & 2 & 3 & 4 & 5 & 6 & 7 \\
\hline
\end{tabular}

2b. Quanto o seu tratamento de anticoagulação limita o consumo de bebidas alcoólicas que você desejaria tomar?

\begin{tabular}{|c|c|c|c|c|c|c|}
\hline $\begin{array}{l}\text { Nada/ } \\
\text { Não limita }\end{array}$ & $\begin{array}{l}\text { Muito } \\
\text { pouco }\end{array}$ & Pouco & Moderadamente & Bastante & Muito & Muitíssimo \\
\hline 1 & 2 & 3 & 4 & 5 & 6 & 7 \\
\hline
\end{tabular}

2c. Quanto o seu tratamento de anticoagulação limita o uso de medicamentos sem receita médica (por exemplo, aspirina, ibuprofeno, vitaminas) que você desejaria usar?

\begin{tabular}{|l|c|c|c|c|c|c|}
\hline $\begin{array}{l}\text { Nada/ } \\
\text { Não } \\
\text { limita }\end{array}$ & Muito pouco & Pouco & Moderadamente & Bastante & Muito & Muitíssimo \\
\hline 1 & 2 & 3 & 4 & 5 & 6 & 7 \\
\hline
\end{tabular}

2d. No geral, quanto o seu tratamento de anticoagulação afeta sua vida diária?

\begin{tabular}{|c|c|c|c|c|c|c|}
\hline Nada & Muito pouco & Pouco & Moderadamente & Bastante & Muito & Muitíssimo \\
\hline 1 & 2 & 3 & 4 & 5 & 6 & 7 \\
\hline
\end{tabular}

Fonte: Versão Português Consenso 1 adaptada por Pelegrino (2009) do instrumento DASS de Samsa et al. (2004) 
Precisar de tratamento de anticoagulação significa fazer muitas coisas, alguns todos os dias e outras com menos freqüência.

Tarefas diárias relacionadas ao tratamento podem incluir: lembrar de tomar o remédio num determinado horário, tomar a dose correta do remédio, não beber muito álcool, seguir dieta alimentar moderada, evitar machucados e sangramentos, e assim por diante.

Tarefas ocasionais relacionadas ao tratamento podem incluir: ir ao hospital para fazer exame de sangue, procurar serviços médicos em caso de sangramento ou outros eventos importantes, e assim por diante.

3a. Quanto as tarefas diárias do tratamento de anticoagulação são difíceis ou inconvenientes?

\begin{tabular}{|c|c|c|c|c|c|c|}
\hline Nada & Muito pouco & Pouco & Moderadamente & Bastante & Muito & Muitíssimo \\
\hline 1 & 2 & 3 & 4 & 5 & 6 & 7 \\
\hline
\end{tabular}

3b. Quanto as tarefas ocasionais do tratamento de anticoagulação são difíceis ou inconvenientes?

\begin{tabular}{|c|c|c|c|c|c|c|}
\hline Nada & Muito pouco & Pouco & Moderadamente & Bastante & Muito & Muitíssimo \\
\hline 1 & 2 & 3 & 4 & 5 & 6 & 7 \\
\hline
\end{tabular}

Considerando o tratamento de anticoagulação no geral (ou seja, tanto as tarefas diárias como também as ocasionais), por favor, avalie as questões a seguir:

3c. Quanto você acha complicado o seu tratamento de anticoagulação?

\begin{tabular}{|c|c|c|c|c|c|c|}
\hline Nada & Muito pouco & Pouco & Moderadamente & Bastante & Muito & Muitíssimo \\
\hline 1 & 2 & 3 & 4 & 5 & 6 & 7 \\
\hline
\end{tabular}

3d. Quanto você acha demorado o seu tratamento de anticoagulação?

\begin{tabular}{|c|c|c|c|c|c|c|}
\hline Nada & Muito pouco & Pouco & Moderadamente & Bastante & Muito & Muitíssimo \\
\hline 1 & 2 & 3 & 4 & 5 & 6 & 7 \\
\hline
\end{tabular}

3e. Quanto você acha frustrante o seu tratamento de anticoagulação?

\begin{tabular}{|c|c|c|c|c|c|c|}
\hline Nada & Muito pouco & Pouco & Moderadamente & Bastante & Muito & Muitíssimo \\
\hline 1 & 2 & 3 & 4 & 5 & 6 & 7 \\
\hline
\end{tabular}

3f. O quanto você acha doloroso o seu tratamento de anticoagulação?

\begin{tabular}{|c|c|c|c|c|c|c|}
\hline Nada & Muito pouco & Pouco & Moderadamente & Bastante & Muito & Muitíssimo \\
\hline 1 & 2 & 3 & 4 & 5 & 6 & 7 \\
\hline
\end{tabular}

3g. No geral, quanto você acha o seu tratamento de anticoagulação um tratamento pesado/sacrificado?

\begin{tabular}{|c|c|c|c|c|c|c|}
\hline Nada & Muito pouco & Pouco & Moderadamente & Bastante & Muito & Muitíssimo \\
\hline 1 & 2 & 3 & 4 & 5 & 6 & 7 \\
\hline
\end{tabular}

3h. No geral, quanto confiante você esta em controlar seu tratamento de anticoagulação?

\begin{tabular}{|c|c|c|c|c|c|c|}
\hline Nada & Muito pouco & Pouco & Moderadamente & Bastante & Muito & Muitíssimo \\
\hline 1 & 2 & 3 & 4 & 5 & 6 & 7 \\
\hline
\end{tabular}

Estas últimas perguntas são sobre o que você conhece e sente sobre seu tratamento de anticoagulação.

4a. Quanto você entende o porquê está tomando anticoagulantes?

\begin{tabular}{|c|c|c|c|c|c|c|}
\hline Nada & Muito pouco & Pouco & Moderadamente & Bastante & Muito & Muitíssimo \\
\hline 1 & 2 & 3 & 4 & 5 & 6 & 7 \\
\hline
\end{tabular}

4b. Quanto você sente seguro devido o seu tratamento de anticoagulação?

\begin{tabular}{|c|c|c|c|c|c|c|}
\hline Nada & Muito pouco & Pouco & Moderadamente & Bastante & Muito & Muitíssimo \\
\hline 1 & 2 & 3 & 4 & 5 & 6 & 7 \\
\hline
\end{tabular}

4d. O quanto você se preocupa com relação a sangramentos ou machucados?

\begin{tabular}{|c|c|c|c|c|c|c|}
\hline Nada & Muito pouco & Pouco & Moderadamente & Bastante & Muito & Muitíssimo \\
\hline 1 & 2 & 3 & 4 & 5 & 6 & 7 \\
\hline
\end{tabular}


4f. No geral, quanto o tratamento de anticoagulação teve um impacto positivo em sua vida?

\begin{tabular}{|c|c|c|c|c|c|c|}
\hline Nada & Muito pouco & Pouco & Moderadamente & Bastante & Muito & Muitíssimo \\
\hline 1 & 2 & 3 & 4 & 5 & 6 & 7 \\
\hline
\end{tabular}

4g. No geral, quanto o tratamento de anticoagulação teve um impacto negativo em sua vida?

\begin{tabular}{|c|c|c|c|c|c|c|}
\hline Nada & Muito pouco & Pouco & Moderadamente & Bastante & Muito & Muitíssimo \\
\hline 1 & 2 & 3 & 4 & 5 & 6 & 7 \\
\hline
\end{tabular}

4f. No geral, quanto satisfeito você está com o seu tratamento de anticoagulação?

\begin{tabular}{|c|c|c|c|c|c|c|}
\hline Nada & Muito pouco & Pouco & Moderadamente & Bastante & Muito & Muitíssimo \\
\hline 1 & 2 & 3 & 4 & 5 & 6 & 7 \\
\hline
\end{tabular}

4i. Quanto é difícil para lidar com o seu tratamento de anticoagulação comparado com outros tratamentos que você fez?

\begin{tabular}{|c|c|c|c|c|c|c|}
\hline Nada & Muito pouco & Pouco & Moderadamente & Bastante & Muito & Muitíssimo \\
\hline 1 & 2 & 3 & 4 & 5 & 6 & 7 \\
\hline
\end{tabular}

4j. Qual a probabilidade de você recomendar esta forma de tratamento de anticoagulação para alguém com a sua doença ou condição médica?

\begin{tabular}{|c|l|c|c|c|c|c|}
\hline Nada & Muito pouco & Pouco & Moderadamente & Bastante & Muito & $\begin{array}{l}\text { Muitíssimo/ } \\
\text { Grande } \\
\text { probabilidade }\end{array}$ \\
\hline 1 & 2 & 3 & 4 & 5 & 6 & 7 \\
\hline
\end{tabular}




\section{Duke Anticoagulation Satisfaction Scale}

Nós gostaríamos de conhecer como o tratamento de anticoagulação (afinar o sangue) te afeta (warfaina/marcoumar), e o que você conhece e sente sobre o seu tratamento. Por favor, escolha a resposta que melhor descreve sua situação. Se a pergunta não se aplica a você, então escolha como resposta a alternativa "nada".

Quando você faz tratamento com anticoagulante você pode ter sangramento ou se machucar mais facilmente. Como resultado, você tem que limitar (atrapalha) suas atividades. Limitar (atrapalhar) significa fazer menos uma atividade ou não fazer atividade nenhuma.

1a. O quanto que a possibilidade de sangrar ou se machucar limita (atrapalha) você a fazer atividade física (por exemplo, serviços domésticos, dançar, esportes, ou qualquer outra atividade que usualmente você faz)?

\begin{tabular}{|c|c|c|c|c|c|c|}
\hline Nada & Muito pouco & Pouco & $\begin{array}{l}\text { Moderadamente/ } \\
\text { mais ou menos }\end{array}$ & Bastante & Muito & Muitíssimo \\
\hline 1 & 2 & 3 & 4 & 5 & 6 & 7 \\
\hline
\end{tabular}

1b. O quanto que a possibilidade de sangrar ou se machucar te limita (atrapalha) passear fora de sua cidade?

\begin{tabular}{|c|c|c|c|c|c|c|}
\hline Nada & Muito pouco & Pouco & $\begin{array}{l}\text { Moderadamente/ } \\
\text { mais ou menos }\end{array}$ & Bastante & Muito & Muitíssimo \\
\hline 1 & 2 & 3 & 4 & 5 & 6 & 7 \\
\hline
\end{tabular}

1c. O quanto que a possibilidade de sangrar ou se machucar limita a realização de qualquer outro tratamento de saúde que você precisar (por exemplo, ir ao dentista, ao fisioterapeuta, ou outro serviço de saúde)?

\begin{tabular}{|c|c|c|c|c|c|c|}
\hline $\begin{array}{l}\text { Nada/ } \\
\text { Não } \\
\text { limita }\end{array}$ & Muito pouco & Pouco & $\begin{array}{l}\text { Moderadamente/ } \\
\text { mais ou menos }\end{array}$ & Bastante & Muito & Muitíssimo \\
\hline 1 & 2 & 3 & 4 & 5 & 6 & 7 \\
\hline
\end{tabular}

1d. O quanto que a possibilidade de sangrar ou se machucar limita (atrapalha) em seu emprego?

\begin{tabular}{|c|c|c|c|c|c|c|}
\hline $\begin{array}{l}\text { Nada/ } \\
\text { Não } \\
\text { limita }\end{array}$ & Muito pouco & Pouco & $\begin{array}{l}\text { Moderadamente/ } \\
\text { mais ou menos }\end{array}$ & Bastante & Muito & Muitíssimo \\
\hline 1 & 2 & 3 & 4 & 5 & 6 & 7 \\
\hline
\end{tabular}

1e. No geral, o quanto que a possibilidade de sangrar ou se machucar afeta (atrapalha) seu dia-a-dia ?

\begin{tabular}{|c|c|c|c|c|c|c|}
\hline Nada & Muito pouco & Pouco & $\begin{array}{l}\text { Moderadamente/ } \\
\text { mais ou menos }\end{array}$ & Bastante & Muito & Muitíssimo \\
\hline 1 & 2 & 3 & 4 & 5 & 6 & 7 \\
\hline
\end{tabular}

O seu tratamento de anticoagulação (afinar o sangue) significa mudar também alguns do seus outros hábitos (costumes).

2a. O quanto que você muda a sua alimentação por causa do tratamento de anticoagulação (afinar o sangue)?

\begin{tabular}{|c|c|c|c|c|c|c|}
\hline $\begin{array}{l}\text { Nada/ } \\
\text { Não } \\
\text { limita }\end{array}$ & Muito pouco & Pouco & $\begin{array}{l}\text { Moderadamente/ } \\
\text { mais ou menos }\end{array}$ & Bastante & Muito & Muitíssimo \\
\hline 1 & 2 & 3 & 4 & 5 & 6 & 7 \\
\hline
\end{tabular}

2b. O quanto que o seu tratamento de anticoagulação (afinar o sangue) limita (atrapalha) o uso de bebidas alcoólicas?

\begin{tabular}{|c|c|c|c|c|c|c|}
\hline $\begin{array}{l}\text { Nada/ } \\
\text { Não limita }\end{array}$ & $\begin{array}{l}\text { Muito } \\
\text { pouco }\end{array}$ & Pouco & $\begin{array}{l}\text { Moderadamente/ } \\
\text { mais ou menos }\end{array}$ & Bastante & Muito & Muitíssimo \\
\hline 1 & 2 & 3 & 4 & 5 & 6 & 7 \\
\hline
\end{tabular}

2c. O quanto que o seu tratamento de anticoagulação (afinar o sangue) limita (atrapalha) o uso de medicamentos para dor, para febre e vitaminas?

\begin{tabular}{|c|l|l|l|c|c|c|}
\hline $\begin{array}{l}\text { Nada/ } \\
\text { Não } \\
\text { limita }\end{array}$ & Muito pouco & Pouco & $\begin{array}{l}\text { Moderadamente/ } \\
\text { mais ou menos }\end{array}$ & Bastante & Muito & Muitíssimo \\
\hline 1 & 2 & 3 & 4 & 5 & 6 & 7 \\
\hline
\end{tabular}

Fonte: Versão Português Consenso 2 adaptada por Pelegrino (2009) do instrumento DASS de Samsa et al. (2004) 
2d. No geral, quanto o seu tratamento de anticoagulação afeta sua vida diária?

\begin{tabular}{|c|c|c|c|c|c|c|}
\hline Nada & Muito pouco & Pouco & Moderadamente & Bastante & Muito & Muitíssimo \\
\hline 1 & 2 & 3 & 4 & 5 & 6 & 7 \\
\hline
\end{tabular}

Precisar de tratamento de anticoagulação (afinar o sangue) significa fazer muitas coisas, algumas coisas todos os dias e outras com menos freqüência.

Atividades diárias relacionadas ao tratamento podem incluir: lembrar de tomar o remédio num determinado horário, tomar a dose correta do remédio, não beber muito, seguir dieta alimentar moderada, evitar machucados e sangramentos, e assim por diante.

3a. O quanto essas atividades dificultam (atrapalham) a sua vida?

\begin{tabular}{|c|l|c|c|c|c|c|}
\hline Nada & Muito pouco & Pouco & $\begin{array}{l}\text { Moderadamente/ } \\
\text { mais ou menos }\end{array}$ & Bastante & Muito & Muitíssimo \\
\hline 1 & 2 & 3 & 4 & 5 & 6 & 7 \\
\hline
\end{tabular}

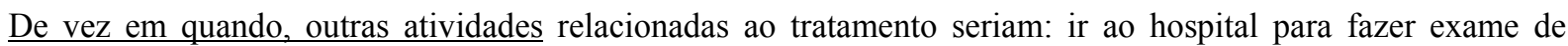
sangue, procurar serviços médicos em caso de sangramento ou outros problemas relacionados ao tratamento anticoagulação (afinar o sangue).

3b. O quanto que essas atividades dificultam (atrapalham) sua vida?

\begin{tabular}{|c|l|c|c|c|c|c|}
\hline Nada & Muito pouco & Pouco & $\begin{array}{l}\text { Moderadamente/ } \\
\text { mais ou menos }\end{array}$ & Bastante & Muito & Muitíssimo \\
\hline 1 & 2 & 3 & 4 & 5 & 6 & 7 \\
\hline
\end{tabular}

Considerando o tratamento de anticoagulação (afinar o sangue) no geral (ou seja, tanto as atividades diárias e de vez em quando), por favor, responda:

3c. O quanto que você acha difícil seguir o seu tratamento de anticoagulação (afinar o sangue)?

\begin{tabular}{|c|l|c|c|c|c|c|}
\hline Nada & Muito pouco & Pouco & $\begin{array}{l}\text { Moderadamente/ } \\
\text { mais ou menos }\end{array}$ & Bastante & Muito & Muitíssimo \\
\hline 1 & 2 & 3 & 4 & 5 & 6 & 7 \\
\hline
\end{tabular}

3d. O quanto que você gasta de seu tempo para seguir o tratamento de anticoagulação (afinar o sangue)?

\begin{tabular}{|c|l|c|c|c|c|c|}
\hline Nada & Muito pouco & Pouco & $\begin{array}{l}\text { Moderadamente/ } \\
\text { mais ou menos }\end{array}$ & Bastante & Muito & Muitíssimo \\
\hline 1 & 2 & 3 & 4 & 5 & 6 & 7 \\
\hline
\end{tabular}

3e. O quanto que você acha que o seu tratamento de anticoagulação (afinar o sangue) te incomoda?

\begin{tabular}{|c|l|c|c|c|c|c|}
\hline Nada & Muito pouco & Pouco & $\begin{array}{l}\text { Moderadamente/ } \\
\text { mais ou menos }\end{array}$ & Bastante & Muito & Muitíssimo \\
\hline 1 & 2 & 3 & 4 & 5 & 6 & 7 \\
\hline
\end{tabular}

3f. O quanto que você acha doloroso o seu tratamento de anticoagulação (afinar o sangue)?

\begin{tabular}{|c|l|c|c|c|c|c|}
\hline Nada & Muito pouco & Pouco & $\begin{array}{l}\text { Moderadamente/ } \\
\text { mais ou menos }\end{array}$ & Bastante & Muito & Muitíssimo \\
\hline 1 & 2 & 3 & 4 & 5 & 6 & 7 \\
\hline
\end{tabular}

3g. No geral, o quanto que você acha o seu tratamento de anticoagulação (afinar o sangue) um sacrifíció?

\begin{tabular}{|c|c|c|c|c|c|c|}
\hline Nada & Muito pouco & Pouco & $\begin{array}{l}\text { Moderadamente/ } \\
\text { mais ou menos }\end{array}$ & Bastante & Muito & Muitíssimo \\
\hline 1 & 2 & 3 & 4 & 5 & 6 & 7 \\
\hline
\end{tabular}

3h. No geral, o quanto que você acredita que consegue seguir seu tratamento de anticoagulação (afinar o sangue) ?

\begin{tabular}{|c|l|c|c|c|c|c|}
\hline Nada & Muito pouco & Pouco & $\begin{array}{l}\text { Moderadamente/ } \\
\text { mais ou menos }\end{array}$ & Bastante & Muito & Muitíssimo \\
\hline 1 & 2 & 3 & 4 & 5 & 6 & 7 \\
\hline
\end{tabular}


Estas últimas perguntas são sobre o que você entende sobre seu tratamento de anticoagulação (afinar o sangue).

4a. O quanto que você sabe sobre o motivo de estar tomando o anticoagulante?

\begin{tabular}{|c|l|c|c|c|c|c|}
\hline Nada & Muito pouco & Pouco & $\begin{array}{l}\text { Moderadamente/ } \\
\text { mais ou menos }\end{array}$ & Bastante & Muito & Muitíssimo \\
\hline 1 & 2 & 3 & 4 & 5 & 6 & 7 \\
\hline
\end{tabular}

4b. O quanto que você acha que o seu tratamento de anticoagulação (afinar o sangue) protege a sua saúde ?

\begin{tabular}{|c|l|c|c|c|c|c|}
\hline Nada & Muito pouco & Pouco & $\begin{array}{l}\text { Moderadamente/ } \\
\text { mais ou menos }\end{array}$ & Bastante & Muito & Muitíssimo \\
\hline 1 & 2 & 3 & 4 & 5 & 6 & 7 \\
\hline
\end{tabular}

4d. O quanto que você se preocupa com o risco de ter sangramentos ou se machucar?

\begin{tabular}{|c|c|c|c|c|c|c|}
\hline Nada & Muito pouco & Pouco & $\begin{array}{l}\text { Moderadamente/ } \\
\text { mais ou menos }\end{array}$ & Bastante & Muito & Muitíssimo \\
\hline 1 & 2 & 3 & 4 & 5 & 6 & 7 \\
\hline
\end{tabular}

4f. No geral, o quanto que o tratamento de anticoagulação (afinar o sangue) melhorou sua vida?

\begin{tabular}{|c|c|c|c|c|c|c|}
\hline Nada & Muito pouco & Pouco & $\begin{array}{l}\text { Moderadamente/ } \\
\text { mais ou menos }\end{array}$ & Bastante & Muito & Muitíssimo \\
\hline 1 & 2 & 3 & 4 & 5 & 6 & 7 \\
\hline
\end{tabular}

4g. No geral, quanto o tratamento de anticoagulação (afinar o sangue) piorou sua vida?

\begin{tabular}{|c|c|c|c|c|c|c|}
\hline Nada & Muito pouco & Pouco & $\begin{array}{l}\text { Moderadamente/ } \\
\text { mais ou menos }\end{array}$ & Bastante & Muito & Muitíssimo \\
\hline 1 & 2 & 3 & 4 & 5 & 6 & 7 \\
\hline
\end{tabular}

4f. No geral, o quanto que você esta satisfeito com o seu tratamento de anticoagulação (afinar o sangue)?

\begin{tabular}{|c|c|c|c|c|c|c|}
\hline Nada & Muito pouco & Pouco & $\begin{array}{l}\text { Moderadamente/ } \\
\text { mais ou menos }\end{array}$ & Bastante & Muito & Muitíssimo \\
\hline 1 & 2 & 3 & 4 & 5 & 6 & 7 \\
\hline
\end{tabular}

4i. Comparado com outros tratamentos que você fez, o quanto é difícil esse tratamento de anticoagulação (afinar o sangue)?

\begin{tabular}{|c|c|c|c|c|c|c|}
\hline Nada & Muito pouco & Pouco & $\begin{array}{l}\text { Moderadamente/ } \\
\text { mais ou menos }\end{array}$ & Bastante & Muito & Muitíssimo \\
\hline 1 & 2 & 3 & 4 & 5 & 6 & 7 \\
\hline
\end{tabular}

4j. Qual a possibilidade de você incentivar uma outra pessoa (com o mesmo problema de saúde que você tem) a seguir o tratamento de anticoagulação (afinar o sangue)?

\begin{tabular}{|c|c|c|c|c|c|c|}
\hline Nenhuma & Muito pouca & Pouca & $\begin{array}{l}\text { Moderada/ mais } \\
\text { ou menos }\end{array}$ & Bastante & Muita & Muitíssima \\
\hline 1 & 2 & 3 & 4 & 5 & 6 & 7 \\
\hline
\end{tabular}




\section{Duke Anticoagulation Satisfaction Scale}

We would like to know how your anti-clot treatment (blood thinner) affects you (Warfarin/Marcomar), and what you know and feel about your treatment. Please check the answer that best describes your situation. If a question does not apply to you, then check "not at all".

When you have anti-clot treatment you may bleed or bruise more easily. You may have to limit your activities as a result.Limit means you do less of an activity or no longer perform the activiy at all.

1a. How much does the possibility of bleeding or bruising limit you from performing a physical activity (for example, housework, dancing, sports or any other activiy you would usually do?

\begin{tabular}{|l|l|l|l|l|l|l|}
\hline $\begin{array}{l}\text { Not at all/Does } \\
\text { not limit }\end{array}$ & $\begin{array}{l}\text { Very } \\
\text { little }\end{array}$ & Somewhat & $\begin{array}{l}\text { Moderately / more } \\
\text { or less }\end{array}$ & Quite a bit & A lot & Very much \\
\hline 1 & 2 & 3 & 4 & 5 & 6 & 7 \\
\hline
\end{tabular}

1b. How much does the possibility of bleeding or bruising limit you from going out of town?

\begin{tabular}{|l|l|l|l|l|l|l|}
\hline $\begin{array}{l}\text { Not at all/Does } \\
\text { not limit }\end{array}$ & $\begin{array}{l}\text { Very } \\
\text { little }\end{array}$ & Somewhat & $\begin{array}{l}\text { Moderately / more } \\
\text { or less }\end{array}$ & Quite a bit & A lot & Very much \\
\hline 1 & 2 & 3 & 4 & 5 & 6 & 7 \\
\hline
\end{tabular}

1c. How much does the possibility of bleeding or bruising limit you from getting any other health treatment you need(for example, going to the dentist, to the pshysical therapist, or other medical care)?

\begin{tabular}{|l|l|l|l|l|l|l|}
\hline $\begin{array}{l}\text { Not at all/Does } \\
\text { not limit }\end{array}$ & $\begin{array}{l}\text { Very } \\
\text { little }\end{array}$ & Somewhat & $\begin{array}{l}\text { Moderately / more } \\
\text { or less }\end{array}$ & Quite a bit & A lot & Very much \\
\hline 1 & 2 & 3 & 4 & 5 & 6 & 7 \\
\hline
\end{tabular}

1d. How much does the possibility of bleeding or bruising limit you (interfere) in your job?

\begin{tabular}{|l|l|l|l|l|l|l|}
\hline $\begin{array}{l}\text { Not at all/Does } \\
\text { not limit }\end{array}$ & $\begin{array}{l}\text { Very } \\
\text { little }\end{array}$ & Somewhat & $\begin{array}{l}\text { Moderately / more } \\
\text { or less }\end{array}$ & Quite a bit & A lot & Very much \\
\hline 1 & 2 & 3 & 4 & 5 & 6 & 7 \\
\hline
\end{tabular}

1e. In general, how much does the possibility of bleeding or bruising affect (interfere) in your daily life?

\begin{tabular}{|l|l|l|l|l|l|l|}
\hline $\begin{array}{l}\text { Not at all/Does } \\
\text { not limit }\end{array}$ & $\begin{array}{l}\text { Very } \\
\text { little }\end{array}$ & Somewhat & $\begin{array}{l}\text { Moderately / more } \\
\text { or less }\end{array}$ & Quite a bit & A lot & Very much \\
\hline 1 & 2 & 3 & 4 & 5 & 6 & 7 \\
\hline
\end{tabular}

Being on an anti-clot treatment means changing some of your other habits as well.

2a. How much do you change your diet because of your anti-clot treatment (blood thinner)?

\begin{tabular}{|l|l|l|l|l|l|l|}
\hline $\begin{array}{l}\text { Not at all/Does } \\
\text { not limit }\end{array}$ & $\begin{array}{l}\text { Very } \\
\text { little }\end{array}$ & Somewhat & $\begin{array}{l}\text { Moderately / more } \\
\text { or less }\end{array}$ & Quite a bit & A lot & Very much \\
\hline 1 & 2 & 3 & 4 & 5 & 6 & 7 \\
\hline
\end{tabular}

2b. How much does your anticoagulation treatment (thinning the blood) limit (interfere) in the use of alcoholic beverages?

\begin{tabular}{|l|l|l|l|l|l|l|}
\hline $\begin{array}{l}\text { Not at all/Does } \\
\text { not limit }\end{array}$ & $\begin{array}{l}\text { Very } \\
\text { little }\end{array}$ & Somewhat & $\begin{array}{l}\text { Moderately / more } \\
\text { or less }\end{array}$ & Quite a bit & A lot & Very much \\
\hline 1 & 2 & 3 & 4 & 5 & 6 & 7 \\
\hline
\end{tabular}

2c. How much does your anti-clot treatment(blood thinner) limit over-the-counter you from taking medication for pain, fever and vitamins?

\begin{tabular}{|l|l|l|l|l|l|l|}
\hline $\begin{array}{l}\text { Not at all/Does } \\
\text { not limit }\end{array}$ & $\begin{array}{l}\text { Very } \\
\text { little }\end{array}$ & Somewhat & $\begin{array}{l}\text { Moderately / more } \\
\text { or less }\end{array}$ & Quite a bit & A lot & Very much \\
\hline 1 & 2 & 3 & 4 & 5 & 6 & 7 \\
\hline
\end{tabular}

2d. In general, how much does your anticoagulation treatment affect your daily life?

\begin{tabular}{|l|l|l|l|l|l|l|}
\hline $\begin{array}{l}\text { Not at all/Does } \\
\text { not limit }\end{array}$ & $\begin{array}{l}\text { Very } \\
\text { little }\end{array}$ & Somewhat & $\begin{array}{l}\text { Moderately / more } \\
\text { or less }\end{array}$ & Quite a bit & A lot & Very much \\
\hline 1 & 2 & 3 & 4 & 5 & 6 & 7 \\
\hline
\end{tabular}


The anti-clot treatment means doing many things, some things every day, and others less often.

Daily activities related to the treatment could include: remembering to take your medication at a certain time, taking the correct dose of your medication, not drinking alcohol, following a moderate diet, avoiding bruising or bleeding, and so on.

3a. How much of a hassle are those acitivites in your daily life?

Occasional activities related to your treatment could be: going to the hospital for blood check-ups, seeking medical care in case of bleeding or other problems related to your anti-clot treatment (blood thinner).

\begin{tabular}{|l|l|l|l|l|l|l|}
\hline $\begin{array}{l}\text { Not at all/Does } \\
\text { not limit }\end{array}$ & $\begin{array}{l}\text { Very } \\
\text { little }\end{array}$ & Somewhat & $\begin{array}{l}\text { Moderately / more } \\
\text { or less }\end{array}$ & Quite a bit & A lot & Very much \\
\hline 1 & 2 & 3 & 4 & 5 & 6 & 7 \\
\hline
\end{tabular}

3b. How much of a hassle are those activities in your life?

\begin{tabular}{|l|l|l|l|l|l|l|}
\hline $\begin{array}{l}\text { Not at all/Does } \\
\text { not limit }\end{array}$ & $\begin{array}{l}\text { Very } \\
\text { little }\end{array}$ & Somewhat & $\begin{array}{l}\text { Moderately / more } \\
\text { or less }\end{array}$ & Quite a bit & A lot & Very much \\
\hline 1 & 2 & 3 & 4 & 5 & 6 & 7 \\
\hline
\end{tabular}

Considering anti-clot treatment in general, (both daily and occasional activities), please answer the following:

3c. How complicated do you find it is to follow your anti-clot treatment(blood thinner)?

\begin{tabular}{|l|l|l|l|l|l|l|}
\hline $\begin{array}{l}\text { Not at all/Does } \\
\text { not limit }\end{array}$ & $\begin{array}{l}\text { Very } \\
\text { little }\end{array}$ & Somewhat & $\begin{array}{l}\text { Moderately / more } \\
\text { or less }\end{array}$ & Quite a bit & A lot & Very much \\
\hline 1 & 2 & 3 & 4 & 5 & 6 & 7 \\
\hline
\end{tabular}

3d. How time-consuming do you find your anti-clot treatment?

\begin{tabular}{|l|l|l|l|l|l|l|}
\hline $\begin{array}{l}\text { Not at all/Does } \\
\text { not limit }\end{array}$ & $\begin{array}{l}\text { Very } \\
\text { little }\end{array}$ & Somewhat & $\begin{array}{l}\text { Moderately / more } \\
\text { or less }\end{array}$ & Quite a bit & A lot & Very much \\
\hline 1 & 2 & 3 & 4 & 5 & 6 & 7 \\
\hline
\end{tabular}

3e. How much do you think your anticoagulation treatment (thinning the blood) bothers you?

\begin{tabular}{|l|l|l|l|l|l|l|}
\hline $\begin{array}{l}\text { Not at all/Does } \\
\text { not limit }\end{array}$ & $\begin{array}{l}\text { Very } \\
\text { little }\end{array}$ & Somewhat & $\begin{array}{l}\text { Moderately / more } \\
\text { or less }\end{array}$ & Quite a bit & A lot & Very much \\
\hline 1 & 2 & 3 & 4 & 5 & 6 & 7 \\
\hline
\end{tabular}

3f. How painful do you find your anti-clot treatment (blood thinner)?

\begin{tabular}{|l|l|l|l|l|l|l|}
\hline $\begin{array}{l}\text { Not at all/Does } \\
\text { not limit }\end{array}$ & $\begin{array}{l}\text { Very } \\
\text { little }\end{array}$ & Somewhat & $\begin{array}{l}\text { Moderately / more } \\
\text { or less }\end{array}$ & Quite a bit & A lot & Very much \\
\hline 1 & 2 & 3 & 4 & 5 & 6 & 7 \\
\hline
\end{tabular}

$3 g_{.}$In general, how much do you find that your anti-clot treatment (blood thinner) is a burden?

\begin{tabular}{|l|l|l|l|l|l|l|}
\hline $\begin{array}{l}\text { Not at all/Does } \\
\text { not limit }\end{array}$ & $\begin{array}{l}\text { Very } \\
\text { little }\end{array}$ & Somewhat & $\begin{array}{l}\text { Moderately / more } \\
\text { or less }\end{array}$ & Quite a bit & A lot & Very much \\
\hline 1 & 2 & 3 & 4 & 5 & 6 & 7 \\
\hline
\end{tabular}

3h. In general, how well do you believe you are able to follow your anticoagulation treatment (thinning the blood)?

\begin{tabular}{|l|l|l|l|l|l|l|}
\hline $\begin{array}{l}\text { Not at all/Does } \\
\text { not limit }\end{array}$ & $\begin{array}{l}\text { Very } \\
\text { little }\end{array}$ & Somewhat & $\begin{array}{l}\text { Moderately / more } \\
\text { or less }\end{array}$ & Quite a bit & A lot & Very much \\
\hline 1 & 2 & 3 & 4 & 5 & 6 & 7 \\
\hline
\end{tabular}

These last questions ask what you know about your anti-clot treatment (blood thinner).

4a. How much do you understand about the reason for following the anti-clot treatment?

\begin{tabular}{|l|l|l|l|l|l|l|}
\hline $\begin{array}{l}\text { Not at all/Does } \\
\text { not limit }\end{array}$ & $\begin{array}{l}\text { Very } \\
\text { little }\end{array}$ & Somewhat & $\begin{array}{l}\text { Moderately / more } \\
\text { or less }\end{array}$ & Quite a bit & A lot & Very much \\
\hline 1 & 2 & 3 & 4 & 5 & 6 & 7 \\
\hline
\end{tabular}


4b. How much do you feel your anti-clot treatment (blood thinner) protects your health?

\begin{tabular}{|l|l|l|l|l|l|l|}
\hline $\begin{array}{l}\text { Not at all/Does } \\
\text { not limit }\end{array}$ & $\begin{array}{l}\text { Very } \\
\text { little }\end{array}$ & Somewhat & $\begin{array}{l}\text { Moderately / more } \\
\text { or less }\end{array}$ & Quite a bit & A lot & Very much \\
\hline 1 & 2 & 3 & 4 & 5 & 6 & 7 \\
\hline
\end{tabular}

4d. How much do you worry about the risk of bleeding and bruising?

\begin{tabular}{|l|l|l|l|l|l|l|}
\hline $\begin{array}{l}\text { Not at all/Does } \\
\text { not limit }\end{array}$ & $\begin{array}{l}\text { Very } \\
\text { little }\end{array}$ & Somewhat & $\begin{array}{l}\text { Moderately / more } \\
\text { or less }\end{array}$ & Quite a bit & A lot & Very much \\
\hline 1 & 2 & 3 & 4 & 5 & 6 & 7 \\
\hline
\end{tabular}

4f. In general, how much has your anti-clot treatment (blood thinner) improved your life?

\begin{tabular}{|l|l|l|l|l|l|l|}
\hline $\begin{array}{l}\text { Not at all/Does } \\
\text { not limit }\end{array}$ & $\begin{array}{l}\text { Very } \\
\text { little }\end{array}$ & Somewhat & $\begin{array}{l}\text { Moderately / more } \\
\text { or less }\end{array}$ & Quite a bit & A lot & Very much \\
\hline 1 & 2 & 3 & 4 & 5 & 6 & 7 \\
\hline
\end{tabular}

4g. In general, how much has your anti-clot treatment (blood thinner) worsened your life?

\begin{tabular}{|l|l|l|l|l|l|l|}
\hline $\begin{array}{l}\text { Not at all/Does } \\
\text { not limit }\end{array}$ & $\begin{array}{l}\text { Very } \\
\text { little }\end{array}$ & Somewhat & $\begin{array}{l}\text { Moderately / more } \\
\text { or less }\end{array}$ & Quite a bit & A lot & Very much \\
\hline 1 & 2 & 3 & 4 & 5 & 6 & 7 \\
\hline
\end{tabular}

4h. In general, how satisfied are you with your anti-clot treatment (blood thinner)?

\begin{tabular}{|l|l|l|l|l|l|l|}
\hline $\begin{array}{l}\text { Not at all/Does } \\
\text { not limit }\end{array}$ & $\begin{array}{l}\text { Very } \\
\text { little }\end{array}$ & Somewhat & $\begin{array}{l}\text { Moderately / more } \\
\text { or less }\end{array}$ & Quite a bit & A lot & Very much \\
\hline 1 & 2 & 3 & 4 & 5 & 6 & 7 \\
\hline
\end{tabular}

4i. Compared with other treatments you have had, how difficult is it to deal with your anti-clot treatment (blood thinner)?

\begin{tabular}{|l|l|l|l|l|l|l|}
\hline $\begin{array}{l}\text { Not at all/Does } \\
\text { not limit }\end{array}$ & $\begin{array}{l}\text { Very } \\
\text { little }\end{array}$ & Somewhat & $\begin{array}{l}\text { Moderately / more } \\
\text { or less }\end{array}$ & Quite a bit & A lot & Very much \\
\hline 1 & 2 & 3 & 4 & 5 & 6 & 7 \\
\hline
\end{tabular}

$4 \mathrm{j}$. How likely would you motivate another person (with the same medical condition as yours) to follow the anticlot treatment (blood thinner)?

\begin{tabular}{|l|l|l|l|l|l|l|}
\hline $\begin{array}{l}\text { Not at all/Does } \\
\text { not limit }\end{array}$ & $\begin{array}{l}\text { Very } \\
\text { little }\end{array}$ & Somewhat & $\begin{array}{l}\text { Moderately / more } \\
\text { or less }\end{array}$ & Quite a bit & A lot & Very much \\
\hline 1 & 2 & 3 & 4 & 5 & 6 & 7 \\
\hline
\end{tabular}




\section{Duke Anticoagulation Satisfaction Scale}

Nós gostaríamos de conhecer como o tratamento de anticoagulação (afinar o sangue) te afeta (warfaina/marcoumar), e o que você conhece e sente sobre o seu tratamento. Por favor, escolha a resposta que melhor descreve sua situação. Se a pergunta não se aplica a você, então escolha como resposta a alternativa "nada".

Quando você faz tratamento com anticoagulante você pode ter sangramento ou se machucar mais facilmente. Como resultado, você tem que limitar (atrapalha) suas atividades. Limitar (atrapalhar) significa fazer menos uma atividade ou não fazer atividade nenhuma.

1a. O quanto que a possibilidade de sangrar ou se machucar limita (atrapalha) você a fazer atividade física (por exemplo, serviços domésticos, dançar, esportes, ou qualquer outra atividade que usualmente você faz)?

\begin{tabular}{|c|c|c|c|c|c|c|}
\hline Nada & Muito pouco & Pouco & $\begin{array}{l}\text { Moderadamente/ } \\
\text { mais ou menos }\end{array}$ & Bastante & Muito & Muitíssimo \\
\hline 1 & 2 & 3 & 4 & 5 & 6 & 7 \\
\hline
\end{tabular}

1b. O quanto que a possibilidade de sangrar ou se machucar te limita (atrapalha) passear fora de sua cidade?

\begin{tabular}{|c|c|c|c|c|c|c|}
\hline Nada & Muito pouco & Pouco & $\begin{array}{l}\text { Moderadamente/ } \\
\text { mais ou menos }\end{array}$ & Bastante & Muito & Muitíssimo \\
\hline 1 & 2 & 3 & 4 & 5 & 6 & 7 \\
\hline
\end{tabular}

1c. O quanto que a possibilidade de sangrar ou se machucar limita a realização de qualquer outro tratamento de saúde que você precisar (por exemplo, ir ao dentista, ao fisioterapeuta, ou outro serviço de saúde)?

\begin{tabular}{|c|c|c|c|c|c|c|}
\hline $\begin{array}{l}\text { Nada/ } \\
\text { limo }\end{array}$ & Muito pouco & Pouco & $\begin{array}{l}\text { Moderadamente/ } \\
\text { mais ou menos }\end{array}$ & Bastante & Muito & Muitíssimo \\
\hline 1 & 2 & 3 & 4 & 5 & 6 & 7 \\
\hline
\end{tabular}

1d. O quanto que a possibilidade de sangrar ou se machucar limita (atrapalha) em seu emprego?

\begin{tabular}{|c|c|c|c|c|c|c|}
\hline $\begin{array}{l}\text { Nada/ } \\
\text { Não } \\
\text { limita }\end{array}$ & Muito pouco & Pouco & $\begin{array}{l}\text { Moderadamente/ } \\
\text { mais ou menos }\end{array}$ & Bastante & Muito & Muitíssimo \\
\hline 1 & 2 & 3 & 4 & 5 & 6 & 7 \\
\hline
\end{tabular}

1e. No geral, o quanto que a possibilidade de sangrar ou se machucar afeta (atrapalha) seu dia-a-dia ?

\begin{tabular}{|c|c|c|c|c|c|c|}
\hline Nada & Muito pouco & Pouco & $\begin{array}{l}\text { Moderadamente/ } \\
\text { mais ou menos }\end{array}$ & Bastante & Muito & Muitíssimo \\
\hline 1 & 2 & 3 & 4 & 5 & 6 & 7 \\
\hline
\end{tabular}

O seu tratamento de anticoagulação (afinar o sangue) significa mudar também alguns do seus outros hábitos (costumes).

2a. O quanto que você muda a sua alimentação por causa do tratamento de anticoagulação (afinar o sangue)?

\begin{tabular}{|c|c|c|c|c|c|c|}
\hline $\begin{array}{l}\text { Nada/ } \\
\text { Não } \\
\text { limita }\end{array}$ & Muito pouco & Pouco & $\begin{array}{l}\text { Moderadamente/ } \\
\text { mais ou menos }\end{array}$ & Bastante & Muito & Muitíssimo \\
\hline 1 & 2 & 3 & 4 & 5 & 6 & 7 \\
\hline
\end{tabular}

2b. O quanto que o seu tratamento de anticoagulação (afinar o sangue) limita (atrapalha) o uso de bebidas alcoólicas?

\begin{tabular}{|c|c|c|c|c|c|c|}
\hline $\begin{array}{l}\text { Nada/ } \\
\text { Não limita }\end{array}$ & $\begin{array}{l}\text { Muito } \\
\text { pouco }\end{array}$ & Pouco & $\begin{array}{l}\text { Moderadamente/ } \\
\text { mais ou menos }\end{array}$ & Bastante & Muito & Muitíssimo \\
\hline 1 & 2 & 3 & 4 & 5 & 6 & 7 \\
\hline
\end{tabular}

2c. O quanto que o seu tratamento de anticoagulação (afinar o sangue) limita (atrapalha) o uso de medicamentos sem prescrição (por exemplo para dor, febre e vitaminas)?

\begin{tabular}{|c|c|c|c|c|c|c|}
\hline $\begin{array}{l}\text { Nada/ } \\
\text { Não } \\
\text { limita }\end{array}$ & Muito pouco & Pouco & $\begin{array}{l}\text { Moderadamente/ } \\
\text { mais ou menos }\end{array}$ & Bastante & Muito & Muitíssimo \\
\hline 1 & 2 & 3 & 4 & 5 & 6 & 7 \\
\hline
\end{tabular}

Fonte: Versão Português Consenso 3 adaptada por Pelegrino (2009) do instrumento DASS de Samsa et al. (2004) 
2d. No geral, quanto o seu tratamento de anticoagulação afeta sua vida diária?

\begin{tabular}{|c|c|c|c|c|c|c|}
\hline Nada & Muito pouco & Pouco & Moderadamente & Bastante & Muito & Muitíssimo \\
\hline 1 & 2 & 3 & 4 & 5 & 6 & 7 \\
\hline
\end{tabular}

O tratamento de anticoagulação (afinar o sangue) significa fazer muitas coisas, algumas coisas todos os dias e outras com menos freqüência.

Atividades diárias relacionadas ao tratamento podem incluir: lembrar de tomar o remédio num determinado horário, tomar a dose correta do remédio, não beber muito, seguir dieta alimentar moderada, evitar machucados e sangramentos, e assim por diante.

3a. O quanto essas atividades dificultam (atrapalham) a sua vida?

\begin{tabular}{|c|l|c|c|c|c|c|}
\hline Nada & Muito pouco & Pouco & $\begin{array}{l}\text { Moderadamente/ } \\
\text { mais ou menos }\end{array}$ & Bastante & Muito & Muitíssimo \\
\hline 1 & 2 & 3 & 4 & 5 & 6 & 7 \\
\hline
\end{tabular}

De vez em quando, outras atividades relacionadas ao tratamento seriam: ir ao hospital para fazer exame de sangue, procurar serviços médicos em caso de sangramento ou outros problemas relacionados ao tratamento anticoagulação (afinar o sangue).

3b. O quanto que essas atividades dificultam (atrapalham) sua vida?

\begin{tabular}{|c|c|c|c|c|c|c|}
\hline Nada & Muito pouco & Pouco & $\begin{array}{l}\text { Moderadamente/ } \\
\text { mais ou menos }\end{array}$ & Bastante & Muito & Muitíssimo \\
\hline 1 & 2 & 3 & 4 & 5 & 6 & 7 \\
\hline
\end{tabular}

Considerando o tratamento de anticoagulação (afinar o sangue) no geral (ou seja, tanto as atividades diárias e de vez em quando), por favor, responda:

3c. O quanto que você acha difícil seguir o seu tratamento de anticoagulação (afinar o sangue)?

\begin{tabular}{|c|l|c|c|c|c|c|}
\hline Nada & Muito pouco & Pouco & $\begin{array}{l}\text { Moderadamente/ } \\
\text { mais ou menos }\end{array}$ & Bastante & Muito & Muitíssimo \\
\hline 1 & 2 & 3 & 4 & 5 & 6 & 7 \\
\hline
\end{tabular}

3d. O quanto que você gasta de seu tempo para seguir o tratamento de anticoagulação (afinar o sangue)?

\begin{tabular}{|c|c|c|c|c|c|c|}
\hline Nada & Muito pouco & Pouco & $\begin{array}{l}\text { Moderadamente/ } \\
\text { mais ou menos }\end{array}$ & Bastante & Muito & Muitíssimo \\
\hline 1 & 2 & 3 & 4 & 5 & 6 & 7 \\
\hline
\end{tabular}

3e. O quanto que você acha que o seu tratamento de anticoagulação (afinar o sangue) te incomoda?

\begin{tabular}{|c|c|c|c|c|c|c|}
\hline Nada & Muito pouco & Pouco & $\begin{array}{l}\text { Moderadamente/ } \\
\text { mais ou menos }\end{array}$ & Bastante & Muito & Muitíssimo \\
\hline 1 & 2 & 3 & 4 & 5 & 6 & 7 \\
\hline
\end{tabular}

3f. O quanto que você acha doloroso o seu tratamento de anticoagulação (afinar o sangue)?

\begin{tabular}{|c|c|c|c|c|c|c|}
\hline Nada & Muito pouco & Pouco & $\begin{array}{l}\text { Moderadamente/ } \\
\text { mais ou menos }\end{array}$ & Bastante & Muito & Muitíssimo \\
\hline 1 & 2 & 3 & 4 & 5 & 6 & 7 \\
\hline
\end{tabular}

3g. No geral, o quanto que você acha o seu tratamento de anticoagulação (afinar o sangue) um sacrifício?

\begin{tabular}{|c|c|c|c|c|c|c|}
\hline Nada & Muito pouco & Pouco & $\begin{array}{l}\text { Moderadamente/ } \\
\text { mais ou menos }\end{array}$ & Bastante & Muito & Muitíssimo \\
\hline 1 & 2 & 3 & 4 & 5 & 6 & 7 \\
\hline
\end{tabular}

3h. No geral, o quanto que você acredita que consegue seguir seu tratamento de anticoagulação (afinar o sangue) ?

\begin{tabular}{|c|c|c|c|c|c|c|}
\hline Nada & Muito pouco & Pouco & $\begin{array}{l}\text { Moderadamente/ } \\
\text { mais ou menos }\end{array}$ & Bastante & Muito & Muitíssimo \\
\hline 1 & 2 & 3 & 4 & 5 & 6 & 7 \\
\hline
\end{tabular}


Estas últimas perguntas são sobre o que você sabe sobre seu tratamento de anticoagulação (afinar o sangue).

4a. O quanto que você compreende o motivo do seu tratamento de anticoagulação?

\begin{tabular}{|c|l|c|c|c|c|c|}
\hline Nada & Muito pouco & Pouco & $\begin{array}{l}\text { Moderadamente/ } \\
\text { mais ou menos }\end{array}$ & Bastante & Muito & Muitíssimo \\
\hline 1 & 2 & 3 & 4 & 5 & 6 & 7 \\
\hline
\end{tabular}

4b.O quanto que você acha que o seu tratamento de anticoagulação (afinar o sangue) protege a sua saúde?

\begin{tabular}{|c|l|c|c|c|c|c|}
\hline Nada & Muito pouco & Pouco & $\begin{array}{l}\text { Moderadamente/ } \\
\text { mais ou menos }\end{array}$ & Bastante & Muito & Muitíssimo \\
\hline 1 & 2 & 3 & 4 & 5 & 6 & 7 \\
\hline
\end{tabular}

4d. O quanto que você se preocupa com o risco de ter sangramentos ou se machucar?

\begin{tabular}{|c|c|c|c|c|c|c|}
\hline Nada & Muito pouco & Pouco & $\begin{array}{l}\text { Moderadamente/ } \\
\text { mais ou menos }\end{array}$ & Bastante & Muito & Muitíssimo \\
\hline 1 & 2 & 3 & 4 & 5 & 6 & 7 \\
\hline
\end{tabular}

4f. No geral, o quanto que o tratamento de anticoagulação (afinar o sangue) melhorou sua vida?

\begin{tabular}{|c|c|c|c|c|c|c|}
\hline Nada & Muito pouco & Pouco & $\begin{array}{l}\text { Moderadamente/ } \\
\text { mais ou menos }\end{array}$ & Bastante & Muito & Muitíssimo \\
\hline 1 & 2 & 3 & 4 & 5 & 6 & 7 \\
\hline
\end{tabular}

4g. No geral, quanto o tratamento de anticoagulação (afinar o sangue) piorou sua vida?

\begin{tabular}{|c|c|c|c|c|c|c|}
\hline Nada & Muito pouco & Pouco & $\begin{array}{l}\text { Moderadamente/ } \\
\text { mais ou menos }\end{array}$ & Bastante & Muito & Muitíssimo \\
\hline 1 & 2 & 3 & 4 & 5 & 6 & 7 \\
\hline
\end{tabular}

4h. No geral, o quanto que você esta satisfeito com o seu tratamento de anticoagulação (afinar o sangue)?

\begin{tabular}{|c|c|c|c|c|c|c|}
\hline Nada & Muito pouco & Pouco & $\begin{array}{l}\text { Moderadamente/ } \\
\text { mais ou menos }\end{array}$ & Bastante & Muito & Muitíssimo \\
\hline 1 & 2 & 3 & 4 & 5 & 6 & 7 \\
\hline
\end{tabular}

4i. Comparado com outros tratamentos que você fez, o quanto é difícil lidar com esse tratamento de anticoagulação (afinar o sangue)?

\begin{tabular}{|c|c|c|c|c|c|c|}
\hline Nada & Muito pouco & Pouco & $\begin{array}{l}\text { Moderadamente/ } \\
\text { mais ou menos }\end{array}$ & Bastante & Muito & Muitíssimo \\
\hline 1 & 2 & 3 & 4 & 5 & 6 & 7 \\
\hline
\end{tabular}

4j. Qual a possibilidade de você incentivar uma outra pessoa (com o mesmo problema de saúde que você tem) a seguir o tratamento de anticoagulação (afinar o sangue)?

\begin{tabular}{|c|c|c|c|c|c|c|}
\hline Nenhuma & Muito pouca & Pouca & $\begin{array}{l}\text { Moderada/ mais } \\
\text { ou menos }\end{array}$ & Bastante & Muita & Muitíssima \\
\hline 1 & 2 & 3 & 4 & 5 & 6 & 7 \\
\hline
\end{tabular}




\section{QUESTIONÁRIO DA ANÁLISE SEMÂNTICA DO INSTRUMENTO DUKE ANTICOAGULATION SATISFACTION SCALE (DASS)}

IDADE:

SEXO:

ESCOLARIDADE (em anos):

TEMPO DE ACO

PARTE A: Avaliação Geral

1) O que você achou do nosso instrumento em geral?

( ) bom ( ) regular ( ) ruim

2) As questões são compreensíveis?

( ) fáceis ( ) regular ( ) difíceis

3) Sobre a escala de resposta, você teve alguma dificuldade em respondê-las?

( ) sim ( ) mais ou menos ( ) não

4) As questões são importantes para quem faz uso de anticoagulantes orais?

( ) sim ( ) mais ou menos ( ) não

5) Você gostaria de mudar alguma coisa no questionário?

( ) não ( ) sim

6) Você gostaria de acrescentar alguma coisa no questionário? ( ) não ( ) sim

7) Teve alguma questão que você não quis responder?

( ) não ( ) sim 
PARTE B: Avaliação Específica

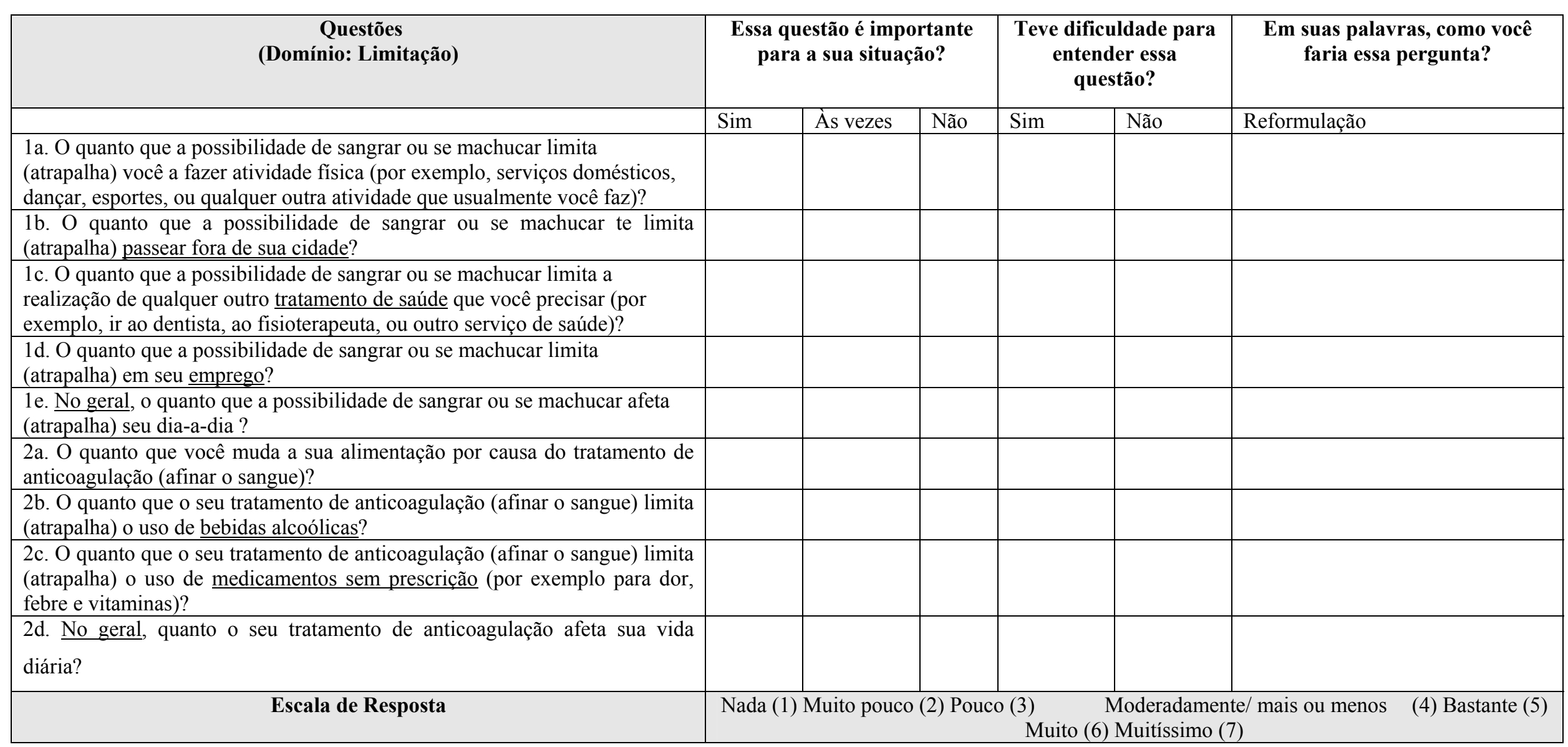


PARTE B: Avaliação Específica

\begin{tabular}{|c|c|c|c|c|c|c|}
\hline $\begin{array}{c}\text { Questões } \\
\text { (Domínio: Tarefa/Sobrecarga) }\end{array}$ & \multicolumn{3}{|c|}{$\begin{array}{l}\text { Essa questão é importante } \\
\text { para a sua situação? }\end{array}$} & \multicolumn{2}{|c|}{$\begin{array}{l}\text { Teve dificuldade para } \\
\text { entender essa } \\
\text { questão? }\end{array}$} & \multirow{2}{*}{$\begin{array}{c}\text { Em suas palavras, como você } \\
\text { faria essa pergunta? }\end{array}$} \\
\hline 3a. O quanto essas atividades dificultam (atrapalham) a sua vida? & Sim & Às vezes & Não & Sim & Não & \\
\hline $\begin{array}{l}\text { 3d. O quanto que você gasta de seu tempo para seguir o tratamento de } \\
\text { anticoagulação (afinar o sangue)? }\end{array}$ & & & & & & \\
\hline $\begin{array}{l}\text { 3f. O quanto que você acha doloroso o seu tratamento de anticoagulação } \\
\text { (afinar o sangue)? }\end{array}$ & & & & & & \\
\hline $\begin{array}{l}\text { 3g. No geral, o quanto que você acha o seu tratamento de anticoagulação } \\
\text { (afinar o sangue) um sacrifício? }\end{array}$ & & & & & & \\
\hline $\begin{array}{l}\text { 3h. No geral, o quanto que você acredita que consegue seguir seu tratamento } \\
\text { de anticoagulação (afinar o sangue)? }\end{array}$ & & & & & & \\
\hline Escala de Resposta & \multicolumn{6}{|c|}{ Nada (1) Muito pouco (2) Pouco (3) } \\
\hline
\end{tabular}


PARTE B: Avaliação Específica

\begin{tabular}{|c|c|c|c|c|c|c|}
\hline \multirow{2}{*}{$\begin{array}{l}\text { Questões } \\
\text { (Domínio: Impacto Psicológico) } \\
\begin{array}{l}\text { 4a. O quanto que você compreende o motivo do seu tratamento de } \\
\text { anticoagulação? }\end{array}\end{array}$} & \multicolumn{3}{|c|}{$\begin{array}{l}\text { Essa questão é importante } \\
\text { para a sua situação? }\end{array}$} & \multicolumn{2}{|c|}{$\begin{array}{l}\text { Teve dificuldade para } \\
\text { entender essa } \\
\text { questão? }\end{array}$} & \multirow{2}{*}{$\begin{array}{l}\begin{array}{c}\text { Em suas palavras, como você } \\
\text { faria essa pergunta? }\end{array} \\
\text { Reformulação }\end{array}$} \\
\hline & Sim & Às vezes & Não & Sim & Não & \\
\hline \multicolumn{7}{|l|}{$\begin{array}{l}\text { 4b. O quanto que você acha que o seu tratamento de anticoagulação (afinar o } \\
\text { sangue) protege a sua saúde? }\end{array}$} \\
\hline \multicolumn{7}{|l|}{$\begin{array}{l}\text { 4d. O quanto que você se preocupa com o risco de ter sangramentos ou se } \\
\text { machucar? }\end{array}$} \\
\hline \multicolumn{7}{|l|}{$\begin{array}{l}\text { 4f. No geral, o quanto que o tratamento de anticoagulação (afinar o sangue) } \\
\text { melhorou sua vida? }\end{array}$} \\
\hline \multicolumn{7}{|l|}{$\begin{array}{l}\text { 4g. No geral, quanto o tratamento de anticoagulação (afinar o sangue) piorou } \\
\text { sua vida? }\end{array}$} \\
\hline \multicolumn{7}{|l|}{$\begin{array}{l}\text { 4h. No geral, o quanto que você esta satisfeito com o seu tratamento de } \\
\text { anticoagulação (afinar o sangue)? }\end{array}$} \\
\hline \multicolumn{7}{|l|}{$\begin{array}{l}\text { 4i. Comparado com outros tratamentos que você fez, o quanto é difícil lidar } \\
\text { com esse tratamento de anticoagulação (afinar o sangue)? }\end{array}$} \\
\hline \multicolumn{7}{|l|}{$\begin{array}{l}\text { 4j. Qual a possibilidade de você incentivar uma outra pessoa (com o mesmo } \\
\text { problema de saúde que você tem) a seguir o tratamento de anticoagulação } \\
\text { (afinar o sangue)? }\end{array}$} \\
\hline Escala de Resposta & \multicolumn{6}{|c|}{$\begin{array}{l}\text { Moderadamente/ mais ou menos } \\
\text { Muitíssimo (7) }\end{array}$} \\
\hline
\end{tabular}




\section{Duke Antioagulation Satisfaction Scale (DASS)}

Nós gostaríamos de conhecer como o tratamento de anticoagulação (afinar o sangue) te afeta (warfaina/marcoumar), e o que você conhece e sente sobre o seu tratamento. Por favor, escolha a resposta que melhor descreve sua situação. Se a pergunta não se aplica a você, então escolha como resposta a alternativa "nada".

Quando você faz tratamento com anticoagulante você pode ter sangramento ou se machucar mais facilmente. Como resultado, você tem que limitar (atrapalha) suas atividades. Limitar (atrapalhar) significa fazer menos uma atividade ou não fazer atividade nenhuma.

1a. O quanto que a possibilidade de sangrar ou se machucar limita (atrapalha) você a fazer atividade física (por exemplo, serviços domésticos, dançar, esportes, ou qualquer outra atividade que usualmente você faz)?

\begin{tabular}{|c|c|c|c|c|c|c|}
\hline Nada & Muito pouco & Pouco & $\begin{array}{l}\text { Moderadamente/ } \\
\text { mais ou menos }\end{array}$ & Bastante & Muito & Muitíssimo \\
\hline 1 & 2 & 3 & 4 & 5 & 6 & 7 \\
\hline
\end{tabular}

1b. O quanto que a possibilidade de sangrar ou se machucar te limita (atrapalha) passear fora de sua cidade?

\begin{tabular}{|c|c|c|c|c|c|c|}
\hline Nada & Muito pouco & Pouco & $\begin{array}{l}\text { Moderadamente/ } \\
\text { mais ou menos }\end{array}$ & Bastante & Muito & Muitíssimo \\
\hline 1 & 2 & 3 & 4 & 5 & 6 & 7 \\
\hline
\end{tabular}

1c. O quanto que a possibilidade de sangrar ou se machucar limita a realização de qualquer outro tratamento de saúde que você precisar (por exemplo, ir ao dentista, ao fisioterapeuta, ou outro serviço de saúde)?

\begin{tabular}{|c|c|c|c|c|c|c|}
\hline $\begin{array}{l}\text { Nada/ } \\
\text { Não } \\
\text { limita }\end{array}$ & Muito pouco & Pouco & $\begin{array}{l}\text { Moderadamente/ } \\
\text { mais ou menos }\end{array}$ & Bastante & Muito & Muitíssimo \\
\hline 1 & 2 & 3 & 4 & 5 & 6 & 7 \\
\hline
\end{tabular}

1d. O quanto que a possibilidade de sangrar ou se machucar limita (atrapalha) em seu emprego?

\begin{tabular}{|c|c|c|c|c|c|c|}
\hline $\begin{array}{l}\text { Nada/ } \\
\text { Não } \\
\text { limita }\end{array}$ & Muito pouco & Pouco & $\begin{array}{l}\text { Moderadamente/ } \\
\text { mais ou menos }\end{array}$ & Bastante & Muito & Muitíssimo \\
\hline 1 & 2 & 3 & 4 & 5 & 6 & 7 \\
\hline
\end{tabular}

1e. No geral, o quanto que a possibilidade de sangrar ou se machucar afeta (atrapalha) seu dia-a-dia ?

\begin{tabular}{|c|c|c|c|c|c|c|}
\hline Nada & Muito pouco & Pouco & $\begin{array}{l}\text { Moderadamente/ } \\
\text { mais ou menos }\end{array}$ & Bastante & Muito & Muitíssimo \\
\hline 1 & 2 & 3 & 4 & 5 & 6 & 7 \\
\hline
\end{tabular}

O seu tratamento de anticoagulação (afinar o sangue) significa mudar também alguns do seus outros hábitos (costumes).

2a. O quanto que você muda a sua alimentação por causa do tratamento de anticoagulação (afinar o sangue)?

\begin{tabular}{|c|c|c|c|c|c|c|}
\hline $\begin{array}{l}\text { Nada/ } \\
\text { Não } \\
\text { limita }\end{array}$ & Muito pouco & Pouco & $\begin{array}{l}\text { Moderadamente/ } \\
\text { mais ou menos }\end{array}$ & Bastante & Muito & Muitíssimo \\
\hline 1 & 2 & 3 & 4 & 5 & 6 & 7 \\
\hline
\end{tabular}

2b. O quanto que o seu tratamento de anticoagulação (afinar o sangue) limita (atrapalha) o uso de bebidas alcoólicas?

\begin{tabular}{|c|c|c|c|c|c|c|}
\hline $\begin{array}{l}\text { Nada/ } \\
\text { Não limita }\end{array}$ & $\begin{array}{l}\text { Muito } \\
\text { pouco }\end{array}$ & Pouco & $\begin{array}{l}\text { Moderadamente/ } \\
\text { mais ou menos }\end{array}$ & Bastante & Muito & Muitíssimo \\
\hline 1 & 2 & 3 & 4 & 5 & 6 & 7 \\
\hline
\end{tabular}

2c. O quanto que o seu tratamento de anticoagulação (afinar o sangue) limita (atrapalha) o uso de medicamentos sem prescrição (por exemplo para dor, febre e vitaminas)?

\begin{tabular}{|c|c|c|c|c|c|c|}
\hline $\begin{array}{l}\text { Nada/ } \\
\text { Não } \\
\text { limita }\end{array}$ & Muito pouco & Pouco & $\begin{array}{l}\text { Moderadamente/ } \\
\text { mais ou menos }\end{array}$ & Bastante & Muito & Muitíssimo \\
\hline 1 & 2 & 3 & 4 & 5 & 6 & 7 \\
\hline
\end{tabular}

Fonte: Versão Português Consenso 4 (Versão Português Final) adaptada por Pelegrino (2009) do instrumento

DASS de Samsa et al. (2004) 
2d. No geral, quanto o seu tratamento de anticoagulação afeta sua vida diária?

\begin{tabular}{|c|c|c|c|c|c|c|}
\hline Nada & Muito pouco & Pouco & Moderadamente & Bastante & Muito & Muitíssimo \\
\hline 1 & 2 & 3 & 4 & 5 & 6 & 7 \\
\hline
\end{tabular}

O tratamento de anticoagulação (afinar o sangue) significa fazer muitas coisas, algumas coisas todos os dias e outras com menos freqüência.

Atividades diárias relacionadas ao tratamento podem incluir: lembrar de tomar o remédio num determinado horário, tomar a dose correta do remédio, não beber muito, seguir dieta alimentar moderada, evitar machucados e sangramentos, e assim por diante.

3a. O quanto essas atividades dificultam (atrapalham) a sua vida?

\begin{tabular}{|c|c|c|c|c|c|c|}
\hline Nada & Muito pouco & Pouco & $\begin{array}{l}\text { Moderadamente/ } \\
\text { mais ou menos }\end{array}$ & Bastante & Muito & Muitíssimo \\
\hline 1 & 2 & 3 & 4 & 5 & 6 & 7 \\
\hline
\end{tabular}

De vez em quando, outras atividades relacionadas ao tratamento seriam: ir ao hospital para fazer exame de sangue, procurar serviços médicos em caso de sangramento ou outros problemas relacionados ao tratamento anticoagulação (afinar o sangue).

3b. O quanto que essas atividades dificultam (atrapalham) sua vida?

\begin{tabular}{|c|l|c|c|c|c|c|}
\hline Nada & Muito pouco & Pouco & $\begin{array}{l}\text { Moderadamente/ } \\
\text { mais ou menos }\end{array}$ & Bastante & Muito & Muitíssimo \\
\hline 1 & 2 & 3 & 4 & 5 & 6 & 7 \\
\hline
\end{tabular}

Considerando o tratamento de anticoagulação (afinar o sangue) no geral (ou seja, tanto as atividades diárias e de vez em quando), por favor, responda:

3c. O quanto que você acha difícil seguir o seu tratamento de anticoagulação (afinar o sangue)?

\begin{tabular}{|c|l|c|c|c|c|c|}
\hline Nada & Muito pouco & Pouco & $\begin{array}{l}\text { Moderadamente/ } \\
\text { mais ou menos }\end{array}$ & Bastante & Muito & Muitíssimo \\
\hline 1 & 2 & 3 & 4 & 5 & 6 & 7 \\
\hline
\end{tabular}

3d. O quanto que você gasta de seu tempo para seguir o tratamento de anticoagulação (afinar o sangue)?

\begin{tabular}{|c|c|c|c|c|c|c|}
\hline Nada & Muito pouco & Pouco & $\begin{array}{l}\text { Moderadamente/ } \\
\text { mais ou menos }\end{array}$ & Bastante & Muito & Muitíssimo \\
\hline 1 & 2 & 3 & 4 & 5 & 6 & 7 \\
\hline
\end{tabular}

3e. O quanto que você acha que o seu tratamento de anticoagulação (afinar o sangue) te incomoda?

\begin{tabular}{|c|c|c|c|c|c|c|}
\hline Nada & Muito pouco & Pouco & $\begin{array}{l}\text { Moderadamente/ } \\
\text { mais ou menos }\end{array}$ & Bastante & Muito & Muitíssimo \\
\hline 1 & 2 & 3 & 4 & 5 & 6 & 7 \\
\hline
\end{tabular}

3f. O quanto que você acha doloroso o seu tratamento de anticoagulação (afinar o sangue)?

\begin{tabular}{|c|c|c|c|c|c|c|}
\hline Nada & Muito pouco & Pouco & $\begin{array}{l}\text { Moderadamente/ } \\
\text { mais ou menos }\end{array}$ & Bastante & Muito & Muitíssimo \\
\hline 1 & 2 & 3 & 4 & 5 & 6 & 7 \\
\hline
\end{tabular}

3g. No geral, o quanto que você acha o seu tratamento de anticoagulação (afinar o sangue) um sacrifício?

\begin{tabular}{|c|c|c|c|c|c|c|}
\hline Nada & Muito pouco & Pouco & $\begin{array}{l}\text { Moderadamente/ } \\
\text { mais ou menos }\end{array}$ & Bastante & Muito & Muitíssimo \\
\hline 1 & 2 & 3 & 4 & 5 & 6 & 7 \\
\hline
\end{tabular}

3h. No geral, o quanto que você acredita que consegue seguir seu tratamento de anticoagulação (afinar o sangue) ?

\begin{tabular}{|c|c|c|c|c|c|c|}
\hline Nada & Muito pouco & Pouco & $\begin{array}{l}\text { Moderadamente/ } \\
\text { mais ou menos }\end{array}$ & Bastante & Muito & Muitíssimo \\
\hline 1 & 2 & 3 & 4 & 5 & 6 & 7 \\
\hline
\end{tabular}


Estas últimas perguntas são sobre o que você sabe sobre seu tratamento de anticoagulação (afinar o sangue).

4a. O quanto que você compreende o motivo do seu tratamento de anticoagulação?

\begin{tabular}{|c|l|c|c|c|c|c|}
\hline Nada & Muito pouco & Pouco & $\begin{array}{l}\text { Moderadamente/ } \\
\text { mais ou menos }\end{array}$ & Bastante & Muito & Muitíssimo \\
\hline 1 & 2 & 3 & 4 & 5 & 6 & 7 \\
\hline
\end{tabular}

4b.O quanto que você acha que o seu tratamento de anticoagulação (afinar o sangue) protege a sua saúde?

\begin{tabular}{|c|l|c|c|c|c|c|}
\hline Nada & Muito pouco & Pouco & $\begin{array}{l}\text { Moderadamente/ } \\
\text { mais ou menos }\end{array}$ & Bastante & Muito & Muitíssimo \\
\hline 1 & 2 & 3 & 4 & 5 & 6 & 7 \\
\hline
\end{tabular}

4d. O quanto que você se preocupa com o risco de ter sangramentos ou se machucar?

\begin{tabular}{|c|c|c|c|c|c|c|}
\hline Nada & Muito pouco & Pouco & $\begin{array}{l}\text { Moderadamente/ } \\
\text { mais ou menos }\end{array}$ & Bastante & Muito & Muitíssimo \\
\hline 1 & 2 & 3 & 4 & 5 & 6 & 7 \\
\hline
\end{tabular}

4f. No geral, o quanto que o tratamento de anticoagulação (afinar o sangue) melhorou sua vida?

\begin{tabular}{|c|c|c|c|c|c|c|}
\hline Nada & Muito pouco & Pouco & $\begin{array}{l}\text { Moderadamente/ } \\
\text { mais ou menos }\end{array}$ & Bastante & Muito & Muitíssimo \\
\hline 1 & 2 & 3 & 4 & 5 & 6 & 7 \\
\hline
\end{tabular}

4g. No geral, quanto o tratamento de anticoagulação (afinar o sangue) piorou sua vida?

\begin{tabular}{|c|c|c|c|c|c|c|}
\hline Nada & Muito pouco & Pouco & $\begin{array}{l}\text { Moderadamente/ } \\
\text { mais ou menos }\end{array}$ & Bastante & Muito & Muitíssimo \\
\hline 1 & 2 & 3 & 4 & 5 & 6 & 7 \\
\hline
\end{tabular}

4h. No geral, o quanto que você esta satisfeito com o seu tratamento de anticoagulação (afinar o sangue)?

\begin{tabular}{|c|c|c|c|c|c|c|}
\hline Nada & Muito pouco & Pouco & $\begin{array}{l}\text { Moderadamente/ } \\
\text { mais ou menos }\end{array}$ & Bastante & Muito & Muitíssimo \\
\hline 1 & 2 & 3 & 4 & 5 & 6 & 7 \\
\hline
\end{tabular}

4i. Comparado com outros tratamentos que você fez, o quanto é difícil lidar com esse tratamento de anticoagulação (afinar o sangue)?

\begin{tabular}{|c|c|c|c|c|c|c|}
\hline Nada & Muito pouco & Pouco & $\begin{array}{l}\text { Moderadamente/ } \\
\text { mais ou menos }\end{array}$ & Bastante & Muito & Muitíssimo \\
\hline 1 & 2 & 3 & 4 & 5 & 6 & 7 \\
\hline
\end{tabular}

4j. Qual a possibilidade de você incentivar uma outra pessoa (com o mesmo problema de saúde que você tem) a seguir o tratamento de anticoagulação (afinar o sangue)?

\begin{tabular}{|c|c|c|c|c|c|c|}
\hline Nenhuma & Muito pouca & Pouca & $\begin{array}{l}\text { Moderada/ mais } \\
\text { ou menos }\end{array}$ & Bastante & Muita & Muitíssima \\
\hline 1 & 2 & 3 & 4 & 5 & 6 & 7 \\
\hline
\end{tabular}




\section{Instrumento para caracterização sócio-demográfica e clínica da amostra}

Número do paciente:

Data da Entrevista:

Início:

Término:

Duração:

\section{A-DADOS SÓCIO-DEMOGRÁFICOS}

Nome/iniciais:

Endereço:

Cidade:

Fone para contato:.

Sexo: ( ) feminino ( ) masculino

Data de nascimento: Profissão.

Raça: ( ) branca ( ) negra ( )parda ( ) amarela ( ) outras:

Estado civil: ( ) solteiro ( ) casado/união consensual ( ) viúvo ( ) separado

Religião: ( ) católica ( ) evangélica ( ) espírita ( ) Outra.....

Nível de instrução .anos (que freqüentou a escola-ensino formal)

Renda familiar: reais No. pessoas que residem com você: ..pessoas

Em relação ao suporte financeiro que você utiliza para seu tratamento com ACO:

( ) possui recursos para tratamento médico particular

( ) possui convênio / seguro saúde

( ) conta com ajuda de familiares

( ) utiliza serviços de saúde conveniados ao SUS

( ) outros 


\section{B- DADOS CLÍNICOS}

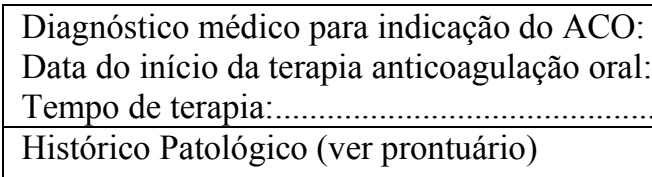

No dia a dia, você apenas utiliza remédios prescritos ou indicados pelo médico?

( ) $\operatorname{Sim}($ ) Não

Se não, quais remédios?

Após o início da terapia de anticoagulação oral, mudou alguma coisa em sua vida?

( ) $\operatorname{Sim}$ ( ) Não.

Qual foi a mudança?

$\mathrm{O}$ fato de você não poder comer uma grande quantidade alguns tipos de alimentos devido o uso do anticoagulante lhe incomoda?

( ) $\operatorname{Sim}($ ) Não

Você deixou de fazer coisas que gostava depois que iniciou o uso do anticoagulante oral?

( ) $\operatorname{Sim}($ ) Não

Você tem algum medo ou algum receio de fazer alguma coisa porque está tomando esta medicação?

( ) $\operatorname{Sim}($ ) Não

Qual é o seu medo ou receio?

Você se sente incomodado com as coletas sangüíneas freqüentes? ( ) Sim ( ) Não

Se sim. Por quê?

O que mais te incomodou após o inicio da terapia anticoagulante oral? 